\title{
iQuiz - Ambiente de autoria para avaliação do aprendizado no Moodle
}

\author{
José Roberto Alves Rodrigues
}

\author{
DISSERTAÇÃO APRESENTADA \\ $\mathrm{AO}$ \\ Instituto De MatemáticA E EstatísticA \\ DA \\ Universidade DE SÃo PAUlo \\ PARA \\ OBTENÇÃO DO TÍTULO \\ $\mathrm{DE}$ \\ Mestre EM CiÊnCIAS
}

Programa: Ciência da Computação

Orientador: Prof. Dr. Leônidas de Oliveira Brandão 


\section{iQuiz - Ambiente de autoria para avaliação do aprendizado no Moodle}

Esta cópia corresponde a versão do trabalho entregue à Comissão Julgadora para defesa da dissertação de Mestrado em Ciência da Computação.

Comissão Julgadora:

- Prof. Dr. Leônidas de O. Brandão (Presidente) - IME-USP

- Prof. Dr. Flávio Soares Corrêa da Silva - IME-USP

- Prof. Dra. Juliana Cristina Braga - UFABC 


\section{Agradecimentos}

À minha mãe Amélia, que embora saiba apenas desenhar o seu próprio nome, sempre se esforçou para manter os filhos na escola e dar-lhes boa educação, consciente de que seria uma importante contribuição para nossas vidas. Sem dúvida ela é uma sábia pessoa.

Agradeço minha esposa Patricia, que sempre apoiou e encentivou essa caminhada, dedicando muitas vezes o pouco tempo que tinha em meu auxílio, sempre com muita paciência e companheirismo, principalmente nos momentos mais difíceis para mim. Seu apoio foi muito importante para a conclusão desse trabalho. Também aos meus filhos Gabriel e Rafael, que sempre foram motivação para minha luta diária na conquista do pão e o leite!

Aos meus orientadores Prof. Leônidas Brandão e Profa. Anarosa, pelo apoio constante e a motivação vindas da visão positiva sobre todas as coisas que fizemos durante o período do meu curso de mestrado. Foram mais do que professores, foram amigos, pessoas magníficas.

Aos amigos do grupo de pesquisa LInE: Romenig, Marcia, Maria José, Danilo, Mauricio e Reginaldo por todo o auxiílio prestado, sugestões e críticas ao meu trabalho. Também aos colegas de sala de aula, com os quais compartilhei experiências e até algumas angústias, mas também muita descontração, cafés e bandejões!

Por fim agredecimento especial a minha amiga e colega de trabalho Renata por seu suporte e ajuda na empresa e com a editoração dos textos, foi imprescindível sua cooperação. Também aos meus compadres Marcelo e Adair pelo apoio com as pesquisas e aos meus colegas Luis e Cássio pelas contribuições na área de usabilidade.

A todas as demais pessoas que não citei explicitamente, que direta ou indiretamente contribuíram para o desenvolvimento e conclusão deste projeto. Muito obrigado a todos! 


\section{Resumo}

RODRIGUES, J. R. A. iQuiz - Ambiente de autoria para avaliação do aprendizado no Moodle. 167 f. Dissertação - Instituto de Matemática e Estatística, Universidade de São Paulo, São Paulo, 2014.

A expansão da modalidade de Educação a Distância (EAD) e a presença cada vez maior das Tecnologias de Informação e Comunicacão (TIC) na educação, tornam a utilização de ferramentas computacionais imprescindíveis no auxílio aos professores, tanto para produção de conteúdos digitais, quanto na tarefa de avaliação do aprendizado.

A avaliação do aprendizado acarreta muito trabalho ao professor, principalmente aquelas de caráter formativo, que favorecem o desenvolvimento continuado do aprendizado dos alunos. Uma forma de aliviar essa carga de trabalho tem sido a utilização dos Sistemas Gerenciadores de Curso (SGC). Dentre esses sistemas encontra-se o Moodle, que disponibiliza o módulo Quiz, que dispõe de recursos para avaliações automáticas. Contudo seu uso não é simples, sendo frequentes as reclamações de professores quanto a sua usabilidade, o que pode desmotivar seu uso.

Nesse contexto, o objetivo do presente trabalho é ajudar a compreender e reduzir as dificuldades enfrentadas por professores no emprego do módulo Quiz do Moodle. Para isso foi realizado um estudo para identificar os principais elementos que interferem na usabilidade de ferramentas para autoria de questionários online. Os resultados obtidos foram utilizados para modelar e produzir um protótipo alternativo ao do módulo Quiz, denominado de $i$ Quiz, que resultou na seguinte contribuição tecnológica: uma interface para aplicação sobre o núcleo do Quiz e um modelo para integração dos componentes envolvidos na composição do novo ambiente.

Para a criação do protótipo foi aplicado a abordagem de desenvolvimento centrado no usuário, utilizando testes de usabilidade em conjunto com outros métodos, tais como avaliação heurística.

Neste trabalho também apresentamos os resultados de uma avaliação do modelo implementado, indicando uma efetiva melhoria de usabilidade. Tanto especialistas em TIC e professores participantes das avaliações mostraram-se mais confortáveis com o uso do iQuiz, alcançando melhores resultados quanto à produção de questionários.

Palavras-chave: Informática na educação, Autoria, Avaliação, Ambientes de aprendizagem, Usabilidade. 


\section{Abstract}

RODRIGUES, J. R. A. iQuiz - Authoring environment for the assessment of learning in Moodle. 167 f. Dissertação - Instituto de Matemática e Estatística, Universidade de São Paulo, São Paulo, 2014.

The expansion of the distance learning education, allied to the ubiquitous presence of the Information and Communications Technology (ICT) in education, make the use of computational tools essential to the teacher. They are used in the content production, as well to help teacher to assess the students.

However, the learning assessment entails a lot of work to the teacher, especially under the model of formative assessments. One way to alleviate this workload, has been the use of Course Management Systems (CMS). Among these systems is Moodle, which provides the Quiz module, used for creating assessments with automatic evaluation. However the Quiz operation is not simple, it is not rare a teacher complains about its usability.

In this context, the objective this work is to help understand and reduce the difficulties faced by teachers in the use of Moodle Quiz. To do this, a study was conducted to identify the main elements that influence the usability of tools for online questionnaire authoring. From this study, was defined a model, that generated an alternative environment to the Quiz module, denoted by iQuiz. This resulted in the two technological contribution: an interface for application to the core of the Quiz and a model for integration of components involved in the composition of the new environment.

To produce the prototype of iQuiz, was used an approach centered in the user, together with usability tests, among other methods, such as heuristic evaluation.

In this work, it is also presented the results of an application of the iQuiz with ICT specialists and teachers, indicating an effective improvement of usability. Both, ICT specialists and teachers, rated iQuiz as comfortable to produce new questionnaires.

For the creation of the prototype has been applied to approach to development focused on the user, using usability tests together with other methods, such as heuristic evaluation. This resulted in significant improvement in the quality of the final interface and consequently, greater user satisfaction, an essential factor to motivate them to use the new environment.

Keywords: Computers in education, Authorship, Assessment, Learning environments, Usability. 


\section{Sumário}

Lista de Abreviaturas $\quad$ xi

Lista de Figuras $\quad$ xiii

Lista de Tabelas $\quad$ xvii

1 Introdução $\quad 1$

1.1 Motivação . . . . . . . . . . . . . . . . . . . . . . . . . . . . 3

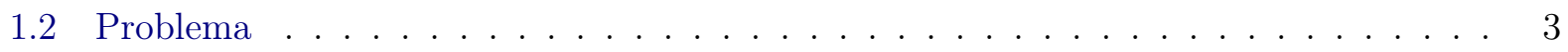

1.3 Hipótese . . . . . . . . . . . . . . . . . . . . . . . . . . . . 4

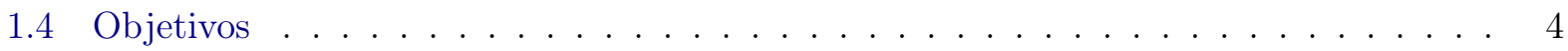

1.5 Metodologia . . . . . . . . . . . . . . . . . . . . 4

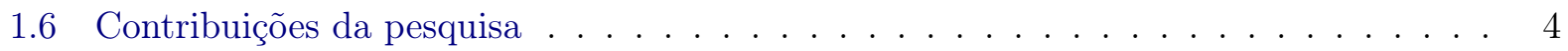

1.7 Organização do trabalho . . . . . . . . . . . . . . . . . . . . . 5

$\begin{array}{lll}2 & \text { Fundamentação } & 7\end{array}$

2.1 Avaliação do aprendizado . . . . . . . . . . . . . . . . . . . 7

2.1.1 Avaliação online da aprendizagem . . . . . . . . . . . . . . . . 8

2.2 Sistemas Gerenciadores de Cursos . . . . . . . . . . . . . . . . . . . . . . . 9

2.2 .1 Moodle . . . . . . . . . . . . . . . . . . . . . . . 10

2.2.2 Moodle Quiz . . . . . . . . . . . . . . . . . . . . . 11

2.3 Usabilidade . . . . . . . . . . . . . . . . . . . . . . . . . . 11

2.3.1 Engenharia de usabilidade . . . . . . . . . . . . . . . . . . . . . . . . 12

2.3 .2 Especificação do processo . . . . . . . . . . . . . . . . . . . . . . 13

2.3.3 Recomendações de usabilidade . . . . . . . . . . . . . . . . . . . . . . . . . 14

2.3 .4 Teste de usabilidade . . . . . . . . . . . . . . . . . . . . . . . . 15

2.3.5 Avaliação heurística . . . . . . . . . . . . . . . . . . . . . . . 15

2.3.6 Questionário System Usability Scale (SUS) . . . . . . . . . . . . . . . . . 17

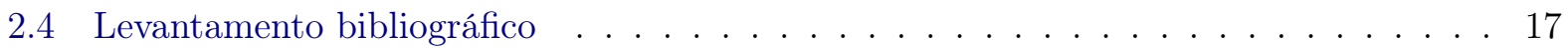

2.5 Trabalhos relacionados . . . . . . . . . . . . . . . . . . . 20

2.6 Módulos de aprendizagem interativa . . . . . . . . . . . . . . . . . 23

2.6.1 Família de componentes para o Moodle . . . . . . . . . . . . . . . . . . 25

3 Métodos $\quad 27$

3.1 Levantamento de evidências . . . . . . . . . . . . . . . . . . . . . . . 27

3.1 .1 Considerações iniciais . . . . . . . . . . . . . . . . . . 27 
3.1.2 Usabilidade do módulo Quiz . . . . . . . . . . . . . . . . . . . 27

3.1.3 Pesquisa de opinião sobre Quiz . . . . . . . . . . . . . . . . . 28

3.2 Métodos aplicados na avaliação do iQuiz . . . . . . . . . . . . . . . . . . . 30

3.2 .1 Avaliação heurística . . . . . . . . . . . . . . . . . . . . . . . 32

3.2 .2 Testes de usabilidade . . . . . . . . . . . . . . . . . . . . . 32

4 O ambiente $i Q u i z \quad 35$

4.1 Estudo de viabilidade do projeto . . . . . . . . . . . . . . . . . 36

4.2 Análise do contexto . . . . . . . . . . . . . . . . . . . . . . 39

4.2 .1 Caracterização de usuários . . . . . . . . . . . . . . . . . . . . . . . . . 39

4.2 .2 Observação e entrevista com usuários . . . . . . . . . . . . . . . . . . . . . 40

4.2 .3 Análise de sistemas similares . . . . . . . . . . . . . . . . . . . . 40

4.2 .4 Análise de tarefas . . . . . . . . . . . . . . . . . . . . . . . 45

4.3 Modelagem da interface . . . . . . . . . . . . . . . . . . . . . . . 49

4.4 Implementação do protótipo . . . . . . . . . . . . . . . . . . . . . . . . 52

5 Resultado das Avaliações $\quad 61$

5.1 Avaliação heurística . . . . . . . . . . . . . . . . . . . . . . . 61

5.2 Testes de usabilidade . . . . . . . . . . . . . . . . . . . . 65

5.2.1 Primeiro Experimento: teste de usabilidade do Quiz . . . . . . . . . . . . 66

5.2.2 Segundo Experimento: primeira avaliação da interface do iQuiz . . . . . . . . 67

5.2.3 Terceiro Experimento: segunda avaliação da interface do iQuiz . . . . . . . . 71

5.2.4 Quarto Experimento: terceira avaliação da interface do iQuiz . . . . . . . . . 75

5.3 Avaliação final . . . . . . . . . . . . . . . . . . . . . . . . . . 80

6 Conclusão $\quad 87$

6.1 Considerações finais . . . . . . . . . . . . . . . . . . . . 87

6.2 Sugestões para pesquisas futuras $\ldots \ldots \ldots \ldots \ldots$

A Relatório pesquisa MoodleMoot $2013 \quad 89$

A.1 Relatório preliminar sobre a pesquisa no evento MoodleMoot . . . . . . . . . . . . . . 89

A.1.1 Perfil do professor encontrado na pesquisa do MoodleMoot . . . . . . . . . . . 91

A.1.2 Perfil dos 'não professores' encontrados na pesquisa do MoodleMoot . . . . . 95

$\begin{array}{ll}\text { B Contexto de sistema e usuários } & 99\end{array}$

C Etapas para criação de um questionário no Quiz $\quad 103$

C.1 Configuração do questionário . . . . . . . . . . . . . . . . . . . . . . . . . . . 104

C.1.1 Inserção das questões no questionário . . . . . . . . . . . . . . . . . 108

C.1.2 Criação das questões . . . . . . . . . . . . . . . . . . . . . . . . . . . . 109

D Etapas para criação de um questionário no iQuiz $\quad 113$

D.1 Criando um questionário . . . . . . . . . . . . . . . . . . . . . 115

D.1.1 Feedback . . . . . . . . . . . . . . . . . . . . 117

D.1.2 Múltiplas tentativas . . . . . . . . . . . . . . . . . 118

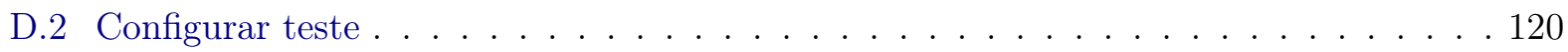


$\begin{array}{lll}\text { F } & \text { Lista de Tarefas do } i Q u i z & 123\end{array}$

F.0.1 Contextualização da Tarefa . . . . . . . . . . . . . . . . . . . 123

F.0.2 Lista de Subtarefas . . . . . . . . . . . . . . . . . . . . . . . 123

F.0.3 Modelo do guia do observador . . . . . . . . . . . . . . . . 125

G Informações complementares dos experimentos com o Quiz e iQuiz $\quad 127$

G.1 Segundo Experimento: primeira avaliação da interface do iQuiz . . . . . . . . . . . 127

G.1.1 Resultado da avaliação SUS . . . . . . . . . . . . . . . . . . . . . . . 127

G.1.2 Respostas do questionário avaliativo (Questões abertas) . . . . . . . . . . . 127

G.2 Terceiro Experimento: segunda avaliação da interface do iQuiz . . . . . . . . . . . 129

G.2.1 Resultado da avaliação SUS . . . . . . . . . . . . . . . . . . . . . . . . . . 129

G.2.2 Respostas do questionário avaliativo (Questões abertas) . . . . . . . . . . . 129

G.2.3 Taxa de conclusão das tarefas no terceiro experimento . . . . . . . . . . . . . 131

G.3 Quarto Experimento: terceiro avaliação da interface do iQuiz . . . . . . . . . . . . 131

G.3.1 Resultado da avaliação SUS . . . . . . . . . . . . . . . . . . . . . . . . . 131

G.3.2 Respostas do questionário avaliativo (Questões abertas) . . . . . . . . . . . 131

G.3.3 Taxa de conclusão das tarefas no quarto experimento . . . . . . . . . . . . . 133

H Questionário SUS em inglês 135

$\begin{array}{lll}\text { I } & \text { Telas de sistemas similares } & 137\end{array}$

$\begin{array}{ll}\text { Referências Bibliográficas } & 141\end{array}$ 


\section{Lista de Abreviaturas}

ACM Association for Computing Machinery

ABED Associação Brasileira de Educação a Distância

AVA Ambiente Virtual de Aprendizagem

EAD Educação a Distância

ENEM Exame Nacional do Ensino Médio

INEP Instituto Nacional de Estudos e Pesquisas Educacionais

IEEE Institute of Electrical and Electronics Engineers

IHC Interação Humano-Computador

iMA Módulo de Aprendizagem Interativa

IME Instituto de Matemática e Estatística

iRCD Repositório de Conteúdos Digitais Interativos

LEM Laboratório de Ensino de Matemática

LInE Laboratório de Informática na Educação

LMS Learning Management System

LPS Linha de Produto de Software

MAAVA Metodologia de Avaliação de Ambientes Virtuais de Aprendizagem

MEC Ministério da Educação

OA Objeto de Aprendizagem (Learning Object)

PISA Programme for International Student Assessment

SBIE Simpósio Brasileiro de Informática na Educação

SGC Sistema Gerenciador de Curso

SUS System Usability Scale

TIC Tecnologia da Informação e Comunicação

(Information and Communications Technology)

USP Universidade de São Paulo

VLE Virtual Learning Environment 


\section{Lista de Figuras}

1.1 Evolução das matrículas na educação superior por modalidade de ensino . . . . . . . 1

2.1 Principais formas de avaliação . . . . . . . . . . . . . . . 8

2.2 Informações estatísticas do Moodle . . . . . . . . . . . . . . . . . . 10

2.3 Processo de projeto centrado no usuário para sistemas interativos . . . . . . . . . . . . . . . . . . . . . . . . .

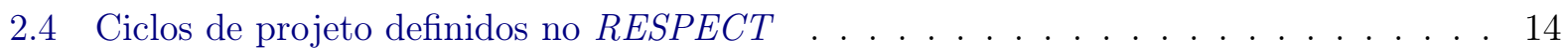

2.5 Exemplo da tela de edição do Quiz para o Moodle $2.0 \ldots \ldots$. . . . . . . . . . 22

2.6 Interface de usuário final após o projeto com a janela do banco de questão aberta . . 23

2.7 Exemplos de alguns módulos da família iMA . . . . . . . . . . . . . . . . . . . . . 24

3.1 Questão Moodlemoot . . . . . . . . . . . . . . . . . . . . . . 29

3.2 Principais etapas e métodos aplicados ao desenvolvimento do iQuiz nas fases do

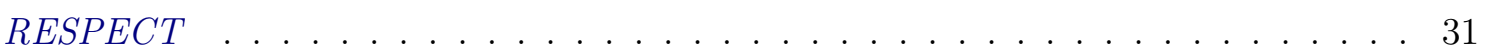

3.3 SUS -System Usability Scale . . . . . . . . . . . . . . . . . . . . . 33

4.1 iQuiz e as Camadas de componentes do Moodle . . . . . . . . . . . . . . 36

4.2 Diagrama de integração da interface do iQuiz ao Moodle . . . . . . . . . . . . . . 37

4.3 Diagrama de integração de componentes do iQuiz ao Moodle . . . . . . . . . . . . . 39

4.4 Fluxo de tarefas do Quiz . . . . . . . . . . . . . . . . . . . . 46

4.5 Fluxo de tarefas do $i$ Quiz . . . . . . . . . . . . . . . . . . . . . . 48

4.6 Rascunho da interface expandida do questionário . . . . . . . . . . . . . . . . 50

4.7 Rascunho da interface de edição de uma questão . . . . . . . . . . . . . . . . . 51

4.8 Rascunho das interfaces iniciais do banco de questões e configurar questionário . . . 52

4.9 Ciclo de vida do projeto, adaptado de Winckler e Pimenta (2002b) . . . . . . . . . . 53

4.10 Tela inicial do iQuiz . . . . . . . . . . . . . . . . . . 54

4.11 Tela com área do questionário expandida . . . . . . . . . . . . . . . . 55

4.12 Tela com a área do questionário e da questão . . . . . . . . . . . . . . . . 55

4.13 Interface com design adaptável, apresentando tela ampliada em $170 \%$. . . . . . . 57

4.14 Tela de configuração do questionário do iQuiz . . . . . . . . . . . . . . . 58

4.15 Bloco duração . . . . . . . . . . . . . . . . . . . . . . . . . . . . . 58

4.16 Tela com plugin iMA iVprog . . . . . . . . . . . . . . . . . . 59

5.1 Respostas ímpares do SUS do segundo experimento . . . . . . . . . . . . . . . 70

5.2 Respostas pares do SUS do segundo experimento . . . . . . . . . . . . . . 70

5.3 Respostas ímpares do SUS do terceiro experimento . . . . . . . . . . . . . . . 74

5.4 Respostas pares do SUS do terceiro experimento . . . . . . . . . . . . . . . 74 
5.5 Proporção da completeza das tarefas no terceiro experimento . . . . . . . . . . . 75

5.6 Respostas ímpares do SUS do quarto experimento . . . . . . . . . . . . . . . . . 77

5.7 Respostas pares do SUS do quarto experimento . . . . . . . . . . . . . . 78

5.8 Taxa de completeza das tarefas no quarto experimento . . . . . . . . . . . . . . 79

5.9 Proporção da completeza das tarefas no quarto experimento . . . . . . . . . . . . . . 79

5.10 Médias das respostas para afirmativas impares do Moodle Quiz e iQuiz . . . . . . . . 83

5.11 Médias das respostas para afirmativas pares do Moodle Quiz e iQuiz . . . . . . . . . 84

5.12 Média das Afirmações do SUS para o Moodle Quiz e iQuiz . . . . . . . . . . . . . . 85

A.1 Questionário pesquisa MoodleMoot 2013 . . . . . . . . . . . . . . . . . . . 90

A.2 Você já utilizou o Quiz para realizar avaliações? . . . . . . . . . . . . . . . . . . . . 91

A.3 Quais tipo de avaliações você realizar com o Quiz? . . . . . . . . . . . . . . . . 92

A.4 Formação dos participantes . . . . . . . . . . . . . . . . . . . . . . . . 92

A.5 Instituição onde os professores participantes lecionam . . . . . . . . . . . . . . . 92

A.6 Modalidade de ensino de atuação dos professores participantes . . . . . . . . . . . . . 92

A.7 Frequência de uso do computador . . . . . . . . . . . . . . . . . . . . . . . 93

A.8 capacitação tecnológica . . . . . . . . . . . . . . . . . . . . . . . . 93

A.9 A criação de questionário no Quiz é rápida? . . . . . . . . . . . . . . . . . . 93

A.10 O processo de criação de questionário no Quiz é intuitiva? . . . . . . . . . . . . . . . 94

A.11 Criar questões múltipla escolha no Quiz é mais fácil? . . . . . . . . . . . . . . . . . 94

A.12 Os formulários do Quiz são extensos? . . . . . . . . . . . . . . . . . . . . . . . . . 94

A.13 As pessoas aprendem o Quiz rapidamente? . . . . . . . . . . . . . . . . . . . . 94

A.14 Recursos da Quiz . . . . . . . . . . . . . . . . . . . . . . . . . . . 95

A.15 Utilizou o Quiz para realizar atividades? . . . . . . . . . . . . . . . . . . . . 95

A.16 Para qual tipo de avaliação? . . . . . . . . . . . . . . . . . . . . . . . 96

A.17 Distribuição do gênero dos não professores . . . . . . . . . . . . . . . . . . . . . 96

A.18 Formação dos não professores . . . . . . . . . . . . . . . . . . . . . . . 96

A.19 Opnião sobre processo de criação de questionários dos não professores . . . . . 97

A.20 Preferência dos não professores por questões múltipla escolha . . . . . . . . . . . . . 97

A.21 Aprendizagem do Quiz . . . . . . . . . . . . . . . . . . . . . . . 98

C.1 Ativar modo de edição . . . . . . . . . . . . . . . . . . . . . . . . . 103

C.2 Adicionar uma atividade ou recurso . . . . . . . . . . . . . . . . . . . . . . . . 104

C.3 Selecionar o questionário . . . . . . . . . . . . . . . . . . . . . . . . . 104

C.4 Bloco geral . . . . . . . . . . . . . . . . . . . . . . 105

C.5 Bloco duração . . . . . . . . . . . . . . . . . . . . . . . . . . 105

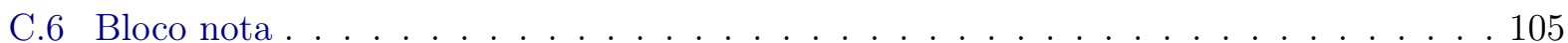

C.7 Bloco layout . . . . . . . . . . . . . . . . . . . . . . 105

C.8 Bloco comportamento da questão . . . . . . . . . . . . . . . . . . . . . . 106

C.9 Bloco opções de revisão ． . . . . . . . . . . . . . . . . . . . . . . . 106

C.10 Bloco visualização . . . . . . . . . . . . . . . . . . . . . . . 106

C.11 Bloco restrições extras nas tentativas . . . . . . . . . . . . . . . . . . 107

C.12 Bloco feedback geral . . . . . . . . . . . . . . . . . . . . . 107

C.13 Bloco configurações comum de módulo . . . . . . . . . . . . . . . . . . . . 107 
C.14 Inserir questões ao questionário . . . . . . . . . . . . . . . . . . . 108

C.15 Editar um questionário . . . . . . . . . . . . . . . . . . . . . . . 108

C.16 Inclusão de perguntas ao banco de questões . . . . . . . . . . . . . . . . 110

C.17 Bloco geral . . . . . . . . . . . . . . . . . . . . . . . 111

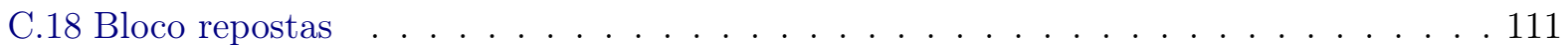

C.19 Bloco feedback combinado . . . . . . . . . . . . . . . . . . . . . . . . 112

C.20 Bloco definição para múltiplas tentativas . . . . . . . . . . . . . . . . . . . 112

D.1 Ativar modo de edição . . . . . . . . . . . . . . . . . . . . . . . . . . . 113

D.2 Adicionar uma atividade ou recurso . . . . . . . . . . . . . . . . . . . 113

D.3 Selecionar o questionário . . . . . . . . . . . . . . . . . . . . . . . . 114

D.4 Tela inicial iQuiz . . . . . . . . . . . . . . . . . . . . . . . . . . 114

D.5 Atribuir nome, descrição e escolher o tipo da questão . . . . . . . . . . . . . . . . 115

D.6 Preenchendo os dados do questionário . . . . . . . . . . . . . . . . 116

D.7 Ocultando e expandindo a barra de formatação e a área da alternativa . . . . . . . 116

D.8 Configuração do Feedback ～. . . . . . . . . . . . . . . . . . . . 117

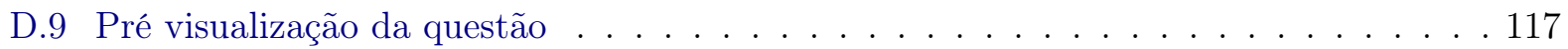

D.10 Múltiplas tentativas ． . . . . . . . . . . . . . . . . . . 118

D.11 Atribuindo uma categoria . . . . . . . . . . . . . . . . . . . . . . 119

D.12 Criar um novo tipo de questão ～. . . . . . . . . . . . . . . . . . . . . . 119

D.13 Configurar Teste . . . . . . . . . . . . . . . . . . . . . 120

I.1 Tela para edição de questionário no Respondus . . . . . . . . . . . . . . . . . . 137

I.2 Tela para edição de questionário no Google Docs ～. . . . . . . . . . . . . . . . . . 138

I.3 Tela para edição de questionário no Edmodo . . . . . . . . . . . . . . . . . . . . . . . 138

I.4 Tela para edição de questionário no Zenler ～. . . . . . . . . . . . . . . . . . . . . . 139

I.5 Tela para edição de questionário no Edubrite . . . . . . . . . . . . . . . . . . . . . 139

I.6 Tela para edição de questionário no Exam General . . . . . . . . . . . . . . . . . . 140 


\section{Lista de Tabelas}

2.1 Buscas de trabalhos relacionados . . . . . . . . . . . . . . . . . . 18

3.1 Pesquisa de opinião sobre o Quiz no MoodleMoot Brasil 2013 . . . . . . . . . . . . . 29

4.1 Principais características dos sistemas similares . . . . . . . . . . . . . . . 41

4.2 Recursos de Interface . . . . . . . . . . . . . . . . . . . . . . . . 44

5.1 Resultado da avaliação heurística . . . . . . . . . . . . . . . . . . 63

5.2 Lista de tarefas das avaliações do $i$ Quiz $\ldots \ldots \ldots$. . . . . . . . . . . . . 65

5.3 Perfil dos participantes do segundo experimento . . . . . . . . . . . . . . 67

5.4 Percentual do grau de concordância acumulado por afirmativa do segundo experimento 69

5.5 Perfil dos participantes do terceiro experimento . . . . . . . . . . . . . 71

5.6 Percentual do grau de concordância acumulado por afirmativa do terceiro experimento 73

5.7 Perfil dos participantes do quarto experimento . . . . . . . . . . . . . . 75

5.8 Percentual do grau de concordância acumulado por afirmativa do quarto experimento 77

5.9 Resposta dos participantes do experimento com o Moodle Quiz . . . . . . . . . . . . 80

5.10 Respostas dos participantes do experimento com o iQuiz . . . . . . . . . . . . . . 81

5.11 Percentual de Concordância por afirmativa da Avaliação do Moodle Quiz, utilizando o SUS . . . . . . . . . . . . . . . . . . . . . 81

5.12 Percentual de Concordância por afirmativa iQuiz . . . . . . . . . . . . . . . . 82

5.13 Médias das respostas por afirmativa . . . . . . . . . . . . . . 82

A.1 Distribuição de professores que usam o Moodle e o Quiz . . . . . . . . . . . . . 89

A.2 Consolidação da opinião sobre o Quiz no MoodleMoot 2013 . . . . . . . . . . . . . . 91

A.3 Distribuição de professores que usam o Moodle e o Quiz . . . . . . . . . . . . . . . 95

A.4 Consolidação da opinião dos não professores sobre o Quiz . . . . . . . . . . . . . 95

B.1 Resumo do projeto . . . . . . . . . . . . . . . . . . . . . . . . 99

B.2 Usuários e Interessados . . . . . . . . . . . . . . . . . . . . . . . . . 100

B.3 Objetivos do usuário e tarefas . . . . . . . . . . . . . . . . . . . 100

B.4 Grupos de usuários . . . . . . . . . . . . . . . . . . . . . . . . . 101

B.5 Ambiente Técnico . . . . . . . . . . . . . . . . . . . . . . 102

F.1 Modelo do guia do observador . . . . . . . . . . . . . . . . . . 126

G.1 Resultado da Avaliação SUS: Primeira avaliação da interface do iQuiz ..... . 127

G.2 Resultado da Avaliação SUS: Segunda avaliação da interface do iQuiz . . . . . . . . . 129 
G.3 Taxa de conclusão das tarefas no terceiro experimento . . . . . . . . . . . . . . . . 131

G.4 Resultado da Avaliação SUS: Terceira avaliação da interface do iQuiz . . . . . . . . . 131

G.5 Taxa de conclusão das tarefas no quarto experimento . . . . . . . . . . . . . . . . 133 


\section{Capítulo 1}

\section{Introdução}

Ao longo dos últimos anos a integração das Tecnologias de Informação e Comunicação (TIC) com as práticas pedagógicas vem se fortalecendo Aldrich (2008); Mantovani et al. (2008); Means et al. (2010); Murphy e Lebans (2008); Raob et al. (2012); Reynolds et al. (2008), sendo a crescente abrangência de uso da internet o principal facilitador desse advento (Caladine et al., 2010; Rea , 2014).

No Brasil, após o Ministério da Educação (MEC) regulamentar a Educação a Distância (EAD), em 1996 (Souza, 1996), a demanda por essa modalidade de ensino tem crescido significativamente. Isso pode ser facilmente constatado a partir do Censo da Educação Superior, realizado anualmente pelo Instituto Nacional de Estudos e Pesquisas Educacionais (INEP) ${ }^{1}$, visando fornecer informações sobre a situação e tendências do ensino superior no Brasil. Resumidamente esse Censo traz informações sobre os cursos de graduação presencial e a distância, tais como: inscrições, matrículas, ingressantes e concluintes.

Um dos Censos mais atuais disponibilizado publicamente é o de 2012, do qual foi extraído o gráfico com informações estatísticas sobre a evolução das matrículas na educação superior por modalidade de ensino no Brasil de 2001 a $2012^{2}$, ilustrado na Figura 1.1.

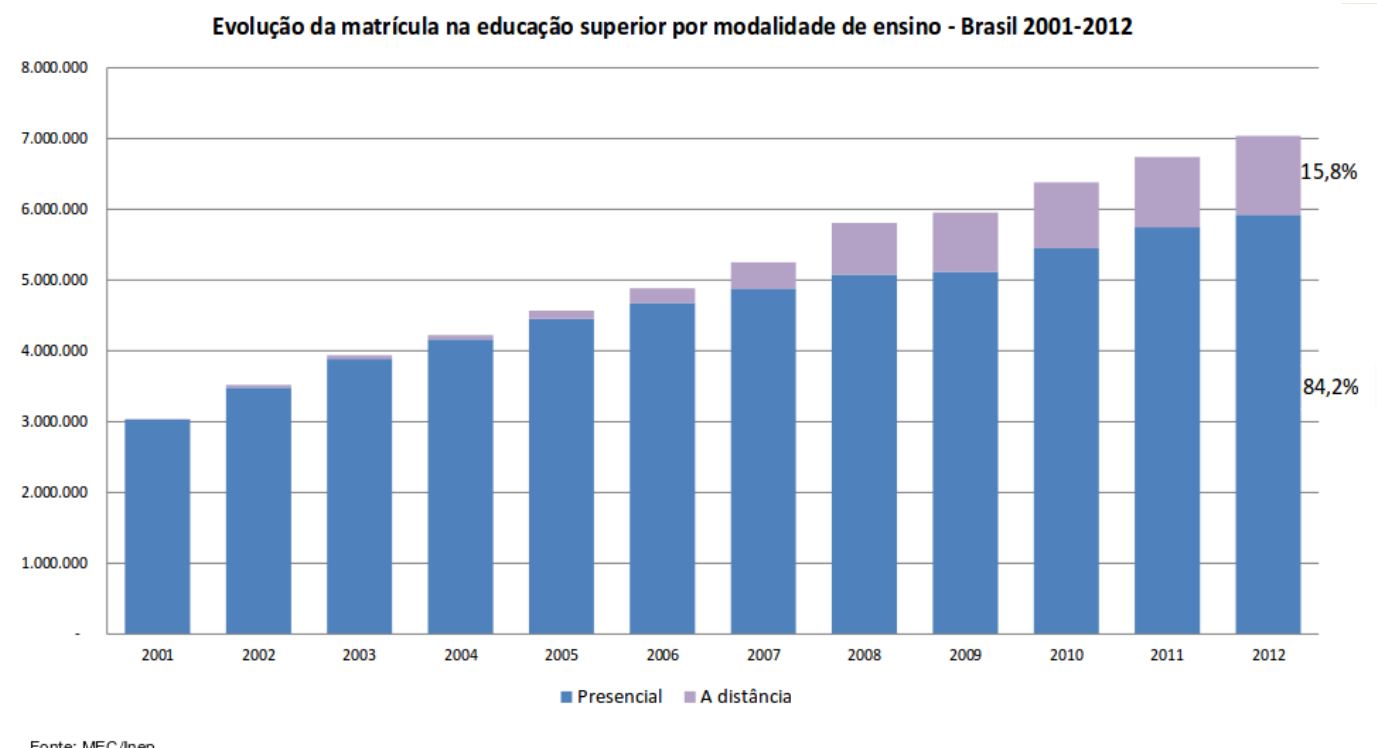

Figura 1.1: Evolução das matrículas na educação superior por modalidade de ensino

A partir desse gráfico é possível constatar uma importante informação: a modalidade de ensino a distância vem crescendo em maiores proporções comparado a modalidade de ensino presencial. Em

\footnotetext{
${ }^{1}$ Disponível em: http://portal.inep.gov.br/web/censo-da-educacao-superior. Acessado em 10 julho de 2014.

${ }^{2}$ Disponível em: http://download.inep.gov.br/educacao_basica/censo_escolar/resumos_tecnicos/apresentacao _ coletiva_censo_superior_2012.pdf. Acessado em 10 de julho de 2014
} 
2012, a participação dos cursos a distância já correspondia a cerca de $16 \%$ do total de matrículas dos cursos de graduação. Somente no período de 2011 à 2012, o crescimento das matrículas no ensino superior nos cursos a distância foi de $12,2 \%$ contra $3,1 \%$ nos cursos presenciais.

Do ponto de vista educacional, esse movimento tem provocado grandes mudanças, como o emprego de sistemas Web para apoiar também os cursos presenciais, no que denotaremos simplesmente como aprendizagem online (Lisbôa et al., 2009; Means et al., 2010; NMC, 2012). Corroborando essas modificações Ethel e Cruz (2012) mostram que metade dos assuntos discutidos em 2011 nas publicações científicas em tecnologias e educação do Simpósio Brasileiro de Informática na Educação (SBIE) envolveram assuntos relacionados com produção de sistemas e ferramentas computacionais para o ensino ou melhoria de processos para favorecer a interação entre aluno e professor.

Desse modo, a fim de atender essas novas demandas, professores passam a necessitar de ferramentas que os auxiliem na produção de conteúdo digital bem como no processo de avaliação do aprendizado em ambiente online. Sendo essa uma tarefa desafiadora, particularmente no contexto da EAD, uma vez que a avaliação do aprendizado tem sido referenciada como um dos aspectos mais complexos do processo de ensino e aprendizagem (Gomes, 2009; Lisbôa et al., 2009; Oliveira, 2010).

Como aponta Young (2011), as avaliações são um instrumento importante no processo de ensino e aprendizagem por indicarem, entre outros, o grau de aproveitamento e os pontos fortes e fracos na aprendizagem dos alunos. Em EAD, as avaliações de caráter formativo, aquelas que favorecem o desenvolvimento continuado da aprendizagem do aluno, acarretam muito trabalho aos professores, principalmente em função do número de alunos (Black e Wiliam, 1998; Oliveira, 2007).

Nesse contexto, os Sistemas Gerenciadores de Cursos (SGC) ${ }^{3}$ podem contribuir significativamente, uma vez que fornecem recursos e ferramentas voltados para o gerenciamento, autoria e distribuição de conteúdo didático-pedagógico (Queiroz, 2011).

Dentre esses sistemas encontra-se o Moodle (acrônimo de Modular Object-Oriented Dynamic Learning Environment), que possui recursos para a autoria de avaliações com possibilidade de correção automática, por meio do módulo Quiz. ${ }^{4}$ Esse módulo disponibiliza pelo menos 10 tipos de questões, dentre as quais destacam-se com cerca de $86 \%$ da utilização as questões do tipo múltipla escolha e falso/verdadeiro (Hunt, 2012). O Quiz é um módulo de destaque dentro Moodle, como mostra sua página de estatísticas ${ }^{5}$, entretanto seu uso é considerado complexo Calm et al. (2012); Hunt (2013) e frequentemente são encontrados problemas referente a sua usabilidade. Esse tipo problema prejudica a utilização eficiente e, consequentemente, a disposição dos usuários em utilizar um sistema. (Nielsen, 1993).

Problemas de usabilidade, conforme aponta Preece et al. (2005), podem causar confusão e desmotivação, isso pode levar os professores a utilizar apenas os recursos do ambiente que lhes pareçam mais simples. Vários desses problemas foram apontados pelos usuários do Quiz e pelo seu mantenedor Hunt (2013). Sendo os mais destacados: o preenchimento de extensos formulários; a falta de clareza; navegação não intuitiva; confusão conceitual relacionada a organização e hierarquia de elementos.

Problemas desse tipo podem ser tratados com a aplicação de técnicas voltadas à usabilidade, mas segundo Savolainen (2010), a aplicação dessas técnicas em sistemas de código aberto não é algo simples, principalmente pela falta de documentação e falta de pesquisas direcionadas aos objetivos do usuário. O Moodle, e por consequência o Quiz, também apresentam esse problema, uma vez que as técnicas de usabilidade não são frequentemente empregadas devido a atitude da comunidade em focar nos resultados concretos, levando ao não envolvimento dos usuários representativos no processo de desenvolvimento do sistema, afetando a produtividade dos usuários e por consequência o interesse no uso do sistema. Diante desse cenário novas propostas de melhoria da usabilidade para o ambiente favorecem os utilizadores e os desenvolvedores da comunidade Moodle.

Nas próximas seções deste capítulo serão apresentados a motivação, o problema da pesquisa, a

${ }^{3} \mathrm{Na}$ literatura podem ser encontradas várias outros termos para descrever este tipo de sistema, tais como: Ambientes Virtuais de Aprendizagem (AVA), Learning Management System (LMS) e Content Management System $(C M S)$.

${ }^{4}$ Disponível em: https://docs.moodle.org/all/pt_br/Modulo_Quiz. Acessado em 20 jun 2014.

${ }^{5}$ Disponível em: http://moodle.org/stats. Acessado em 20 jun 2014. 
hipótese de estudo, o objetivo, a metodologia, as contribuições desta pesquisa e a organização deste trabalho.

\subsection{Motivação}

A motivação para a realização deste trabalho surgiu a partir das observações realizadas na disciplina "Noções de Ensino de Matemática usando o Computador", oferecida aos alunos do curso de licenciatura em Matemática do Instituto de Matemática e Estatística da Universidade de São Paulo (IME-USP) e durante os cursos de aperfeiçoamento do Laboratório de Ensino de Matemática $(\mathrm{LEM})^{6}$, oferecidos nos cursos de verão ${ }^{7}$, no IME-USP. Em ambas as disciplinas, os estudantes examinam a questão do uso das TIC no ensino e na aprendizagem, além de realizarem várias atividades práticas. Boa parte dessas atividades empregam ferramentas desenvolvidas pelo Laboratório de Informática da Educação $(\mathrm{LInE})^{8}$. Dentre as atividades propostas encontra-se o desenvolvimento de cursos online no Moodle, contemplando desde a inserção de conteúdo digital até a criação de avaliações.

O uso de avaliações com correção automática tem sido amplamente discutido pela comunidade científica e por várias instituições, principalmente por reduzir a carga de trabalho do professor por meio de mecanismos de automatização da avaliação (CAA, 2013; IMS, 2013; JISC, 2007; Means et al., 2010; OpenLearn, 2013).

No entanto, notou-se ao utilizar o Quiz para criação de questionários, significativa desmotivação dos participantes (professores ou alunos de licenciatura) durante a realização dessa tarefa. Em entrevistas informais com esses participantes constatou-se que a origem dessa desmotivação estava vinculada a complexidade percebida por eles para realizar tarefas no ambiente do Quiz.

\subsection{Problema}

Com base nos apontamentos apresentados na introdução e nas considerações preliminares colocase o problema e a questão de pesquisa deste estudo.

\section{Problema:}

Os problemas de usabilidade do Quiz são apontadas pelos professores como um forte obstáculo para o desenvolvimento de avaliações no ambiente Moodle. A dificuldade enfrentada pelos professores pode ser uma das causas da desmotivação para o uso dessa ferramenta, embora demonstrem bastante interesse em utilizá-la.

Nesse contexto, pretende-se tratar o problema de usabilidade da ferramenta Quiz do Moodle.

\section{Questão da pesquisa:}

Quais são as possíveis melhorias na usabilidade da ferramenta Quiz do Moodle para tratar as dificuldades na utilização dessa ferramenta?

\footnotetext{
${ }^{6}$ Laboratório de Ensino de Matemática. Disponível em: http://www.ime.usp.br/lem/. Acessado em: 12 de Janeiro de 2014

${ }^{7}$ Cursos de verão do IME-USP. Disponível em: http://www.ime.usp.br/ verao. Acessado em 10 de Janeiro de 2014

${ }^{8}$ Laboratório de Informática da Educação. Disponível em: http://www.ime.usp.br/ line/. Acessado 15 de Janeiro de 2014
} 


\section{$1.3 \quad$ Hipótese}

A hipótese a ser verificada no presente estudo é de que melhorar a usabilidade da ferramenta Quiz do Moodle pode diminuir as dificuldades na utilização dessa ferramenta durante a criação de questionários para avaliação do aprendizado. E consequentemente, contribuir com o aumento do uso de avaliações formativas no processo de ensino e aprendizagem em cursos EAD.

\subsection{Objetivos}

O objetivo geral deste trabalho é identificar os principais elementos que interferem negativamente e positivamente na usabilidade de ferramentas para autoria de questionários online e a partir desses elementos melhorar o processo de autoria realizado pelos professores com a ferramenta Quiz do Moodle.

Como objetivos específicos visa-se: i) definir um fluxo de trabalho que facilite para os professores a autoria de questionários; ii) especificar e modelar uma interface com as melhorias de usabilidade; iii) definir um modelo para integração da nova interface ao Moodle; iv) Integrar os Módulos de Aprendizagem Interativa $(i M A)^{9}$ ao questionário do Moodle.

\subsection{Metodologia}

Esta pesquisa foi conduzida conforme os procedimentos metodológicos apresentados a seguir.

A primeira etapa compreendeu na definição da hipótese a ser investigada, seguida por um levantamento de evidências, com o objetivo de identificar fatos relevantes para o estudo (mais detalhes na Seção 3.1). Essa etapa iniciou-se por uma busca dos problemas relacionados ao uso do Quiz, a fim de identificar quais eram esses problemas. Para isso foi realizada uma pesquisa de opinião sobre o Quiz com profissionais técnicos e professores atuantes no desenvolvimento de ferramentas e cursos no Moodle. Seguido de um levantamento bibliográfico a fim de encontrar trabalhos relacionados.

Para verificar a viabilidade da hipótese que orienta esse estudo, foi projetado um protótipo. A segunda etapa compreendeu na definição desse protótipo (mais detalhes na Seção 4.1), orientado por: (i) experimentos observacionais da utilização do Quiz; (ii) identificação de recursos e facilidades quanto a usabilidade de sistemas semelhantes/concorrentes ao Quiz; (iii) um estudo para definir o fluxo de iteração do sistema.

A terceira etapa envolveu o desenvolvimento do protótipo (mais detalhes na Seção 4.4). Iniciando pela escolha da ferramenta de desenvolvimento e prototipação. Seguida pela definição das tecnologias a serem utilizadas no sistema. Foi empregado um processo cíclico de implementação, de tal forma que as implementações foram realizadas em etapas intercaladas por experimentações.

Para avaliar a hipótese formulada, na quarta e última etapa, realizou-se um experimento utilizando o protótipo final, a partir do qual foi possível apresentar o resultado de um estudo comparativo quanto a satisfação da usabilidade do Quiz original com do protótipo proposto neste estudo (mais detalhes no Capítulo 5).

\subsection{Contribuições da pesquisa}

A principal contribuição desta pesquisa consiste no resultado das análises do estudo sobre a usabilidade de ferramentas para autoria de questionários para avaliações online, assim como a aplicação dos resultados desse estudo no desenvolvimento de uma interface que sob a perspectiva dos usuários, fosse fácil de utilizar. Também contribui com outros grupos de pesquisa que estudam ou avaliam processos e métodos aplicados na melhoria da usabilidade de software e com a comunidade de software livre, em especial a comunidade Moodle que também poderá utilizar os resultados obtidos

\footnotetext{
${ }^{9}$ iMA são applets Java com avaliação automática, aplicáveis a geometria, funções, programação entre outros.
} 
nessa pesquisa para apoiar as práticas de projeto voltadas à melhoria da usabilidade dos módulos do ambiente. Por fim oferece contribuição substancial ao grupo de pesquisa rumo a integração das ferramentas educacionais no Moodle.

Como contribuição tecnológica essa pesquisa fornece o protótipo para um ambiente de autoria denominado iQuiz, composto pela interface e pelo modelo de integração dos recursos do ambiente ao Moodle, dentre os quais constam os Módulos de Avaliação Interativa (iMA).

\subsection{Organização do trabalho}

No Capítulo 2 são apresentados os fundamentos teóricos essenciais para o entendimento do estudo apresentado neste trabalho. Iniciando pelos principais conceitos sobre avaliação do aprendizado, os tipos mais comuns de avaliações é as avaliações na modalidade de EAD. Em seguida são apresentados os Sistemas Gerenciadores de Cursos (SGC), em especial o Moodle e seus recursos para criação de questionários. Por último encontra-se os conceitos de usabilidade pertinentes ao estudo e a apresentação dos aplicativos educacionais desenvolvidos pelo grupo de pesquisa que estão relacionados a este trabalho.

No Capítulo 3 destaca-se as evidências da hipótese apontada neste trabalho e os demais métodos aplicados no desenvolvimento e avaliação do mesmo. No Capítulo 4 apresenta-se a definição e o desenvolvimento do protótipo. No Capítulo 5 apresenta-se as avaliações realizadas na etapa de desenvolvimento do protótipo e seus resultados. No Capítulo 6 são apresentados as considerações finais e as sugestões para pesquisas futuras

No Apêndice A encontra-se o relatório da pequisa MoodleMoot que faz parte do levantamento de evidências da pesquisa. No Apêndice B encontra-se informações sobre o contexto do sistema e de usuários. No Apêndice C encontra-se as etapas para criação de um questionários utilizando o Quiz, seguido pelo Apêndice D onde encontra-se as etapas para criação de um questionário utilizando a interface do $i$ Quiz. No Apêndice E encontra-se as tarefas utilizadas pelos professores no experimento do Quiz. No Apêndice F encontra-se as tarefas utilizadas pelos professores no experimento com o protótipo do iQuiz. No Apêndice G encontra-se as Informações complementares aos resultados dos experimentos realizados com o Quiz e iQuiz. O Apêndice H apresenta as questões do questionário SUS em inglês. E por último no Apêndice I encontra-se as telas dos sistemas similares, analisados durante o levantamento de requisitos para o $i$ Quiz. 


\section{Capítulo 2}

\section{Fundamentação}

Neste capítulo são apresentados os embasamentos teóricos essenciais para o entendimento da proposta apresentada neste trabalho. O referencial teórico constitui uma importante etapa da pesquisa, contendo os principais conceitos e teorias das áreas pesquisadas. A Seção 2.1 apresenta a avaliação do aprendizado. Em seguida na Seção 2.2, são apresentados os Sistemas Gerenciadores de Cursos (SGC), na Seção 2.3 os conceitos de Engenharia da Usabilidade e os principais métodos para avaliação da usabilidade de um sistema, a Seção 2.4 apresenta o processo e os resultados do levantamento bibliográfico, na Seção 2.5 é apresentado o principal trabalhado relacionado e por fim na Seção 2.6 são apresentados os aplicativos educacionais desenvolvidos pelo grupo de pesquisa e que estão relacionados a este trabalho.

\subsection{Avaliação do aprendizado}

A avaliação do aprendizado é sempre um tema relevante e atual no processo de ensino e aprendizagem. Como aponta Saul (2012), isso é facilmente evidenciado pelo grande número de publicações em revistas de educação, pelos resultados de avaliações de ensino de caráter nacional e internacional, ENEM $^{1}$ e o PISA ${ }^{2}$.

Na visão de Oliveira (2007), avaliar deve ser para o aluno um instrumento imprescindível na verificação de seu aprendizado efetivo. Já para o professor uma forma de fornecer subsídios ao seu trabalho, de tal forma que possa adequar suas abordagens pedagógicas no contexto de estudo e nas condições individuais de seus alunos.

Como ressalta Paulo Freire, citado por Saul (2012) em seu trabalho, a relação da prática do docente e a avaliação é algo próximo de "vital", em suas palavras: "O trabalho de avaliar a prática jamais deixa de acompanhá-la. A prática precisa de avaliação como os peixes precisam de água e a lavoura da chuva. [...] Não é possivel praticar sem avaliar a prática. Avaliar a prática é analisar o que se faz, comparando os resultados obtidos com as finalidades que procuramos alcançar com a prática. A avaliação da prática revela acertos, erros e imprecisões. A avaliação corrige a prática, melhora a prática, aumenta a nossa eficiência"

Sobre o mesmo aspecto, Sell Filho et al. (2012), afirma que "no dicionário Aurélio, avaliar significa determinar o valor, medir, apreciar, estimar o merecimento, calcular, fazer a apreciação e ajuizar. Em geral, pode-se dizer que o processo de avaliação tem como fim apurar o "valor" de uma determinada pessoa. A falta de conceitos corretos em relação a esse termo é um dos grandes problemas da avaliação escolar. Se visto de maneira empírica, a avaliação pode ser usada para referir-se e medir o quanto o aluno aprendeu, atribuindo-se ao termo "medida", uma conotação quantitativa".

\footnotetext{
${ }^{1}$ Exame Nacional do Ensino Médio. Disponível em: http://enem.inep.gov.br/index.html. Acessado em 10 julho de 2014.

${ }^{2}$ Programme for International Student Assessment. Disponível em: http://www.oecd.org/pisa/. Acessado em 10 julho de 2014.
} 
No âmbito escolar as formas de avaliação mais relevantes e utilizadas, e consequentemente mais presentes nos estudos acadêmicos, concentram-se em três tipos, que combinadas compõe o processo de avaliação, sendo elas: diagnóstica, formativa e somativa. Representadas na Figura 2.1 e descritas a seguir.

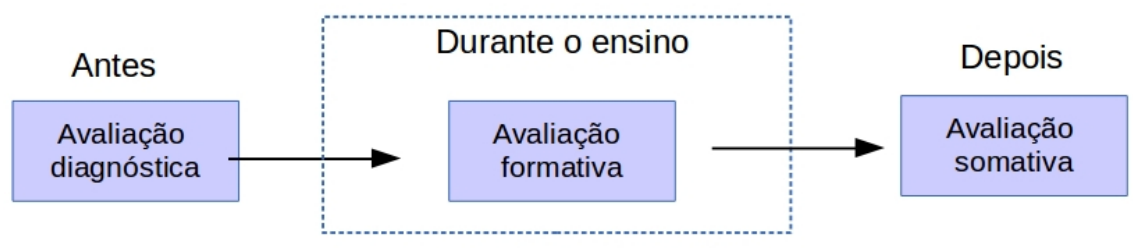

Figura 2.1: Principais formas de avaliação.

- Avaliação diagnóstica: focada no levantamento de informações sobre o conhecimento prévio dos alunos em relação a um determinado estudo, com a finalidade de averiguar o domínio do aluno face às aprendizagens anteriores, no sentido de prever as dificuldades futuras e até mesmo resolver situações presentes (Sell Filho et al., 2012).

- Avaliação formativa: focada na coleta de dados para reorientação do processo de ensino e aprendizagem. Essa avaliação tem como objetivo comparar o rendimento do aprendizado dos alunos quanto a compatibilidade com os objetivos pretendidos, isso é realizado principalmente por meio de mecanismos de feedback, que permitem ao professor detectar deficiências no método de ensino possibilitando melhorias e aperfeiçoamento em seu trabalho didático (Oliveira, 2007).

Segundo Sell Filho et al. (2012), a avaliação formativa fundamenta-se nos aspectos cognitivos, afetivos e relacionais do processo de aprendizagem, não tendo por objetivo classificar ou selecionar, mas sim a aprendizagem significativa. Para Haydt (1995), a avaliação formativa permite constatar se os alunos estão, de fato, atingindo os objetivos pretendidos. Verifica a coexistência da relação de objetivos e resultados das atividades propostas. É uma forma de o aluno conhecer seus erros e acertos.

- Avaliação somativa: focada nos resultados obtidos durante o processo de ensino e aprendizagem, essa avaliação traduz quantificadamente a distância em que o aluno ficou da meta estabelecida, ou seja, mensura o aprendizado final de uma unidade de aprendizagem, no sentido de aferir os resultados das avaliações formativas e obter indicadores que possibilitem aperfeiçoar o processo de ensino (Miccione, 2006; Sell Filho et al., 2012).

Segundo Haydt (1995), "a avaliação somativa pode ser facilmente utilizada como um instrumento de certificação social na medida em que permite seriar os alunos de acordo com o seu mérito social, constituindo a função social da avaliação".

De um modo geral, a avaliação pode ser considerada como forma de coletar e processar evidências necessárias para melhorar o processo de ensino e aprendizagem, contribuindo na tomada de decisão e na melhoria da qualidade do ensino. E particularmente no sistema educacional a avaliação é inerente ao processo de ensino e aprendizagem, sendo a avaliação um instrumento, geralmente preparado pelo próprio professor, que tem como objetivo medir o aproveitamento do aluno, ou seja, seu desempenho.

\subsubsection{Avaliação online da aprendizagem}

O avanço das tecnologias digitais, a popularização crescente da internet aliados a demanda por flexibilidade de espaço e tempo pelos aprendizes da atualidade, tem contribuído fortemente para a adoção da EAD pelas instituições de ensino. Nessa modalidade de ensino, onde aluno e professor estão separados no tempo e espaço, a avaliação do aprendizado ganha novos desafios (Gomes, 2003; Moore e Kearsley, 1996; Moran, 2000). 
A partir da literatura pode-se notar que a aprendizagem online tem inquietado muitos pesquisadores, levando-os a desenvolver diversos estudos sobre esse tema. Como por exemplo, a revisão sistemática sobre aprendizagem online realizado por Means et al. (2010), pesquisa do Departamento de Educação dos Estados Unidos, apontando alguns fatos sobre o aprendizado online, dentre eles um relevante está relacionado ao aproveitamento da aprendizagem, segundo o estudo, o desempenho do aluno no ensino online é ligeiramente melhor do que no presencial, ficando ainda melhor quando os dois modelos de ensino são aplicados simultaneamente, ou seja, de forma mista. Isso é justificado não somente por causa dos meios eletrônicos, mas também porque os alunos passam a dedicar mais tempo estudando fora da sala de aula.

Tal dedicação pode ser estimulada pelo professor ao possibilitar uma aprendizagem com qualidade, provendo a interatividade entre os agentes do processo. Desenvolver atividades individuais, coletivas, colaborativas e cooperativas. Buscando sempre despertar o interesse dos alunos, e para isso deve apresentar aos alunos atividades criativas, bem delimitadas e planejadas (Rodrigues e Borges, 2013).

A avaliação em EAD acontece ao longo do curso, de modo contínuo, baseando-se nas atividades propostas, nos comentários postados pelos alunos, nas participações do aluno nos grupos de discussão e chats. Dentre as atividades propostas é comum o uso de testes online, assim tanto professor como aluno podem mensurar o aprendizado, e principalmente detectar pontos falhos na aprendizagem e buscar meios para resgatá-los ainda durante o curso (Junqueira, 2012).

No processo avaliativo do aprendizado online destaca-se o papel dos SGC, apresentados na próxima seção.

\subsection{Sistemas Gerenciadores de Cursos}

Os Sistemas Gerenciadores de Cursos (SGC) ${ }^{3}$ vem sendo desenvolvidos com o objetivo de apoiar a educação, buscam centralizar e simplificar a gestão do processo de ensino e aprendizagem a distância via Web. Os SGC podem ser utilizados como apoio em cursos presenciais, visando aumentar as interações além da sala de aula, em cursos semi presenciais, onde as atividades são parcialmente realizadas a distância, ou em cursos não presenciais, nas quais as atividades são realizadas totalmente a distância.

Para isso, esses sistemas são compostos por ferramentas que facilitam o gerenciamento, a autoria de conteúdos e a interação síncrona e assíncrona entre os participantes (Schelemmer, 2005), tais como: chat, e-mail, blog, fórum, lista de discussão e videoconferência. Alguns exemplos conhecidos de SGC são: Moodle ${ }^{4}$, Claroline $^{5}$, Amadeus $^{6}$, Sakai $^{7}$, Tídia AE ${ }^{8}$, Teleduc $^{9}$, BlackBoard $^{10}$, AulaNET $^{11}$, Rooda ${ }^{12}$ e ATutor $^{13}$.

Diversas são as vantagens advindas do uso de SGC como apoio no processo de ensino e aprendizagem, dentre as principais estão: (i) disponibilizar diversos materiais de estudo na forma digital; (ii) possibilitar que o aluno controle seu próprio ritmo de aprendizagem, escolhendo a sequência, o tempo e o local para desenvolver suas atividades; (iii) possibilitar ao professor acompanhar o desenvolvimento individual dos alunos, por meio de avaliações formativas; (iv) proporcionar a aprendizagem colaborativa, estimulando a cooperação entre os participantes.

\footnotetext{
${ }^{3}$ Também conhecidos por LMS (Learning Management Systems ou Sistema Gerenciador de Aprendizagem) ou AVA (Ambiente Virtual de Aprendizagem).

${ }^{4}$ Disponível em: http://www.moodle.org. Acessado em: 20 de Agosto de 2014

${ }^{5}$ Disponível em: http://www.claroline.net/. Acessado em: 21 de Agosto de 2014

${ }^{6}$ Disponível em: http://amadeus.cin.ufpe.br/. Acessado em: 25 de Agosto de 2014

${ }^{7}$ Disponível em: http://www.sakaiproject.org/. Acessado em: 23 de Agosto de 2014

${ }^{8}$ Disponível em: http://www.tidia-ae.usp.br/portal. Acessado em: 18 de Agosto de 2014

${ }^{9}$ Disponível em: http://www.teleduc.org.br/. Acessado em: 24 de Agosto de 2014

${ }^{10}$ Disponível em: http://www.blackboard.com/. Acessado em: 20 de Agosto de 2014

${ }^{11}$ Disponível em: http://groupware.les.inf.puc-rio.br/. Acessado em: 29 de Agosto de 2014

${ }^{12}$ Disponível em: https://www.ead.ufrgs.br/rooda/. Acessado em: 10 de Agosto de 2014

${ }^{13}$ Disponível em: http://atutor.ca/. Acessado em: 5 de Agosto de 2014
} 
Para atender as necessidades da EAD os SGC são constantemente atualizados e aprimorados, visando melhorar a troca de informações, a construção do conhecimento, a interatividade e o trabalho colaborativo entre os participantes.

Atualmente um dos mais utilizados SGC no mundo é o Moodle, um software livre que tem se destacado no cenário internacional estando presente em grande número de servidores na internet. Ele está sendo utilizado por vários tipos de instituições e tem um papel importante neste trabalho uma vez que a principal motivação para realização deste estudo partiu das observações realizadas em uma ferramenta desse SGC.

\subsubsection{Moodle}

O Moodle ${ }^{14}$ (acrônimo de Modular Object-Oriented Dynamic Learning Environment) é um SGC de grande abrangência mundial, distribuído sob a licença $\mathrm{GNU}^{15}$, assim pode ser instalado, utilizado, modificado e mesmo distribuído. Desenvolvido para a gestão do ensino e aprendizagem de cursos via Web, sob uma metodologia pedagógica sócio construtivista, de modo que os integrantes do cursos constroem conhecimentos colaborativamente por meio do ambiente (Cole e Foster, 2008).

Conforme mostra os dados estatísticos do Moodle ${ }^{16}$ seu número de usuários é bastante significativo, como pode ser observado na Figura 2.2. Em julho de 2014 seu uso abrange 235 países, com aproximadamente 64.000 servidores.

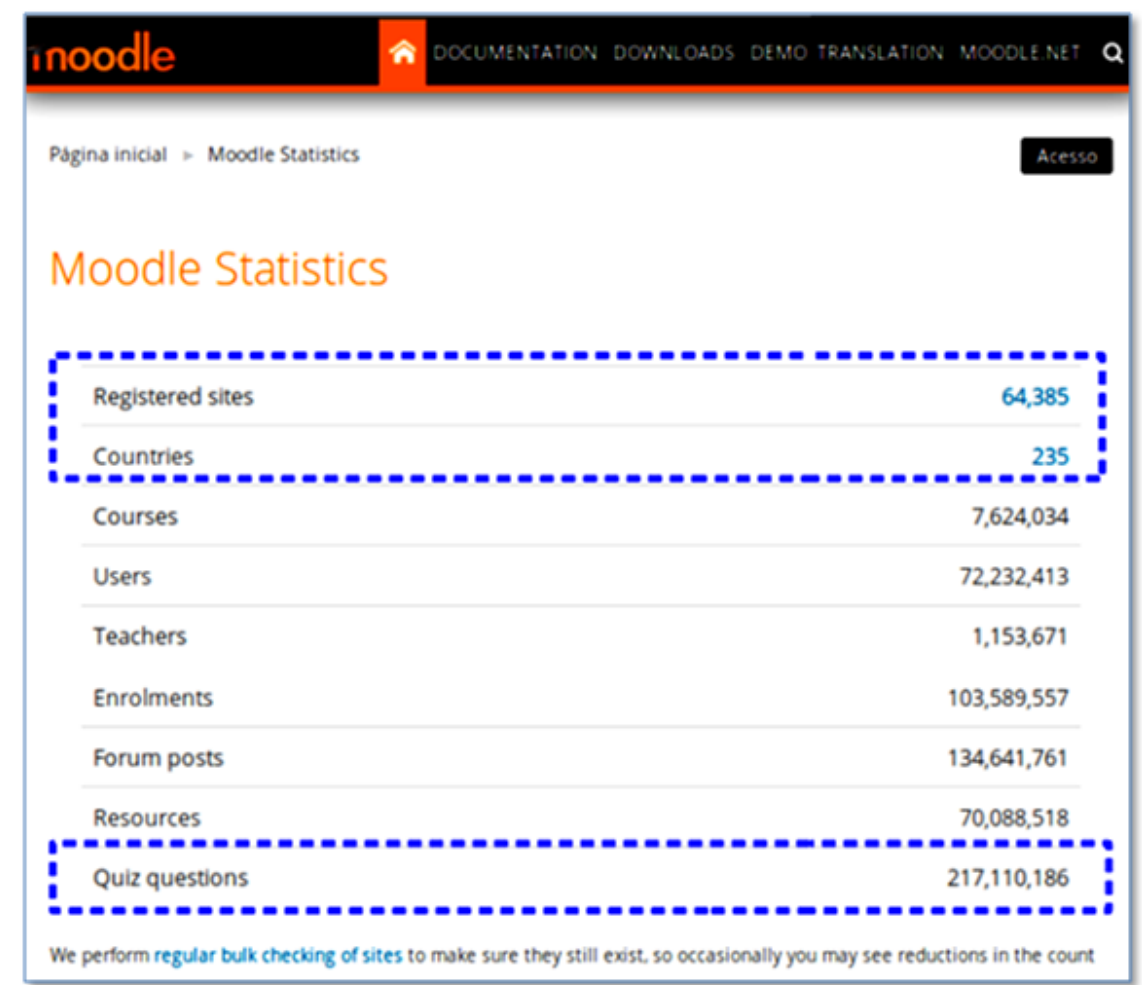

Figura 2.2: Informações estatísticas do Moodle

Na página de estatísticas também pode-se constatar que o Brasil é o terceiro maior usuário do Moodle, sendo também essa uma das motivações pela escolha desse SGC para este trabalho.

Esse sistema disponibiliza diversos recursos para o desenvolvimento de cursos online, além dos distribuídos em sua versão padrão, a comunidade de desenvolvedores Moodle, que reúne milhares de profissionais de diversos países, mantém plugins adicionais para os mais variados recursos, buscando suprir e complementar as necessidades de seus adeptos. Dentre os módulos mais utilizados

\footnotetext{
${ }^{14}$ Disponível em: http://moodle.org/. Acessado em 24 de jun de 2014

15 The GNU Manifesto. Disponível em: http://www.gnu.org/gnu/manifesto.html. Acessado em 24 de jun de 2014

${ }^{16}$ Disponível em: http://moodle.org/stats. Acessado em 30 jul 2014.
} 
do ambiente destaca-se o Quiz, com cerca de 217 milhões de questões criadas e registradas pelos servidores do Moodle, como pode ser constatado na Figura 2.2.

\subsubsection{Moodle Quiz}

O Quiz é um módulo do Moodle utilizado para a criação de questionários avaliativos. Os questionários podem ser compostos por diversos tipos de questões, sendo múltipla escolha e falso/verdadeiro as mais utilizadas no Quiz, como aponta Hunt (2012). As questões utilizadas para construir os questionários no Quiz são mantidas em um banco de questões onde podem ser organizadas por categorias e reutilizadas em outros questionários, além de favorecer o reuso entre cursos por meio dos exportadores e importadores de questões (Nakamura, 2011).

Desde seu desenvolvimento, a comunidade de usuários Moodle vem acrescentando a esse módulo um grande número de opções e alternativas para torná-lo mais flexível. Atualmente o Quiz permite vários ajustes a fim de atender às necessidades dos professores quanto à aplicação de avaliações.

Dentre as principais características do Quiz pode-se destacar (Nakamura, 2011):

- Possibilitar a criação de questionários com diferentes tipos de questões escolhidas a partir do banco de questões, inclusive com questões escolhidas aleatoriamente;

- É possível aleatorizar a exibição dos questionários, embaralhando as questões ou as respostas para cada aluno;

- O professor pode permitir que os alunos refaçam um questionário diversas vezes;

- A correção das questões pode ser automática, imediatamente após o envio da solução, exceto em questões do tipo dissertativas, essas o professor deve corrigir manualmente e registrar seu feedback;

- O professor pode optar por fornecer feedback ou mostrar as respostas corretas, isso automaticamente;

- Dispõe de uma ampla variedade de relatórios para uso do professor em suas avaliações.

Desse modo, o Quiz proporciona estratégias normalmente inviáveis ao ensino presencial, como por exemplo, permitir que os alunos refaçam os testes diversas vezes com correção automática sem gerar trabalho adicional aos professores. Entretanto, segundo Filho e Rangel (2009), o Quiz é uma das ferramentas mais complexas do Moodle. Tal complexidade espelha a variedade de recursos e possibilidades do módulo. Em contrapartida sistemas assim podem tornar-se difíceis de utilizar caso não seja previsto em seus projetos testes de usabilidade com os usuários característicos durante o processo de desenvolvimento, podendo afetar a qualidade de uso do software.

\section{$2.3 \quad$ Usabilidade}

A qualidade de uso de um software está estreitamente relacionado com a capacidade e a facilidade dos usuários atingirem suas metas com eficiência e satisfação. O conceito de qualidade de uso mais amplamente utilizado é o de usabilidade, um termo proveniente da área de estudo da Interação Humano Computador (IHC), cuja preocupação é avaliar e sugerir melhores formas de interação usuário computador, de forma que um sistema atinja os objetivos para os quais foi projetado. Desse modo, o objetivo é facilitar a vida dos usuários na utilização e percepção dos recursos disponíveis pelos sistemas.

Para Preece et al. (2005), "A usabilidade é geralmente considerada como o fator que assegura que os produtos são fáceis de usar, eficientes e agradáveis - da perspectiva do usuário". 
A norma ISO 9241-11 (ISO, 1998), define usabilidade como sendo a "capacidade de um produto ser usado por usuários específicos, para atingir objetivos específicos, com eficácia, eficiência e satisfação em um contexto especifico de uso".

Usabilidade portanto é um conceito utilizado para descrever a qualidade da interação dos usuários com uma determinada interface (Bevan, 1995).

Considera-se que a interface tem um problema de usabilidade se um determinado usuário ou um grupo de usuários encontra dificuldades para realizar uma tarefa nessa interface. Tais dificuldades podem ter origens variadas e ocasionar perda de dados, diminuição da produtividade e mesmo a total rejeição do software por parte dos usuários (Winckler e Pimenta, 2002a). Interfaces desenvolvidas sem o atendimento aos requisitos de qualidade de uso, levam ao desempenho deficiente e a redução de qualidade da interação do usuário com um aplicativo (Santos, 2006).

A usabilidade permite avaliar a qualidade de um sistema em relação a fatores que os projetistas definem como sendo prioritários ao sistema. Segundo Cybis et al. (1998), as avaliações de usabilidade permitem obter alguns resultados, como: (i) constatar, observar e registrar problemas efetivos de usabilidade durante a interação; (ii) calcular métricas objetivas para eficácia, eficiência e produtividade do usuário na interação com o sistema; (iii) diagnosticar as características do projeto que possam atrapalhar a interação por desconformidade com padrões implícitos e explícitos de usabilidade; (iv) prever dificuldades de aprendizado na operação do sistema; (v) prever os tempos de execução das tarefas; (vi) conhecer a opinião do usuário em relação ao sistema; (vii) sugerir as ações do reprojeto mais evidentes diante dos problemas de interação efetivos ou diagnosticados.

Conforme destaca Nielsen (1993) a usabilidade não é uma propriedade única, unidimensional de uma interface de usuário, mas que possui múltiplas componentes associadas a cinco atributos:

- apreensibilidade (learnability): facilidade para o usuário realizar tarefas básicas pela primeira vez;

- eficiência (eficiency): rapidez com que o usuário realiza uma tarefa, uma vez aprendida;

- recordação (memorability): facilidade em relembrar como fazer algo novamente;

- erros (errors): o sistema deve ter uma baixa taxa de erro, de modo que os usuários cometam poucos erros durante o uso do sistema;

- satisfação (satisfaction): quão agradável é utilizar o sistema.

Para Nielsen (2013c), a usabilidade também refere-se aos métodos utilizados para melhorar a facilidade de uso durante o processo de desenvolvimento de uma interface. Nesse caso ele se remete a aplicação dos métodos formais da disciplina de engenharia de usabilidade no processo para desenvolvimento de software.

\subsubsection{Engenharia de usabilidade}

A disciplina de engenharia de usabilidade é uma abordagem empregada no desenvolvimento de software, por meio da qual a usabilidade de um produto é especificada em termos quantitativos e essa especificação ocorre antes do processo de desenvolvimento do produto (Good et al., 1986).

Para Tyldesley (1988), a engenharia de usabilidade é um processo por meio do qual a usabilidade de um produto é especificada quantitativamente, permitindo que seja demonstrado se um produto acabado obteve ou não os níveis de usabilidade exigidos.

A norma ISO $13407^{17}$ (ISO, 2010), corrobora com essas visões, definindo um conjunto de princípios que incorporam a perspectiva do usuário no processo de desenvolvimento de software. De acordo com a norma, há quatro atividades principais, que devem ser empregadas para incorporar requisitos de usabilidade no processo de desenvolvimento de software centrado no usuário. A Figura 2.3 apresenta as etapas do processo recomendadas por essa norma.

\footnotetext{
${ }^{17}$ ISO 13407 é o padrão para procedimentos e métodos sobre projetos de sistemas interativos centrado no usuário.
} 


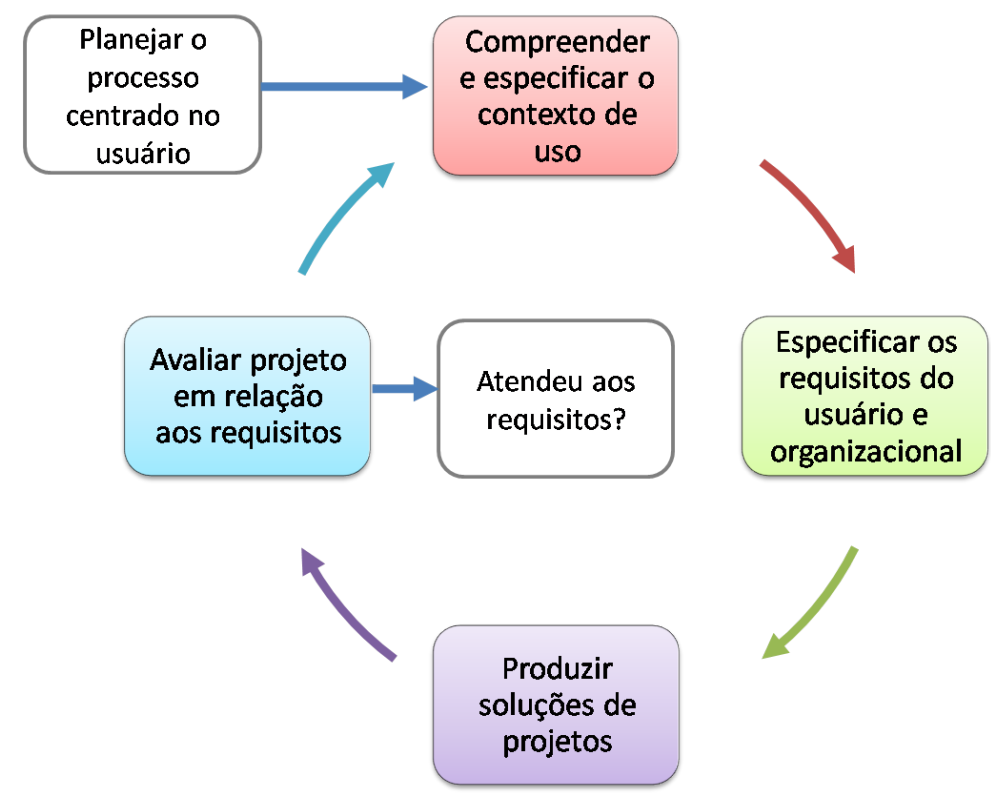

Figura 2.3: Processo de projeto centrado no usuário para sistemas interativos

A engenharia de usabilidade portanto direciona o processo de desenvolvimento de software para a usabilidade do produto. Utiliza metas de usabilidade, tais como: eficiência, efetividade e satisfação para cumprir os objetivos estabelecidos em projeto de software centrado no usuário.

A ideia chave é definir os objetivos de usabilidade mensuráveis logo no início do desenvolvimento do software e, a seguir, utilizados como parâmetros de avaliação repetindo-se durante o processo de desenvolvimento para assegurar que esses objetivos sejam atingidos (Santos, 2006).

\subsubsection{Especificação do processo}

Para aplicar a abordagem da engenharia de usabilidade é necessário a definição de um processo que estabeleça as diretrizes para o desenvolvimento do projeto que incorpore as metas de usabilidade previamente estabelecidas. Uma forma de facilitar a implementação desse processo é utilizar arcabouços desenvolvidos por equipes experientes, um bom exemplo é o RESPECT, um arcabouço para captura de requisitos de usuário que oferece uma base formal para a coleta de dados, utilizando um processo iterativo, elaborado a partir da norma ISO 13407 (ISO, 2010), para facilitar a utilização de projetos centrado no usuário, resultando em um conjunto documentado de requisitos de usuário e o projeto preliminar do sistema (Maguire, 1998).

O RESPECT é composto por um ciclo de três iterações: (1) contexto do usuário e projeto inicial, (2) teste de prototipagem e usuário, (3) documentação dos requisitos de usuário, como ilustra a Figura 2.4. Cada fase passa por quatro etapas fundamentais: (i) entendimento do contexto, (ii) especificação das necessidades, (iii) elaboração de protótipo e (iv) testes com os usuários.

Ao final de cada fase é realizada uma avaliação sobre os resultados obtidos. Se forem satisfatórios segue-se para próxima fase. Normalmente, o processo inicia-se com uma proposta de projeto ou rascunho. Isso descreve o que se deseja do sistema em termos gerais, a partir desse ponto inicia-se os ciclos com as fases. A seguir essas fases são detalhadas:

- Fase 1: Contexto do usuário e o projeto inicial. Visa analisar os processos das tarefas atuais. Nessa fase é feito um resumo do projeto: identificado os usuários e as partes interessadas; especificado as características do usuário; e descrito o ambiente técnico, físico, social e organizacional. São identificados objetivos do usuário e as tarefas, bem como os processos atuais. Também são revistos sistemas similares e executada uma revisão por peritos dos projetos. Por fim, é feita uma avaliação para saber se as ideias de projeto e conceitos formam uma base suficientemente boa para o desenvolvimento de um protótipo. Se assim for, então o 


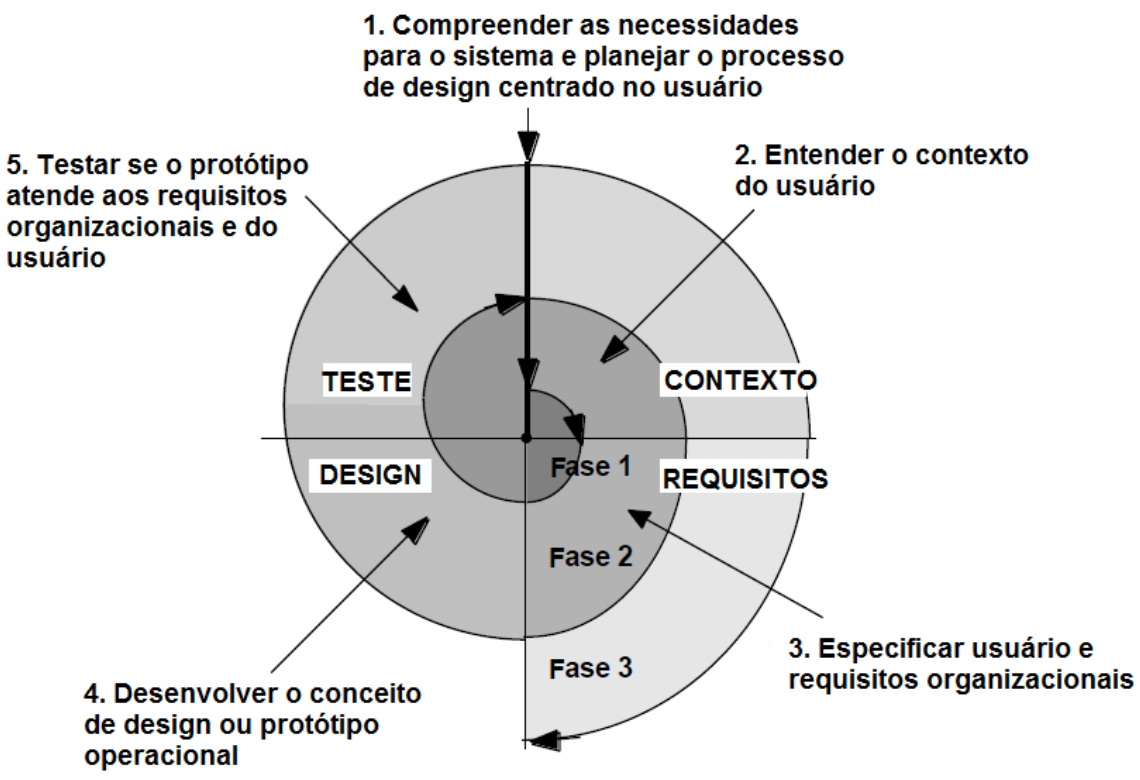

Figura 2.4: Requisitos de usuário e ciclos de projeto definidos no RESPECT. Adaptado de Maguire (1998)

processo continua.

- Fase 2: Prototipagem e teste de usuário. O objetivo é desenvolver novos processos e identificar novas funções. Essa fase procura definir os objetivos gerais e as diretrizes de usabilidade para o processo de design da interface, identificar restrições sobre o processo de design, identificar cenários de tarefas, propor novos processos, desenvolver o protótipo interativo, testar protótipo com usuários e avaliar o custo/beneficio para o usuário. Ao final são consideradas a aceitabilidade das tarefas revistas e os resultados do teste com o protótipo. Se o protótipo foi bem sucedido, o projeto pode ser usado como base para especificação dos requisitos de usuário na realização da fase 3 .

- Fase 3: Documentação de requisitos do usuário. As fases anteriores forneceram subsídios para produção de uma lista de requisitos orientada ao usuário, estruturada sob diferentes tópicos, tais como: projeto de interface do usuário, funções e características, cenários de tarefas e etapas de interação, apoio ao usuário, plano de teste, entre outros.

Comparativamente ao processo tradicional da análise de requisitos na engenharia de software, essa etapa é definida em termos das necessidades dos usuários, ao invés de como elas serão atendidas pelo sistema proposto. As abordagens tradicionais de engenharia de requisitos concentram-se na identificação de requisitos funcionais para assegurar que o produto desenvolvido atende a esses requisitos. Outros requisitos não funcionais (eficiência, confiabilidade, usabilidade, facilidade de manutenção e portabilidade), são tratados com menor importância. No entanto, do ponto de vista do usuário, os requisitos não funcionais podem ser críticos para a implementação bem sucedida de um novo sistema (Maguire, 1998).

O manual do RESPECT recomenda métodos e técnicas adicionais para induzir o sistema a validar requisitos do ponto de vista do usuário, incluindo as funções necessárias para apoiar as tarefas do usuário, as interfaces do sistema com o usuário, suporte necessário ao usuário, exigências físicas e organizacionais e as metas de usabilidade que devem ser alcançadas.

\subsubsection{Recomendações de usabilidade}

Geralmente a usabilidade de um sistema é atingida quando recomendações de usabilidade são aplicadas desde a fase inicial do projeto. A aplicação de tais recomendações se reflete no sistema por 
meio de atributos como a facilidade de aprendizado, a eficiência de uso, a facilidade de memorização, a baixa taxa de erros, assim como a satisfação subjetiva. As recomendações são baseadas em estudos realizados por vários autores ao longo de décadas, os quais recomendam que no processo de desenvolvimento de sistemas e interfaces, o usuário seja a referência inicial, mais que isso, o usuário deve ser o elemento chave do processo de desenvolvimento (Bastien e Scapin, 1993; Dul e Weerdmeester , 2004; Jordan, 1998; Nielsen, 2005; Shneiderman, 1998). Dentre as muitas publicações existentes destaca-se o Research-Based Web Design and Usability Guidelines, que possui recomendações de design e usabilidade para a Web, envolvendo os princípios e contrastando trabalhos e suas conclusões. Esse guia é uma compilação sistemática dos trabalhos publicados até a atualidade sobre princípios e conceitos do design e da usabilidade, colocados sob a avaliação de equipes de especialistas que classificaram e agruparam em recomendações para Web (Health e Services, 2006). Suas orientações incluem a importância relativa e a força de evidência para cada recomendação juntamente com a revisão da literatura. Desse modo este é o guia dos guias de recomendações, constituindo-se uma importante referência para desenvolvedores de sistemas ao projetarem, testarem e finalizarem os softwares.

Neste trabalho o processo de usabilidade foi planejado utilizando o RESPECT e as recomendações de usabilidade do Research-Based Web Design and Usability Guidelines, por oferecerem diretrizes capazes de atender as premissas do projeto. Após a definição de um processo que contemple boas recomendações de usabilidade, também se faz necessário estabelecer um conjuntos de métodos para avaliar se as métricas de usabilidade estão sendo atingidas no decorrer do projeto. Dentre os vários métodos disponíveis destacam-se os testes de usabilidade, avaliações heurísticas e questionários para avaliação subjetiva.

\subsubsection{Teste de usabilidade}

Os testes de usabilidade buscam avaliar a qualidade de usabilidade presente em um software, avaliando principalmente o desempenho do usuário, representando o principal método a ser utilizado para medição de desempenho e validação dos protótipos. De um modo geral, o objetivo desses testes é obter indicações de como melhorar a qualidade de uso da interface.

Segundo Nielsen (2013a), os testes de usabilidade podem ser realizados com apenas 5 usuários. Ele mostra que o número de problemas de usabilidade detectados em um teste com $n$ utilizadores é N(1-(1-L)n), onde $N$ é o número total de problemas de utilização na criação e $L$ é a proporção de problemas de utilização detectados durante o teste de um único usuário, sendo o valor típico de L de $31 \%$. Seus estudos mostram que este número apresenta a melhor relação custo benefício. Isto porque o teste com um usuário identifica aproximadamente $30 \%$ dos problemas da aplicação. E cada novo usuário, encontra 30\% de problemas. Uma parte desses representa os novos problemas, enquanto a outra representa problemas encontrados pelos usuários anteriores. Assim, a cada novo teste é reduzido o número de novos problemas, e aumenta-se o número de problemas já encontrados.

Dessa forma com 5 usuários é possível encontrar aproximadamente $85 \%$ dos problemas da aplicação e o benefício dos novos erros encontrados vale o custo do teste executado. Essa relação foi demonstrada por meio de um estudo de caso com 83 projetos conduzido por Nielsen (2013b).

\subsubsection{Avaliação heurística}

Avaliação heurística é um método analítico que tem como base um conjunto de diretrizes de usabilidade que descrevem características desejáveis da interação e da interface, chamadas por Nielsen (1993) de heurísticas e visa identificar problemas de usabilidade. Esse método orienta os avaliadores a inspecionar sistematicamente a interface em busca de problemas que prejudiquem a usabilidade (Barbosa e Silva, 2012). Os avaliadores podem ser especialistas em usabilidade, mas também podem ser consultores de desenvolvimento de software especializados em um determinado estilo de interface.

Por ser um método de inspeção, a avaliação heurística foi proposta como uma alternativa de avaliação rápida e de baixo custo, quando comparada a métodos empíricos (Nielsen, 2005, 1993). 
O método foi utilizado pela primeira vez em uma interface Web em 1994, para o estudo de um Web site da Sun Microsystems (Nielsen e D., 1995).

As 10 heurísticas de Nielsen (2005), foram descritas com muita clareza por Winckler e Pimenta (2002b):

Diálogos Simples e Naturais: as interfaces de usuários devem ser o mais simples possível. Interfaces devem combinar as tarefas do usuário de forma a simplificar o mapeamento entre os conceitos computacionais e os do usuário. Deve-se apresentar exatamente a informação que o usuário precisa - nem mais nem menos - na hora e lugar exatos onde é necessária. Informação que será usada em conjunto deve ser exibida em conjunto, ao menos na mesma tela. Tanto os objetos de informação quanto as operações devem ser acessados em uma sequência compativel com o modo pelo qual os usuários irão realizar suas tarefas efetiva e produtivamente. Muitas vezes tais sequências são forçadas pela interface, mas normalmente é melhor permitir que o usuário controle o diálogo o máximo possivel, de tal forma que a sequência possa se ajustar às preferências do usuário.

Falar a Linguagem do Usuário: a terminologia da interface deve ser baseada na linguagem do usuário, e não orientada ao sistema. Para tanto, deve-se verificar quais termos são utilizados com maior frequência pelos usuários. As informações também devem ser organizadas conforme o modelo mental que o usuário possui do domínio.

Minimizar a Sobrecarga de Memória do Usuário: o software deve exibir elementos de diálogo para o usuário e permitir que o mesmo faça suas escolhas, sem a necessidade de lembrar deste ou daquele comando específico. Para facilitar a utilização da interface, deve ser apresentado ao usuário um pequeno número de recomendações que se aplicam por toda a interface. Se o número de recomendações é grande o usuário terá de aprender/lembrar todas as recomendações, o que pode não ser tão simples. Por outro lado, se o software não tiver regra alguma, então o usuário deverá lembrar de cada elemento de diálogo. $O$ uso de comandos genéricos é uma maneira de se ter um pequeno conjunto de recomendações. Comandos genéricos fazem com que coisas similares ocorram em diferentes circunstâncias, sendo suficiente ao usuário aprender poucos comandos para trabalhar com vários tipos de dados.

Consistência: consistência é um dos princípios básicos de usabilidade. Se os usuários souberem que um mesmo comando ou uma mesma ação terá sempre o mesmo efeito, eles ficarão mais confiantes no uso do software, e serão encorajados a fazerem novas descobertas. A mesma operação deverá ser apresentada na mesma localização em todas as telas e deverá ser formatada da mesma maneira para facilitar o reconhecimento.

Feedback: O sistema deverá informar continuamente ao usuário sobre o que ele está fazendo. O tempo de resposta influi no tipo de feedback que deve ser dado ao usuário. Um décimo de segundo $(0,1 s)$ é o limite para o usuário pensar que o sistema está reagindo instantaneamente, o que significa que nenhum feedback especial é necessário; um segundo (1,0s) é o limite para que o fluxo de pensamento do usuário não seja interrompido, mesmo que o usuário perceba uma certa demora; e dez segundos (10s) é o limite para manter a atenção do usuário focalizada no diálogo. Muitas vezes, feedbacks especiais são necessários para mostrar o andamento de uma tarefa ou contextualizar uma navegação mais demorada do usuário.

Saidas Claramente Marcadas: De modo a fazer com que o usuário sinta que pode controlar o software, deverá ser fácil sair das situações mais variadas possiveis. Por exemplo, todas as caixas de diálogo devem possuir um botão Cancelar para abortar uma tarefa. Muitas vezes, as saídas podem ser fornecidas por meio de uma facilidade de desfazer (undo) a última operação e retornar ao estado anterior. Os usuários rapidamente aprendem a confiar neste mecanismo e portanto ele deve estar disponivel como um comando genérico por todo o software. Neste caso, o usuário poderá confiar no aprendizado por exploração, pois saberá desfazer eventuais erros.

Atalhos: embora deva ser possivel operar a interface conhecendo-se apenas algumas regras gerais, deveria também ser possivel para o usuário experiente executar mais rapidamente operações frequentemente utilizadas, através de atalhos. Aceleradores típicos incluem abreviações, teclas de função, clique duplo do mouse, ou botões especiais para funções frequentes. Também podem ser apresentados através da exibição dos últimos comandos executados, ou da função de volta (back- 
track) em sistemas de hipertexto. Atalhos são também necessários quando por uma política de uma empresa ou organização a informação que se encontra em uma maior profundidade da árvore navegacional tenha que ser recuperada diretamente pela interface principal. Por exemplo, na página da Receita Federal, na época de declarar o IRPF, deve haver um link na primeira página para declaração online ou para download dos programas de declaração ao invés de obrigar o usuário a navegação pelo site até achar a página correta, o que muitas vezes não é fácil.

Boas mensagens de erro: as mensagens de erro devem seguir algumas regras: linguagem clara e sem códigos. Devem ser precisas. Devem ajudar o usuário a resolver o problema. Não devem intimidar ou culpar o usuário.

Prevenir Erros: melhor do que possuir boas mensagens, é evitar situações de erro. Conhecendose as situações que mais provocam erro, sempre é possivel modificar a interface e tornar muito improvável que este erro ocorra.

Ajuda e Documentação: o melhor é que um software que seja tão fácil de usar que não necessite de ajuda ou documentação. No entanto, se preciso, esta ajuda deve estar facilmente acessivel online. Além disto, sabidamente usuários raramente leem a documentação".

Além destas recomendações outras publicações com heurísticas que se intercalam ou se completam sob outros aspectos foram publicados, como as de Jordan (1998) e Dul e Weerdmeester (2004).

A avaliação heurística aparece na revisão sistemática de Martins et al. (2013), como método de inspeção mais utilizado em trabalho de usabilidade. Nielsen (1995) também confirma por meio de estudos, que esse é um método muito eficiente. Ainda segundo ele pelo menos 3 avaliadores são necessários para trazer bons resultados, a medida que esse número aumenta, atingindo de 5 a 15 avaliadores, os resultados vão melhorando.

\subsubsection{Questionário System Usability Scale (SUS)}

O System Usability Scale (SUS) é um tipo de questionário, desenvolvido em língua inglesa que possibilita uma avaliação subjetiva simples, apresentando uma visão global do usuário em relação ao sistema. O SUS possui uma escala de usabilidade de dez itens desenvolvida em 1986 por Brooke (2014), para um programa de usabilidade na Digital Equipment ${ }^{18}$. Cada afirmativa do questionário contém uma declaração relativa ao aspecto de interesse, a qual é associada a uma escala de Likert de 5 pontos (1 a 5 ), variando de strongly disagree (discordo fortemente) a strongly agree (concordo fortemente).

O questionário original em inglês encontra-se no Apêndice H. Para calcular a pontuação do SUS é necessário somar as contribuições de cada item com valores de 0 a 4 . Para as questões ímpares a contribuição é calculada pela posição da escala menos 1 . Para as questões pares, calcula-se 5 menos o valor da posição da escala. Depois multiplica-se a soma dos valores por 2,5 e obtém-se a pontuação, com amplitude entre 0 a 100, (Brooke, 2014).

\subsection{Levantamento bibliográfico}

A pesquisa bibliográfica buscou na literatura trabalhos relacionados aos problemas do Quiz e possíveis soluções. A partir do resultado dessa busca foi possível destacar algumas informações relevantes sobre problemas de usabilidade do Quiz.

As buscas foram realizadas no SBIE ${ }^{19}$, na Association for Computing Machinery (ACM) ${ }^{20} \mathrm{e}$ no Institute of Electrical and Electronics Engineers (IEEE) ${ }^{21}$. Foram elaboradas strings para filtrar trabalhos que incluíssem os termos "usabilidade", "Moodle" e "Quiz", com possibilidade de variar a palavra Moodle com os termos AVA ou SGC. De modo que deveriam: (i) conduzir a problemas de

\footnotetext{
${ }^{18}$ Disponível em: http://pt.wikipedia.org/wiki/Digital_Equipment_Corporation. Acessado em: 22 de Julho de 2014

${ }^{19}$ Disponível em: http://www.br-ie.org/pub/index.php/sbie. Acessado em 10 mai 2014.

${ }^{20}$ Disponível em: http://dl.acm.org/. Acessado em 31 jul 2014.

${ }^{21}$ Disponível em: http://ieeexplore.ieee.org/Xplore/home.jsp. Acessado em 20 jun 2014.
} 
usabilidade avaliados no ambiente ou (ii) técnicas aplicadas na solução de problemas de usabilidade no Moodle e eventualmente em outros ambientes. Os termos usabilidade, AVA e SGC foram trocados por usability, VLE e $L M S$, nas buscas em inglês.

As buscas no SBIE foram realizadas manualmente, em função de problemas com a máquina de busca, que não reconhecia adequadamente as combinações and e or. Assim foram separados inicialmente os artigos dos últimos cinco anos que continham os termos no resumo. Depois uma nova triagem realizada pela leitura da introdução e eventualmente conclusão. Foram separado 9 (nove) artigos considerados relevantes para análise e considerações.

$\mathrm{Na}$ ACM a busca com o termo Quiz não retornou artigos, assim foi utilizada a string, "usability and Moodle", para localizar os artigos dos últimos cinco anos pelo abstract. Após a triagem inclusive retirando artigos duplicados, apenas 2 dois eram relevantes. O mesmo procedimento aplicado na busca pela ACM, foi repetido no IEEE, dos quais 4 foram selecionados.

A seguir a Tabela 2.1, apresenta a lista de artigos selecionados, após analise do resumo e introdução.

\section{RESULTADOS DA PESQUISA BIBLIOGRÁFICA}

\begin{tabular}{|c|c|}
\hline Conferência & Fonte \\
\hline SBIE & 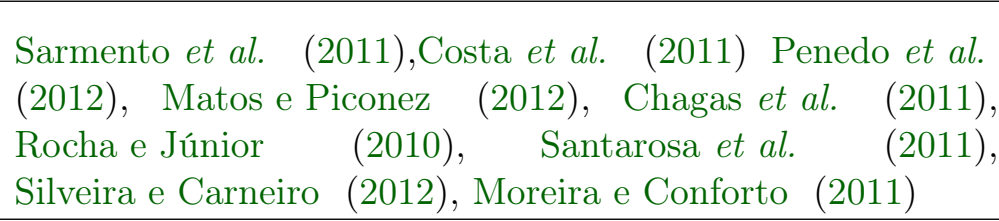 \\
\hline $\mathrm{ACM}$ & Forment et al. (2012), Magalhães et al. (2010) \\
\hline IEEE & $\begin{array}{l}\text { Kakasevski et al. (2008), Skellas e Ioannidis (2011), } \\
\text { Baytiyeh (2011), Álfredo Figueira e Cunha (2009) }\end{array}$ \\
\hline
\end{tabular}

Tabela 2.1: Resultado da pesquisa sobre trabalhos relacionados

Embora todos os artigos listados na Tabela 2.1, tenham contribuido para este trabalho, nenhum deles tratou diretamente dos problemas de usabilidade do Quiz como retratado no trabalho de (Savolainen, 2010), seção 2.5. Alguns artigos contribuiram para identificação de métodos e técnicas aplicados na identificação ou resolução de problemas de usabilidade, enquanto outros trouxeram dados sobre problemas comuns de usabilidade em ambientes virtuais ou mesmo no Moodle. De modo geral auxiliaram com a visão apresentada sobre os problemas de usabilidade dos ambientes, nas tentativas de melhoria e também com apontamentos sobre a literatura relacionada. A seguir são descritos brevemente cada um dos artigos:

O artigo Sarmento et al. (2011) descreve o processo de avaliação de usabilidade de um SGC, o Solar, e o uso desta avaliação para melhoria desse ambiente. O objetivo principal, portanto, do trabalho é mostrar uma estratégia de análise de usabilidade como peça chave inicial ao planejamento da criação ou melhoria de ambientes virtuais de aprendizagem, juntamente com a proposta pedagógica ao qual deverá aderir.

O trabalho de Costa et al. (2011) teve como objetivo avaliar a usabilidade da plataforma Moodle Mobile e da ferramenta de autoria Quiz Mobile em relação ao Moodle para computadores, para identificar possibilidades, funcionalidades e limitações dos ambientes voltados para uso em aparelhos celulares em relação ao sistema tradicional, para uso em computadores.

O objetivo do trabalho de Penedo et al. (2012) foi apresentar um estudo de usabilidade de um sistema EAD utilizando a inspeção baseada em modelos Markovianos em conjunto com a inspeção baseada em taxonomia. 
O primeiro método apresentou resultados quantitativos, o que permitiu identificar informações como o caminho percorrido pelos usuários dentro do sistema, tempo de permanência em cada ferramenta disponibilizada, quais as ferramentas mais utilizadas. O segundo método apresentou resultados qualitativos que permitiu caracterizar, por exemplo, requisitos relacionados à exibição de informação e requisitos relacionados à entrada de dados. A combinação desses dois métodos de inspeção mostrou ser simples de aplicar e tornou a avaliação da usabilidade do sistema mais completa.

Dada a relevância de estudo sobre as relações entre tecnologia e propostas pedagógicas apoiadas por recursos tecnológicos presentes nos sistemas de ensino, formais e não formais, o trabalho de Matos e Piconez (2012) apresenta alguns resultados de uma pesquisa de natureza qualitativa que investiga o papel da usabilidade de um fórum, enquanto concepção tecnológica na implementação de uma proposta pedagógica de um curso mediado por recursos da Internet sob a ótica de seus usuários finais.

O trabalho de Chagas et al. (2011) descreve uma metodologia, chamada MAAVA - Metodologia de Avaliação de Ambientes Virtuais de Aprendizagem, destinada à avaliação de um ambiente configurado para um curso, fundamentado: i) na importância de atrelar os objetivos educativos das ferramentas do SGC aos objetivos pedagógicos, dos quais se pretende que os alunos alcancem ao final de um curso e/ou disciplina e; ii) na importância de ter um SGC com boa usabilidade, comunicabilidade e sociabilidade para não afetar o atendimento aos objetivos pedagógicos.

O trabalho feito por Rocha e Júnior (2010) realizou um estudo propondo algumas técnicas com o objetivo de acelerar o processo de aprendizado principalmente para aqueles indivíduos que nunca tiveram nenhum tipo de contato com a informática ou aqueles que têm pouco conhecimento.

Para este fim, utilizaram as heurísticas de usabilidade de Jakob Nielsen como entrada para árvores de decisão. A ideia foi verificar qual heurística possui o melhor ganho de informação, que ajudará no processo de utilização de uma interface adaptada a qualquer tipo de usuário.

O trabalho realizado por Santarosa et al. (2011) buscou projetar uma interface a partir de princípios de usabilidade e de acessibilidade para o ambiente de aprendizagem Eduquito que investiga e projeta um conjunto de ferramentas acessíveis e usáveis para garantir que a fluidez do universo virtual seja uma realidade para indivíduos com as mais distintas características e necessidades especiais.

O trabalho de Silveira e Carneiro (2012) destaca que os Objetos de Aprendizagem (OA) podem ser desenvolvidos de várias formas, sem seguir regras ou padrões. Contudo para garantir que os OA sejam eficazes para o aprendizado e possam ser reutilizados parcial ou integralmente para atividades, esses devem ser produzidos segundo critérios e processos tecnológicos e pedagógicos.

Assim, o intuito do trabalho foi contribuir para uma produção de OA, com a proposta de diretrizes para a avaliação da usabilidade de objetos de aprendizagem. Essa proposta foi elaborada a partir de estudos teóricos e da análise de objetos de aprendizagem, análise esta feita por uma equipe técnica e por professores envolvidos na produção de OA.

Para a elaboração das diretrizes propostas, a primeira etapa constou da análise de referencial teórico, na qual foram feitos estudos sobre avaliação de interfaces e interação em geral, bem como sobre objetos de aprendizagem e sua avaliação. Na segunda etapa, foi realizada a análise de objetos de aprendizagem sob a ótica da área de IHC, aplicando-se, a um conjunto destes, o método de inspeção de usabilidade denominado avaliação heurística.

O trabalho feito por Moreira e Conforto (2011) mostra um cenário de discussão, problematizando a modelagem de recursos digitais, em especial $\mathrm{OA}$, quanto às possibilidades de acesso, à funcionalidade da interface e apropriação do conteúdo que disponibiliza.

A investigação, metodologicamente, desencadeou uma pesquisa exploratória, do tipo multicaso, por eleger como corpus de análise, três OA disponíveis no Banco Internacional de Objetos Educacionais (BIOE) para a verificação da Acessibilidade e a da Usabilidade. As categorias de análise para a verificação da Acessibilidade e da Usabilidade dos OA tiveram como base os princípios da W3C/WCAG 2.0 (2008) e as heurísticas de (Nielsen, 1993); (Nielsen, 2005).

$\mathrm{O}$ artigo de Forment et al. (2012) descreve um conjunto de características que motores de pes- 
quisa exigem para compor cenários educacionais colaborativos de sucesso. Os autores exploram múltiplas questões que lidam com pesquisas durante as atividades de aprendizagem. Uma das primeiras questões a resolver é o suporte de software para metodologias de avaliação. O segundo é escolher entre usar um motor de pesquisa integrado dentro do Sistema de Gestão da Aprendizagem ou um motor independente de pesquisa externo. Vantagens e desvantagens de ambas as opções desta segunda edição são discutidos. As diferentes implicações de cada opção, na medida que os alunos são avaliados, feedback, e classificação estão também são analisados. Entre os resultados esperados, os mais notáveis são incentivos para incorporar pesquisas no processo de ensino, melhorias significativas na usabilidade, permitindo que os professores forneçam mais feedback instantaneamente o que permite contribuições individuais de seus alunos em atividades de pesquisa.

No artigo de Magalhães et al. (2010) é apresentado uma avaliação de usabilidade do sistema de gestão da aprendizagem Moodle IFAM, que é usado na educação a distância. Para essa avaliação foi aplicado os métodos: Cognitive Walkthrough e Comunicabilidade. Reunindo informações úteis sobre como melhorar a usabilidade do Moodle e também verificar algumas práticas de administrador e tutores do sistema pode melhorá-lo.

O artigo de Kakasevski et al. (2008) traz uma avaliação de usabilidade de módulos padrão no Moodle. O objetivo da pesquisa foi obter resultados e informações para administradores, professores e alunos sobre como melhorar o uso eficaz do sistema.

O estudo de Baytiyeh (2011) avalia a usabilidade do Moodle com base nas percepções de 189 professores e 1.867 estudantes da Universidade Americana de Beirute. Os participantes foram convidados a participar de uma pesquisa online que reflete o desempenho do sistema de ensino e de aprendizagem, os resultados foram classificados e feito um ranking composto por um conjunto de 30 itens relativos à usabilidade, os cinco atributos mais relevantes foram: apreensibilidade, eficiência, memorização, prevenção de erros e satisfação. Além de testar os atributos de usabilidade e avaliação do sistema de gestão do curso, o estudo teve como objetivo atestar a qualidade do software de código aberto em instituições acadêmicas na região do Oriente Médio.

No trabalho Álfredo Figueira e Cunha (2009) é mostrado a importância de ambientes de aprendizagem, onde todos os participantes podem apresentar suas ideias, sendo em sua opinião essencial para melhorar o processo de aprendizagem e também importante para o desenvolvimento da motivação e sentido de responsabilidade. O módulo de oficina do Moodle parecia resolver esse problema, no entanto foi observado que esse módulo era raramente usado e, estava previsto para ser removido da próxima versão. Foi então realizado um conjunto de testes e investigações que levaram a concluir que a sua usabilidade é muito baixa, sua interface era pouco compreensível e as notas finais para a atividade eram confusas. No trabalho é apresentado uma reformulação do módulo de oficina em que diz respeito à interface de configuração, o módulo de administração e a página notas finais. Os resultados preliminares indicaram uma melhoria de mais de $300 \%$ da usabilidade.

Problemas de usabilidade no Moodle são frequentemente investigados, mas foram poucos os trabalhos que contribuiram diretamente para melhorias. Parte dos problemas de usabilidade é atribuída a comunidade de desenvolvimento do Moodle, que não emprega em seus processos métodos para avaliar a usabilidade do sistema com os usuários finais do ambiente. Muitos artigos tratam do mesmo problema em outras ferramentas, o que aponta uma certa generalização dos problemas de usabilidade em sistemas gerenciadores de cursos. A partir dessas descobertas uma investigação foi realizada na documentação do Moodle de onde obteve-se a informação sobre o trabalho relacionado descrito na Seção 2.5 .

\subsection{Trabalhos relacionados}

O trabalho relacionado com objetivos bem próximo ao deste trabalho foi o realizado por Savolainen (2010), no qual a refatoração da interface ${ }^{22}$ do Quiz no Moodle 1.9 fez parte de uma prova de con-

\footnotetext{
${ }^{22}$ Disponível em: http://docs.moodle.org/dev/Quiz_UI_redesign_prototype. Acessado em 28 de maio de 2013
} 
ceito da sua dissertação, intitulada "User experience design in open source development: Approaches to usability work in the Moodle community".

Quando o trabalho iniciou o objetivo era integrar Moodle e a funcionalidade do módulo Quiz em um sistema personalizado para fazer avaliações, chamado Tenttis. No sistema, os estudantes podiam reservar um computador por meio do site e em seguida fazer suas avaliações em uma sala de aula vigiada por câmera de vídeo no Centro de Tecnologia de Aprendizagem da Universidade de Tampere.

O departamento responsável pelo apoio com o Moodle e documentação para professores na universidade é denominado por Centro de Tecnologia de Aprendizagem (LTC). Eles relataram durante o projeto Tenttis que muitos dos professores da universidade, potenciais utilizadores do Tenttis, eram novatos com Quiz, e muitos deles, também no uso de computadores. Sendo que a interface do Quiz para edição era muito difícil de entender e exigia um nível muito alto de comprometimento.

Os motivos que levaram o autor desse trabalho relacionado a iniciar sua pesquisa, assemelhase aos nossos, assim como ele, também foi identificado tais dificuldades durante a aplicação de um curso para professores no Moodle e de forma semelhante a necessidade de utilizar o Quiz do Moodle. No caso de Savolainen (2010) a motivação era integrar os sistemas para obter os recursos de criação de questionários do Quiz para realizar as avaliações dos alunos na universidade. No caso deste trabalho a necessidade de uso do Quiz foi em razão da aplicação de uso dos $i M A$ dentro do ambiente do Moodle para permitir que fosse possível a utilização desse tipo de atividade nos questionários. O ponto em comum é que ambos os projetos iniciaram-se pela necessidade de uso do Quiz e se depararam com sua dificuldade de uso relacionada aos problemas de usabilidade.

Em janeiro de 2007, Savolainen (2010) verificou que nenhum trabalho estava sendo feito com relação aos problemas de interface de usuários no Moodle. Esse foi o primeiro trabalho voltado a estudar a interface utilizada pelos professores no Moodle. Segundo Savolainen (2010) nesta ocasião ao se aproximar da comunidade Moodle para saber mais sobre o projeto, descobriu que não havia nenhuma documentação de requisitos para o módulo e também notou que o ponto de vista dos membros sobre a interface eram divergentes dentro da comunidade. Ainda segundo Savolainen (2010) a visão sobre o fluxo de trabalho do questionário era de um instrumento secundário para apresentar as perguntas aos alunos, sendo que o gerenciamento das questões era realizado separadamente no módulo banco de questões.

O problema de usabilidade era um dos pontos que constituía uma barreira aos professores e o projeto Tenttis teria de ser capaz de possibilitar que os professores criassem os seus questionários facilmente, então Savolainen (2010) propôs modificações na interface, que foram rejeitadas pela comunidade Moodle. Devido a isso, ele procurou se aproximar mais da comunidade Moodle e entender sua dinâmica, assim pode concluir que a comunidade se aplica a resolver problemas técnicos, essa aplicação está relacionada também ao status que um membro adquire na comunidade por resolver problemas importantes e difíceis. Para eles problemas de usabilidade não constitui desafio e não são vistos como importantes e consequentemente não geram status.

Quando um módulo é liberado para testes ele fica na esfera da comunidade onde os usuários são avançados mais técnicos do que a maioria dos usuários dos módulos. Assim eles não percebem as dificuldades que nesta pesquisa se procura evidenciar.

Diante da sua constatação Savolainen (2010) procurou Tim Hunt, responsável por gerir o módulo para conduzir as melhorais sem contrariar a comunidade. Assim os dois trabalharam juntos nas modificações do Quiz.

Após levantamento de problemas e testes de usabilidade, em agosto de 2008 a refatoração da interface de usuário foi concluída e o código incorporado ao Moodle 2.0.

Durante o projeto foi realizado testes de usabilidade que listaram inúmeros problemas, um deles derivado em seis categorias, mostrando a diversidade dos problemas encontrados ${ }^{23}$, como apresentado a seguir:

\footnotetext{
${ }^{23}$ Disponível em: http://docs.moodle.org/dev/Usability_testing_in_August_2008/Issues_found. Acessado em 30 de maio de 2013
} 
- Simplificação do formulário de questões: havia confusão no preenchimento de formulários;

- Classificar os modos de visualização: problemas em localizar funcionalidades e suas diferenças entre papéis ou funções do usuário no sistema;

- Teste de navegação geral: problemas na navegação, dificuldade para localização das informações na tela;

- Links e cores: falhas na identificação de links e cores;

- Nomes das questões: problemas relacionados a localização do tipo de questão;

- Variados: foram identificados problemas com ícones, botões, visualização de elementos e hierarquia de elementos.

Outro teste de usabilidade com usuários foi realizado e identificados 52 problemas que descreviam: confusão sobre onde adicionar perguntas, problemas com o banco de questões, confusão conceitual (categorias / questões aleatórias), dificuldade de encontrar ajuda, dentre outros ${ }^{24}$.

Posteriormente, um teste já com o protótipo de Savolainen (2010), foi realizado com 6 usuários e mais 32 problemas foram encontrados.

A Figura 2.5 apresenta a tela principal de como o Quiz deveria aparentar, resultado da proposta de redesign de Savolainen (2010). Sua principal ideia é que as informações deveriam ser agrupadas em abas, para que fossem sendo reveladas por demanda para reduzir a quantidade de informações iniciais na tela. Ele pensou em disponibilizar um painel de controle (Dashboard) na primeira aba contendo informações sucintas do questionário e links para as tarefas de configurar, editar e pré visualizar o questionário seguido das opções de relatório.

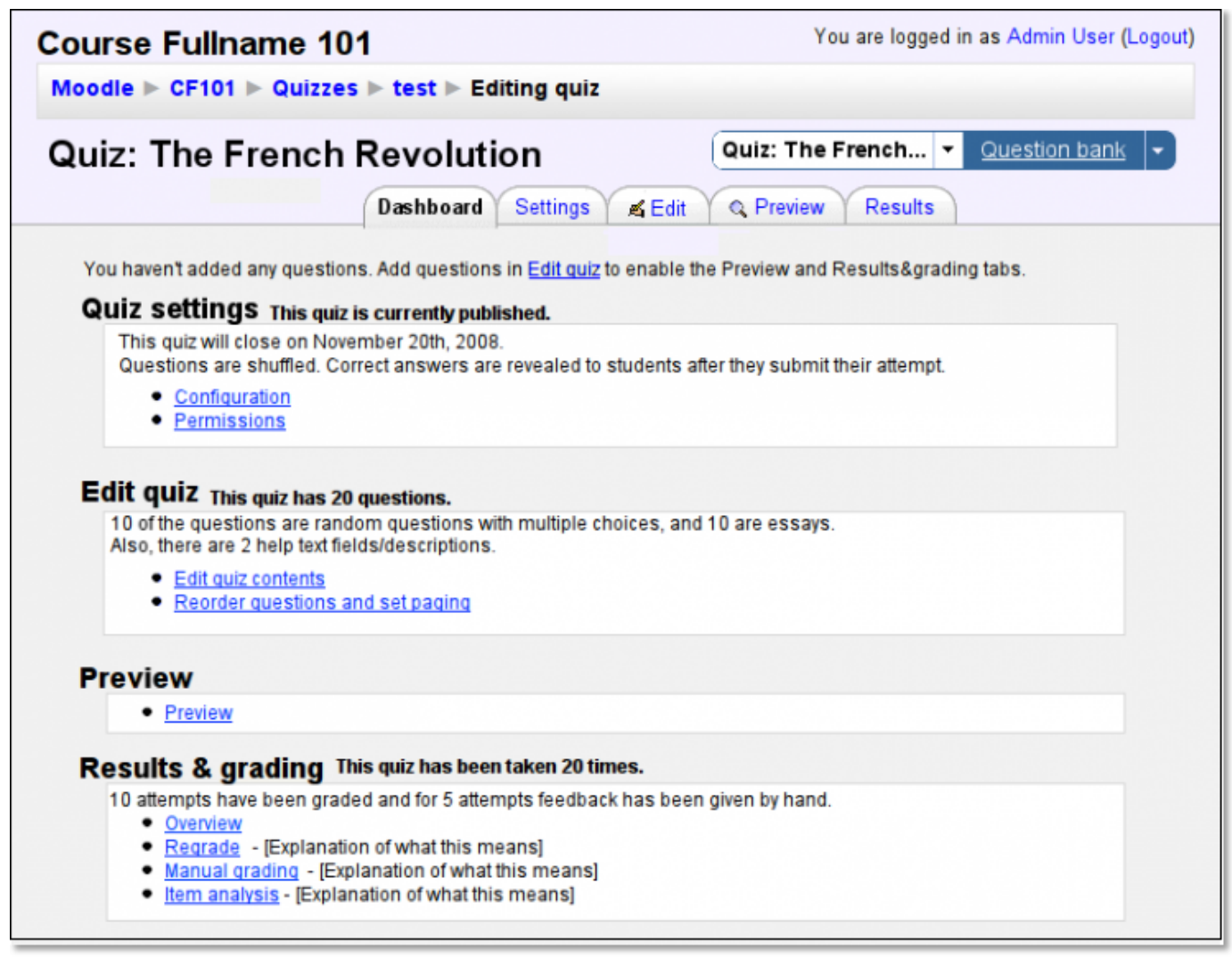

Figura 2.5: Exemplo da tela de edição do Quiz para o Moodle 2.0 refatorada. Fonte: Moodle (2013b)

\footnotetext{
${ }^{24}$ Disponível em: http://docs.moodle.org/dev/Quiz_UI_redesign/usability_testing_of_August_2008/Issues. Acessado em 5 de Julho de 2013
} 
Os detalhes das opções descritas no painel seriam disponibilizadas nas próximas quatro abas disposta ao lado do painel de controle (Dashboard), seriam elas: configurações (settings), edição (edit), pré visualizar (preview) e resultado (results). Como foi verificado na versão 2.0 do Moodle, esta modificação não foi implementada exatamente da forma desejada, mas como mostrado na Figura 2.6

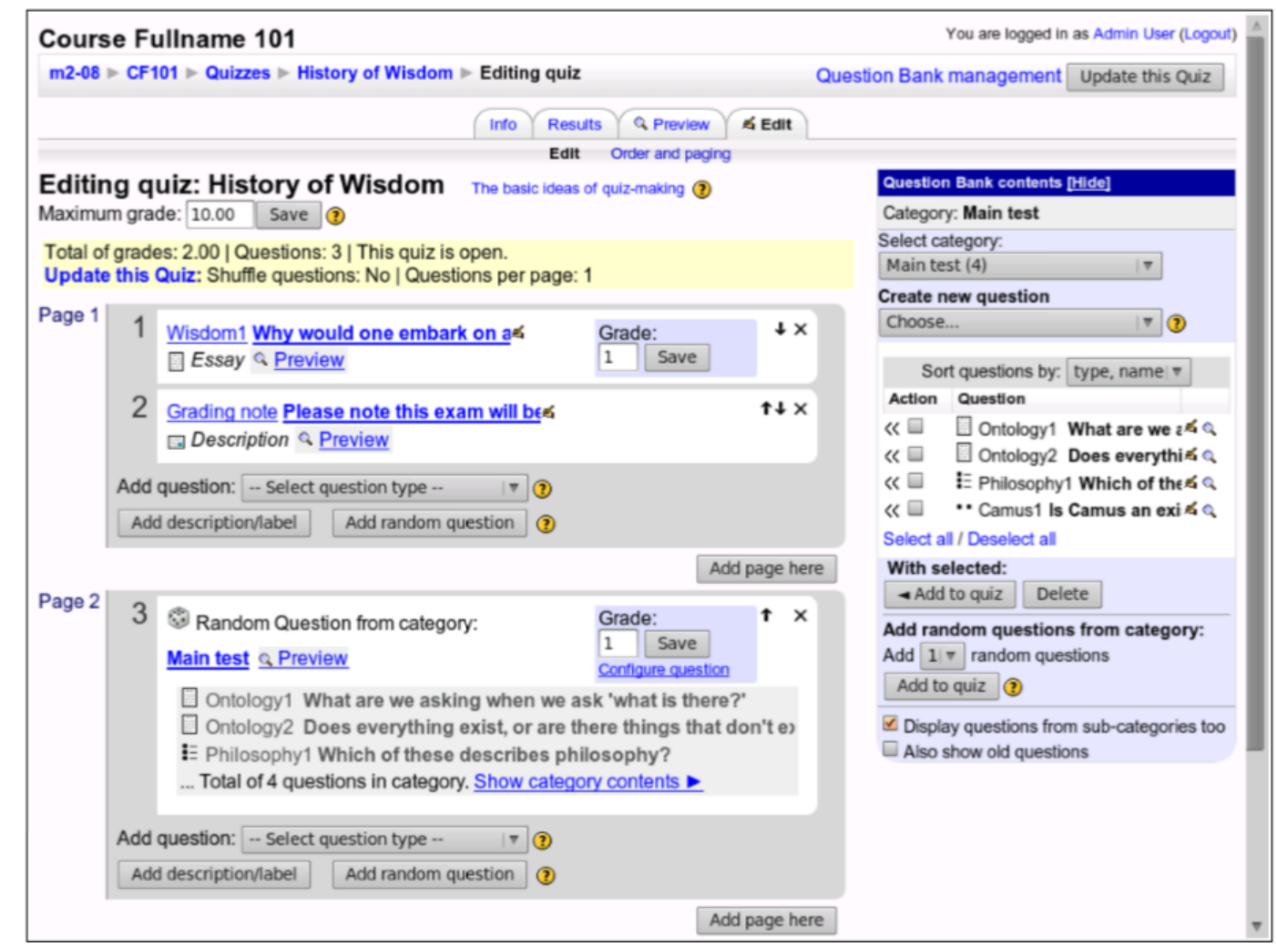

Figura 2.6: Interface de usuário final após o projeto com a janela do banco de questão aberta. Fonte: Savolainen (2010)

O trabalho de Savolainen (2010) no Quiz, se dedicou a corrigir problemas de usabilidade e atender melhor as necessidades dos usuários; foram feitas mudanças para reorganizar informações nos formulários, mudança no fluxo de trabalho e refatoração parcial da interface, além de mudanças estruturais. Embora tenha ocorrido melhorias, os mantenedores do código afirmam que ainda tem muito por ser feito (Hunt (2013); Moodle (2013b)). Como um colaborador, Savolainen vem aos poucos tentando estabelecer diretrizes de usabilidade ${ }^{25}$ para o Quiz e o Moodle. Embora os esforços de Savolainen tenham sido válidos, os problemas de usabilidade persistem e seguem prejudicando a usabilidade do módulo Quiz e afetando seus principais usuários, os professores. Desse modo há necessidade de modificações mais profundas no módulo, em especial na interface com o usuário, implementando-se uma nova interface desenvolvida a partir das necessidades dos professores, a fim de promover melhora na facilidade de uso do Quiz, assim como melhorar sua eficiência, eficácia e a satisfação de seus usuários.

\subsection{Módulos de aprendizagem interativa}

Os Módulos de Aprendizagem Interativa (iMA) são aplicativos educacionais que vem sendo desenvolvidos pelo grupo de pesquisa do Laboratório de Informática na Educação (LInE), desde 2000. Tais aplicativos têm por objetivo minimizar as dificuldades dos alunos nas áreas introdutórias da Matemática e Computação (Brandão e Isotani, 2003).

\footnotetext{
${ }^{25}$ Disponível em: http://docs.moodle.org/dev/Talk:Moodle_User_Interface_Guidelines. Acessado em 5 de maio de 2013
} 
Um $i M A$ pode ser qualquer ferramenta interativa que funciona sob um navegador Web. Normalmente, um $i M A$ é um applet Java ou um pacote HTML5 ${ }^{26}$ com alguns métodos de comunicação (obrigatórios), tudo baseado no protocolo HTTP. Atualmente existem quatro $i M A$ disponibilizados gratuitamente na Web. Apresentados na Figura 2.7 e descritos a seguir:

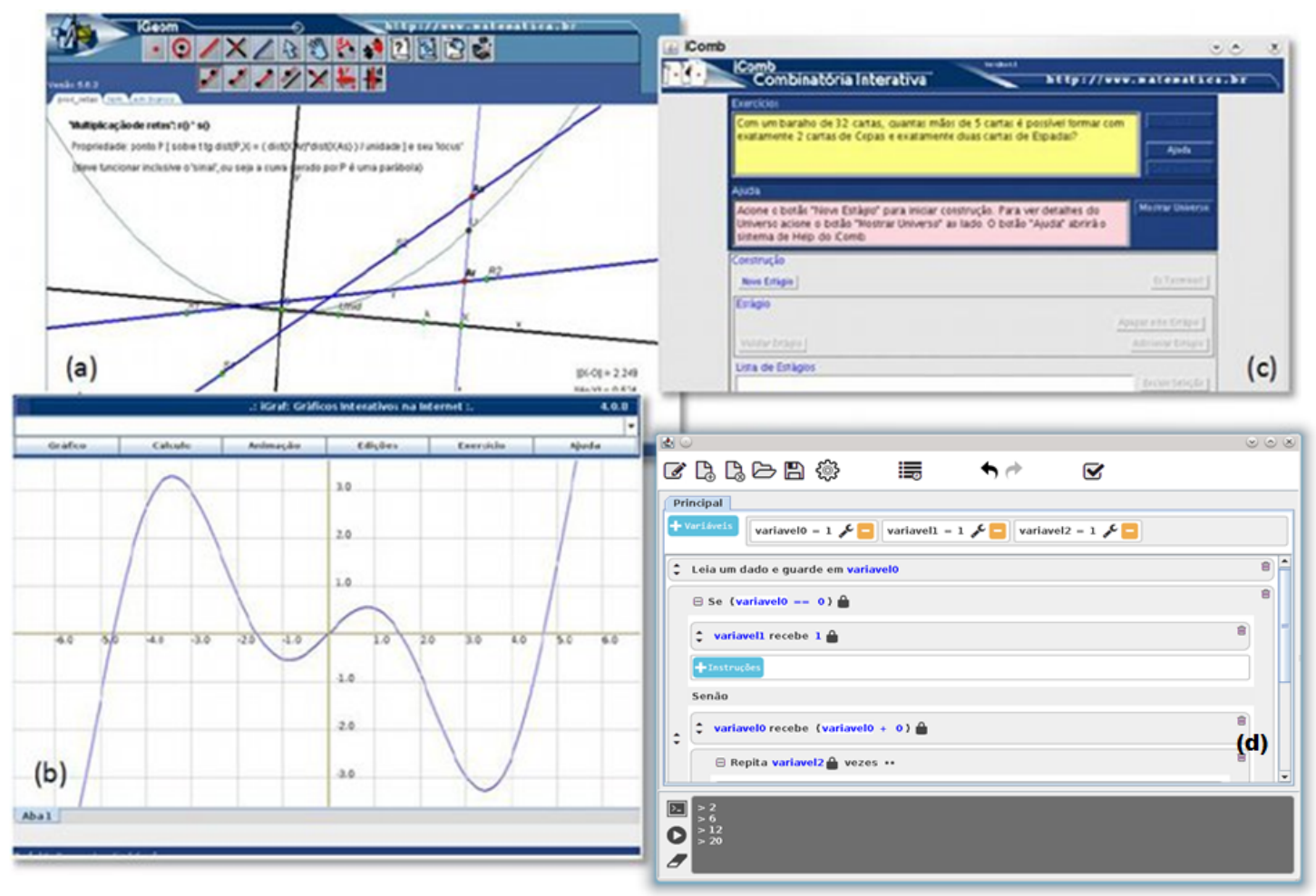

Figura 2.7: Exemplos de alguns módulos da família iMA: a) iGeom; b) iGraf; c) iComb e d) iVProg. Fonte: Dalmon (2012)

- iGeom - Geometria Interativa na Internet ${ }^{27}$ : permite ao usuário realizar construções geométricas e interagir com elas, visando o ensino e aprendizagem de geometria. Dentre os principais recursos são destacados: a autoria e avaliação automática de exercícios e a construção de scripts com recorrência (Brandão e Isotani, 2003);

- iGraph - Gráficos Interativos na Internet ${ }^{28}$ : permite ao usuário o estudo de funções e gráficos. Dentre as características mais interessantes destaca-se: os gráficos animados, que possibilitam a construção e visualização de gráficos em movimento utilizando parâmetros para estudar diversos conceitos como crescimento, decrescimento ou concavidade. Também dispõe de ferramentas de autoria para o professor e avaliação automática de exercícios (Prado, 2008);

- iComb - Combinatória Interativa na Internet ${ }^{29}$ : possibilita o estudo de tópicos relacionados a combinatória. Também dispõe de ferramentas de autoria para o professor e avaliação automática de exercícios (Eisenmann, 2009);

- iVProg - Programação Visual na Internet ${ }^{30}$ : ambiente visual interativo voltado ao ensino de programação (Kamiya e Brandão, 2009; Silva Ribeiro et al., 2012).

Por apresentarem características comuns entre si, o grupo denominou esses aplicativos por "família $i M A "$ ". Todos tem por objetivo principal facilitar e aprimorar a qualidade do trabalho do

\footnotetext{
${ }^{26}$ Disponível em: http://www.w3schools.com/html/html5_intro.asp. Acessado em: 20 de Julho de 2014

${ }^{27}$ Disponível em: http://www.matematica.br/igeom. Acessado em 15 de Março de 2014

${ }^{28}$ Disponível em: http://www.matematica.br/igraf. Acessado em 12 de Abril de 2014

${ }^{29}$ Disponível em: http://www.matematica.br/icomb. Acessado em 18 de Abril de 2014

${ }^{30}$ Disponível em: http://www.matematica.br/ivprog. Acessado em 11 de Maio de 2014
} 
professor durante suas aulas, provendo recursos interativos e retroação imediata ao seus usuários. Atualmente os $i M A$ são desenvolvidos sob uma Linha de Produtos de Software (LPS) voltada para o domínio de aplicativos educacionais e composta por um arcabouço e manuais do seu funcionamento interno (Dalmon, 2012).

\subsubsection{Família de componentes para o Moodle}

A partir das experiências adquiridas do trabalho com o Moodle, uma nova família de ferramentas começou a surgir. Embora os $i M A$ sejam Applets executáveis em variadas plataformas e muito úteis dentro dos domínios para os quais foram concebidos, sua integração aos SGC necessita significativo esforço de desenvolvimento para integrá-los. Em virtude do seu amplo uso, o Moodle foi escolhido como plataforma de integração dos $i M A$ e por consequência o surgimento de módulos exclusivos para SGC, como por exemplo, o iTarefa.

- iTarefa - Tarefa Interativa ${ }^{31}$ : É um pacote de recursos desenvolvido para proporcionar maior interatividade na aprendizagem dos alunos. Para isso, permite que seja usado qualquer $i M A$ integrado ao Moodle (Rodrigues, 2011).

Deste modo, o professor dispõe de um importante recurso para autoria de aulas e exercícios com grande interatividade e o aluno, por sua vez, dispõe de ferramentas interativas com acesso imediato para realizar suas atividades, inclusive desfrutar de retroação imediata.

As principais funcionalidades do pacote iTarefa estão distribuídas em três grupos de recursos, descritos a seguir: i) recurso para incorporar atividades interativas desenvolvidas em algum dos $i M A$; ii) relatório específico para professor e aluno acompanhar o andamento das atividades interativas; iii) incorporação de conteúdos criados num $i M A$ em qualquer contexto assíncrono do Moodle, como páginas Web, fóruns, glossários e wikis. Possibilitando o desenvolvimento de textos interativos.

- iRepositório - Repositório Interativo de Conteúdos Digitais para cursos baseados na Internet ${ }^{32}$ : Seu objetivo é disponibilizar um sistema integrado ao Moodle. Além de compartilhar Objetos de Aprendizagem entre cursos do Moodle, pode disponibilizar recursos aos outros módulos, para armazenamento, classificação e busca de OA ou ainda manipulação dos $i M A$. Algumas de suas características são: aperfeiçoamento da classificação e busca de OA pelos seus metadados; alta granularidade e controle de dependências entre os materiais; trilhas de auditoria e controle de versão; reputação de OA pelos demais autores de conteúdo (Nascimento, 2014).

O Capítulo 3 tratará sobre os métodos aplicados no levantamento de evidências e desenvolvimento do trabalho.

\footnotetext{
${ }^{31}$ Disponível em: http://www.matematica.br/iassign. Acessado em 17 de Março de 2014

${ }^{32}$ Disponível em: http://www.matematica.br/iRepositorio. Acessado em 10 de Junho de 2014
} 


\section{Capítulo 3}

\section{Métodos}

Neste capítulo é apresentado o levantamento de evidências sobre os problemas de usabilidade do Quiz, que justificam este trabalho, Seção 3.1, assim como os demais métodos aplicados no desenvolvimento e avaliação do mesmo, Seção 3.2.

\subsection{Levantamento de evidências}

Esta seção apresenta os trabalhos realizados a fim de buscar evidências sobre as possíveis causas das dificuldades apresentadas pelos professores ao utilizar o Quiz. Fornecendo a essa pesquisa informações, e conclusões valiosas, uma delas foi a pesquisa de opinião descrita na Seção 3.1.3.

\subsubsection{Considerações iniciais}

Conforme relatado no primeiro capítulo, a motivação para esta pesquisa surgiu de observações em cursos para professores, realizados na Universidade de São Paulo. Notou-se que os professores após serem apresentados ao módulo Quiz durante o curso LEM 4, mostravam significativo interesse em utilizá-lo, mas ao iniciar as atividades, muitos mostravam-se frustrados. Como principais motivos foram apontados: a dificuldade de uso e o trabalho demandado para criar um questionário.

Os professores ficavam confusos durante o processo de autoria dos questionários e não era raro esquecerem os passos das tarefas, parecendo ser um fluxo contra intuitivo. Ao se perceber as dificuldades dos professores, iniciou-se uma investigação visando identificar os motivos, assim um estudo para levantar evidências do problema e as causas associadas foi realizado. Inicialmente alguns fatores foram considerados como potenciais elementos às causas das dificuldades, tais como experiência computacional e idade. A falta de treinamento foi descartada, pois durante os cursos na universidade, foi observado que mesmo após treinamento, os professores (alunos no curso) continuaram com algumas dúvidas e reincidiam em erros comuns.

Após uma pesquisa de opinião no evento Moodle Moot Brazil 2013 e um levantamento bibliográfico foi possível concluir que esses fatores não eram os principais influenciadores nas dificuldades dos professores ao utilizar o Quiz e sim problemas de usabilidade, constantemente relatados em artigos encontrados durante pesquisa exploratória. Parte dessa conclusão veio da análise do perfil dos professores, descrito na Seção 3.1.3, que revela boa fluência computacional dos professores e significativa insatisfação com uso do Quiz. Identificou-se ainda, que além do Moodle, outros SGC e mesmo sistemas comerciais de grande abrangência são afetados por problemas de usabilidade.

Desse modo o levantamento de evidências descrito nas próximas seções passou a considerar a usabilidade dos sistemas para autoria de questionários como fator norteador nas investigações realizadas.

\subsubsection{Usabilidade do módulo Quiz}

As comunidades de desenvolvimento de softwares livres, como a que mantém o Moodle, são surpreendentes pelos resultados que alcançam, pelo número de pessoas envolvidas e como sua sis- 
temática de desenvolvimento colaborativo funciona. No entanto Savolainen (2010), aponta que em softwares de código aberto, tais como Moodle, frequentemente são observados problemas de usabilidade, embora geralmente sejam softwares tecnicamente eficientes. Dentre as causas para esses problemas está a carência de documentação e diretrizes claras sobre a aplicação de métodos no processo de desenvolvimento que garantam a qualidade de uso desses softwares.

Problemas com usabilidade no Moodle, são apontados em vários trabalhos relacionados ao uso geral do ambiente, em contrapartida os trabalhos que fazem referência ao Quiz foram poucos, apenas dois artigos relevantes e uma página do Moodle destinada a discussão do problema. Esses trabalhos estão disponíveis na Seção 2.5, são eles Moodle (2013b) e o trabalho de Savolainen (2010) diretamente relacionados a melhoria da usabilidade do Quiz. Outro apontamento significativo foi obtido a partir de um pesquisa de opinião conduzida neste trabalho, a fim de identificar o perfil e a satisfação do usuários com o Quiz. Essa pesquisa é descrita na próxima seção.

\subsubsection{Pesquisa de opinião sobre Quiz}

Durante o principal evento sobre Moodle no Brasil, o MoodleMoot $2013^{1}$, que reuniu desenvolvedores e usuários do Moodle de todo o país, uma pesquisa de opinião com os participantes desse evento foi realizada com objetivo de investigar o perfil e a opinião dos usuários sobre o módulo Quiz.

Para esse levantamento de dados foi elaborado um questionário e distribuído aleatoriamente a 450 participantes do evento. O modelo do questionário e a consolidação das informações estão disponível no Apêndice A. Esses participantes foram convidados a contribuírem com a pesquisa, respondendo ao questionário de forma voluntária.

O MoodleMoot de 2013 foi organizado por eixos temáticos, sendo eles: Moodle em processos educacionais; Moodle em domínios corporativos; Tecnologias e ferramentas.

No eixo "Moodle em processos educacionais", destinados a professores, foram distribuídos 300 questionários. Já nos outros dois eixos, destinado a administradores e desenvolvedores do sistema, foram distribuídos 150 questionários. Dos 450 questionários distribuídos, 49 foram preenchidos, dos quais 24 foram respondido por 'professores' e 25 por 'não professores'.

No grupo dos 'professores' respondentes pode-se destacar as seguintes informações:

- $44 \%$ lecionam em instituição pública e $56 \%$ em particular;

- $44 \%$ atuam na EAD;

- $36 \%$ atuam no Ensino Superior;

- $80 \%$ são pós graduados;

- $72 \%$ apontam sua familiaridade no uso do computador como muito boa ou excelente;

- $72 \%$ afirmam já ter participado de algum tipo de capacitação tecnológica;

- $76 \%$ utilizam o Moodle;

- $78 \%$ dos que utilizam o Moodle, utilizam o Quiz;

No grupo dos respondentes 'não professores', $84 \%$ utilizam o Moodle e 71,5\% afirmam já terem utilizado o Quiz. Esse grupo é bastante misto, composto por pessoas de várias áreas, tais como: programador Moodle, gerente administrativo, diretor de escola, coordenador pedagógico, bancário, designer, engenheiro e advogado.

Dentre os respondentes 'não professores', 8 estão ligados especificamente a área técnica. Para fins de comparação esse grupo será denominado por 'técnicos'.

O ponto mais relevante dessa pesquisa pode ser constatado a partir dos dados da questão 12 do questionário, ilustrada na Figura 3.1. Essa questão contém seis afirmações sobre o Quiz, onde

\footnotetext{
${ }^{1}$ Disponível em: http://www.moodlemoot.com.br. Acessado em 10 de maio de 2013.
} 
os participantes deveriam responder utilizando uma escala de Likert que variou de 1 'concordo totalmente' a 5 'discordo totalmente'.

12. Referente às afirmações abaixo indique o seu grau de concordância sobre o Quiz (atividade Questionário do Moodle).

\begin{tabular}{|l|lccccc|}
\hline \multicolumn{1}{|c|}{} & $\begin{array}{c}\text { Concordo } \\
\text { totalmente }\end{array}$ & Concordo & Neutro & Discordo & $\begin{array}{c}\text { Discordo } \\
\text { totalmente }\end{array}$ \\
\hline P1 & A criação de questionários no Quiz é rápida. & $\square$ & $\square$ & $\square$ & $\square$ & $\square$ \\
\hline P2 & $\begin{array}{l}\text { O processo de criação de um questionário no Quiz } \\
\text { não é intuitivo. }\end{array}$ & $\square$ & $\square$ & $\square$ & $\square$ \\
\hline P3 & $\begin{array}{l}\text { Criar questões do tipo múltipla escolha é preferível } \\
\text { por ser mais fácil. }\end{array}$ & $\square$ & $\square$ & $\square$ & $\square$ \\
\hline P4 & $\begin{array}{l}\text { O formulário que o Quiz apresenta para criação de } \\
\text { questões é muito extenso. }\end{array}$ & $\square$ & $\square$ & $\square$ & $\square$ \\
\hline P5 & A maioria das pessoas aprende o Quiz rapidamente. & $\square$ & $\square$ & $\square$ & $\square$ \\
\hline P6 & $\begin{array}{l}\text { O Quiz possui todos os recursos necessários para } \\
\text { criar questionários de avaliação. }\end{array}$ & $\square$ & $\square$ & $\square$ & $\square$ \\
\hline
\end{tabular}

Figura 3.1: Questão 12 do questionário do MoodleMoot

A Tabela 3.1 apresenta a consolidação das respostas para as seis afirmações da questão 12. Para fins de comparação as respostas foram agrupadas em 'discordo', ' neutro' e 'concordo', apresentando para cada um desses grupos o percentual de respostas dos professores e dos técnicos.

\section{Pesquisa de opinião sobre o Quiz}

\begin{tabular}{l|c|c|c|c|c|c}
\hline & \multicolumn{2}{|c|}{ Discordo } & \multicolumn{2}{c|}{ Neutro } & \multicolumn{2}{c}{ Concordo } \\
\hline Afirmação & Profs. & Técnicos & Profs. & Técnicos & Profs. & Técnicos \\
\hline P1 & $50 \%$ & $25 \%$ & $14 \%$ & $13 \%$ & $36 \%$ & $63 \%$ \\
P2 & $29 \%$ & $0 \%$ & $21 \%$ & $75 \%$ & $50 \%$ & $25 \%$ \\
P3 & $28 \%$ & $13 \%$ & $29 \%$ & $25 \%$ & $43 \%$ & $62 \%$ \\
P 4 & $29 \%$ & $13 \%$ & $14 \%$ & $63 \%$ & $57 \%$ & $24 \%$ \\
P5 & $57 \%$ & $25 \%$ & $21 \%$ & $37 \%$ & $21 \%$ & $38 \%$ \\
P6 & $71 \%$ & $13 \%$ & $14 \%$ & $25 \%$ & $15 \%$ & $63 \%$ \\
\hline
\end{tabular}

Tabela 3.1: Pesquisa de opinião sobre o Quiz no MoodleMoot Brasil 2013

Ao comparar os dados da Tabela 3.1 é possível evidenciar a visão divergente dos usuários do Moodle em relação aos recursos e a satisfação do Quiz.

Para cerca de $50 \%$ dos 'professores' respondentes, o processo para criação de questionários no Quiz não é rápido nem intuitivo. Já $63 \%$ dos respondentes 'não professores' consideram criação de questionários no Quiz rápida.

A maioria dos 'professores' consideram os formulários do Quiz muito extensos e discordam que a maioria das pessoas aprende o Quiz rapidamente. Enquanto a maioria dos 'não professores' consideram a criação de questionários no Quiz rápida e apenas $25 \%$ dos técnicos discordam que a maioria das pessoas aprende o Quiz rapidamente.

Para $43 \%$ dos 'professores' criar questões do tipo múltipla escolha é preferível por ser mais fácil, apenas $24 \%$ dos 'não professores' são da mesma opinião.

No grupo de 'professores' apenas $29 \%$ concordam que o Quiz possui todos os recursos necessários para criar questionários de avaliação. Já no grupo dos 'não professores' $63 \%$ possuem a mesma opinião.

Ao analisar essas informações foi possível constatar uma percepção divergente entre os grupos 'professores' e 'não professores'. 
Os usuários mais técnicos tem uma opinião mais favorável ao Quiz do que os professores, embora o grau de neutralidade sobre algumas perguntas tenha sido bastante alto.

Em seu artigo Kissel (1995), descreve um experimento que avaliou o desempenho e a percepção dos usuários no desenvolvimento de uma mesma tarefa em três tipos de interface com alternativas de design diferentes, que contemplava (i) uma linha de comando; (ii) um menu de nível 2; (iii) uma caixa de listagem.

Foi analisada a relação entre avaliações subjetivas e medidas objetivas de testes de usabilidade de software e sua relação com medidas de experiência com o computador. Kissel (1995) concluiu que a experiência computacional dos usuários interfere na sua percepção sobre usabilidade e desempenho durante a realização das tarefas.

Os resultados indicam também que as avaliações subjetivas e medidas objetivas de desempenho muitas vezes não correspondem. Esse nível de correspondência é, em parte, dependente da experiência computacional já adquirida. Piteira e Costa (2006), colocaram sob investigação as seguintes questões de pesquisa: (i) hipótese 1 - A idade afeta a percepção da usabilidade; (ii) hipótese 2 - A experiência computacional afeta a percepção da usabilidade; (iii) hipótese 3 - A experiência profissional afeta a percepção da usabilidade; (iv) hipótese 4 - O desempenho afeta a percepção da usabilidade. Todas as questões obtiveram resposta positiva.

Em contraste com a pesquisa realizada no MoodleMoot pode-se observar que mesmo professores com maior experiência na utilização de computadores, com carga horária de uso superior a 40hs semanais, também já conhecedores do domínio da aplicação e a maioria com formação acadêmica no nível de especialização, encontraram dificuldades na utilização do Quiz.

Outro dado relevante é fornecido pela Associação Brasileira da Educação a Distância ABED (2012), apontando que 63\% das instituições de EAD no Brasil utiliza o próprio pessoal da equipe de EAD responsável pelo conteúdo instrucional, apoiados por um especialista técnico para produzir o conteúdo dos cursos e avaliações, muitas vezes esse trabalho é transferido para uma produtora independente da instituição. Isso significa que a maior parte do corpo docente das instituições não está envolvido no processo e portanto não fazem uso das ferramentas durante o curso para a finalidade de autoria, sendo provável que uma pesquisa com os grupos de EAD possa revelar melhor percepção na usabilidade de ferramentas como o Quiz, pois trata-se de usuários experientes e geralmente com boa fluência computacional, afetando assim sua percepção sobre as ferramentas.

Diante dos apontamentos realizados até aqui, foi possível evidenciar a insatisfação dos professores e também constatar as dificuldades observadas anteriormente. Desse modo, deve-se considerar relevante a opinião dos 'professores' da pesquisa MoodleMoot, pois de fato são eles os potenciais utilizadores do Quiz enquanto os integrantes do grupo 'não professores' avaliam o Quiz sob a perspectiva de administradores e desenvolvedores de sistema.

\subsection{Métodos aplicados na avaliação do $i Q u i z$}

Os principais métodos e diretrizes utilizados no processo para concepção e validação do iQuiz, estão representados na Figura 3.2, assim como as principais etapas dentro de cada fase do processo orientado pelo arcabouço RESPECT. 


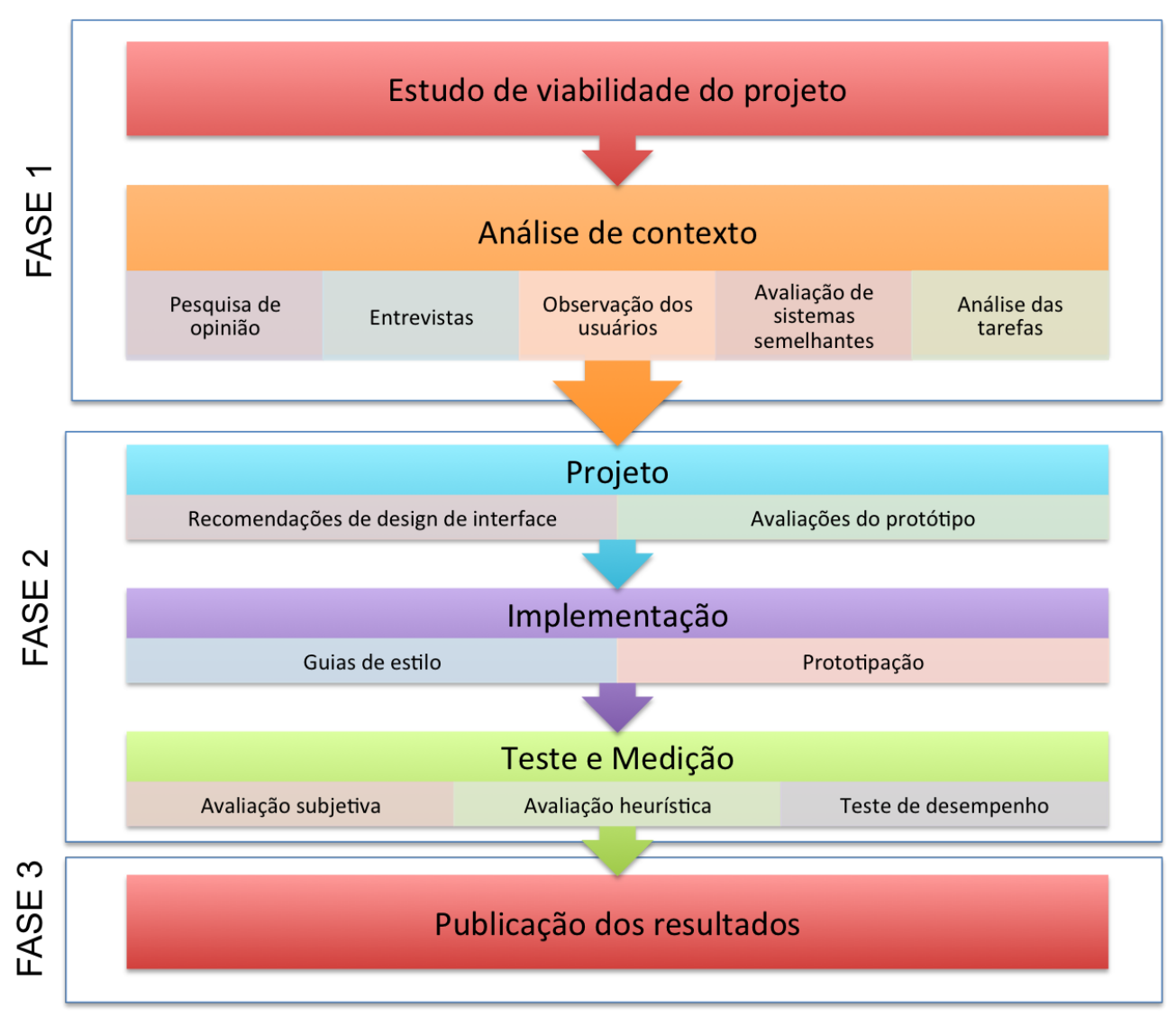

Figura 3.2: Principais etapas e métodos aplicados ao desenvolvimento do iQuiz nas fases do RESPECT

O processo é resumido em 6 etapas, distribuídas nas 3 fases: $\mathrm{Na} 1^{\mathrm{a}}$ fase, composta pelas etapas: (1) estudo de viabilidade do projeto e (2) análise do contexto, foram utilizados os métodos: Pesquisa de opinião, entrevistas, observações dos usuários, avaliação dos sistemas concorrentes e análise das tarefas. Já na $2^{\mathrm{a}}$ fase, composta pelas etapas: (3) projeto, (4) implementação e (5) teste e medição, foram utilizados: recomendações de design de interface, avaliações do protótipo, guias de estilo, prototipação, avaliação subjetiva, avaliação heurística e teste de desempenho. E a $3^{\mathrm{a}}$ e última fase foi composta pela etapa: (6) publicação dos resultados.

Esse diagrama tem o propósito de apresentar em que momento os principais métodos foram utilizados para obter as informações necessárias em cada fase do RESPECT. Até este ponto foi apresentado a abordagem e o processo empregado no desenvolvimento do projeto de interface e interação com usuário para o iQuiz.

A efetividade, eficiência e satisfação são frequentemente consideradas como medidas ou metas de usabilidade (Preece et al., 2005; Santos, 2006). Essas três componentes da usabilidade definem os aspectos relacionados a qualidade do software.

Desse modo, avaliar os resultados alcançados por este trabalho sob o ponto de vista dessas três componentes é importante para que se determine qual foi o avanço obtido e se de fato ocorreu melhoria no processo de autoria dos questionários.

Embora a usabilidade esteja relacionada a muitos fatores humanos, em geral a maioria dos dados pode ser produzido quantitativamente de forma controlada. Para avaliar este trabalho foi utilizado um misto de métodos quantitativos e qualitativos, que permitiram medir o desempenho e satisfação dos usuários.

Existe uma grande variedade de métodos que podem ser aplicados com o propósito de avaliar o desempenho e a satisfação (Usabilitynet, 2013). A verificação de hipóteses deste trabalho utiliza dois métodos principais: a análise heurística e os testes de usabilidade. Esses métodos são apoiados por observações, entrevistas e pesquisas de opinião. Os testes de usabilidade permeiam todas as fases do desenvolvimento, devido a característica iterativa do processo centrado no usuário. 
Para o iQuiz, as métricas subjetivas a avaliar são: (i) o atendimento das expectativas do usuário pelo sistema; (ii) facilidade de uso do sistema; (iii) facilidade de realização de tarefas específicas; (iv) facilidade de aprendizado do sistema.

As principais métricas de desempenho a serem avaliadas são: (i) taxa de sucesso ou falha nas tarefas; (ii) número de passos para concluir a tarefa. Outros aspectos como: tempo para realizar uma tarefa; tempo para saber como fazer uma tarefa, embora fossem desejáveis, não foram analisadas durante as avaliações de usabilidade. Segundo Nielsen (1995), testes de medição em usabilidade devem ser bastante praticados antes pela equipe de desenvolvimento para assegurar resultados confiáveis.

Na próxima seção são detalhados os dois principais métodos aplicados para avaliar a evolução do protótipo como previsto no ciclo do processo interativo, que são: a avaliação heurística utilizada para inspecionar a interface antes dos testes com os usuários, e os testes de usabilidade que inclui além das medições e observações, o uso de questionários especializado para avaliação da satisfação dos usuários após os testes, constituindo-se todos esses instrumentos um aparato importante na avaliação final deste trabalho.

\subsubsection{Avaliação heurística}

No desenvolvimento da interface do iQuiz foi aplicada a avaliação heurística para inspecionar a interface após a liberação do protótipo inicial, conforme apresentado na Seção 5.1 Embora a recomendação seja no mínimo 3 avaliadores, apenas 2 consultores, especialistas nesse estilo de interface foram utilizados para realizar a avaliação. O principal motivo foi a dificuldade em localizar pessoas com este perfil. Além dos avaliadores outros 3 membros do grupo de trabalho também realizaram uma avliação individual que contribuiu para localizar problemas adicionais não descobertos pelos dois avaliadores.

\subsubsection{Testes de usabilidade}

Os testes de usabilidade foram utilizados em cada fase de melhoria da interface para medir o desempenho e a satisfação dos usuários com o iQuiz e também com o Quiz, a partir de tarefas propostas para serem realizadas durante os testes controlados. Os professores eram observados e suas ações registradas por observadores, e também pela gravação da tela do computador para analise posterior, sendo contabilizados aproximadamente $15 \mathrm{hs}$ de gravações.

Após os testes os usuários preenchiam o questionário System Usability Scale (SUS), para medir o nível de satisfação dos usuários ao concluir os testes nos dois ambientes. Para os experimentos deste trabalho foi utilizada a versão traduzida por Tenório et al. (2011) desse questionário, apresentado na Figura 3.3, o questionário original em inglês encontra-se no Apêndice H.

Pode-se observar que o questionário alterna as afirmativas de tal forma que nas afirmativas ímpares uma resposta concordo fortemente (opção 5 na escala), tem valor oposto nas alternativas pares, ou seja, as afirmativas ímpares são positivas enquanto as pares são negativas. Se um participante desejar atribuir nota máxima ao sistema, deverá assinalar na escala a opção 5 alternadamente. O propósito desse procedimento é fazer com que os participantes pensem sobre a afirmativa antes de assinalarem suas respostas.

Segundo Tenório et al. (2011), fonte da versão traduzida do questionário utilizado por este trabalho, para preservar a validação em língua portuguesa, o questionário foi traduzido de forma reversa. As questões foram traduzidas para a língua portuguesa e depois um tradutor profissional realizou a tradução novamente para a língua inglesa, no intuito de manter fielmente o significado e estrutura do texto.

Para esta pesquisa a palavra "imaginaria" da afirmação 7 foi alterada para "acho". Isso após ser notado nos pré testes uma melhor compreensão dessa questão por parte dos usuários, após a troca.

A Figura 3.3 apresenta o questionário traduzido com um código relacionado a cada afirmativa. Esse código é utilizado nas tabelas de respostas dos participantes, para facilitar a visualização dos dados. 


\begin{tabular}{|c|c|c|c|c|c|c|}
\hline Código & Afirmativas & \multicolumn{3}{|c|}{$\begin{array}{l}\text { Discordo } \\
\text { fortemente }\end{array}$} & \multicolumn{2}{|c|}{$\begin{array}{l}\text { Concordo } \\
\text { Fortemente }\end{array}$} \\
\hline \multirow[t]{2}{*}{ AF1 } & Eu acho que gostaria de utilizar este sistema frequentemente. & & & & & \\
\hline & & 1 & 2 & 3 & 4 & 5 \\
\hline \multirow[t]{2}{*}{ AF2 } & Eu achei o sistema desnecessariamente complexo. & & & & & \\
\hline & & 1 & 2 & 3 & 4 & 5 \\
\hline \multirow[t]{2}{*}{ AF3 } & Eu achei o sistema fácil para usar. & & & & & \\
\hline & & 1 & 2 & 3 & 4 & 5 \\
\hline \multirow[t]{2}{*}{ AF4 } & Eu acho que precisaria do apoio de um suporte técnico para ser possivel & & & & & \\
\hline & usar este sistema. & 1 & 2 & 3 & 4 & 5 \\
\hline \multirow[t]{2}{*}{ AF5 } & Eu achei que as diversas funçôes neste sistema foram bem integradas. & & & & & \\
\hline & & 1 & 2 & 3 & 4 & 5 \\
\hline \multirow[t]{2}{*}{ AF6 } & Eu achei que houve muita inconsistência neste sistema. & & & & & \\
\hline & & 1 & 2 & 3 & 4 & 5 \\
\hline \multirow[t]{2}{*}{ AF7 } & Eu acho que a maioria das pessoas aprenderia a usar esse sistema & & & & & \\
\hline & rapidamente. & 1 & 2 & 3 & 4 & 5 \\
\hline \multirow[t]{2}{*}{ AF8 } & Eu achei o sistema muito pesado para uso. & & & & & \\
\hline & & 1 & 2 & 3 & 4 & 5 \\
\hline \multirow[t]{2}{*}{ AF9 } & Eu me senti muito confiante usando esse sistema. & & & & & \\
\hline & & 1 & 2 & 3 & 4 & 5 \\
\hline \multirow[t]{2}{*}{ AF10 } & Eu precisei aprender uma série de coisas antes que eu pudesse & & & & & \\
\hline & continuar a utilizar esse sistema. & 1 & 2 & 3 & 4 & 5 \\
\hline
\end{tabular}

Figura 3.3: SUS -System Usability Scale. Adaptado de Tenório et al. (2010)

A seguir, no Capítulo 4 é descrito as principais etapas que culminaram no desenvolvimento conceitual da interface e depois o desenvolvimento do protótipo Quiz. 


\section{Capítulo 4}

\section{O ambiente $i Q u i z$}

O Quiz é o principal módulo voltado para a autoria de questionários no Moodle, conforme apresentado na Seção 2.2.1, tratando-se de uma ferramenta que oferece ao usuário uma grande variedade de recursos e funcionalidades.

No entanto, o Quiz é avaliado por seus utilizadores como uma ferramenta de uso complexo, como evidenciado na Seção 3.1. Os problemas de usabilidade do Quiz foram constatados pelo principal mantenedor do módulo, Hunt (2013), e pesquisas a respeito já foram realizadas, inclusive com implementações na versão do Moodle 2.0 (Savolainen, 2010).

Entretanto, esses problemas ainda não foram completamente resolvidos e continuam sendo apontados como causa desmotivadora ao uso do Quiz. Conforme aponta a pesquisa de opinião apresentada na Seção 3.1.3, ainda são necessários avanços para alcançar um nível razoável de satisfação dos utilizadores do Quiz.

As implementações do trabalho de Savolainen (2010) tiveram como objetivo refatorar o Quiz visando melhorar a usabilidade (Moodle, 2013b). No entanto, foi necessário manter as restrições determinadas pelo Moodle, uma vez que as modificações iriam para o núcleo do sistema. Restrições essas que envolvem desde a aprovação da comunidade técnica do Moodlesobre o tipo de alteração e o grau das modificações até o uso de tecnologias, como JavaScript ${ }^{1}$, ou ainda seguir padrões para apresentação de informações e a estrutura de navegação do ambiente.

Outro aspecto a ser destacado é que o Moodle respeita as leis internacionais impostas aos sistemas públicos em vários países, para garantir a acessibilidade ${ }^{2}$, desse modo todas as implementações devem obrigatoriamente garantir primeiro que os recursos possam ser utilizados com as tecnologias básicas da Web, ficando os recursos produzidos em JavaScript como suplementares. Porém JavaScript é uma das principais tecnologias empregadas na melhoria da interatividade e por consequência também na usabilidade de sistemas Web (Deitel e Deitel, 2008).

Por estas razões esta pesquisa visa produzir uma alternativa ao Quiz sem realizar intervenções no núcleo, implementações com JavaScript, HTML5 e Ajax ${ }^{3}$ serão utilizadas para melhorar a usabilidade. A proposta deste trabalho é contribuir com o desenvolvimento conceitual e implementação do iQuiz, um ambiente alternativo para criação de questionários no Moodle. O objetivo desse ambiente é contribuir com melhorias no processo de autoria de questionários, por meio de uma nova interface para professores, utilizando o processo de desenvolvimento centrado no usuário, descrito na Seção 2.3.2.

A interface é elemento central do ambiente iQuiz, ela integrara-se a outros módulos que terão suas funcionalidades gerenciáveis por seu intermédio.

Para que o ambiente possa ser disponibilizado como um plugin para o Moodle, três etapas são necessárias: (i) a primeira é especificar e produzir a interface; (ii) a segunda é especificar um modelo de integração do iQuiz com o Moodle e entre os seus componentes; (iii) a terceira etapa é codificar a camada de infraestrutura do plugin que realiza a integração dos módulos do iQuiz ao Moodle

\footnotetext{
${ }^{1}$ Disponível em: https://docs.moodle.org/dev/CodingJavaScript. Acessado em: 20 de Julho de 2014

${ }^{2}$ Disponível em: https://docs.moodle.org/dev/Accessibility. Acessado em: 20 de Julho de 2014

${ }^{3}$ Disponível em: http://www.w3schools.com/ajax/. Acessado em: 22 de Julho de 2014
} 
para disponibilizá-lo como um plugin ${ }^{4}$. As duas primeiras etapas são atribuições desta pesquisa, a terceira etapa ficará como trabalho futuro e fará parte de uma próxima etapa de trabalhos do grupo de pesquisa.

Desse modo, ao comparar este trabalho ao de Savolainen (2010), este diferencia-se em vários aspectos, uma vez que a interface proposta não é uma refatoração, mas sim uma nova interface desenvolvida a partir das necessidades dos usuários característicos do sistema, visando seguir diretrizes de usabilidade para prevenir os problemas de uso. A mudança no fluxo de trabalho e a integração de novos componentes adicionando novas funcionalidades e a implementação do ambiente como um plugin caracterizam essa diferença.

Na Seção 4.1 são tratados as decisões de projeto e os aspectos conceituais do modelo definido e também as novas funcionalidades adquiridas com a integração dos componentes. A Seção 4.2 trata da modelagem de contexto realizada para obter os requisitos para a interface do iQuiz, destacandose os trabalhos de análise dos sistemas similares, análise do fluxo trabalho no Quiz, a proposta de um novo fluxo e a caracterização dos usuários. Na Seção 4.3 é apresentado a modelagem conceitual da interface e, por fim, a Seção 4.4 descreve o desenvolvimento do protótipo e a interface final.

\subsection{Estudo de viabilidade do projeto}

Ao iniciar este projeto surge o primeiro desafio: decidir entre estender o módulo Quiz ou alterálo. Após estudo decidiu-se por estender o módulo do Quiz, gerando um novo plugin, que poderá ser instalado no Moodle sem intervir no funcionamento do Quiz. Desse modo, quando o iQuiz for instalado ambos os módulos ficarão disponíveis no ambiente.

O fato do Quiz fazer parte do núcleo do Moodle implicou fortemente nesta decisão, uma vez que alterar o Quiz diretamente geraria uma versão paralela do Moodle, não sendo esse o propósito deste trabalho.
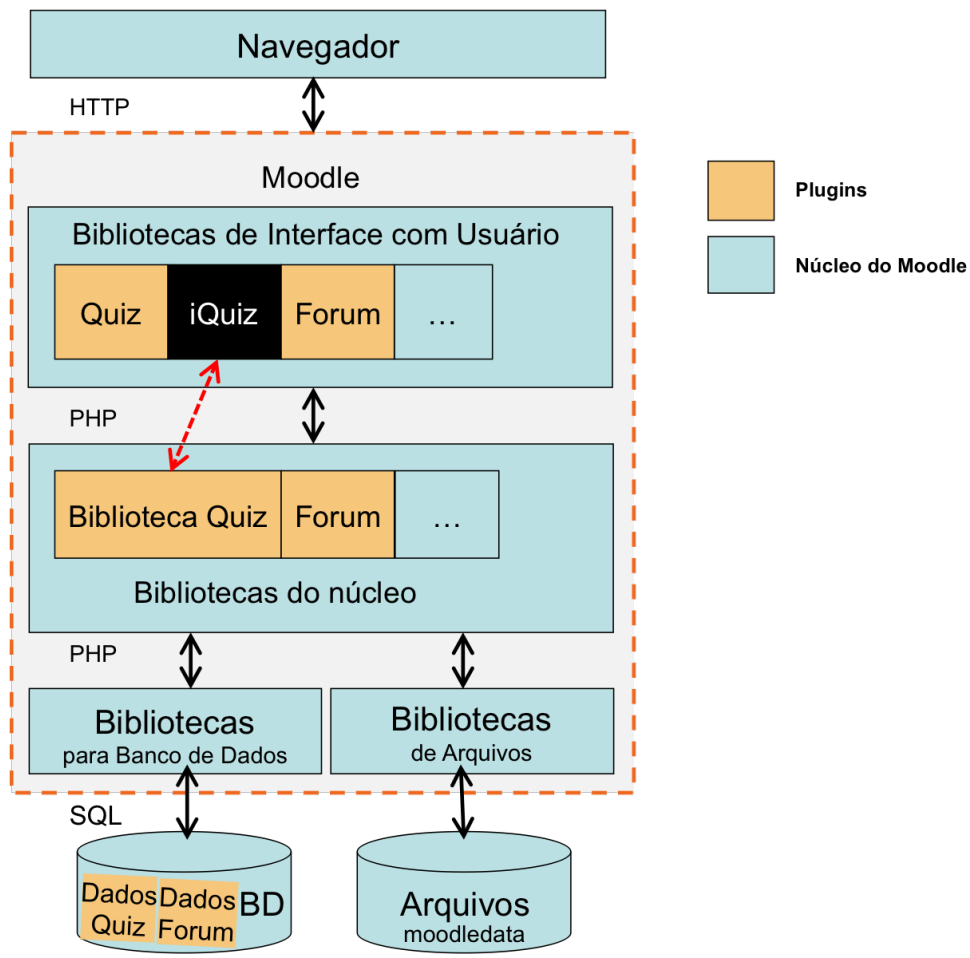

Figura 4.1: iQuiz e as Camadas de componentes do Moodle, adaptado de Abasic Introduction to the Moodle Architecture $^{5}$

Um fator favorável a extensão do Quiz é a arquitetura modularizada do Moodle, permitindo a

\footnotetext{
${ }^{4}$ Estrutura básica de um módulo no Moodle, Disponível em: http://www.aosabook.org/en/moodle.html. Acessado em 10 de Abril de 2014
} 
incorporação de novos componentes ao sistema sem alterar o núcleo do mesmo (Moodle, 2013a). Essa arquitetura alinhada a técnica de desenvolvimento em camadas MVC (Model View Controller) foram fundamentais para a extensão do iQuiz.

A Figura 4.1 apresenta uma ilustração das três camadas de bibliotecas utilizadas pelos módulos no Moodle que são: as bibliotecas de interface do usuário (IU), bibliotecas do núcleo, e as bibliotecas para arquivos e banco de dados. A comunicação entre as camadas é feita em $P H P$ e $S Q L$, entretanto na camada de interface residem as demais tecnologias (HTML, CSS, JavaScript, Ajax) gerenciadas pelos módulos que podem ser inclusive arcabouços como é o caso da biblioteca $Y U I^{6}$ e $D O J O^{7}$. Pode-se observar que o Quiz permeia todas as camadas e que o iQuiz está na camada de interface. Essa ilustração mostra que a interface utiliza a (biblioteca Quiz) e por consequência os demais recursos atrelados ao Quiz.

Para que o iQuiz funcione na camada de interface é necessário implementar a estrutura básica de um módulo em PHP para ser possível sua integração ${ }^{8}$ ao Moodle. Assim o iQuiz deverá ter a mesma infra estrutura de bibliotecas de qualquer outro módulo, entretanto utilizará as bibliotecas do núcleo além das suas próprias. A seguir, na Figura 4.2 é apresentado o modelo essencial de integração do módulo do iQuiz ao Moodle. Esse modelo também define o escopo do trabalho dessa pesquisa em relação ao processo de implementação do protótipo, exceto a camada de integração.

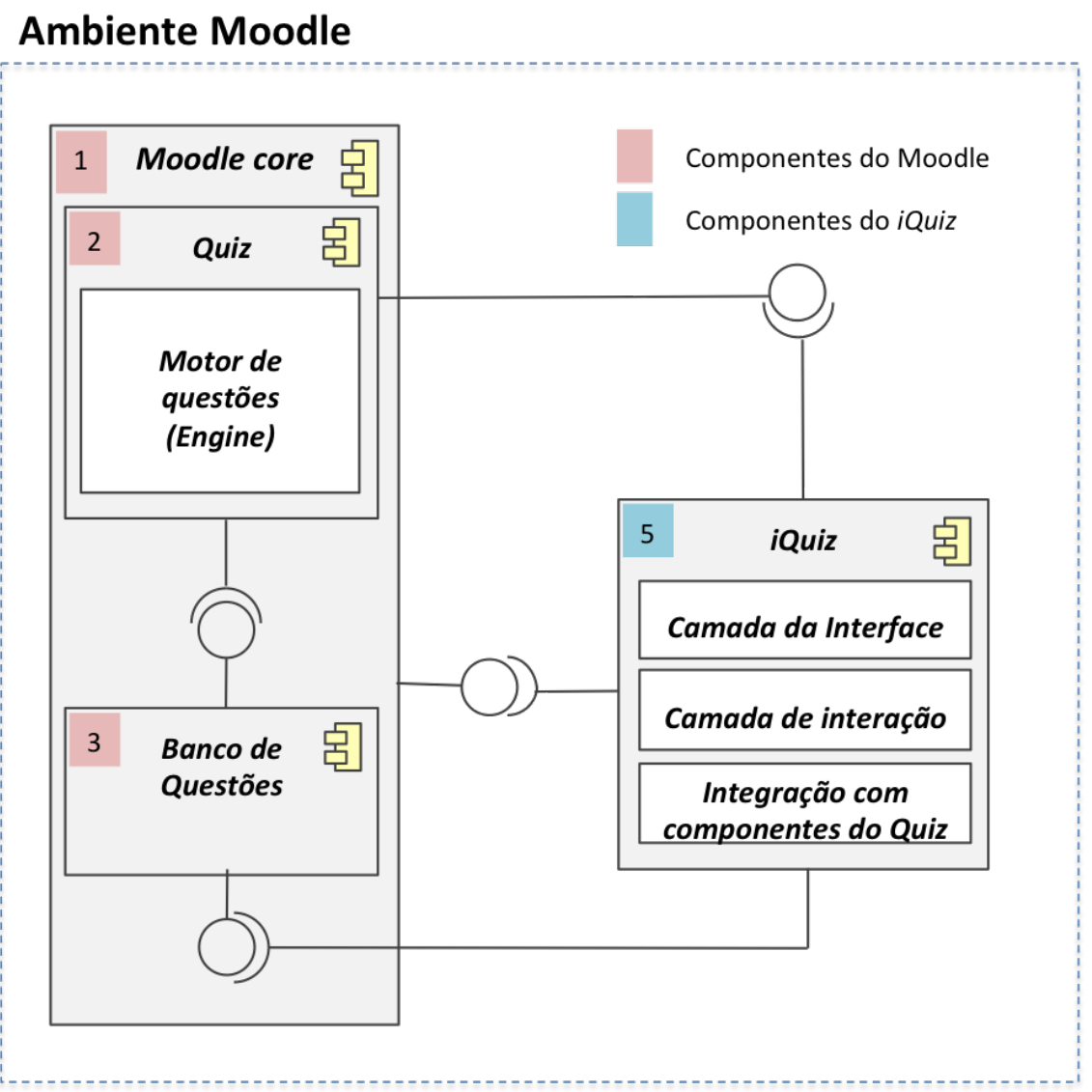

Figura 4.2: Diagrama de integração da interface do iQuiz ao Moodle

(1) Moodle (núcleo): esse componente representa o núcleo do Moodle, composto pelos componentes de base e as bibliotecas de funções utilizadas por outros componentes do ambiente.

(2) Quiz: representa o principal módulo envolvido no processo de autoria e publicação dos ques-

\footnotetext{
${ }^{6}$ Disponível em: http://yuilibrary.com/. Acessado em: 12 de Julho de 2014

${ }^{7}$ Disponível em: http://dojotoolkit.org/. Acessado em: 15 de Julho de 2014

${ }^{8}$ Disponível em: http://www.aosabook.org/en/moodle.html. Acessado em 10 de Abril de 2014
} 
tionários de avaliação. O submódulo Engine ${ }^{9}$ ao Moodle é o motor de questões, possibilita controlar todo o processo de apresentação e tentativa dos questionários, foi planejado para ser utilizado por outros módulos dentro do Moodle.

(3) Banco de questões: responsável pelo gerenciamento do banco de questões, os dados do banco são acessíveis tanto pelo Quiz quanto pelo iQuiz.

(4) iQuiz: as camadas de interface, interação e comunicação são encapsuladas como um plugin de atividade. Desse modo, o iQuiz tem acesso aos recursos do Moodle e também as bibliotecas de funções (APIs) do Quiz e do banco de questões, sem necessidade de interferir em qualquer um deles. Pode ser verificado na Figura 4.2 que o iQuiz é um consumidor dos recursos oferecidos pelo ambiente do Moodle, ou seja, ele se acopla aos módulos e estabelece a comunicação necessária para utilizar o que precisa. O funcionamento é simples: por meio da interface a camada de interação recebe os estímulos do usuário e solicita os recursos para a camada de integração que interage com os demais componentes do Moodle. Assim a interface controla o fluxo das tarefas e a interação com os usuários sem deixar de oferecer os recursos do Quiz.

\section{Modelo de integração}

Uma das motivações para esta pesquisa é possibilitar o uso dos $i M A$ dentro dos questionários do Moodle, entretanto deverá haver um suporte adequado para integrá-los. Atualmente é possível utilizar os iMA no Moodle por meio do plugin iTarefa (Rodrigues e Brandão, 2012) em atividades interativas com questões que incorporam $i M A$, porém o iTarefa não possibilita o uso dessas questões em questionários do Quiz. Desse modo, vislumbrou-se a oportunidade de por meio do iQuiz integrar os iMA nos questionários do Moodle.

Para viabilizar isso, foi criado um tipo de questão denominado $i M A$, ainda em testes, implementando o protocolo de integração. Esse protocolo é responsável por obter as informações dos $i M A$ e repassá-las ao plugin de questão $i M A$, e vice versa.

Alinhado aos objetivos dessa integração existe outro importante trabalho realizado no grupo, o iRepositório (Nascimento, 2014). Já disponível para uso no Moodle como um serviço para repositório de conteúdo digital colaborativo. No entanto, o iRepositório trabalha submerso no ambiente e deve ser apoiado por uma interface para tornar-se mais visível para os usuários, que por meio dela poderão contar com uma forma de compartilhar questões e questionários. Além de possibilitar o registro da reputação desses conteúdos.

O diagrama ilustrado na Figura 4.3 apresenta o modelo de integração completo do iQuiz e a integração ao Moodle.

A seguir é apresentada uma breve descrição dos principais requisitos:

(4) Tipo de questão: é a camada responsável pela gestão dos tipos de questões. Tipos nativos, como múltipla escolha, ou contribuições são administrados por esse componente. Os novos tipos de questões devem atender a especificações desse módulo para serem incluídos no Moodle.

(6) Repositório de Conteúdo Digital Interativo (iRepositório): recebe o conteúdo dos $i M A$ e do Moodle, sua integração ao iQuiz permite a colaboração e o compartilhamento de questionários e questões.

(7) Módulos de Aprendizagem Interativa ( $i M A$ :) são módulos para autoria de conteúdo digital interativo, fornece conteúdo para o iRepositório e o gerenciador de questões para o Moodle (Tipo de questão $i M A$ ) e são incorporados pelo iQuiz como tipo de questão.

(8) Tipo de questão $i M A$ : implementa o protocolo $i M A$, responsável pela integração do conteúdo dos $i M A$ ao questionário, ou seja, ao ambiente do Quiz e ao iQuiz.

\footnotetext{
${ }^{9}$ Disponível em: https://docs.moodle.org/dev/Using_the_question_engine_from_module. Acessado em 16 de Abril de 2014
} 


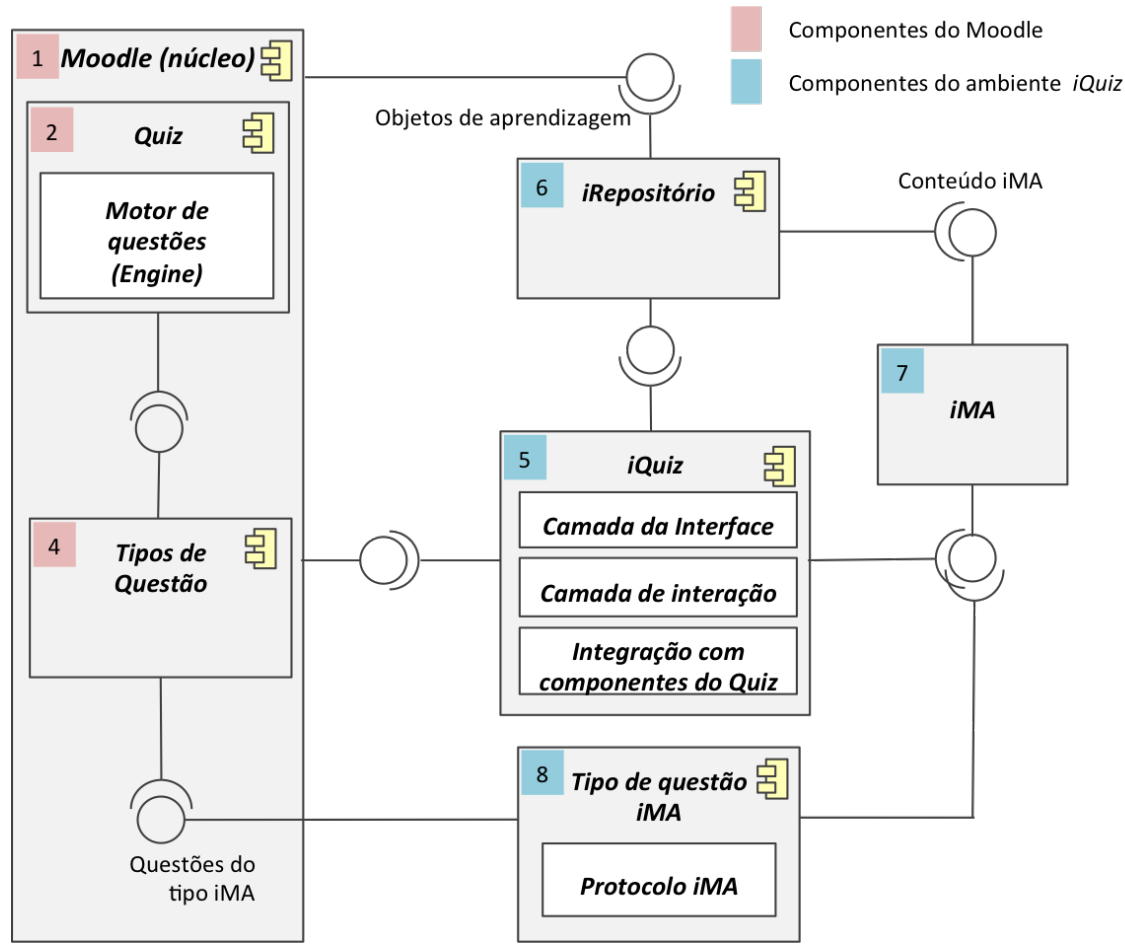

Figura 4.3: Diagrama de integração de componentes do iQuiz ao Moodle

\subsection{Análise do contexto}

A análise de contexto de uso, em usabilidade, refere-se a modelagem do contexto onde o sistema será utilizado, ou seja, um processo análogo a análise de requisitos na engenharia de software, mas que visa caracterizar a situação existente antes do desenvolvimento do sistema.

Para isso, foram: (i) caracterizados os usuários utilizados do sistema; (ii) identificadas as tarefas realizadas por eles; e (iii) os produtos semelhantes ou concorrentes.

No Apêndice B encontra-se um resumo das informações utilizadas na caracterização dos usuários do Quiz, bem como as tarefas realizadas por eles e o ambiente técnico. Essas informações foram utilizadas como referência para o desenvolvimento da nova interface e demais artefatos.

\subsubsection{Caracterização de usuários}

Para compor a amostra de usuários representativos da população de utilizadores do Quiz se fez necessário identificar o perfil dos usuários do Moodle. Sendo essa uma tarefa nada trivial, principalmente por se tratar de um grupo de usuários heterogêneo sob diversos parâmetros, tais como: formação, faixa etária, fluência digital, área de atuação, modalidade de ensino, contexto de uso e tipos de aplicação do ambiente.

Para isso, decidiu-se por tentar identificar esses usuários por meio de duas ações: (i) realizar uma investigação no fórum de discussão do Quiz, mantido pela comunidade de usuário do Moodle; e (ii) realizar uma pesquisa de opinião no evento MoodleMoot Brasil 2013, sendo esse um evento focado em temas relacionados ao Moodle presumiu-se ser o público ideal para a realização dessa investigação.

Ambas ações foram realizadas, no entanto, a primeira não forneceu informações significativas para traçar o perfil dos usuário, trouxe informações sobre os pontos de vista divergentes da comunidade e uma de lista problemas frequentes. Desse modo, apenas as informações coletadas na pesquisa de opinião foram utilizadas nessa caracterização.

Após a consolidação dos dados, identificou-se que: a maioria dos professores respondentes são pós graduados; lecionam em instituições pública e privada com semelhante distribuição; atuam predominantemente na modalidade de ensino EAD e Ensino Superior; avaliam sua fluência compu- 
tacional como muito boa ou excelente; não utilizam o Quiz com frequência para realizar avaliações formativas.

O resultado dessa pesquisa forneceu informações para caracterizar o usuário do Quiz bem como identificar sua opinião e satisfação quanto ao uso dessa ferramenta. Mais detalhes sobre os resultados dessa pesquisa encontra-se na Seção 3.1.3 e Apêndice B.4.

\subsubsection{Observação e entrevista com usuários}

Dentre as observações realizadas pode-se destacar o uso do Quiz no curso "LEM 4: Autoria de Atividades Interativas no Moodle com iTarefa e iGeom", oferecido nos cursos de verão do IME$\mathrm{USP}^{10}$, destinado a professores. Esse curso proporcionou observações relevantes sobre a utilização, a produtividade e satisfação dos professores com relação ao Quiz. Principalmente por meio das entrevistas informais e questionários aplicados após a conclusão do curso.

Outra importante fonte de observações foi o fórum oficial de discussão do Quiz, principalmente por expor as dúvidas e opiniões dos mais variados usuários do Quiz, uma vez que o Moodle é utilizado em cerca de 80 países.

Em seu trabalho (Savolainen, 2010) salienta que poucas mudanças na interface do usuário foram feitas com base nas entrevistas e cenários. Nessa pesquisa as observações com os usuários parecem ter sido mais proveitosas, pois evidenciou-se uma série de ações e reações importantes dos usuários ao utilizarem o Quiz, contribuindo para a compreensão do fluxo de interação inserido na interface, desambiguidade de termos, implicações sobre o modelo de ajuda do sistema, dentre outros.

Foi observado, por exemplo, que quando usuários utilizam o ambiente com pouca frequência, esquecem com facilidade os passos para configurar e editar o questionário. Os professores demoravam mais tempo para compreender alguns conceitos, tais como, adicionar uma pergunta aleatória ou acrescentar múltiplas questões previamente selecionadas. Os usuários em geral não gostam de consultar a ajuda, precisam ser estimulados. Outro aspecto negativo é que muitas explicações do sistema de ajuda se tornam confusas ao serem traduzidas ou mesmo palavras que não representam um termo adequado ao que um professor brasileiro está acostumado. Como por exemplo, a expressão (Marcação padrão) que seria a pontuação da questão, situada no questionário de edição da questão, conforme apresentado na Figura C.17 do Apêndice C.

\subsubsection{Análise de sistemas similares}

Uma pesquisa sobre sistemas similares ao Moodle Quiz foi realizada para avaliar recursos, características das interfaces e o fluxo de tarefas. Esse é um método conhecido como análise da concorrência, de uso comum em outras áreas, tais como: Administração e Marketing. Tem por objetivo adquirir conhecimento sobre estratégias, serviços ou produtos concorrentes, que operam no mesmo mercado alvo. Afim de conhecer pontos fortes e fracos e utilizá-los para obter vantagem competitiva sobre a concorrência. Isso acaba refletindo na melhoria da qualidade e na satisfação dos clientes, pois geralmente são agregados diferenciais significativos aos produtos ou serviços.

Neste estudo esse método foi utilizado com o mesmo sentido, analisar sistemas semelhantes ou concorrentes para que se possa: melhorar a partir das fraquezas e os pontos fortes de outros sistemas; avaliar modelos, técnicas, processos e funcionalidades já implementados e inferir novas ideias a partir dos conceitos observados.

Para proceder com essa análise, alguns critérios foram adotados na seleção das aplicações, sendo que aplicações para Web tiveram preferência por fazerem parte do mesmo tipo de plataforma em que a interface a ser projetada estará presente. Além disso foram selecionadas apenas aplicações que houvesse a possibilidade de serem testadas, mesmo as comerciais que oferecem acesso as versões de avaliação. A procura pelos sistemas foi realizada pelo mecanismo de busca do Google e filtrados os resultados que apontavam para aplicações em uso, que pudessem ser testadas e avaliadas.

Para isso foram utilizadas na composição das strings de busca as seguintes palavras chaves: "quizz online", "questionário online", "create questionaire", "teste online", "criação de testes on-

\footnotetext{
${ }^{10}$ Disponível em: http://www.ime.usp.br/ verao. Acessado em 10 de agosto de 2014.
} 
line", "tests and quizzes". Essa busca resultou os seguintes sistemas: Respondus, Google Docs, Edmodo, Zenler, Edubrite e Exam General. A Tabela 4.1 apresenta as principais características desses sistemas: plataforma de uso, tipos de questões disponíveis e licença de uso.

\begin{tabular}{|c|c|c|c|}
\hline \multicolumn{4}{|c|}{ Sistemas Similares } \\
\hline Sistema & Plataforma & Tipos de Questões & Licença \\
\hline Quiz & online & $\begin{array}{l}\text { Associação; Cálculo simples; Calculado; Correspon- } \\
\text { dência de resposta curta randômica; Ensaio; Múlti- } \\
\text { pla escolha; Múltipla escolha calculada; Numérico; } \\
\text { Resposta curta; Resposta embutidas; Verdadeiro ou } \\
\text { Falso. }\end{array}$ & não comercial \\
\hline Respondus & desktop & $\begin{array}{l}\text { Múltipla escolha; Verdadeiro ou Falso; Ensaio; Cor- } \\
\text { respondência; Preencher lacunas; Múltiplas respos- } \\
\text { tas; Algoritmos. }\end{array}$ & comercial \\
\hline Zenler & desktop & $\begin{array}{l}\text { Verdadeiro ou Falso; Múltipla escolha; Múltipla res- } \\
\text { posta; Sequência; Correspondência. }\end{array}$ & comercial \\
\hline Edmodo & online & $\begin{array}{l}\text { Múltipla escolha; Verdadeiro ou Falso; Resposta } \\
\text { curta; Preencher lacunas; Correspondência. }\end{array}$ & não comercial \\
\hline Edubrite & online & $\begin{array}{l}\text { Resposta simples; Múltipla resposta; Grade horizon- } \\
\text { tal; Grade horizontal com múltipla seleção; Grade } \\
\text { vertical; Grade vertical com múltipla seleção; Ensaio. }\end{array}$ & comercial \\
\hline Google & online & $\begin{array}{l}\text { Múltipla escolha; Escala; Grade; Ensaio; Caixa de } \\
\text { seleção; Escolha de uma lista; Data horário; Texto. }\end{array}$ & não comercial \\
\hline Exam General & online & $\begin{array}{l}\text { Múltipla escolha; Ensaio; Verdadeiro ou Falso; Res- } \\
\text { posta ponderada }\end{array}$ & comercial \\
\hline
\end{tabular}

Tabela 4.1: Principais características dos sistemas similares

Dentre os sistemas apresentados quatro são pagos e foram analisados a partir das versões disponibilizadas para avaliação. Sabidamente, sistemas pagos possuem um processo de desenvolvimento mais rígido quanto a sua usabilidade, principalmente porque precisam ser viabilizados financeiramente para sua continuidade no mercado de produtos. Os tipos de questões foram também inseridos para que se observe os tipos de questões e a quantidade delas por sistema. Ressalta-se a existência de vários plugins de tipos de questões para o Quiz que não fazem parte do seu núcleo e, portanto não estão sendo apresentadas na Tabela 4.1.

Dentre esses sistemas aquele com características mais distante do Quiz é oGoogle Docs, por apresentar muitos tipos de questões voltadas para pesquisa de opinião, ainda assim foi importante pois forneceu as características procuradas para análise.

Além do pesquisador, dois designs e dois professores fizeram parte das análises. Os designs forneceram o ponto vista técnico dos profissionais da área, já os professores, como utilizadores, foram observados durante o uso e depois entrevistados. Isso permitiu caracterizar melhor os aspectos que sobressaiam em cada sistema.

A seguir é apresentado uma breve descritiva sobre as características e contribuições de cada sistema, as ilustrações das telas de cada um deles encontra-se no Apêndice I:

\section{- Respondus}

O Respondus ${ }^{11}$ é uma aplicação comercial, projetada para uso em Desktop e possui 6 tipos de questões. A principal contribuição foi a compacta forma de organizar e apresentar absolutamente todos os recursos que o usuário necessita para criar uma questão em uma única tela, diferente do que ocorre no Quiz. Embora consiga eficiente compactação na apresentação das informações, a interface é "carregada"visualmente, ou seja, é uma tela com muitas informações.

Destacou-se os seguintes elementos: área para lista de questões integrada a área de edição da questão; barra de ferramentas ou botões contextuais; organização do conteúdo em abas.

\footnotetext{
${ }^{11}$ Disponível em: https://www.respondus.com. Acessado em 20 de junho de 2014
} 


\section{- Google Docs}

A criação de formulários no Google Docs ${ }^{12}$, tem bastante objetividade, com bons exemplos de organização e estruturação das informações. Visual leve e fluxo bem intuitivo. Sua principal contribuição está na metáfora utilizada para representar o formulário com questões e os ícones contextuais. Outro aspecto interessante é o fato de que as questões são editadas diretamente sobre o formulário e ícones para manipulação da questão são apresentados apenas quando o usuário precisa deles.

No topo da tela do Google Docs é apresentado detalhes da configuração do questionário, logo abaixo vem o título e a descrição. E em seguida vem a área para edição da questão, onde é requisitado o título da questão, o enunciado e o tipo de questão. Logo após vem os campos para a inserção das alternativas, que surgem por demanda, cada vez que um campo é utilizado, aparece o próximo. Esse também foi um dos conceitos considerados no iQuiz.

\section{- Edmodo}

O Edmodo ${ }^{13}$ é um ambiente colaborativo, com várias características interessantes a serem exploradas. Para esta pesquisa contribuiu com a disposição da lista de questões enquanto o questionário é editado e os botões para adicionar e carregar questões prontas. Os principais recursos são visualizados com facilidade, os elementos importantes possuem destaque adequado e o fluxo de tarefas é objetivo. Outra característica interessante é o sistema de dicas com balões de texto que orientam o usuário na tarefa.

No topo da tela do Edmodo é apresentado o nome do questionário e o limite de tempo. Na lateral esquerda fica a lista com os números das questões e logo abaixo as opções para adicionar ou carregar uma questão pronta, no centro fica a área para edição da questão.

\section{- Zenler}

O Zenler ${ }^{14}$ é uma premiada aplicação, que possui vários recursos e um completo fluxo de trabalho para o desenvolvimento de questionários de avaliação. Suas principais contribuições para esta pesquisa estão relacionadas a apresentação da lista de questões em conjunto com a área de edição da questão, além de ideias para o uso de modelos.

A tela do Zenler é composta por três áreas: no topo fica uma barra organizada em blocos, sendo o primeiro bloco os tipos de questões que podem ser escolhidas. Na lateral esquerda é apresentado a lista de questões com um trecho do enunciado, o restante da tela acomoda a área para edição das questões. A área de edição de questões é o principal destaque, ela consegue reunir todos os elementos exigidos pelo tipo de questão por meio da organização em abas, deixando a tela suave e menos carregada que no Respondus. Esta aplicação juntamente com o Respondus tiveram forte influência na composição do layout da interface do iQuiz.

\section{- Edubrite}

O ambiente EduBrite ${ }^{15}$ se auto define como um SGC pessoal, sua aplicação resume-se na criação de cursos que permite a inclusão de SCORM, lição e questionários como conteúdo. O fluxo de atividade também é bem direto, um questionário pode ser criado mesmo antes da criação de um curso. No painel de controle são apresentadas abas para o usuário selecionar o recurso que deseja utilizar, uma das abas acessa o gerenciamento de questionários, nesse ponto o usuário pode visualizar a lista de questionários, editá-los ou criar um novo.

O Edubrite apresenta uma interface leve e bem limpa, mantém sempre uma barra de ferramentas no topo da área de edição para cada uma das opções das abas. As ferramentas para gerenciar a edição das questões e as alternativas estão todas na barra, separadas por grupos, algo que pode

\footnotetext{
${ }^{12}$ Disponível em: http://www.google.com.br/intl/pt-BR/about/products/. Acessado em 20 de junho de 2014

${ }^{13}$ Disponível em: http://www.edmodo.com. Acessado em 22 de junho de 2014

${ }^{14}$ Disponível em: http://www.zenler.com. Acessado em 20 de junho de 2014

${ }^{15}$ Disponível em: http://edubrite.com/oltpublish/theme-eb-www/cms.do. Acessado em 24 de junho de 2014
} 
levar um usuário a excluir uma questão inteira, quando sua intenção era excluir uma alternativa, ou levar mais tempo para localizar a ferramenta que intenciona usar.

Ao iniciar uma questão múltipla escolha, os campos iniciais já estão preenchidos por um exemplo, mas o usuário tem que limpá-los para digitar suas próprias informações. Após preenchidas as duas alternativas disponibilizadas o usuário deve acessar a barra para adicionar as próximas. Pontos positivos são sua leveza no design, organização em abas, organização das informações e vídeo tutorial logo na abertura da aplicação.

\section{- Exam General}

O Exam General ${ }^{16}$, esta aplicação Web assemelha-se com o Quiz na forma de disponibilizar campos e itens de ajuda. Apresenta logo de início os campos para configurar o questionário e logo abaixo uma área para adicionar as questões. Cada vez que o botão "adicionar questão"é acionado uma nova janela é aberta para editar a questão, sobrepondo o questionário. É esteticamente "poluído"com muitas informações, mas apresenta uma forma mais direta no fluxo de criação do questionário, comparado ao Quiz. Os pontos interessantes da aplicação: a organização do conteúdo em abas e o guia passo a passo para ajuda.

Outros elementos como funcionalidades e fluxo de trabalho foram avaliados e constatou-se que com relação as funcionalidades, nenhum dos sistemas oferece a quantidade de funcionalidades disponibilizadas pelo Quiz, os tipos de questões são limitadas e restringe-se as mais populares: múltipla escolha, falso/verdadeiro, correspondências, resposta curta e dissertativa.

Sobre o fluxo de trabalho foi possível perceber variadas soluções para a tarefa de criar questionários, entretanto, alguns sistemas foram capazes de simplificar o processo sem confundir ou ditar um fluxo rígido para a tarefa. O Exam General por exemplo, possui um fluxo idêntico ao do Quiz para esta tarefa, porém simplificou ao dar continuidade na mesma tela com a lista de questões. Esse processo porém teve a ajuda do tamanho do questionário, mais sucinto.

O Google Docs, embora seja voltado para criação de questionário de opinião, também utilizou modo corrido, apresentando uma folha única para usuário configurar detalhes do questionário e permitido a edição diretamente sobre o formulário, algo que as pessoas estão acostumadas a fazer com um editor de textos.

Os sistemas Respondus e Zenler se sobressaem quando centralizam todos os recursos na mesma tela,sem uso extensivo das barras de rolagem verticais e horizontais, isso foi obtido com a utilização de abas um recurso que permite revelar as informações por demanda.

Cada sistema contribuiu com alguma característica para composição da nova interface, aquelas consideradas mais relevantes para solucionar os problemas já identificados no Quiz foram agrupadas e relacionadas na Tabela 4.2, as características sem correspondência a nenhum sistema foram soluções idealizadas.

$\mathrm{Na}$ primeira coluna estão relacionadas as características que vieram a fazer parte da interface do Quiz, sendo que nas demais colunas estão os outros sistemas que contribuíram com alguma característica avaliada como útil e importante sob o aspecto da interação com o usuário. A tabela foi organizada de tal modo que todas as características presentes no Quiz, foram relacionadas na segunda coluna e em seguida as características em comum aos demais sistemas inclusive o Quiz, posicionado na terceira coluna.

\footnotetext{
${ }^{16}$ Disponível em: http://examtime.com/quiz-maker. Acessado em 25 de junho de 2014
} 


\begin{tabular}{|c|c|c|c|c|c|c|c|c|}
\hline \multicolumn{9}{|c|}{ Recursos de Interface } \\
\hline Itens & $i Q u i z$ & Quiz & Respondus & Google & Edmodo & Zenler & Edubrite & $\begin{array}{c}\text { Exem } \\
\text { General }\end{array}$ \\
\hline $\begin{array}{l}\text { Área para lista } \\
\text { de questões inte- } \\
\text { grada a área de } \\
\text { edição da questão }\end{array}$ & $\mathrm{x}$ & & $\mathrm{x}$ & & $\mathrm{x}$ & $\mathrm{x}$ & $\mathrm{x}$ & \\
\hline $\begin{array}{l}\text { Barra de ferra- } \\
\text { mentas ou botões } \\
\text { contextuais }\end{array}$ & $\mathrm{x}$ & & $\mathrm{x}$ & $\mathrm{x}$ & & & $\mathrm{x}$ & \\
\hline $\begin{array}{l}\text { Navegação em } \\
\text { abas }\end{array}$ & $\mathrm{x}$ & $\mathrm{x}$ & $\mathrm{x}$ & & & $\mathrm{x}$ & $\mathrm{x}$ & $\mathrm{x}$ \\
\hline Painel deslizante & $\mathrm{x}$ & & & & & & & \\
\hline $\begin{array}{l}\text { Adaptação ao } \\
\text { tamanho da tela } \\
\text { (Design adaptá- } \\
\text { vel) }\end{array}$ & $\mathrm{x}$ & $\mathrm{x}$ & & $\mathrm{x}$ & & & & \\
\hline $\begin{array}{l}\text { Dicas com balões } \\
\text { nas caixas de tex- } \\
\text { tos }\end{array}$ & $\mathrm{x}$ & & & & $\mathrm{x}$ & & & \\
\hline $\begin{array}{l}\text { Dica que descreve } \\
\text { valor esperado de } \\
\text { um campo }\end{array}$ & $\mathrm{x}$ & & & $\mathrm{x}$ & & & $\mathrm{x}$ & \\
\hline Ajuda contextual & $\mathrm{x}$ & & & & & & & \\
\hline $\begin{array}{l}\text { Vídeo tutorial } \\
\text { para ajuda }\end{array}$ & $\mathrm{x}$ & & & & & & $\mathrm{x}$ & \\
\hline $\begin{array}{l}\text { Expandir / com- } \\
\text { primir campos e } \\
\text { caixa de texto }\end{array}$ & $\mathrm{x}$ & & & & & & & \\
\hline $\begin{array}{l}\text { Destaque para al- } \\
\text { ternativas corre- } \\
\text { tas }\end{array}$ & $\mathrm{x}$ & & & & & & & \\
\hline
\end{tabular}

Tabela 4.2: Recursos de Interface

Embora não tenha sido catalogado na Tabela 4.2, vale ressaltar que também foi realizado uma pesquisa sobre funcionalidades que ajudam os usuários a desempenharem melhor suas atividades dentro de um sistema. Sendo duas consideradas importantes para iQuiz: (i) os modelos, por apresentarem um conjunto de configurações prévias e variadas, que evitam o preenchimento de extensos formulários e com isso reduzem o tempo na criação das avaliações, aumentando a produtividade durante a autoria dos questionários; (ii) os assistentes, por guiarem o usuário durante um processo, facilitando a tarefa, eles ajudam a reduzir os erros cometidos pelos usuários e facilitam a aprendizagem das tarefas do sistema.

Os sistemas similares analisados nessa seção contribuíram para a identificação de aspectos importantes na interação dos usuários com a interface, na disposição e organização de informações e elementos na tela e também na avaliação do fluxo de trabalho. Buscou-se os elementos que pareciam mais objetivos na realização das tarefas sem causar confusão ou dúvidas durante a navegação ou desempenho da tarefa, sendo esse um valioso método para este trabalho. 


\subsubsection{Análise de tarefas}

A análise de tarefas tem como objetivo a caracterização das tarefas realizadas pelos utilizadores do sistema, podendo ser definida como o estudo do que um usuário é obrigado a fazer em termos de ações e/ou processos cognitivos para realizar uma tarefa. Uma análise minuciosa de tarefas pode ser realizada para compreender o sistema atual e os fluxos de informações dentro dele.

A partir da análise de tarefas é possível projetar e atribuir tarefas adequadamente dentro do novo sistema. Assim as funções a serem incluídas no sistema e a interface do usuário podem ser determinadas com maior precisão (Maguire, 1998).

A descrição das tarefas podem ser realizadas de várias formas, cada uma delas correspondendo a um modelo que propicia uma determinada visão. Dadas as características das tarefas a serem modeladas, a mais conveniente para esta pesquisa é o fluxo de trabalho determinado pela sequência das tarefas.

O processo de autoria realizado no Quiz tem se apresentado bastante confuso para muitos professores, isso em decorrência do conceito aplicado principalmente a sequência das tarefas. Assim como discutido no projeto de Savolainen (2010), o fluxo das tarefas é um dos primeiros complicadores na utilização do Quiz.

Desse modo, decidiu-se a partir das observações com os usuários e da avaliação de outros sistemas, encontrar um fluxo desatrelado daquele que atualmente tem o Quiz. A interface de usuário e o fluxo de interação são capazes de resolver essa dinâmica sem intervenções na camada de processos do Quiz. O que possibilita essa liberdade nas mudanças para iQuiz é justamente o fato do seu desenvolvimento resultar em um plugin ao invés de mudanças no núcleo, como efetuado no trabalho de Savolainen (2010). Para uma compreensão minuciosa desse processo foi inserido o Apêndice C, que apresenta passo a passo sobre o processo para criação de questionários no Quiz, demonstrando o fluxo com ilustrações das telas, com alguns comentários sobre potenciais problemas em determinados pontos.

As informações do Apêndice foram sintetizadas em fluxos para compreensão de todo processo. $\mathrm{O}$ diagrama das tarefas apresentado na Figura 4.4, representa o fluxo com o Quiz desde as mudanças implementadas na versão 2.0, que nesse sentido em nada mudou até a versão 2.6 quando ainda este trabalho estava em andamento. 


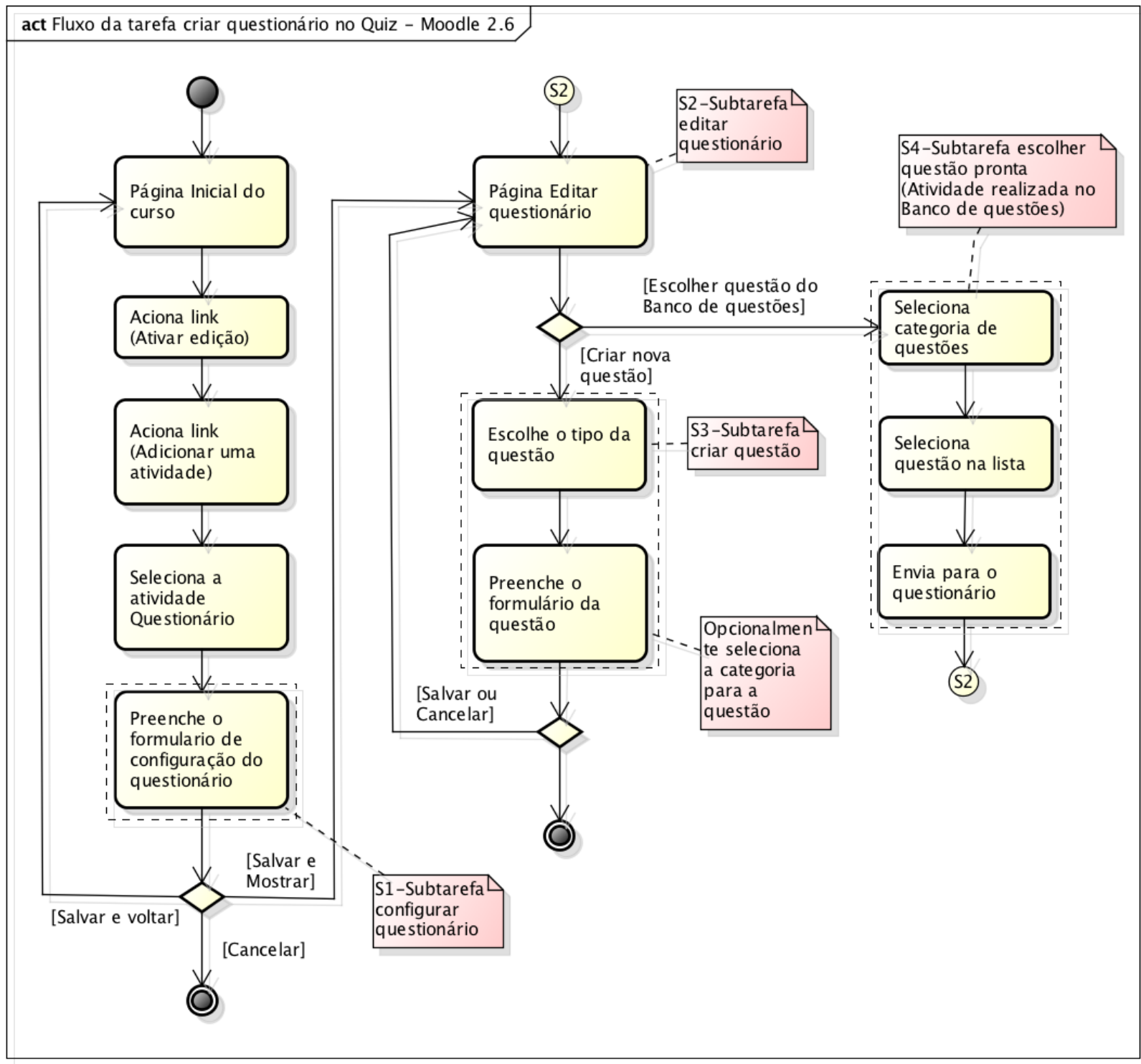

Figura 4.4: Fluxo de tarefas do Quiz

No Quiz o processo pode ser iniciado a partir da página do curso. Partindo desse ponto é dado uma sequência de três passos: (1) ativar o modo edição de atividades, (2) escolher a opção "Adicionar uma atividade" e (3) selecionar a atividade desejada, nesse caso o Quiz. Após ser selecionada a opção, inicia-se o processo de configuração do questionário, quando uma tela para preencher o formulário de configuração é apresentada. Assim os usuários devem definir quais regras serão aplicadas durante a tentativa de resposta do questionário. E só então a atividade irá aparecer como um item para o curso.

O problema nesse ponto é que durante as observações com os usuários criando os questionários, vários deles introduziam dados da questão que pretendiam inserir no questionário, até que se davam conta que os campos eram sobre o questionário e corrigem o erro, mas às vezes com demora, sendo esse um indício de que algo no processo não está natural uma vez que ainda vazio, apenas com suas configurações gerais, esperavam iniciar com a digitação da questão ao invés de inserir dados sobre o questionário.

O passo seguinte, após o questionário ser gravado, o usuário pode ser levado de volta a página do curso ou para página de edição do questionário. Essa é uma outra subtarefa (S2) dentro do processo de criação do questionário. A partir dai, pode-se criar uma questão nova o que resulta em outra subtarefa (S3) no processo, ou buscar no banco de questões (S4). Essa possibilidade foi uma das modificações realizadas por Savolainen (2010), anteriormente ao seu trabalho, o fluxo exigia 
que as questões fossem criadas primeiro no banco de questões e depois inseridas no questionário. O que ele fez foi acrescentar o botão (Salvar e Mostrar) ao final da etapa de configuração levando o fluxo para a tela de edição, depois o usuário poderia acionar o botão (Criar nova questão) e iniciar a edição da questão ao invés de fazer isso primeiro, tendo que iniciar o processo pelo banco de questões. Após estas modificações, tornou-se possível escolher as questões prontas na tela do banco de questões posicionada ao lado da tela de edição do questionário e/ou disparar o processo de criação de questões para inserir as questões no questionário e também no banco.

Nota-se que a sequência de passos de uma tarefa pode ser determinada pelo fluxo de interação do usuário com interface, assim foi feito quando o botão (Criar nova questão) foi acrescentado na tela do questionário. O fluxo de trabalho nesse contexto é um processo conceitual que define as funcionalidades a serem utilizadas no decorrer de uma tarefa, dessa forma pode ser controlado pela interface se existe a modularidade das funcionalidades no sistema. O próprio Savolainen (2010) define essa ideia ao concluir sobre o resultado obtido com as mudanças que fez na interface para a versão 2.0 do Moodle, dizendo que embora a nova interface seja visualmente muito semelhante a antiga, nela foi introduzido mudanças conceituais importantes aproximando a interface de um modelo centrado no usuário, ao organizar questionário e questões em primeiro plano no processo.

Após considerações sobre as observações e entrevistas, realizadas com os usuários e análise dos sistemas similares em conjunto com a análise das tarefas no Quiz, foi possível sugerir uma alternativa para o fluxo na criação de questionários que parece ser mais natural para os usuários caracterizados nessa etapa. O diagrama de tarefas sugerido para o iQuiz está representado na Figura 4.5. 


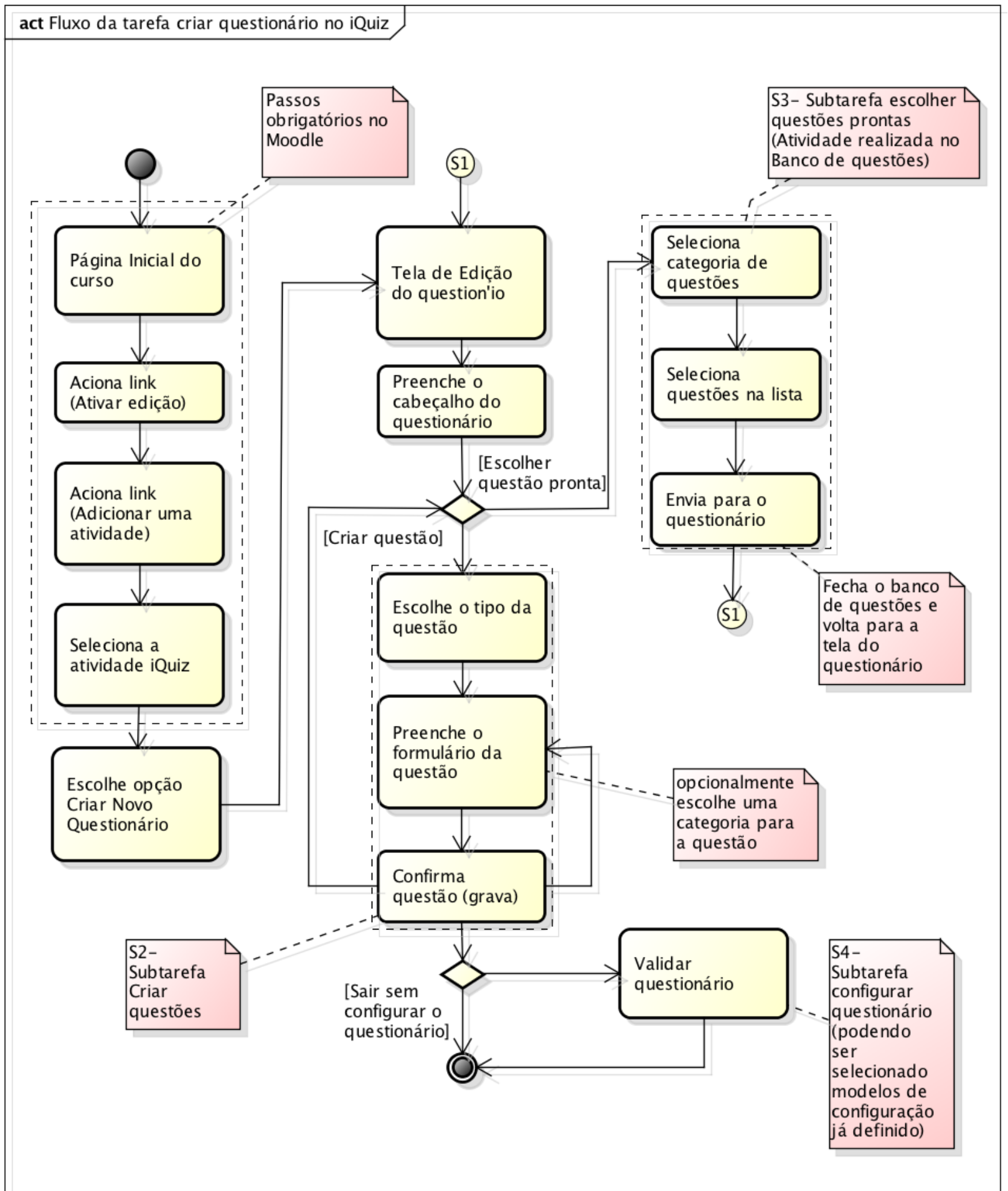

Figura 4.5: Fluxo de tarefas do iQuiz

No iQuiz o processo segue inicialmente o mesmo fluxo que o Quiz, a partir da página inicial do curso é dado uma sequência de três passos: (1) ativar o modo edição de atividades; (2) escolher a opção (Adicionar uma atividade) e (3) selecionar a atividade desejada, nesse caso o iQuiz. Após ser selecionada a opção, Criar novo teste, Abrir um teste, Utilizar Modelo, Utilizar assistente, Banco de questões, ao escolher (Criar novo teste), inicia-se o processo de edição, quando o fluxo chega a tela do questionário com dois campos: o título do questionário e a descrição. Até esse ponto a diferença em relação ao fluxo do Quiz é que são apresentadas opções com outras possibilidades para criar o questionário antes de iniciar-se a edição, como por exemplo utilizar um modelo pré-formatado. Feito a escolha, o professor terá que preencher um formulário com apenas dois campos, que representam 
o cabeçalho do questionário.

No passo seguinte o usuário decide se quer obter as questões do banco de questões ou adicionar uma questão nova. Ambas as tarefas podem ser intercaladas, mas quando a opção for criar uma nova questão, o fluxo foi dinamizado em relação ao Quiz, porque o formulário para edição da questão permanece disponível na tela para a digitação de uma nova questão caso seja do mesmo tipo. Se o interesse for por outro tipo de questão então volta-se ao fluxo inicial no ponto de decisão para escolher o novo tipo ou uma questão pronta. Cada vez que a questão for concluída será gravada no banco de questões e referenciada no questionário.

Por último, ao gravar-se ou sair da tela de edição do questionário é feita a validação, ou seja, o sistema checa se a configuração foi completada. Caso a configuração não esteja completa o usuário poderá completar, ou aceitar a configuração padrão ou ainda escolher uma configuração pré existente como por exemplo um modelo de prova. Desse modo, o fluxo proposto atende aos usuários inexperientes sem prejudicar a produtividade daqueles já habilidosos com o sistema.

Nessa seção foi sugerido um fluxo de trabalho para o $i$ Quiz, um requisito fundamental para a elaboração conceitual da interface, que é o componente chave do ambiente uma vez que integra e disponibiliza funcionalidades, determina o tipo interação com o usuário para fornecimento dos recursos. Assim é fundamental que a definição do fluxo de trabalho seja orientado as expectativas de quem utiliza o sistema.

\subsection{Modelagem da interface}

A interface no contexto de um sistema computacional é um mecanismo de interação essencial entre o usuário e os componentes funcionais do sistema. Sua finalidade é tornar a interação o mais simples e eficiente possível para o usuário, permitindo a realização dos seus objetivos. A elaboração da interface envolve atividades interdisciplinares, dentre as quais se inclui o design de interface de usuário. Segundo Preece et al. (2005), o design é uma atividade prática e criativa, que consiste no processo de desenvolvimento de um produto para ajudar os usuários a atingir suas metas.

O processo criativo de desenvolvimento da interface para $i Q u i z$ iniciou-se a partir das informações obtidas com base nos requisitos de usuários, durante a primeira fase.

Após a obtenção de informações sobre os usuários, fluxo de tarefas, sistemas e as funcionalidades definidas, o trabalho de desenho conceitual foi realizado.

Primeiramente, foi necessário definir o aspecto e funcionamento geral da interface, analisar a forma de apresentação e ocupação do espaço dentro da tela do Moodle. Embora o resultado final da interface deixe de seguir o padrão estético do Moodle, essa é uma flexibilidade permitida a qualquer plugin, que pode executar seus próprios arquivos de estilo para camada visual mantendo a convivência com o tema principal do Moodle.

Os aspectos relacionados a cores, fontes e ícones também foram ponderados, guias de estilos foram avaliado e só então foi rascunhado a primeira interface. Nessa etapa o objetivo foi criar telas estáticas por meio de um software de desenho para apresentar os conceitos fundamentais da interface. Partiu-se do princípio que deveria haver uma organização visual que integrasse todos os conceitos identificados, desde os recurso da interface ao fluxo de trabalho e que essa organização comporia um padrão de uso consistente para qualquer tipo de questão que fosse ser utilizada sem, entretanto, descartar as especificidades de cada tipo de questão.

As questões do tipo "múltipla escolha" e "falso/verdadeiro" utilizam uma tela de edição muito semelhante, já a questão "preencher lacunas" ou "palavra cruzada" podem exigir recursos na tela de edição inexistentes nas outras.

Os $i M A$ são outro exemplo, como fazem parte de uma linha de produtos de software, apresentam certa padronização como barras de ferramentas e botões específicos que precisam ser harmonizados com o ambiente.

Assim os aspectos relacionados a flexibilidade da interface e as possíveis variações demandadas pelos tipos de questões foram ponderados e então definido um estilo que tornasse possível acomodar os tipos de questões do Moodle e os iMA. Para cada tipo de questão do Moodle foi feita uma análise 
para determinar a melhor disposição dos elementos na tela, estratégias para evidenciar informações importantes, hierarquia e agrupamento de informações e o próprio fluxo de edição da questão. Para testar e validar a interface foi definido que seriam elaborados o corpo da interface, a estrutura geral e uma questão. O tipo de questão escolhido para implementação inicial no protótipo foi a questão de múltipla escolha, por ser a questão com maior utilização no Quiz. Segundo Hunt (2012) 75,85\% das questões mais utilizadas é do tipo múltipla escolha, seguido pelo tipo falso/verdadeiro com 12,04\%. Esses dois tipos de questão utilizam praticamente a mesma tela para edição, facilitando a realização dos testes de usabilidade.

A Figura 4.6 apresenta o rascunho da tela de criação dos questionários. O conceito aplicado foi o de correspondência com o mundo real, a metáfora de um folha foi utilizada para representar o questionário. Ideia herdada do Google Docs. No fim da lista de questões foram colocados os botões para (adicionar questão) ou (abrir questão pronta) do banco de questões. As abas no topo da tela agrupam as tarefas, mantendo em destaque apenas a tarefa em uso, nesse exemplo além da opção para editar o questionário, tem-se as abas para configurar o questionário, acessar ao banco de questões e ajuda.

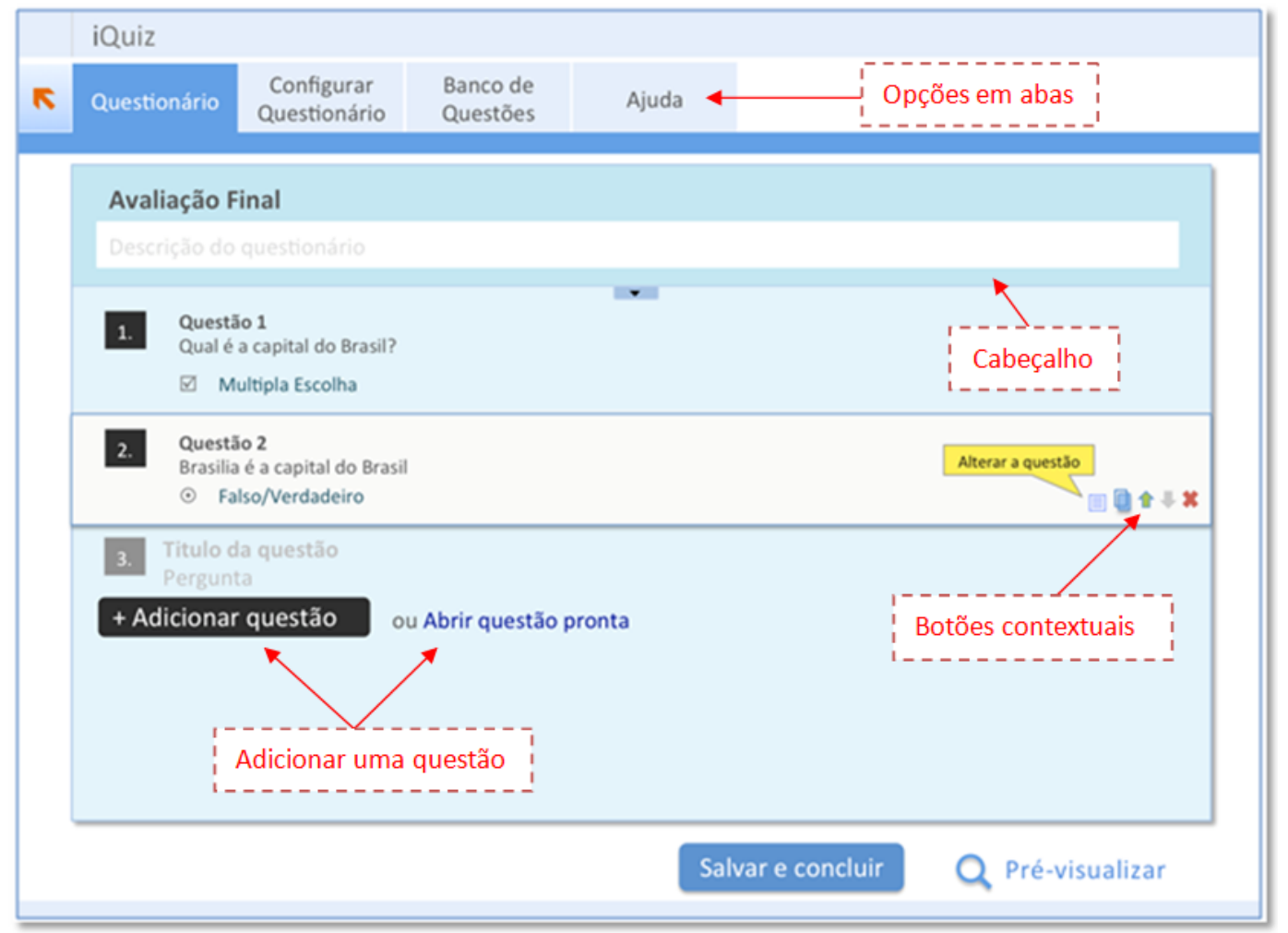

Figura 4.6: Rascunho da interface expandida do questionário

Assim que o botão (adicionar questão) é acionado ou o botão contextual exibido sobre a questão para editá-la a tela da Figura 4.7 é apresentada ao usuário. A região pontilhada destacada na tela representa a área de edição da questão. Quando a edição está ocorrendo a tela do questionário é reduzida a uma proporção menor na sua largura, mas ainda assim garantindo a visualização dos dados das questões já produzidas. Se for necessário, mais espaço durante a edição da questão, a tela poderá ser totalmente expandida. Essa solução garante a adequação em dispositivos com telas pequenas como tablets.

Essa organização da tela com a área para edição da questão, associada a lista de questões na mesma tela, foi um recurso encontrado nos sistemas Zenler, Edmodo, Edubrite e Respondus. A principal diferença implementada no iQuiz foi o conceito de painéis deslizantes. Ambas as áreas, tanto do questionário quanto da questão podem ser expandidas para ocupar a tela inteira. Desse modo, o usuário tem a possibilidade de navegar na folha de questões como no Google Docs e no 
Exam General ou editar uma questão utilizando todo espaço disponível na tela.

$\mathrm{Na}$ área da questão as informações foram organizadas em abas, aplicando o conceito de revelação gradual das informações. Esse tipo de organização de dados de uma questão foi verificado no Zenler, Edubrite e no Exam General. A organização das informações da questão teve uma solução não encontrada nos outros sistemas. Em questões como múltipla escolha foi verificado que geralmente é previsto alternativas curtas entre uma e duas linhas, mas existem casos em que utiliza-se muito mais linhas e até figuras nas alternativas. Para resolver esse problema sem comprometer a visão global da questão e sem a necessidade de barras de rolagem como ocorre no Quiz, foi introduzido um botão contextual para expandir ou contrair o campo da alternativa, quando essa situação acontecer. Os botões contextuais, foram usados amplamente na interface para evitar a "poluição visual" como ocorre no Quiz e no Exam General. Barras de ferramentas e botões contextuais só aparecem para o usuário quando o elemento em uso é passível da ação dos botões. Esse tipo de recurso foi encontrado no Google Docs, Respounds, e Edubrite.

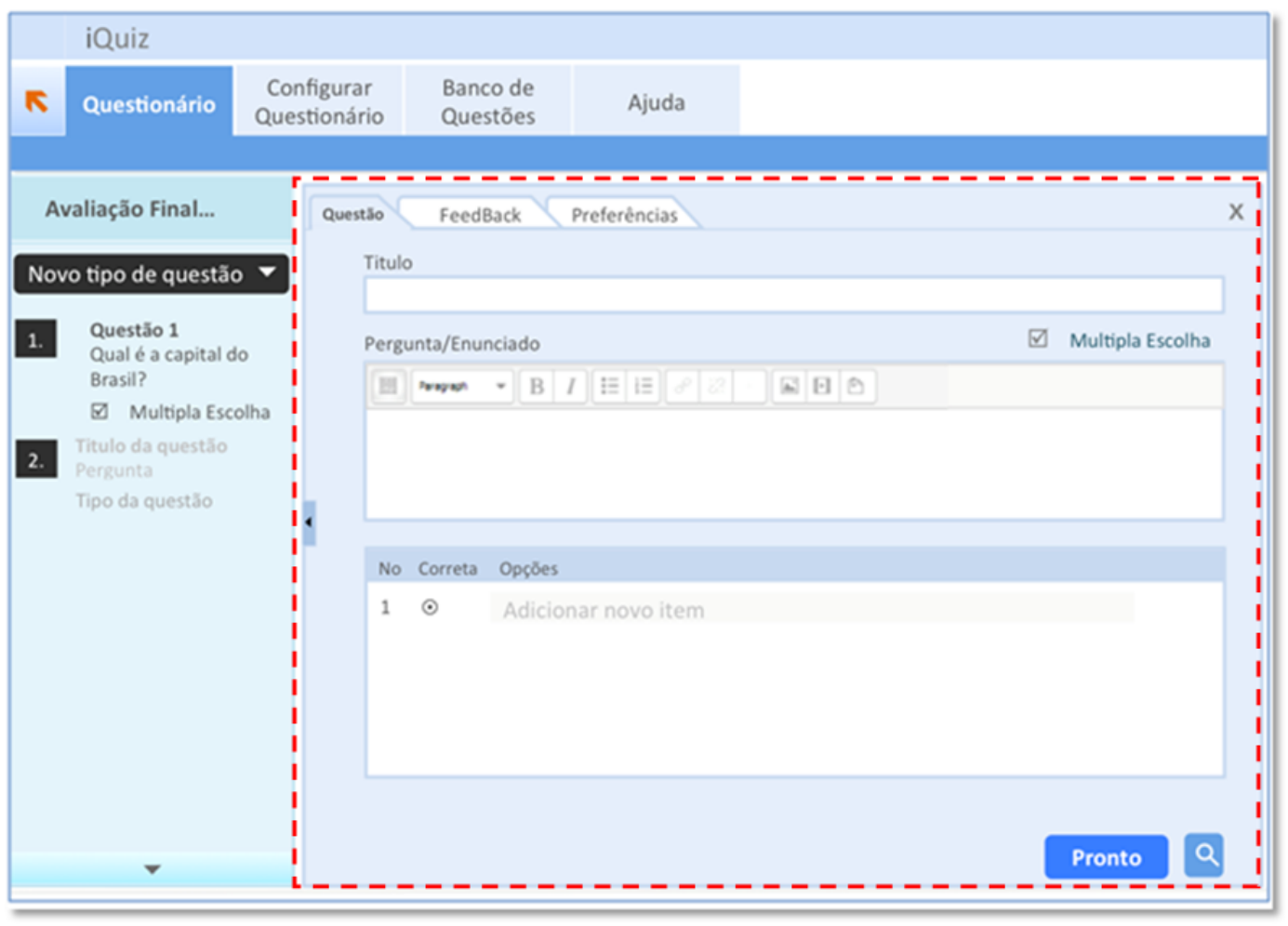

Figura 4.7: Rascunho da interface de edição de uma questão

A Figura 4.8 apresenta o rascunho do gerenciador do banco de questões e da configuração do questionário. Tanto o banco de questões quanto a opção configuração do questionário, tem o conteúdo organizado em subabas, esse tipo de organização foi visto no Respondus, para organizar as questões dentro da tela do questionário. A diferença aqui seria que estas abas na tela de configuração do questionário funcionam também como um indicador de posição no formulário, quando o usuário estiver configurando o questionário ele poderá utilizar a rolagem para acessar todos os itens ao invés de clicar nas abas, quando isso ocorre a aba equivalente é ativada. Isso assegura agilidade para usuários avançados e facilidade para usuários iniciantes. 


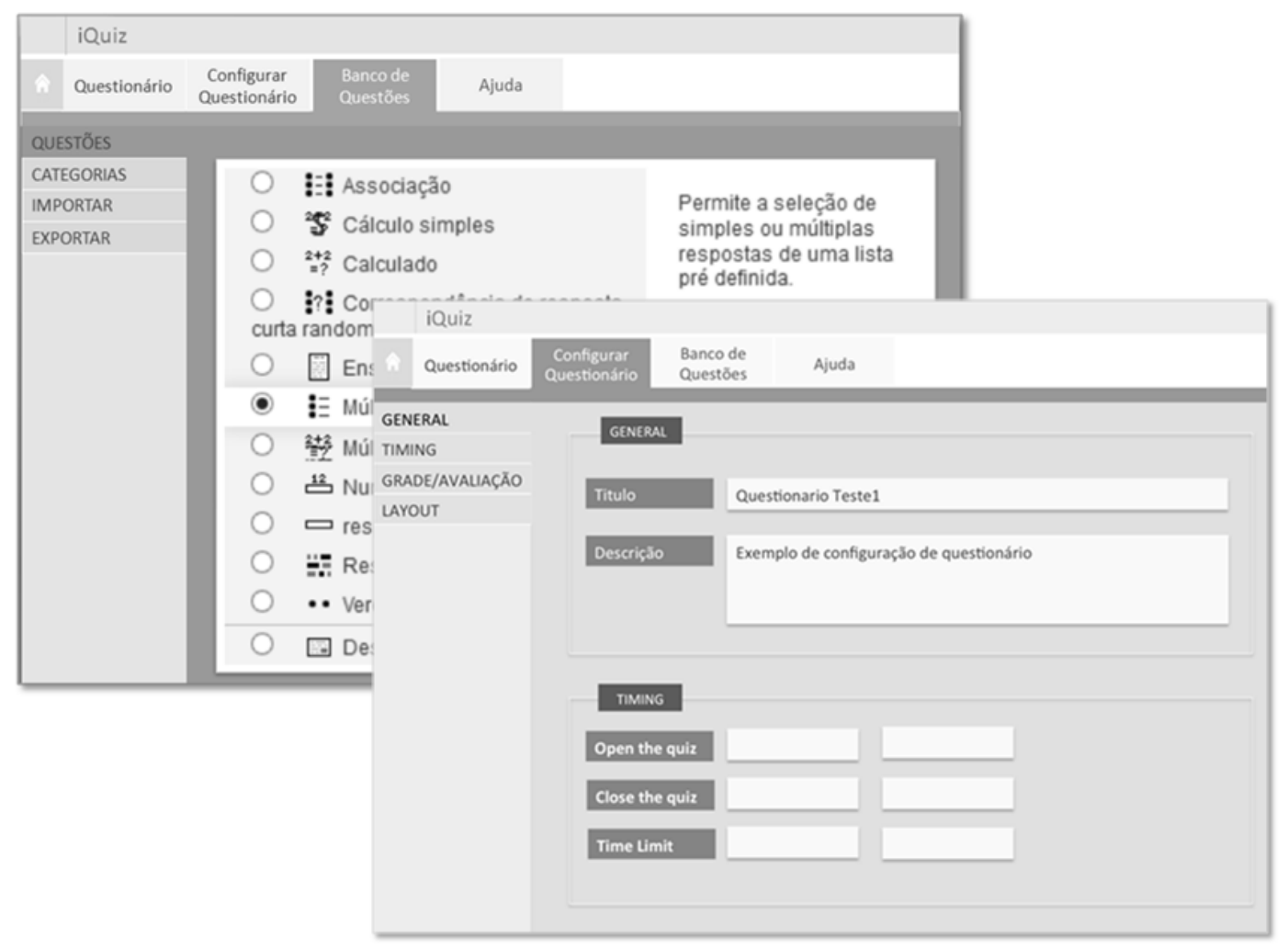

Figura 4.8: Rascunho das interfaces iniciais do banco de questões e configurar questionário

Os rascunhos apresentados nessa seção foram submetidos a uma discussão técnica e após avaliação do protótipo em papel, notou-se a necessidade de realizar um protótipo mais dinâmico, com nível de interação maior, pois algumas ideias estavam diretamente ligadas ao fato da interação. Muitas vezes os usuários não formulam um modelo mental equivalente ao do projetista apenas com as telas e as descritivas.

Durante as observações de usuários foi verificado que pequenos detalhes eram suficientes para ocasionar confusão ou frustração ao tentar utilizar os recurso no Quiz. Para contrastar a expectativa de uso dos usuários com a resposta da interface optou-se por fazer protótipos iniciais de alta fidelidade, onde os usuários poderiam interagir com as telas e participar do fluxo de navegação. Dessa forma, a cada validação era exigido um nível de interação maior até chegar ao ponto em que foi preciso implementar a camada de código completa para interação com a interface. Esse procedimento porém só foi possível com a formação de um grupo de consultores, que envolvia duas pessoas da área técnica que também eram professores e mais dois professores não técnicos que eram diretamente consultados sobre a interface durante a prototipação.

Embora tenha sido trabalhoso, esse procedimento evitou muito reprocesso, alcançando um bom nível de refinamento para entrar nos ciclos de testes de usabilidade. Durante a prototipação os consultores eram chamados para opinar sobre as ideias de uso da interface, após algum nível de refinamento, espaçou-se o tempo para que esses consultores opinassem. Finalmente numa segunda etapa a primeira avaliação em laboratório foi realizada. Esse experimento é comentado na Seção 5.2.2. Na próxima seção será apresentado a implementação do protótipo.

\subsection{Implementação do protótipo}

A implementação do protótipo ocorreu após uma criteriosa análise sobre as tecnologias que deveriam ser utilizadas; quais seriam as ferramentas com melhor custo/beneficio para desenvolver o protótipo e quais linguagens ou arcabouços seriam envolvidos no processo de desenvolvimento. A primeira decisão foi desenvolver o protótipo utilizando JavaScript, HTML5 e Ajax, para viabilizar melhor interação da interface com os usuários. Isso não seria possível apenas com HTML e CSS. 
A segunda decisão foi definir um arcabouço JavaScript que tivesse integração assegurada com Moodle. A recomendação encontrada na documentação do Moodle, foi a biblioteca JavaScript e CSS de código aberto denominada $Y U I$, mas a opção pela ferramenta de prototipação Maqetta ${ }^{17}$, direcionou a escolha da biblioteca para o DOJO, outro arcabouço de código aberto com sintaxe e recursos semelhante ao $Y U I$, do qual esta ferramenta faz uso para possibilitar a produção de interfaces Web para computadores, tablets e celulares em HTML5 e Ajax.

O ambiente de desenvolvimento NetBeans $^{18}$ foi utilizado para produzir os demais códigos de programação para o iQuiz.

\section{Prototipação da Interface}

A prototipação da interface foi conduzida com os documentos produzidos na primeira fase do projeto. O rascunho da interface, o guia de estilo e as recomendações de usabilidade completaram a documentação.

Após identificar os usuários e suas tarefas o processo de prototipação entrou no ciclo de iterações que envolveu o desenvolvimento da interface e as avaliações de usabilidade.

Segundo Winckler e Pimenta (2002b) a maioria dos autores concorda que esse processo é um ciclo continuo de design e avaliações de usabilidade quando se refere ao desenvolvimento de interfaces com foco na usabilidade. A figura 4.9 ilustra como foi esta fase da pesquisa, representada pelos dois últimos blocos, prototipação e avaliação da usabilidade foram intercalados até se obter a interface final.

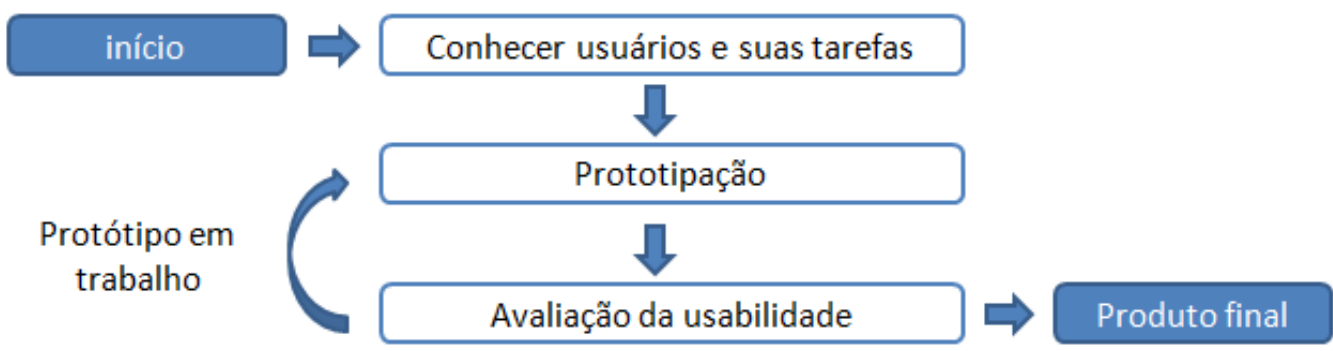

Figura 4.9: Ciclo de vida do projeto, adaptado de Winckler e Pimenta (2002b)

A figura 4.10, apresenta a tela com as principais funcionalidades definida para o iQuiz.

\footnotetext{
${ }^{17}$ Disponível em: http://maqetta.org/. Acessado em 18 de Novembro de 2013

${ }^{18}$ Disponível em: https://netbeans.org/. Acessado em 25 de Novembro de 2013
} 


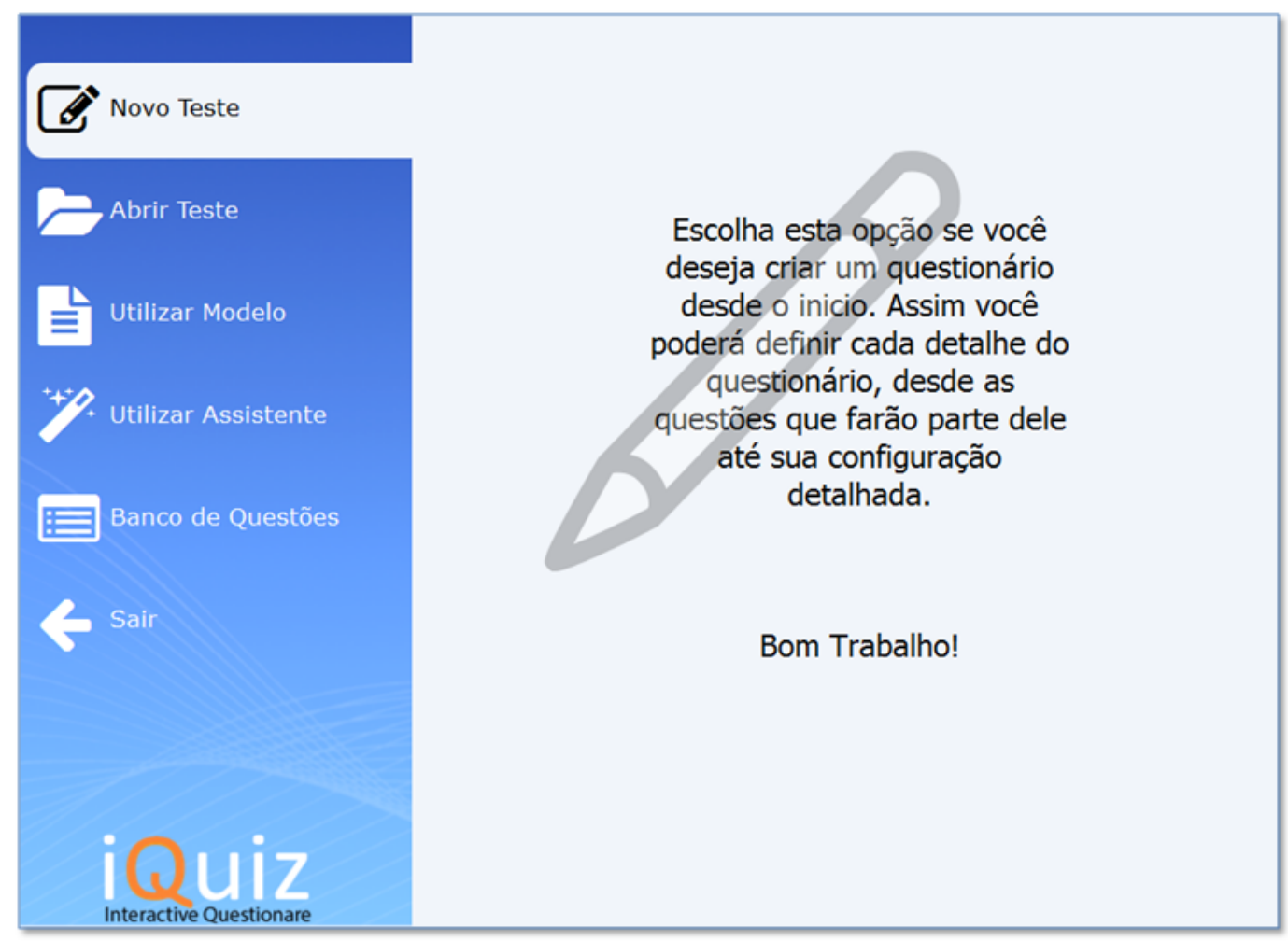

Figura 4.10: Tela inicial do iQuiz

- Novo teste: utilizado para se criar um novo questionário, sem nenhuma configuração prévia.

- Utilizar Modelo: com esta opção o questionário é iniciado com configuração previamente definida a partir de uma lista de modelos. Com esta opção por exemplo, pode-se escolher um modelo de questionário do tipo prova, que habilita as configurações de segurança para bloquear teclas de atalho como copiar/colar e restringir o acesso ao navegador.

- Abrir um teste: possibilita abrir um questionário pronto que poderá ser editado se ainda não houver tentativas de respostas ou abrir como cópia para criar outro questionário.

- Utilizar assistente: ativa o processo passo a passo para criar um questionário, nesse caso o fluxo da tarefa é guiado pelo sistema, orientando o professor sobre o que deve ser feito em cada etapa.

- Banco de questões: acessa o gerenciador do banco de questões.

Nesta tela foram feitas duas modificações após os testes de usabilidade, itens com a palavra "questionário" foram trocados por "teste", pois alguns professores, não associavam de imediato a opção "Novo questionário" para criar uma avaliação.

A outra mudança foi inserir nessa tela um vídeo tutorial apresentando os recursos do iQuiz. Depois de assistirem ao vídeo os professores melhoraram significativamente a taxa de conclusão das tarefas.

A partir desse ponto o trabalho de implementação da interface seguiu o fluxo de criação de um questionário, a tarefa principal dentro do processo de autoria que se desejava melhorar.

A Figura 4.11 apresenta a tela de edição do questionário. Nessa tela o professor preenche apenas os campos referente ao título do questionário e sua descrição, para evitar que eles inserissem os dados da questão nos campos do questionário, como ocorria na etapa de configuração no Quiz, os campos passaram a apresentar dicas com descrição do valor esperado, esse recurso é conhecido como placehold. Ao clicar sobre o campo o placehold desaparece e um balão de dica surge com informações até que o professor inicie a digitação. 


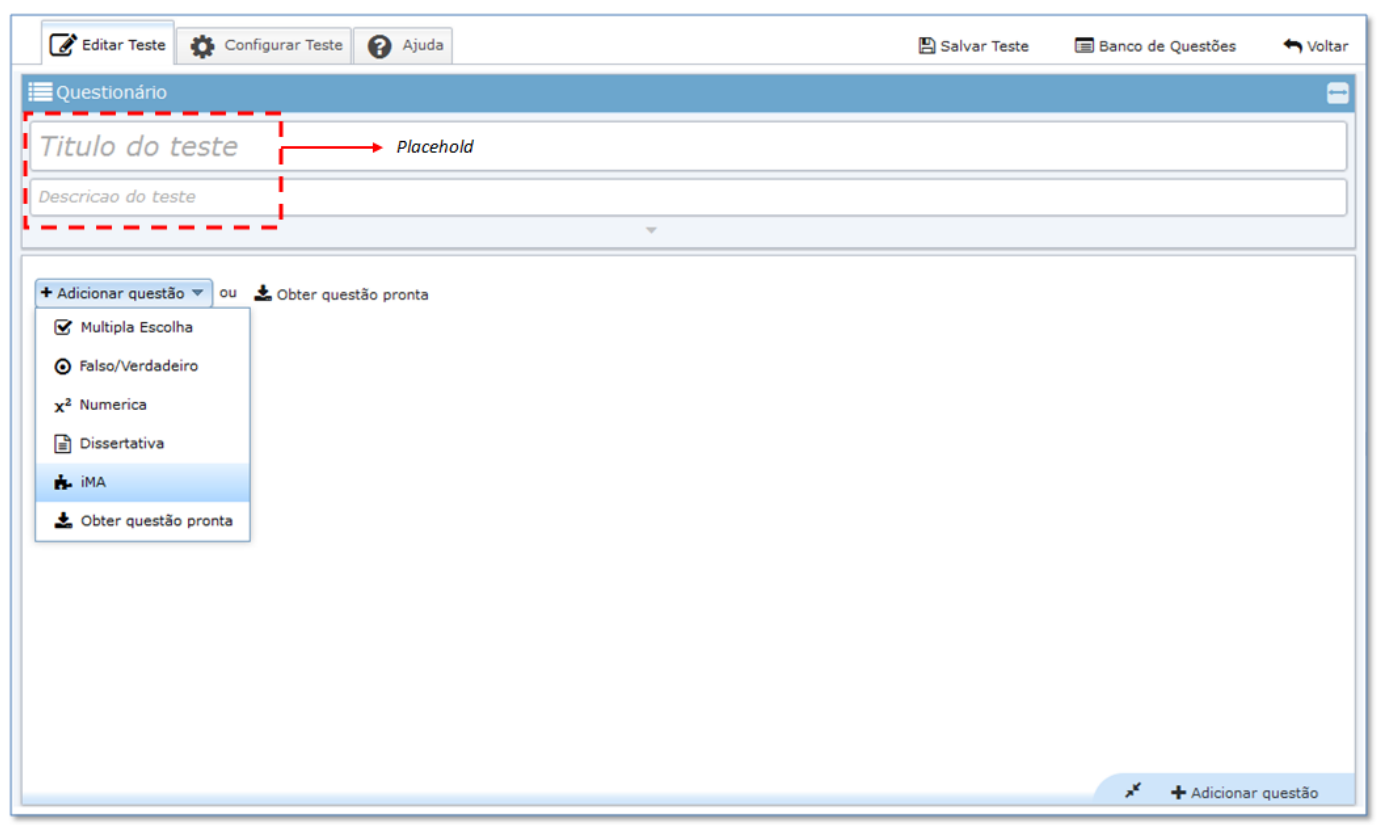

Figura 4.11: Tela com área do questionário expandida

Após o preenchimento dos campos iniciais o professor poderá selecionar um dos botões logo abaixo para adicionar uma nova questão ou obter uma questão pronta do banco de questões. Esses dois botões deixam claro a bifurcação do fluxo das tarefas. Se as questões desejadas estiverem no banco de questões ou no iRepositório o professor só precisa selecioná-las para compor o questionário e em seguida gravá-lo.

Se a opção for por criar a própria questão, o professor seleciona o tipo da questão na lista e preenche os dados da questão no painel que surge na lateral direita "empurrando" a área do questionário, fazendo com que essa área seja reduzida para acomodar os dois formulários, como mostra a Figura 4.12.

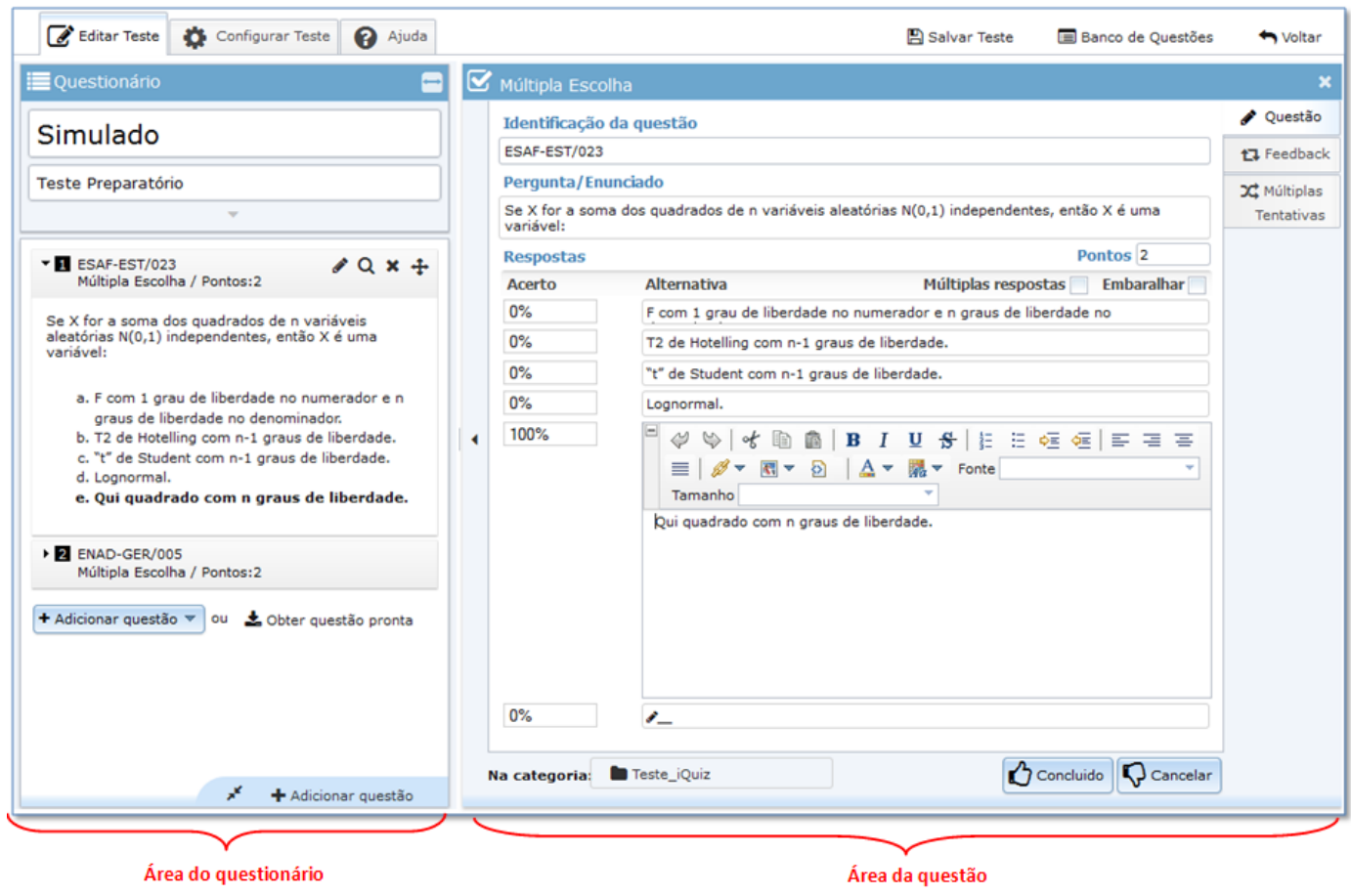

Figura 4.12: Tela com a área do questionário e da questão

Ao preencher os dados da questão tais como: identificação da questão e o enunciado novamente 
são utilizados placehold e balões de dicas. Para estes dois campos os rótulos foram modificados em relação aos termos utilizados pelo Quiz, que na versão 2.6 do Moodle, são respectivamente "Nome da pergunta" e "Texto da questão". Notou-se que esses termos não identificavam adequadamente os campos sob a percepção dos professores. O mesmo ocorreu com o campo "marcação da questão", rótulo atribuído ao campo para informar a pontuação da questão.

A área para inserir as alternativas, foi composta por apenas dois campos: acerto para se identificar o percentual de acerto da alternativa e o assunto para a alternativa.

Se a questão múltipla escolha possibilitar mais de uma resposta, o professor deverá ativar a caixa "múltipla respostas" e a partir disso o campo acerto poderá ser definido com combinações percentuais, ou seja, uma questão com resposta única deverá ter uma das alternativas com 100\% no campo acerto, já para múltiplas respostas poderá haver por exemplo, uma alternativa com $60 \%$ e outra com $40 \%$. Esse é um conceito que está no Quiz e foi mantido.

Neste ponto houve muitas dúvidas sobre como utilizar o recurso, a maioria dos professores envolvidos nos testes estavam inclinados a definir a alternativa como certa ou errada. Após a introdução do vídeo tutorial explicando o conceito não houve mais dúvidas.

A tela inicia com campos para apenas uma alternativa e após um dos campos ser selecionado, a linha de campos da próxima alternativa é apresentada. Isso mantém a tela limpa e promove o aparecimento gradual das informações evitando volume desnecessário de informação na tela, como ocorre com o formulário do Quiz. Outros recursos como expandir verticalmente ou manter contraído os campos das alternativas ou o surgimento da barra de ferramentas para edição dos campos de texto apenas quando o campo é acionado para edição, evita o excesso de informações na tela.

Para organizar a tela apenas com as informações necessárias a cada etapa do processo de criação da questão, o conteúdo foi distribuído em abas. No exemplo da Figura 4.12, pode-se observar que a aba em edição chama-se "Questão" e outras duas guardam o restante dos campos do formulário, são elas: "Feedback", utilizada para os comentários a serem apresentados após a resposta daquela questão em específico e a aba "Múltiplas Tentativas", utilizada para a inserção de dicas e penalidades a serem aplicadas quando é dado ao aluno a possibilidade de tentar responder a questão mais de uma vez.

Ainda na tela de edição da questão é possibilitado ao professor visualizar apenas a área de edição, expandindo o painel para ocupar toda a área do questionário. Essa necessidade pode ser ocasionada principalmente pelo uso de telas pequenas como as de um tablet ou netbooks. Da mesma forma o painel do questionário pode ser expandido e ocupar a área da questão para permitir uma navegação mais confortável sobre a lista de questões.

Outro aspecto importante da interface é que ela foi produzida com ícones SVG, uma tecnologia que permite a criação de gráficos vetoriais escaláveis, com isso ao ser acionado um zoom de $170 \%$ por exemplo, os ícones não se deformam e ficam tão nítidos quanto antes. Além dessa tecnologia foi empregado na interface a técnica de design adaptável, essa técnica ajusta a interface ao tamanho da tela do dispositivo em uso, como ilustra a Figura 4.13. 


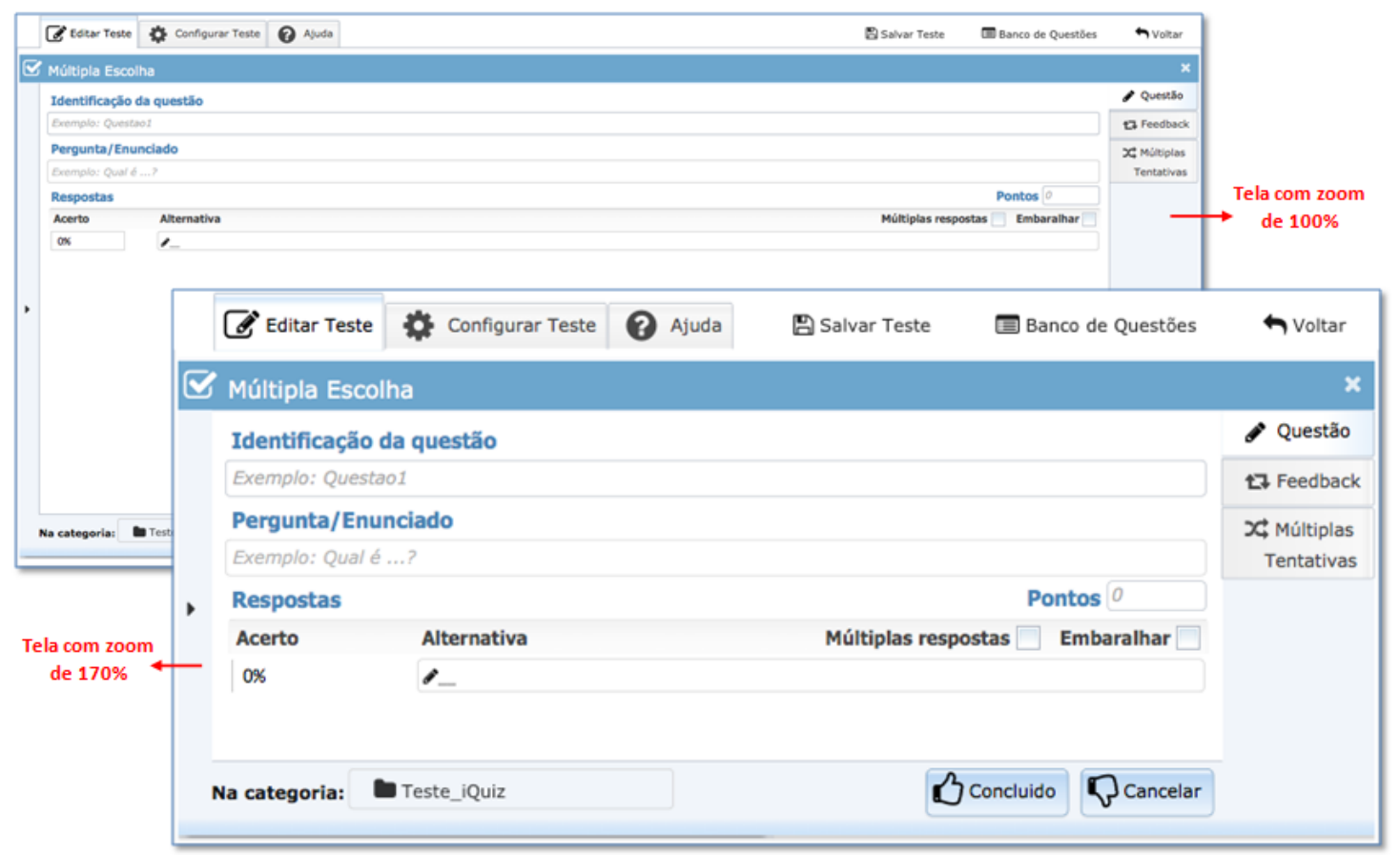

Figura 4.13: Interface com design adaptável, apresentando tela ampliada em 170\%

Com isso quando um usuário amplia sua tela ela é readaptada ao nível de zoom, ou quando ele acessa o iQuiz com dispositivos de telas menores. A tecnologia SVG e a técnica de design adaptável melhoram a acessibilidade. Esse recurso pode ser complementando com a alternância dos painéis de questionário e de questão principalmente com telas pequenas.

Os formulários do iQuiz vem sendo melhorados por seus mantenedores desde as mudanças da versão 2.0 do Moodle. A mais significativa, ocorreu com o agrupamento dos blocos de informação do formulário de configuração e criação de uma questão, que podem ser expandidos pelo usuário a medida que o questionário é preenchido ou podem ser expandidos todos de uma só vez.

Apesar dessas melhorias os questionários apresentam muitas ambiguidades possivelmente decorrentes das traduções, do jargão técnico e também falhas na organização e agrupamento das informações.

Foi procurado corrigir essas falhas aplicando-se as recomendações de usabilidade sobre os problemas encontrados. Um exemplo dessas modificações pode ser visto na área pontilhada da Figura 4.14, que apresenta a tela de configuração do questionário no iQuiz e a Figura 4.15 que apresenta o mesmo bloco de informação presente no questionário do Quiz. 


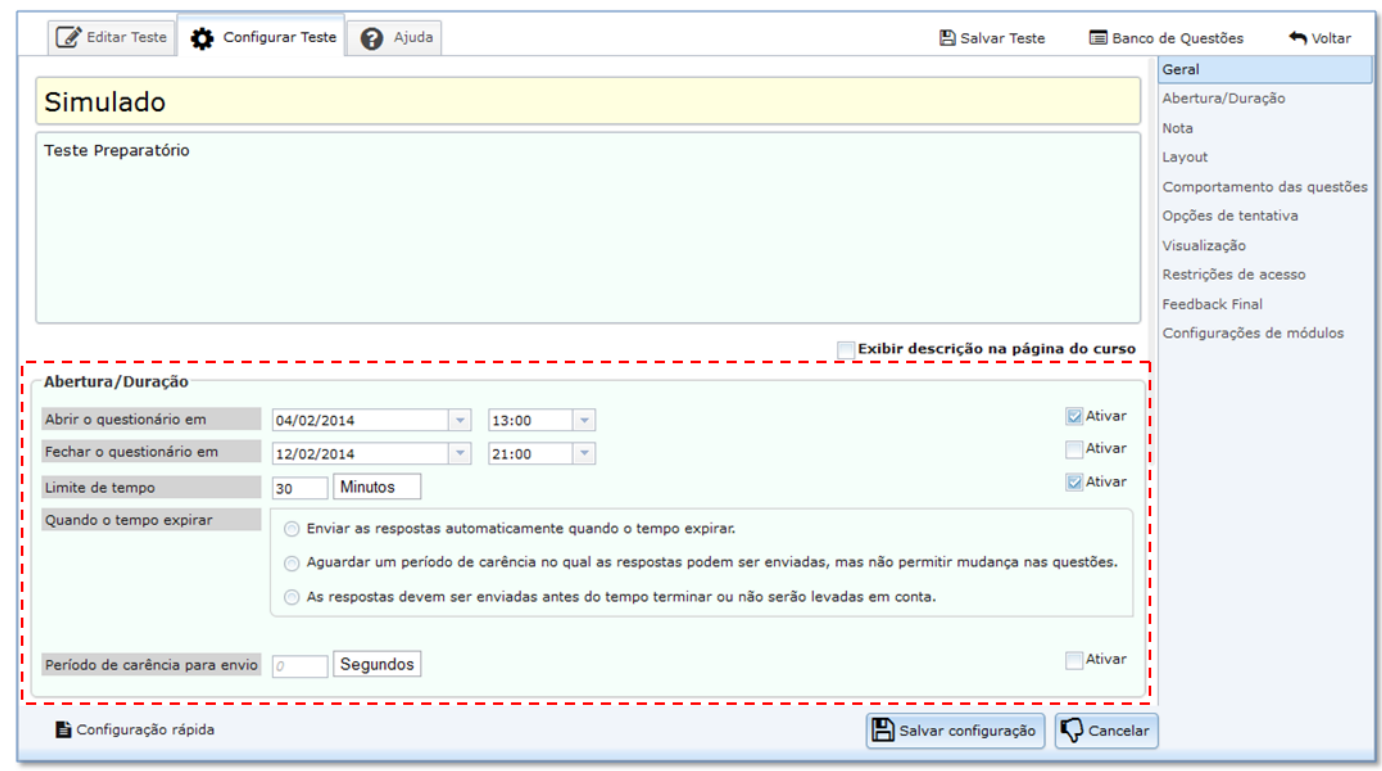

Figura 4.14: Tela de configuração do questionário do iQuiz

A área pontilhado da Figura 4.14 é equivalente a Figura 4.15 no formulário do Quiz.

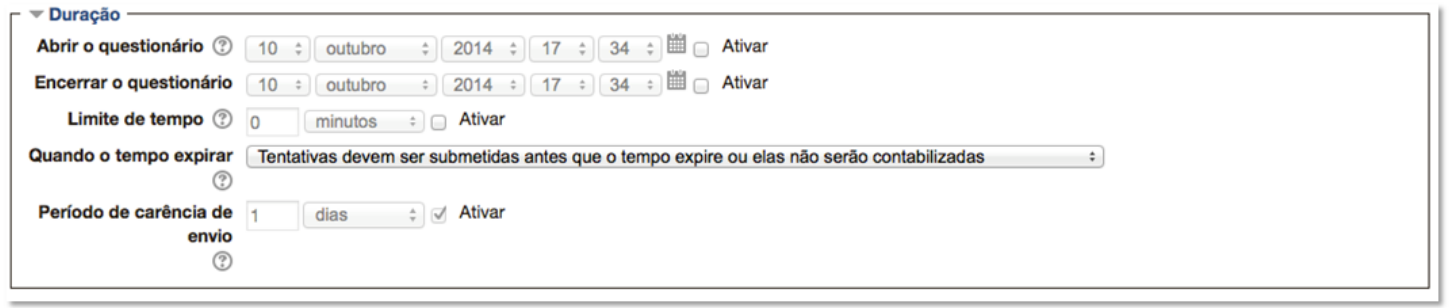

Figura 4.15: Bloco duração

Neste exemplo duas recomendações de Health e Services (2006) foram aplicadas: (i) permitir que os usuários insiram informações usando campos de entrada de dados (em vez de selecionar a partir de caixas de listagem), se você está projetando para acelerar o desempenho humano; (ii) fornecer botões de rádio quando os usuários precisam escolher uma resposta a partir de uma lista de opções mutuamente exclusivas.

No iQuiz este bloco do questionário é utilizado para definir a abertura e encerramento do questionário, não é permitido a digitação direta da data e da hora, somente a seleção de valores, o que ocasiona perda de produtividade. Em um outro campo com o rótulo "Quando o tempo expirar" é utilizado uma lista suspensa para itens mutuamente exclusivos. Ao observar as duas figuras é possível identificar a aplicação das duas recomendações. Esse tipo de procedimento foi aplicado por toda a interface, visando melhorar a usabilidade com a aplicação das recomendações.

Em relação ao rascunho da interface o conceito para o layout do questionário foi mantido com a opção de rolagem vertical e abas laterais para os tópicos do questionário, mas a disposição dos campos mudou.

Um outro aspecto importante sobre a interface foi a integração e harmonização dos $i M A$. O padrão visual dos $i M A$ produzidos seguindo a especificação da LPS permitiu enquadrar o layout deles dentro da área de questões com perfeita aderência. Quando se trata de $i M A$ produzido com $H T M L 5$ essa aderência é ideal, entretanto quando o $i M A$ é uma applet, as variações no tamanho da tela podem afetar a acomodação visual.

A Figura 4.16 apresenta o $i M A$ iVprog funcionando como um tipo de questão no $i Q u i z$. 


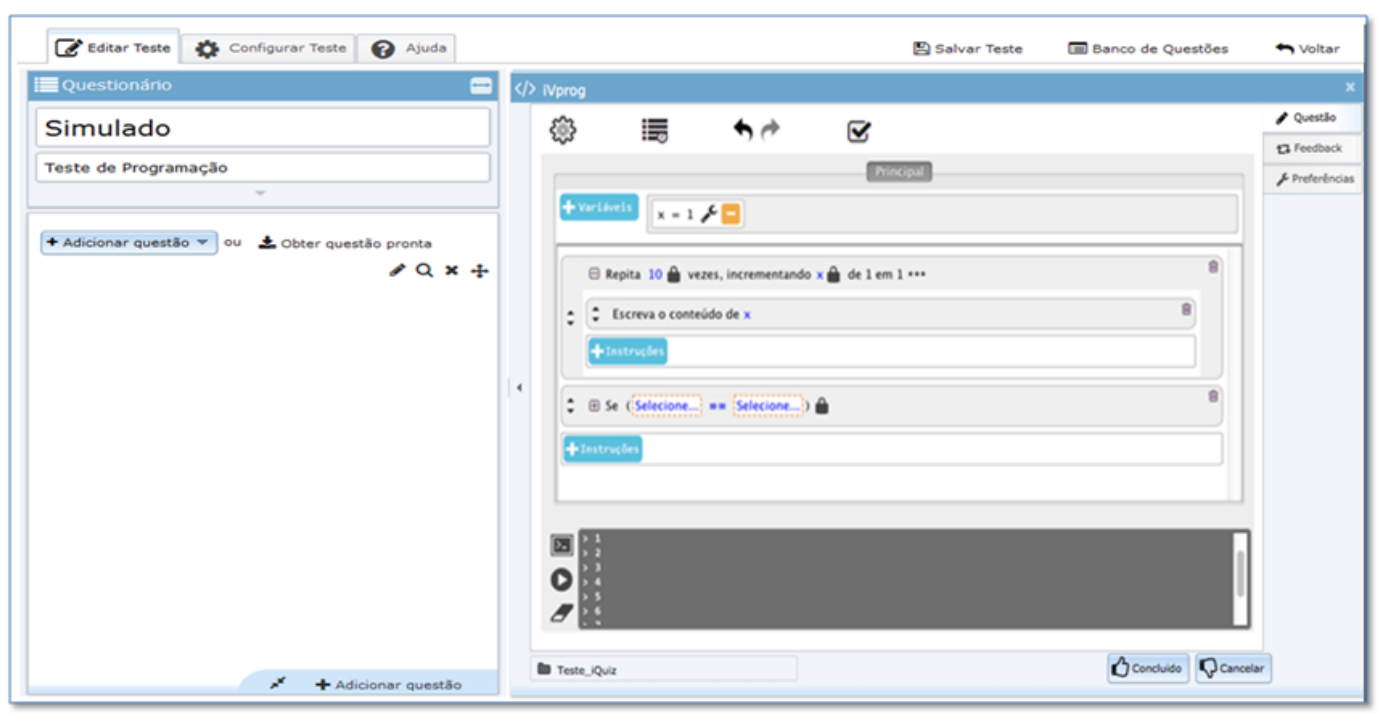

Figura 4.16: Tela com plugin iMA iVprog

Os $i M A$ entretanto deixaram de fazer parte das avaliações com os professores durante os testes de usabilidade, sendo importante a realização de testes específicos da sua utilização no $i Q u i z$.

Por fim, a interface foi tetada em computadores $P C$ e $M A C$, com os principais navegadores: Internet Explorer, Firefox, Safari e Google Chrome, nas plataformas operacionais Windows, versão 7 e 8, Linux Ubuntu versão 14.10 e MAC OS versão 10.9. Para que a interface tivesse o comportamento esperado, o sistema detecta a plataforma e faz ajustes em alguns elementos que sofrem variações visuais e comportamentais quando ocorre a mudança entre navegadores na mesma plataforma operacional ou do mesmo navegador em plataformas diferentes. 


\section{Capítulo 5}

\section{Resultado das Avaliações}

Neste capitulo apresenta-se os resultados obtidos com os experimentos realizados e a avaliação final entre as interfaces do Quiz e do iQuiz.

\subsection{Avaliação heurística}

Neste trabalho foi aplicada a avaliação heurística para inspecionar a interface após a liberação do protótipo inicial. Para realizar a avaliação heurística foram convidados dois especialistas em Interação Homem Computador (IHC). Ambos compreenderam facilmente o domínio da aplicação, sem apresentar qualquer dúvida sobre a aplicação do protótipo. Possivelmente, devido um deles ser atuante na área acadêmica (denominado por A1) e outro professor atuante no ensino superior (denominado por A2)

A aplicação da avaliação ocorreu da seguinte forma: (i) os avaliadores receberam, via email, um resumo do projeto com os objetivos da avaliação; e as instruções para a realização do teste; (ii) nas instruções lhes foram fornecido o endereço online do protótipo e um roteiro sugestivo de tarefas a ser realizada no mesmo; (iii) os avaliadores preencheram um formulário com seus apontamentos sobre a interface do protótipo; (iv) após envio de suas avaliações, lhes foi enviado um link do vídeo tutorial apresentando os recursos do protótipo, para confirmarem se haviam notado e aplicado corretamente todos os recursos do protótipo.

Os apontamentos realizados pelos especialistas foram consolidados na Tabela 5.1

\begin{tabular}{|l|l|l|l|l|}
\hline Ref & Apontamentos & Heurística violada & A1 & A2 \\
\hline 01 & $\begin{array}{l}\text { Não consigo criar uma ta- } \\
\text { bela }\end{array}$ & $\begin{array}{l}\text { Uma das questões para serem criadas (como suges- } \\
\text { tão), possui uma tabela, porém não consegui adicio- } \\
\text { nar uma ao questionário }\end{array}$ & - \\
\hline \multicolumn{3}{|c|}{ Nível de severidade = 1 } & X \\
\hline 02 & $\begin{array}{l}\text { Não consigo aumentar a } \\
\text { área de edição de texto de } \\
\text { uma pergunta/enunciado. }\end{array}$ & $\begin{array}{l}\text { Fica difícil com enunciados que tenham imagens. } \\
\text { Escolha do valor do } \\
\text { Acerto para as alternati- } \\
\text { vas. }\end{array}$ & $\begin{array}{l}\text { Prevenção de Erros vs Eficiência: O uso de uma } \\
\text { lista drop-down para selecionar os percentuais de } \\
\text { acertos me pareceu um excesso de zelo. Parece que } \\
\text { a intenção é ajudar o professor com exemplos seleci- } \\
\text { onáveis e evitar erros garantindo o intervalo [-100\%, } \\
\text { +100\%]. Mas a procura pelo valor desejado nessa } \\
\text { lista bastante grande acaba diminuindo a eficiência, } \\
\text { que seria mais fácil ser digitada. }\end{array}$ & X \\
\hline
\end{tabular}




\begin{tabular}{|c|c|c|c|c|}
\hline 04 & $\begin{array}{l}\text { Exibição de respostas cor- } \\
\text { retas no preview da lateral } \\
\text { esquerda. }\end{array}$ & $\begin{array}{l}\text { Visibilidade e Linguagem do Usuário: Uma vez } \\
\text { que as questões exibidas na lateral esquerda incluem } \\
\text { as alternativas, deve ser interessante exibir também } \\
\text { quais são corretas (e/ou parcialmente corretas). Tal- } \\
\text { vez usando a marcação em vermelho como no seu } \\
\text { exemplo (algo bastante condizente com o que se faz } \\
\text { em gabaritos no mundo real, na verdade). }\end{array}$ & - & $\mathrm{X}$ \\
\hline \multicolumn{5}{|c|}{ Nível de severidade $=2$} \\
\hline 05 & $\begin{array}{l}\text { Não há mensagem infor- } \\
\text { mando que é obrigató- } \\
\text { rio preencher "Identifica- } \\
\text { ção da questão". }\end{array}$ & $\begin{array}{l}\text { Boas mensagens de erro: Ao tentar salvar uma } \\
\text { questão sem identificação, não consigo salvar, e a } \\
\text { única dica que recebo é que o campo de identifica- } \\
\text { ção está ativo. Uma mensagem ou colorir o campo } \\
\text { de vermelho pode ajudar. }\end{array}$ & $\mathrm{X}$ & - \\
\hline 06 & $\begin{array}{lll}\text { Botão expandir não faz } \\
\text { nada. }\end{array}$ & $\begin{array}{l}\text { Consistência e Padronização: O botão expandir, } \\
\text { disponível abaixo do título e descrição do questioná- } \\
\text { rio, contém uma seta para baixo e apresenta a dica } \\
\text { "Expandir" quando o ponteiro do mouse é posici- } \\
\text { onado nele. Mas, o clique não faz nada. O usuário } \\
\text { é levado a acreditar que pode haver outros campos } \\
\text { a serem preenchidos, e a falta de resposta ao clique } \\
\text { parece uma falha do sistema e pode levar a confusão. }\end{array}$ & - & $\mathrm{X}$ \\
\hline \multicolumn{5}{|c|}{ Nível de severidade $=3$} \\
\hline 07 & $\begin{array}{l}\text { Falha na exibição da } \\
\text { pontuação correta para } \\
\text { as questões. A pontuação } \\
\text { que configurei em uma } \\
\text { questão não aparece no } \\
\text { menu lateral. E quando } \\
\text { retorno à questão, a } \\
\text { pontuação não é mantida. }\end{array}$ & $\begin{array}{l}\text { Consistência e Feedback: Desejo atribuir pesos } \\
\text { diferentes a questões diferentes. Quando edito esse } \\
\text { campo, imagino que a função está disponível. As in- } \\
\text { formações exibidas na barra lateral esquerda estão } \\
\text { inconsistentes (sempre mostra "Pontos: } 1 \text { "). Esse fe- } \\
\text { edback é imediato e causa estranheza pela "sensação" } \\
\text { de erro (pois o valor da pontuação é armazenado cor- } \\
\text { retamente). }\end{array}$ & $\mathrm{X}$ & $\mathrm{X}$ \\
\hline 08 & $\begin{array}{l}\text { Navegação entre campos } \\
\text { por meio da tecla TAB. }\end{array}$ & $\begin{array}{l}\text { Consistência e Padronização: A navegação entre } \\
\text { campos durante preenchimento dos títulos do questi- } \\
\text { onário e de perguntas não segue exatamente o padrão } \\
\text { esperado de navegação em formulários. Após digitar } \\
\text { um campo e pressionar a tecla TAB (tabulação), o } \\
\text { foco vai para o próximo campo, mas o campo não en- } \\
\text { tra imediatamente no modo de edição. Fiz um teste } \\
\text { "colando"o texto do clipboard e a ação não funcio- } \\
\text { nou justamente porque o campo não estava em modo } \\
\text { de edição. Um usuário habilidoso em digitação, que } \\
\text { possa estar digitando o texto enquanto olha para um } \\
\text { rascunho (isto é, olha para outro foco de atenção } \\
\text { que não seja a tela), pode perder tempo digitando } \\
\text { sem perceber que seu texto não está sendo aceito. } \\
\text { NOTAS: o foco não aceita a digitação de texto, mas } \\
\text { passa a aceitar a partir do pressionamento da pri- } \\
\text { meira tecla de espaço, podendo resultar em proble- } \\
\text { mas maiores como perda de parte da entrada di- } \\
\text { gitada; esse problema não ocorre sempre nos cam- } \\
\text { pos das alternativas das perguntas, mas ocorre sem- } \\
\text { pre nos demais campos; se o usuário navegar com o } \\
\text { mouse (clicando nos campos), não há problema de } \\
\text { navegação. }\end{array}$ & $\mathrm{X}$ & $\mathrm{X}$ \\
\hline
\end{tabular}




\begin{tabular}{|c|c|c|c|c|}
\hline 09 & $\begin{array}{l}\text { Entendimento do valor do } \\
\text { Acerto para as alternati- } \\
\text { vas. }\end{array}$ & $\begin{array}{l}\text { Ajuda e documentação: Não está claro o papel } \\
\text { da escolha de um percentual para cada alternativa. } \\
\text { Por se tratar de um percentual, o usuário pode ser le- } \\
\text { vado a crer que a escolha de } 100 \% \text { deve ser dada ape- } \\
\text { nas à alternativa correta, em casos em que só exista } \\
\text { uma, e que variações disso devem ser dadas no caso } \\
\text { de múltiplas alternativas. Só que a opção "Múltiplas } \\
\text { respostas" deixa de fazer sentido. "Usando o chapéu" } \\
\text { de um professor preenchendo o questionário, eu tam- } \\
\text { bém não entendi a possibilidade de escolher valores } \\
\text { percentuais negativos (se a intenção é definir uma } \\
\text { "distância" de uma alternativa incorreta até a alter- } \\
\text { nativa correta, a escolha do rótulo "Acerto" pode não } \\
\text { ser a melhor).. }\end{array}$ & - & $\mathrm{X}$ \\
\hline 10 & $\begin{array}{l}\text { Alternância de estado de } \\
\text { edição com mudança de } \\
\text { foco da janela }\end{array}$ & $\begin{array}{l}\text { Flexibilidade e eficiência no uso: Quando o usuá- } \\
\text { rio está digitando um campo e muda o foco da ja- } \\
\text { nela (faz ALT+TAB, por exemplo), ao voltar para } \\
\text { a janela do seu aplicativo o campo não está mais no } \\
\text { modo de edição. Isso é disruptivo na experiência de } \\
\text { utilização e diminui drasticamente a produtividade, e } \\
\text { deve acontecer bastante considerando-se que se trata } \\
\text { de um professor construindo um questionário para } \\
\text { avaliação de seus alunos (provavelmente ele irá copi- } \\
\text { ar/reutilizar material pronto, que nem sempre estará } \\
\text { em texto impresso). }\end{array}$ & - & $\mathrm{X}$ \\
\hline \multicolumn{5}{|c|}{ Nivel de severidade $=4$} \\
\hline 11 & $\begin{array}{l}\text { Quando não tenho ne- } \\
\text { nhuma questão aberta e o } \\
\text { editor de questões está fe- } \\
\text { chado, ao mover o cursor } \\
\text { do mouse para a direita da } \\
\text { tela o editor de questões é } \\
\text { aberta sem qualquer ques- } \\
\text { tão, mas quando salvo essa } \\
\text { questão, a última questão } \\
\text { que alterei é substituída } \\
\text { pelos valores adicionados. }\end{array}$ & $\begin{array}{l}\text { Consistência: Espero ver o formulário de edição de } \\
\text { questões apenas ao clicar em "criar questão" ou "edi- } \\
\text { tar questão". Além disso, ao salvar essa questão eu } \\
\text { perco todas as informações inseridas para outra ques- } \\
\text { tão. }\end{array}$ & $\mathrm{X}$ & - \\
\hline 12 & $\begin{array}{l}\text { Visibilidade das respostas } \\
\text { parcialmente corretas }\end{array}$ & $\begin{array}{l}\text { Visibilidade: Não é fácil relacionar quais questões } \\
\text { são "parcialmente corretas" e "totalmente incorre- } \\
\text { tas". Se essa relação está incluída no percentual de } \\
\text { acerto, fica ainda mais difícil o entendimento con- } \\
\text { siderando as possibilidades de valores negativos (se } \\
33 \% \text { significa uma questão parcialmente correta, o } \\
\text { que significa -33\%). }\end{array}$ & - & $\mathrm{X}$ \\
\hline
\end{tabular}

Tabela 5.1: Resultado da avaliação heurística

Abaixo segue os comentários sobre os apontamentos relatados pelos avaliadores, usou-se o código de referência da primeira coluna da tabela para identificar cada apontamento.

REF-01: Recurso indisponível nesta versão do protótipo, em um dos experimentos anteriores, a falta do recurso foi observada por quase todos os participantes.

REF-02: Problema conceitual, não foi possibilitado estender a área de visualização do enunciado como ocorre com as alternativas, desse modo o recurso foi acrescentado.

REF-03: Esse modelo para escolha das alternativas corretas foi herdado do Moodle Quiz, foi verificado que a maioria dos usuários tem dúvida sobre como aplicar os percentuais. Uma solução pensada foi que quando a opção múltiplas respostas não estiver selecionada então o campo acerto apresenta apenas $0 \%$ ou 100\%, significando certo ou errado. Se o usuário seleciona o opção múltiplas 
respostas a lista completa de percentuais é apresentada. Quanto ao uso dos percentuais negativos, esta é mais uma sofisticação das questões do Quiz, que permite-se descontar pontuação quando o aluno escolhe uma alternativa incorreta, como ocorre no sistema de múltiplas tentativas. Se o aluno acerta, ganha ponto positivo, se erra ganha ponto negativo. Esse é um problema conceitual, que precisa ser resolvido com a apresentação de exemplos para o professor, talvez por meio de dicas mais incisivas durante a edição das alternativas.

REF-04: A sugestão foi implementada para os experimentos seguintes.

REF-05: Uma falha de programação ocorrida quando o foco era retornado ao campo, a consistência não era ativada e por isso o usuário não recebia as mensagens de aviso. O problema ocorre somente quando o usuário tenta concluir a questão sem digitar nada no campo.

REF-06: O botão foi colocado em estado desabilitado, esse botão ao ser acionado expande para baixo a área do painel para mostra informações adicionais sobre a pontuação total do questionário, pontuação máxima definida e número de questões já criadas.

REF-07: Pontuação não aparece, erro de programação corrigido.

REF-08: O defeito está relacionado com uma falha apresentada pelo DOJO, não foi verificado se em versões mais atualizadas o problema foi corrigido com o componente utilizado pelo protótipo. De todo modo o editor base para a edição das questões se baseará no editor padrão do Moodle.

REF-09: Falha em dois componentes do DOJO, problema será corrigido por meio de programação complementar.

REF-10: Essa observação foi muito pertinente, pois de fato os professores usam bastante copiar/colar. Esse problema também está relacionado com a REF-08 e será corrigido com a implementação do editor final.

REF-11: Este era um recurso que servia como atalho para restaurar os painéis, mas foi removido.

REF-12: Esta questão está relacionada com a REF-09, sendo preciso entender o conceito de perda de ponto quando o aluno responde uma questão errada.

\section{Resultados e Discussão}

Foi possível constatar que a aplicação do método de avaliação heurística é bastante importante e permite poupar tempo e recursos até a submissão do protótipo para teste com os usuários do sistema. Muitos defeitos técnicos e conceituais foram encontrados mesmo após várias verificações durante o processo de elaboração da interface e codificação da camada de interação.

O envio do vídeo para os especialistas, após a avaliação, permitiu que eles mensurassem o quanto tinham explorado da interface. Como comentou um dos especialistas:

"Comparando o vídeo com o que eu fiz, eu diria que a interação está muito boa. Uns 80\% do ideal".

Também foi útil para identificar quais recursos não haviam sido explorados, como informou o outro especialista:

"Legal o vídeo. O ponto que ele apresenta e eu não tinha entendido foi em relação à pasta onde a questão será armazenada. Até vi a possibilidade de clicar e navegar em uma árvore de pastas, mas não tinha entendido o objetivo".

De modo geral ambos os especialista avaliaram muito bem o protótipo. A principal recomendação foi a criação de tarefas em que o questionário criado fosse grande (com muitas perguntas), para ajudar a perceber o desempenho, eficiência e eficácia na interação para a construção do questionário, e também eventualmente identificar necessidades relacionadas à visibilidade (pesquisa de conteúdo e até filtros na aba lateral esquerda por tipo de questão - certos professores podem desejar balancear a quantidade de perguntas de cada tipo).

Embora Nielsen (2005) apontar o método heurístico como muito eficiente, fez ressalva apontando que existem uma faixa de erros nas avaliações. Pode-se comprovar que problemas técnicos interferem muito na usabilidade do software haja visto o número de problemas e falhas apontadas que eram pequenos erros de programação. 


\subsection{Testes de usabilidade}

Durante o desenvolvimento deste trabalho foram realizados quatro experimentos, sendo, um levantamento de requisitos e três avaliações da interface do protótipo. Uma descrição sucinta de cada um deles é apresentada a seguir:

- Levantamento de requisitos: Um experimento realizado com o objetivo de levantar os requisitos mínimos para o desenvolvimento do protótipo. Nesse experimento 13 professores foram observados utilizando o Quiz durante autoria de questionários. A partir dessa observação e da pesquisa de avaliação sobre o uso do Quiz preenchida pelos professores foi possível realizar o levantamento de requisitos;

- $1^{\mathrm{o}}$ avaliação: o objetivo desse experimento foi avaliar a interface da primeira versão teste do iQuiz realizado com um grupo misto de 5 participantes composto por professores e técnicos. A partir do resultado dessa avaliação o protótipo foi atualizado gerando a segunda versão teste.

- $2^{\mathbf{o}}$ avaliação: o objetivo desse experimento foi avaliar a interface da segunda versão do iQuiz realizado com um grupo de 5 participantes composto por professores atuante no ensino superior. A partir do resultado dessa avaliação o protótipo foi atualizado gerando a terceira versão teste.

- $3^{\mathbf{o}}$ avaliação: o objetivo desse experimento foi avaliar a interface da terceira versão do $i Q u i z$ realizado com um grupo de 5 participantes composto por professores atuante no ensino fundamental II. A partir do resultado dessa avaliação o protótipo foi atualizado gerando a versão final.

Nas três avaliações do iQuiz os participantes foram submetidos a realizar a seguinte lista de tarefas:

\begin{tabular}{l|l}
\hline T1 & $\begin{array}{l}\text { Criar questionário em branco (o professor deve escolher a opção correta e preencher } \\
\text { os campos iniciais). }\end{array}$ \\
\hline T2 & $\begin{array}{l}\text { Criar uma questão múltipla escolha com opções mínimas (identificação, enunciado, } \\
\text { pontuação, acerto e alternativas). }\end{array}$ \\
\hline T3 & Criar uma questão múltipla escolha com múltiplas respostas e feedback combinado. \\
\hline T4 & Criar uma questão múltipla escolha permitindo ao aluno múltiplas tentativas. \\
\hline T4.1 & Localizar e manipular os ícones das alternativas (expandir conteúdo, excluir etc). \\
\hline T4.2 & Localizar o botão para expandir o painel da questão sobre o painel do questionário. \\
\hline T5 & Inserir um feedback específico nas alternativas de uma questão já concluída. \\
\hline T6 & Localizar a opção para inserir questões a partir do banco de questões. \\
\hline T7 & Configurar o questionário com informações básicas. \\
\hline T8 & Localizar a opção inserir questões no banco de questões. \\
\hline
\end{tabular}

Tabela 5.2: Lista de tarefas das avaliações do iQuiz

A partir dessa lista de tarefas pretendia-se as seguintes ações dos participantes:

Tarefa T1: Espera-se que o professor a partir da tela inicial, escolha a primeira opção, que permite criar um questionário desde o início. Caso seja outra opção, perguntar o motivo daquela escolha e registrar.

Tarefa T2: Espera-se por conta da sucinta solicitação, que o professor escreva o título da questão, o enunciado, a pontuação e as alternativas. Entretanto observar se ele percorre outras opções como a guia feedback, se ele introduz alguma informação além das citadas ou se ele faz alguma pergunta a respeito das outras opções disponíveis. O professor poderá explorar e preencher 
as demais guias, porém deve ser registrado o tempo da sua atividade até completar os quatro itens (título, enunciado, pontuação e alternativas).

Tarefa T3: Espera-se que o professor relacione a guia feedback com a necessidade de apresentar uma mensagem de retorno ao aluno. E que em seguida ele localize o item (Feedback Combinado) para escrever as mensagens. Havendo dúvida, espera-se que ele veja o ponto de interrogação, que representa a ajuda contextual para o item.

Tarefa T4: Espera-se que o professor faça uso da aba múltiplas tentativas.

Tarefa T4.1: Espera-se que o professor acione o ícone com o botão (Expandir/Contrair painel) que aparece na divisão entre os painéis do questionário e da questão em edição.

Tarefa T4.2: Espera-se que o professor acione o ícone com o botão (Deslizar painel) que aparece sobre o painel da questão em edição.

Tarefa T5: Espera-se que o professor acione o ícone (Feedback) que aparece sobre o campo da alternativa. O professor poderá ter a impressão de que tenha a ver com a opção (Feedback Geral) da questão, esse detalhe deve ser observado e registrado caso ocorra.

Tarefa T6: Espera-se que o professor acione a opção (obter questão pronta), posicionada ao lado do botão (Adicionar questão).

Tarefa T7: Espera-se que o professor acione a aba (configurar questionário ou atalho), posicionada ao lado do botão (Adicionar questão).

Tarefa T8: Espera-se que o aluno volte na tela inicial ou acione o botão (banco de questões) e tente inserir as questões.

Nas próximas seções os quatro experimentos são apresentados com detalhes e resultados.

\subsubsection{Primeiro Experimento: teste de usabilidade do Quiz}

Este experimento teve como objetivo a coleta de dados para o levantamento de requisitos, sendo esse considerado o experimento de controle. Realizado com os 13 professores participante do curso "LEM 4: Autoria de Atividades Interativas no Moodle com iTarefa e $i$ Geom", oferecido no curso de verão do IME-USP. Sendo $57 \%$ do gênero masculino e $43 \%$ do gênero feminino, inseridos na faixa etária de 21 a 58 anos, com titulação distribuída entre graduação, especialização, pós-graduação e doutorado. Do total de participantes, $51 \%$ definiu sua fluência digital como intermediária. Todos afirmaram já ter tido contato com algum ambiente virtual de aprendizagem.

O curso foi presencial, aplicado em meados de janeiro de 2014 e teve duração total de 30 horas, distribuídas em 5 dias de aulas. Nesse curso os participantes aprendem a utilizar o Moodle para desenvolver cursos a distância, utilizando as ferramentas iTarefa e iGeom. Em um dos dias do curso os participantes aprenderem como criar questionários para avaliação no Moodle utilizando para isso o Quiz. Após as explicações e demonstrações de como usar o Quiz os participantes foram submetidos a tarefa de realizar um questionário, com o objetivo de testar a usabilidade do Quiz e avaliar a satisfação dos professores após o treinamento prévio no Quiz.

Os resultados sobre a satisfação dos participantes desse experimento foi comparado, aos resultados dos professores que utilizaram o iQuiz em condições semelhantes.

Foi aplicado como tarefa a criação de um questionário com 5 (cinco) questões, durante a realização dessa tarefa, as telas dos computadores em uso pelos participantes foram gravadas para posterior observação. A lista de tarefas esta disponível no Apêndice E. Ao final da atividade eles responderam o questionário SUS.

\section{Resultados}

Com a utilização do questionário SUS, foi possível mensurar o grau de satisfação quanto a usabilidade da interface do Quiz. Nesse experimento foi obtida a média de 60,19 e desvio padrão de 14,08. Este e outros resultados foram detalhados na Seção 5.3, onde é feita uma comparação com os resultados dos testes do iQuiz. Por isso não serão comentados nesta seção para evitar repetitividade de informações. 


\subsubsection{Segundo Experimento: primeira avaliação da interface do $i Q u i z$}

Este experimento teve como objetivo avaliar a interface da primeira versão teste do iQuiz. Afim de mensurar a satisfação dos participantes durante a realização de um questionário. Para esse experimento foram selecionados 6 participantes: três professores e três especialistas em computação (técnicos). A média da faixa etária dos três professores é de 40 anos enquanto a dos três especialistas em computação é de 26 anos. Conforme apresentado na Tabela 5.3.

\begin{tabular}{c|c|c|c|c|c}
\hline \multicolumn{7}{c}{ Perfil dos participantes do segundo experimento } \\
\hline Participante & Idade & Gênero & Disciplina & $\begin{array}{c}\text { Uso semanal } \\
\text { computador }\end{array}$ & $\begin{array}{c}\text { Utilizou avaliação } \\
\text { online }\end{array}$ \\
\hline P1 & 42 & Feminino & Matemática & mais de 40hs & Sim \\
\hline P2 & 39 & Feminino & Biologia & mais de 40hs & Sim \\
\hline P3 & 41 & Masculino & Administração de empresas & mais de 40hs & Sim \\
\hline P4 & 26 & Masculino & - & mais de 40hs & Sim \\
\hline P5 & 29 & Masculino & - & mais de 40hs & Sim \\
\hline P6 & 23 & Masculino & - & mais de 40hs & Sim \\
\hline
\end{tabular}

Tabela 5.3: Perfil dos participantes do segundo experimento

O primeiro professor atua no ensino fundamental II e já participou com seus alunos em experiências na utilização do computador para ensino de matemática. Esse participante utiliza o computador mais de 40hs semanais e avalia sua familiaridade com computador como moderada. Já participou de capacitações tecnológicas e também já utilizou algum sistema de avaliação online.

O segundo professor trabalha no período diurno como gerente de Tecnologia da Informação e no período noturno como professor na área de Administração, há cerca de 5 anos. Utiliza o computador mais de $40 \mathrm{hs}$ semanais e classificou sua familiaridade com o computador como excelente.

O terceiro professor ingressou no ensino superior a menos de 1 ano e atua no ensino fundamental II a cerca de 5 anos. Utilizava o computador entre 1 hs e $10 \mathrm{hs}$ semanais e classificou sua familiaridade com o computador como moderada.

Os demais participantes, os três especialistas em computação, são alunos do programa de pós graduação em Ciência da Computação do IME-USP. Um deles trabalha como editor de conteúdo digital e os demais como desenvolvedores de sistemas. Todos utilizam o computador por mais de 40hs semanais e avaliam sua familiaridade com o computador como excelente. Também já utilizaram algum ambiente de avaliação online.

\section{Lista de Tarefas}

Dentre as tarefas elaboradas para serem realizadas pelos participantes utilizando o iQuiz, a principal foi criar um questionário com quatro questões do tipo múltipla escolha, totalizando 10 pontos.

Nenhum treinamento ou detalhes conceituais sobre a interface do $i Q u i z$ foi fornecido aos participantes. No inicio do experimento lhes foi explanado que o objetivo do experimento era avaliar a usabilidade da interface do protótipo, deixando claro que eles, os participantes não estavam sendo avaliados.

Resumidamente a tarefa inicia-se com a criação de um pequeno teste, e para isso, os participantes tinham que identificar a opção "criar questionário" na tela inicial. Em seguida, preencher os campos básicos do questionário e depois selecionar o tipo de questão múltipla escolha. Seguindo para o preenchimento dos campos do formulário da questão e adicioná-la à lista de questões do questionário. Representado pela metáfora de uma folha do lado esquerdo da tela.

A primeira questão foi composta apenas pelo enunciado, alternativas e pontuação. O objetivo era verificar se as dicas e a descrição dos campos dispostos na interface seriam suficientes para a completeza da tarefa. 
Caso isso ocorresse, já seria um indicativo de que o fluxo de tarefa e o conceito básico da interface do iQuiz estava no caminho esperado.

As demais questões permitiram a consolidação do uso dos recursos já utilizados ao passo que forçavam o uso de novos recursos, tais como: expandir a área de visualização do texto das alternativas, criar questões com múltiplas respostas, usar ferramentas do editor de texto como "Inserir figuras ou tabelas". Além disso, lhes foi solicitado que explorassem todos os elementos da interface e apontassem os não compreendido na aplicação. O Apêndice F contém as tarefas aplicadas nesta fase.

\section{Aplicação do teste}

De modo geral todos os participantes se mantiveram tranquilos e demonstraram bastante interesse em participar do experimento. Dois participantes fizeram o teste em seu local de trabalho. Os outros quatro em uma sala reservada para o teste dentro da própria universidade em que ocorre esta pesquisa. Somente um usuário utilizou o computador cedido para o teste, os demais acessaram o sistema pelo endereço eletrônico em seus próprios computadores.

Inicialmente foi solicitado que eles fizessem a tarefa e que pedissem ajuda somente quanto ao entendimento das tarefas. Um observador acompanhava e anotava o desenvolvimento das tarefas. Após a conclusão os participantes preencheram dois questionários de avaliação: o SUS e um questionário com 5 questões abertas. O SUS foi utilizado como previsto no planejamento da pesquisa, já o segundo questionário abriu a possibilidade de se perceber mais claramente a visão dos participantes sobre o protótipo bem como dar-lhes a oportunidade de contribuir com suas opiniões e observações sobre o iQuiz. Desse questionário pode-se destacar algumas palavras com avaliação positiva, tais como: visual limpo, interface agradável, layout bonito, fácil uso, gostei das dicas, gostei da visualização do questionário. Como críticas destacou-se: falta de diferenciação entre uma questão nova e em edição, problemas durante o uso do editor, tais como o cursor desaparecer ou não ter ferramentas para criar uma tabela ou fórmulas e também sugestões como: faltou dica, melhor utilização do recurso múltiplas tentativas e entrar com a barra de ferramentas do editor reduzida. A maioria das críticas e sugestões foi realizada pelos técnicos já os elogios foram bem distribuídos entre ambos.

Foi possível notar que o ponto de vista entre técnicos e professores novamente diferenciaramse, no aspecto que os especialistas em computação se preocuparam mais com os detalhes técnicos da interface (bugs, tipo de fonte, cores, disposição de elementos na tela, recursos do editor etc), enquanto os professores com a aplicação e uso da interface para desenvolver a tarefa.

O principal ponto observado nesse experimento foi a falta de uso do sistema de ajuda disponível na interface. Simplesmente os participante não acessaram a aba Ajuda, que se encontrava bastante visível na tela, representada por um ponto de interrogação. Apenas um participantes notou esse recurso mas não fez uso do mesmo.

Todos os usuários completaram a tarefa, entretanto, como foi definido apenas a inserção das questões como subtarefas obrigatória, metade dos participantes não exploraram o item múltiplas tentativas e dois deles não inseriram feedback.

Outro aspecto relevante, na tarefa que solicitava a criação de uma tabela, somente um participante usou tabulação, os demais reclamaram a falta do recurso no editor.

Esse elemento do teste foi provocativo, o editor não tinha o recurso, pretendia-se observar se a falta de um recurso para desempenhar uma tarefa seria percebida pelos usuários.

O fato é importante pois pode demonstrar que determinados tipos de questões podem necessitar de recurso que o editor não possua e isso desestimulará seu uso pelos professores. Isto pode ocorrer com questões matemáticas que precisam não apenas de simbologia matemática, mas de aplicação fácil dos elementos para apresentação de fórmulas mais complexas. Embora as versões mais recentes do Moodle possuam uma editor de fórmulas, o mesmo não é prático. 


\section{Resultados}

A partir do resultado desse experimento foi possível mensurar o grau de satisfação quanto a usabilidade da interface da primeira versão do protótipo iQuiz. A principal ferramenta utilizada para essa medição foi o SUS.

Os dados estatísticos obtidos a partir do resultado da avaliação do SUS, apresentado na Tabela G.1 do Apêndice G, mostram que a média de satisfação dos participantes, em uma escala de 0 a 100, foi de 76,25 com desvio padrão de 10,92. Se considerarmos apenas os professores essa média fica em 83,33 com desvio padrão de 6,29. A partir desses dados pode-se concluir que a satisfação foi avaliada como boa uma vez que o coeficiente de variação é igual a 14,33\% indicando uma baixa dispersão na opinião dos participantes.

Um resumo consolidado da avaliação do SUS é apresentado na Tabela 5.4 composto por frequência acumulada das respostas por afirmativas. É importante ressaltar que o percentual acumulado na coluna escala de concordância refere-se a quantidade de vezes que aquele grau da escala foi escolhido para cada afirmativa. Assim as melhores avaliações devem concentrar-se nas extremidades da escala. Vale lembrar, para as afirmações ímpares as respostas com concordâncias favoráveis atingem o ponto máximo quando a escolha é 5 (cinco). Já nas afirmações pares as respostas favoráveis atingem o ponto máximo quando a escolha é 1 (um). Desse modo, ambas as afirmações AF1 e AF3, por exemplo, detém $66 \%$ da concordância entre o grau 4 (quarto) e 5 (cinco) da escala. A afirmação AF4 que é par, detém $83 \%$ de discordância absoluta, pois esse percentual se concentra no grau 1 (um), que descorda plenamente da afirmativa.

\begin{tabular}{|c|c|c|c|c|c|}
\hline \multicolumn{6}{|c|}{$\begin{array}{l}\text { Percentual do grau de concordância acumulado por } \\
\text { afirmativa do segundo experimento }\end{array}$} \\
\hline \multirow{2}{*}{ Afirmações } & \multicolumn{5}{|c|}{ Escala de Concordância } \\
\hline & 1 & 2 & 3 & 4 & 5 \\
\hline $\begin{array}{l}\text { AF1 - Eu acho que gostaria de utilizar este sistema frequen- } \\
\text { temente. }\end{array}$ & $0 \%$ & $17 \%$ & $17 \%$ & $33 \%$ & $33 \%$ \\
\hline AF2 - Eu achei o sistema desnecessariamente complexo. & $17 \%$ & $50 \%$ & $17 \%$ & $17 \%$ & $0 \%$ \\
\hline AF3 - Eu achei o sistema fácil para usar. & $0 \%$ & $17 \%$ & $17 \%$ & $33 \%$ & $33 \%$ \\
\hline $\begin{array}{l}\text { AF4 - Eu acho que precisaria do apoio de um suporte técnico } \\
\text { para ser possível usar este sistema. }\end{array}$ & $83 \%$ & $17 \%$ & $0 \%$ & $0 \%$ & $0 \%$ \\
\hline $\begin{array}{l}\text { AF5 - Eu achei que as diversas funções neste sistema foram } \\
\text { bem integradas. }\end{array}$ & $0 \%$ & $0 \%$ & $33 \%$ & $33 \%$ & $33 \%$ \\
\hline AF6 - Eu achei que houve muita inconsistência neste sistema. & $33 \%$ & $50 \%$ & $0 \%$ & $17 \%$ & $0 \%$ \\
\hline $\begin{array}{l}\text { AF7 - Eu acho que a maioria das pessoas aprenderia a usar } \\
\text { esse sistema rapidamente. }\end{array}$ & $0 \%$ & $0 \%$ & $17 \%$ & $67 \%$ & $17 \%$ \\
\hline AF8 - Eu achei o sistema muito pesado para uso. & $67 \%$ & $33 \%$ & $0 \%$ & $0 \%$ & $0 \%$ \\
\hline AF9 - Eu me senti muito confiante usando esse sistema. & $17 \%$ & $17 \%$ & $17 \%$ & $17 \%$ & $33 \%$ \\
\hline $\begin{array}{l}\text { AF10 - Eu precisei aprender uma série de coisas antes que } \\
\text { eu pudesse continuar a utilizar esse sistema. }\end{array}$ & $50 \%$ & $33 \%$ & $17 \%$ & $0 \%$ & $0 \%$ \\
\hline
\end{tabular}

Tabela 5.4: Percentual do grau de concordância acumulado por afirmativa do segundo experimento

Outra fonte de leitura desses dados é por meio dos gráficos ilustrados nas Figuras 5.1 e 5.2. O primeiro gráfico apresenta a distribuição do grau de concordância das respostas com afirmações ímpares, no qual é possível notar que a maioria das respostas se concentram na área representada pelo gráfico entre o grau 3 (três) e 5 (cinco). Nota-se que a afirmativa AF7 (Eu acho que a maioria das pessoas aprenderiam a usar esse sistema rapidamente), obteve grande destaque no grau 4 (quatro) da escala. 


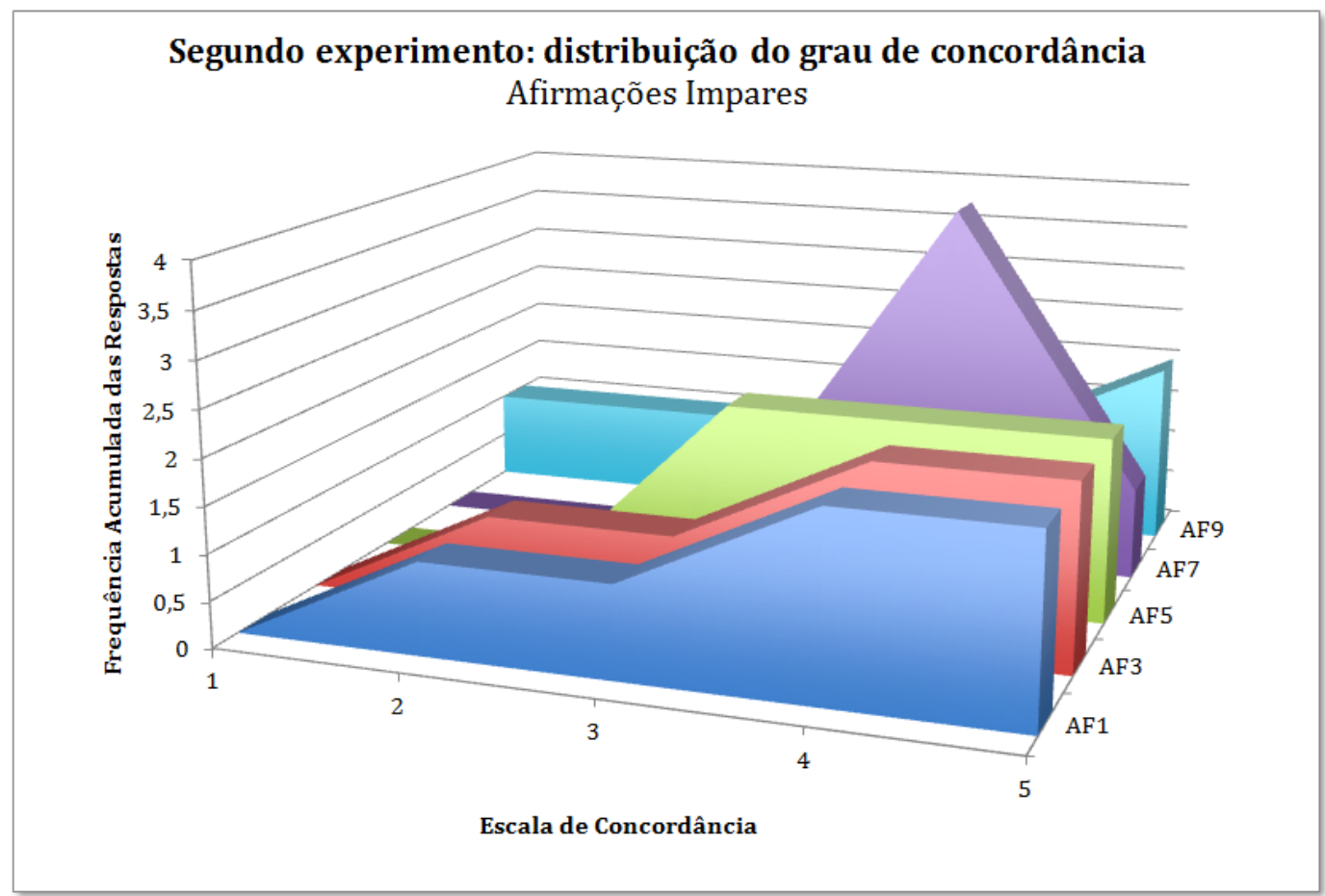

Figura 5.1: Respostas ímpares do SUS do segundo experimento

No segundo gráfico, o mesmo ocorre, entretanto do lado oposto da escala, onde é possível verificar que as afirmações AF4, AF8 e AF10 tiveram seus picos no grau 1 (um) da escala e que da mesma forma que na Figura 5.1, a maioria das respostas se concentram do grau 3 (três) ao 1 (um), indicando forte discordância com as afirmativas.

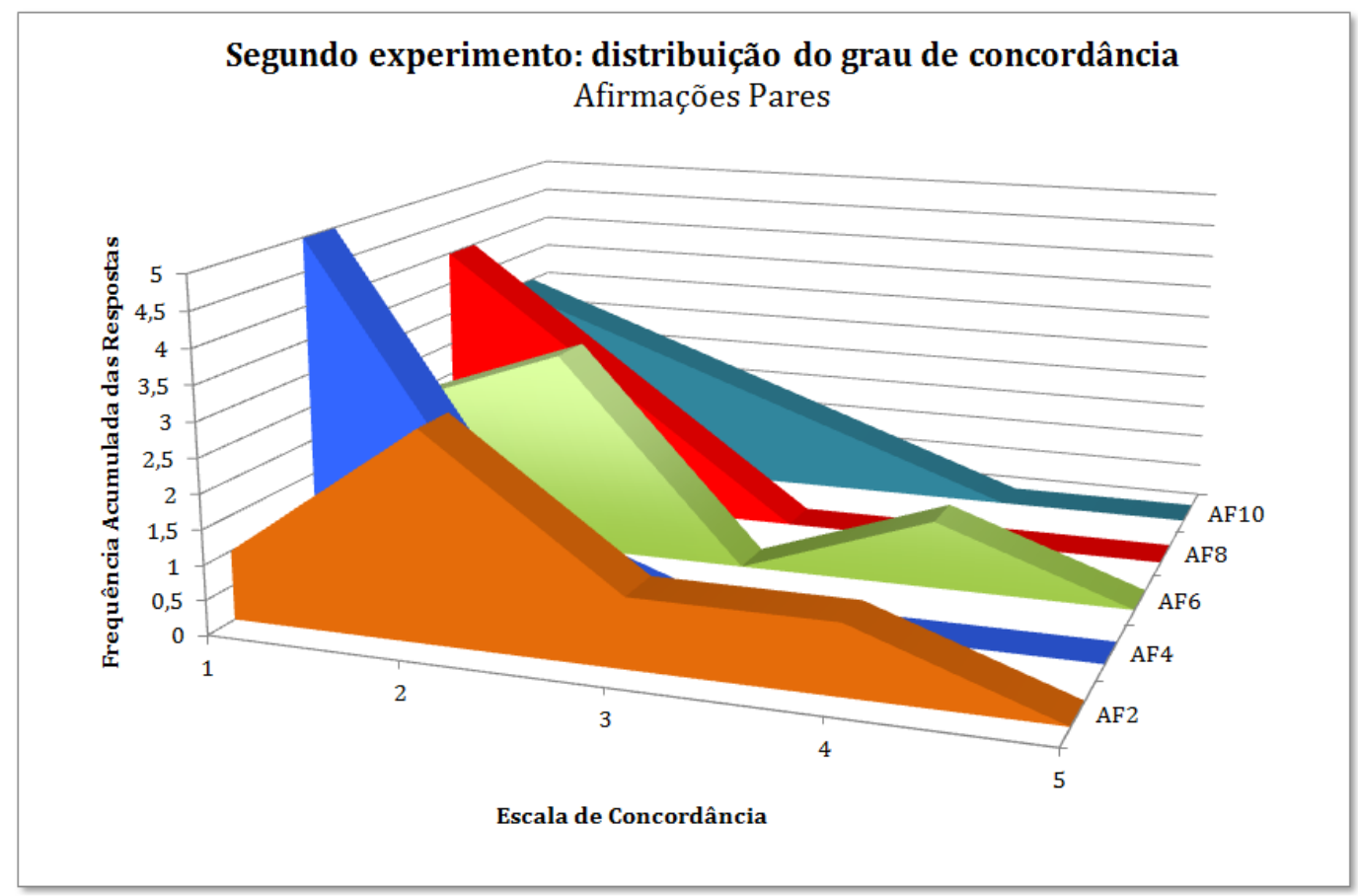

Figura 5.2: Respostas pares do SUS do segundo experimento

Nessa avaliação houve maior interesse em detectar se as opiniões e observações dos usuários estavam em consonância com o que os consultores apontavam durante o estágio inicial do desenvolvimento da interface. Até este ponto foi notório que o desenho ou redesenho de uma interface 
precisa ser o mais completo e próximo daquilo que o usuário espera testar. Pequenos detalhes fazem diferença: um botão posicionado inadequadamente, ou um rótulo ambíguo, podem causar confusão ou desestimulo ao usuário. Se botões, campos ou funcionalidades não são manipuláveis, ou incompletos, os usuários não percebem esse elemento como algo que se queira simular a funcionalidade ou existência no sistema, mas como um recurso que não funciona ou que funciona mal. E isso pode interferir em sua avaliação subjetiva sobre o sistema em teste.

Sendo o objetivo principal desse experimento medir a satisfação dos usuários e obter comentários e opiniões sobre a interface, os resultados obtidos foram bastante significativos. Pode-se concluir que o fluxo das tarefas foi bem aceito e pareceu natural para todos os participantes.

\subsubsection{Terceiro Experimento: segunda avaliação da interface do $i Q u i z$}

O objetivo deste experimento foi avaliar a interface da segunda versão teste do iQuiz. Afim de mensurar a satisfação dos participantes durante a citação de um questionário e medir as taxas de conclusão e erros cometido. Neste experimento fizeram parte 5 participantes atuantes no ensino superior, todos pós-graduados, que utilizam o computador em média 30hs semanais, inseridos na faixa etária entre 33 a 71 anos, utilizavam o ambiente virtual da universidade que trabalham para realizar avaliações. Detalhes do perfil é apresentado na Tabela 5.5.

\begin{tabular}{c|c|c|c|c|c}
\hline \multicolumn{7}{c}{ Perfil dos participantes do terceiro experimento } \\
\hline Participante & Idade & Gênero & Disciplina & $\begin{array}{c}\text { Uso semanal } \\
\text { computador }\end{array}$ & $\begin{array}{c}\text { Utilizou avaliação } \\
\text { online }\end{array}$ \\
\hline P1 & 71 & Masculino & Ciência Social & 20h a 40hs & Não \\
\hline P2 & 51 & Masculino & Engenharia de Estruturas & mais de 40hs & Sim \\
\hline P3 & 66 & Masculino & Administração & 1h a 10hs & Sim \\
\hline P4 & 33 & Feminino & Economia & $10 \mathrm{~h}$ a 20hs & Não \\
\hline P5 & 39 & Feminino & Nutrição & 10h a 20hs & Sim \\
\hline
\end{tabular}

Tabela 5.5: Perfil dos participantes do terceiro experimento

Somente o participante P4 avaliou sua familiaridade com o computador como muito boa, todos os demais avaliaram como moderada.

A carga horária semanal de utilização do computador pelos professores são variadas, assim como sua faixa etária. O gênero predominante foi o masculino e a experiência prévia com ambientes de avaliação online também foi balanceada. Assim obteve-se uma amostra representativa do grupo de professores universitários.

\section{Lista de Tarefas}

A lista de tarefas aplicada neste experimento apresenta modificações em relação a aplicada no experimento anterior (segundo experimento). Uma das questões foi retirada para evitar que o teste ficasse muito longo e cada tarefa foi explicitamente definida e descrita por meio de cenários. Os cenários são situações hipotéticas que visam contextualizar situações comuns que requerem o uso de recursos do protótipo em testes. Essa modificação possibilitou contabilizar a taxa de conclusão das tarefas e mensurar os erros, acertos e a utilização da ajuda pelos participantes durante a realização do teste.

No Apêndice F encontra-se a lista de tarefas entregue aos participantes e também o guia utilizado pelos observadores, que permitiu determinar a conclusão das tarefas, os caminhos corretos ou incorretos percorridos. Além de anotações específicas sobre dúvidas e procedimentos dos professores durante o teste. Em todos os testes foi gerado um vídeo com a gravação da tela do computador durante a realização da tarefa, desse modo foi possível complementar informações e tirar dúvidas sobre procedimentos ocorridos durante o experimento. 


\section{Aplicação dos testes}

O observador deste experimento relatou que embora os professores estivessem em um ambiente familiar, a sala dos professores, onde realizam diversas atividades, como criar e corrigir provas, ainda assim dois dos cinco participantes demonstraram apreensão durante o teste. No entanto todos os participantes afirmaram terem ficado satisfeito em participar do experimento.

Inicialmente foi solicitado que realizassem a tarefa e pedissem ajuda somente quanto ao entendimento das tarefas. Desse modo, nenhuma informação sobre os recursos ou funcionamento do protótipo foi passada durante a realização do teste. Um observador acompanhava e anotava o desenvolvimento das tarefas, realizando as anotações e seguindo as instruções do guia do observador quanto ao nível de ajuda ou intervenção, bem como quais procedimentos deveriam receber maior atenção. Foi utilizado um notebook preparado para o teste com o protótipo do iQuiz instalado localmente.

Após a conclusão da tarefa os participantes avaliaram o protótipo iQuiz por meio dos questionários: SUS e um questionário com questões abertas. Os resultados desses questionários encontram-se, respectivamente, nos Apêndices G.2.1 e G.2.2.

\section{Resultados}

Nesse experimento, assim como nos experimentos anteriores os participantes não utilizaram a ajuda do sistema, preferiram fazer indagações ao observador.

Principais problemas observados foram: inserir alternativas junto com enunciado; dificuldade para determinar a resposta correta (100\%); dificuldade com os ícones das alternativas; dificuldade para expandir o painel de questões e Incompreensão da tarefa (feedback específico).

Foi observado maior incidência de solicitação de ajuda pelos participantes durante a realização do teste. Algumas tarefas não foram bem compreendidas pelos participantes, assim o observador explicou verbalmente as tarefas.

Foram percebidas as seguintes dúvidas conceituais: dificuldade em associar os percentuais de acertos e feedbacks nas alternativas das questões; distinguir tipos de feedback, por questão e por alternativa; dificuldade em compreender o termo "questionário" no contexto da aplicação.

Apesar dessas dificuldades, o protótipo foi bem avaliado pelos participantes. A maioria relatou ser capaz de aprender a utilizar o sistema sem grandes problemas mediante a um breve treinamento.

O Apêndice G.2.2 apresenta os comentários dos participantes registrado no questionário com as perguntas abertas.

Um resumo consolidado da avaliação do SUS é apresentado na Tabela G.2 do Apêndice G, composto por frequência acumulada das respostas por afirmativas.

Os dados estatísticos obtidos a partir desse resultado mostram que a média de satisfação dos participantes, em uma escala de 0 a 100, foi de 82,5 com desvio padrão de 15 . A partir desses dados pode-se concluir que a satisfação dos participantes melhorou em relação a dos participantes do experimento anterior (primeira avaliação). Uma vez que a média do anterior foi 76,25 e o desvio padrão foi 10,92. No entanto o coeficiente de variação desse experimento foi igual a $18,18 \%$, um pouco maior que o anterior que foi $14,33 \%$, indicando um aumento na variabilidade da satisfação na opinião dos participantes. De um modo geral pode-se concluir que o resultado a satisfação com a segunda versão teste do iQuiz foi animador, porém as dificuldades conceituais precisaram ser avaliadas, notou-se que seria preciso introduzir alguns conceitos que os usuários não estavam habituados mesmo para o uso em questões múltipla escolha. As tarefas tiveram a redação revisada e foi decidido realizar um experimento em que os professores assistissem a um vídeo apresentando os recursos do iQuiz antes do teste.

A Tabela 5.6 resume a frequência acumulada das respostas por afirmativas. É importante ressaltar que o percentual acumulado na coluna escala de concordância refere-se a quantidade de vezes que aquele grau da escala foi escolhido para cada afirmativa. Assim as melhores avaliações devem concentra-se nas extremidades da escala. Para as afirmações impares as respostas com concordâncias favoráveis atingem o ponto máximo quando a escolha é cinco. Já para as afirmações pares as 
respostas favoráveis atingem o ponto máximo quando a escolha é um.

\begin{tabular}{l|ccccc}
\hline \multicolumn{5}{c}{$\begin{array}{c}\text { Percentual do grau de concordância acumulado por } \\
\text { afirmativa do terceiro experimento }\end{array}$} \\
\cline { 2 - 6 } & \multicolumn{7}{c}{ Escala de } & & \\
\hline Afirmaçones & 1 & 2 & 3 & 4 & 5 \\
\hline AF1 - Eu acho que gostaria de utilizar este sistema frequen- & $0 \%$ & $0 \%$ & $20 \%$ & $20 \%$ & $60 \%$ \\
temente & & & & & 5 \\
AF2 - Eu achei o sistema desnecessariamente complexo & $60 \%$ & $20 \%$ & $20 \%$ & $0 \%$ & $0 \%$ \\
AF3 - Eu achei o sistema fácil para usar & $0 \%$ & $0 \%$ & $0 \%$ & $40 \%$ & $60 \%$ \\
AF4 - Eu acho que precisaria do apoio de um suporte técnico & $40 \%$ & $20 \%$ & $0 \%$ & $0 \%$ & $40 \%$ \\
para ser possível usar este sistema & & & & & \\
AF5 - Eu achei que as diversas funções neste sistema foram & $0 \%$ & $0 \%$ & $20 \%$ & $20 \%$ & $60 \%$ \\
bem integradas & & & & & \\
AF6 - Eu achei que houve muita inconsistência neste sistema & $60 \%$ & $40 \%$ & $0 \%$ & $0 \%$ & $0 \%$ \\
AF7 - Eu acho que a maioria das pessoas aprenderia a usar & $0 \%$ & $0 \%$ & $0 \%$ & $40 \%$ & $60 \%$ \\
esse sistema rapidamente & & & & & \\
AF8 - Eu achei o sistema muito pesado para uso & $80 \%$ & $20 \%$ & $0 \%$ & $0 \%$ & $0 \%$ \\
AF9 - Eu me senti muito confiante usando esse sistema & $0 \%$ & $0 \%$ & $20 \%$ & $40 \%$ & $40 \%$ \\
AF10 - Eu precisei aprender uma série de coisas antes que & $40 \%$ & $60 \%$ & $0 \%$ & $0 \%$ & $0 \%$ \\
eu pudesse continuar a utilizar esse sistema & & & & & \\
\hline
\end{tabular}

Tabela 5.6: Percentual do grau de concordância acumulado por afirmativa do terceiro experimento

Pode-se observar que a afirmação AF4 (Eu acho que precisaria do apoio de um suporte técnico para ser possível usar este sistema) obteve plena concordância de $40 \%$ refletindo provavelmente os problemas de entendimento conceitual sobre os tipos de feedback e acertos mal compreendidos por boa parte dos professores, entre outros itens.

Outra fonte de leitura desses dados é por meio dos gráficos ilustrados nas Figuras 5.3 e 5.4. A exemplo dos gráficos demonstrados no experimento anterior, aqui ocorre o mesmo, o primeiro gráfico apresenta a distribuição do grau de concordância das respostas com afirmações ímpares, no qual é possível notar que a maioria das respostas se concentram mais na área representada pelo gráfico entre o grau 4 (quatro) e 5 (cinco), demonstrando a melhora em relação ao experimento anterior nesses itens. 


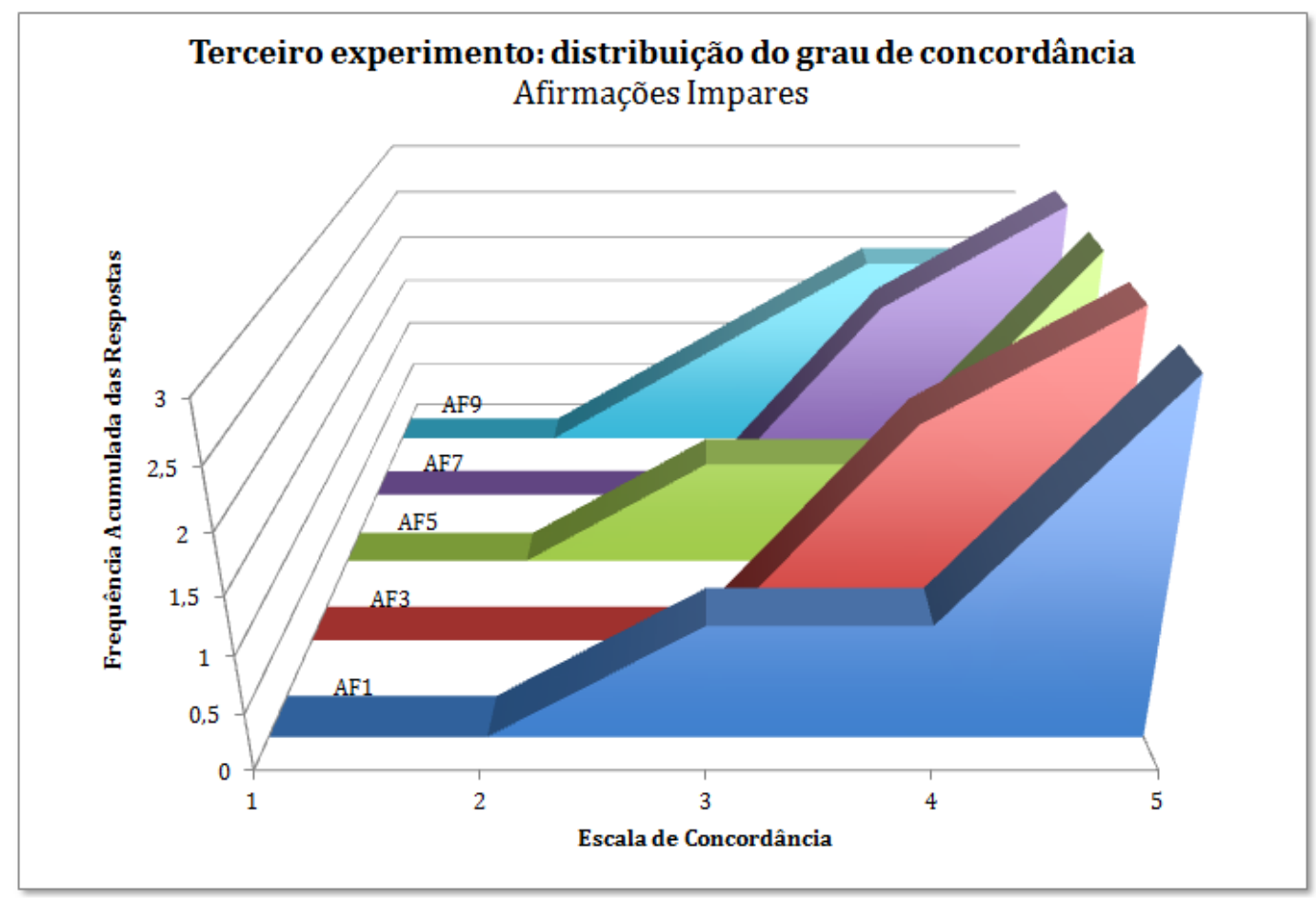

Figura 5.3: Respostas impares do SUS do terceiro experimento

A Figura 5.4 representa as respostas pares (negativas) que ocorreu maior variabilidade, mas a maioria das respostas se concentram entre os graus 1 (um) e 2 (dois), indicando boa avaliação dos itens. Pode-se observar também que a afirmação AF4 se sobressai no lado oposto do gráfico.

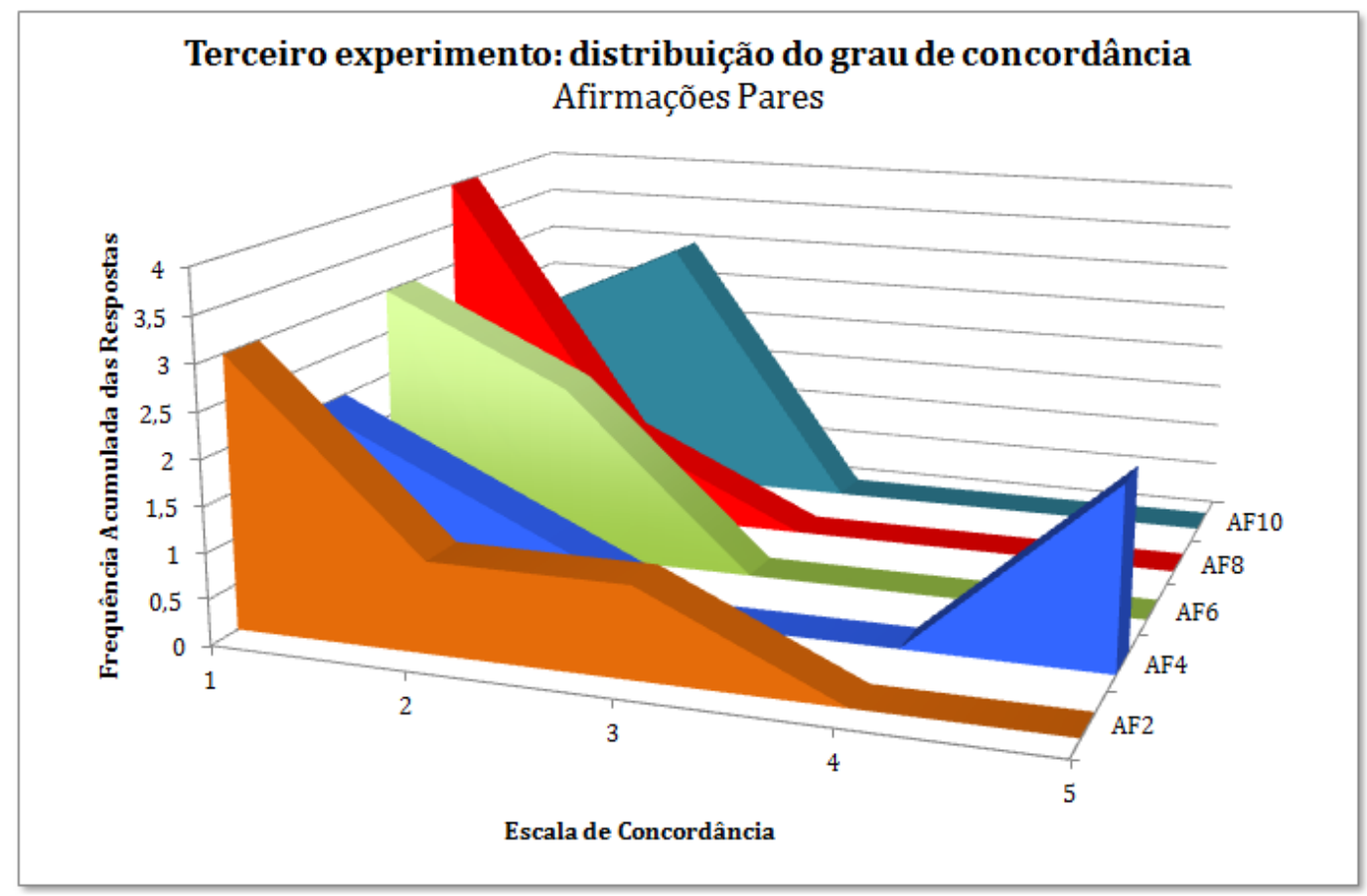

Figura 5.4: Respostas pares do SUS do terceiro experimento

Nesse experimento além de avaliar a satisfação dos participantes também foi mensurado a taxa de conclusão das tarefas. Com objetivo de avaliar a evolução da interface das versões do protótipo. Os dados sobre as taxas de conclusão foram registrados e encontram-se na Tabela G.3 no Apêndice G.2.3. Após calcular a frequência acumulada dos acertos da tabela, obteve-se os seguinte resultado: 
tarefas não completadas (7); tarefas completadas com dificuldade ou ajuda (27); tarefas facilmente completadas (16). O gráfico ilustrado na Figura 5.5 monstra a proporção de completeza das tarefas realizadas nesse experimento.

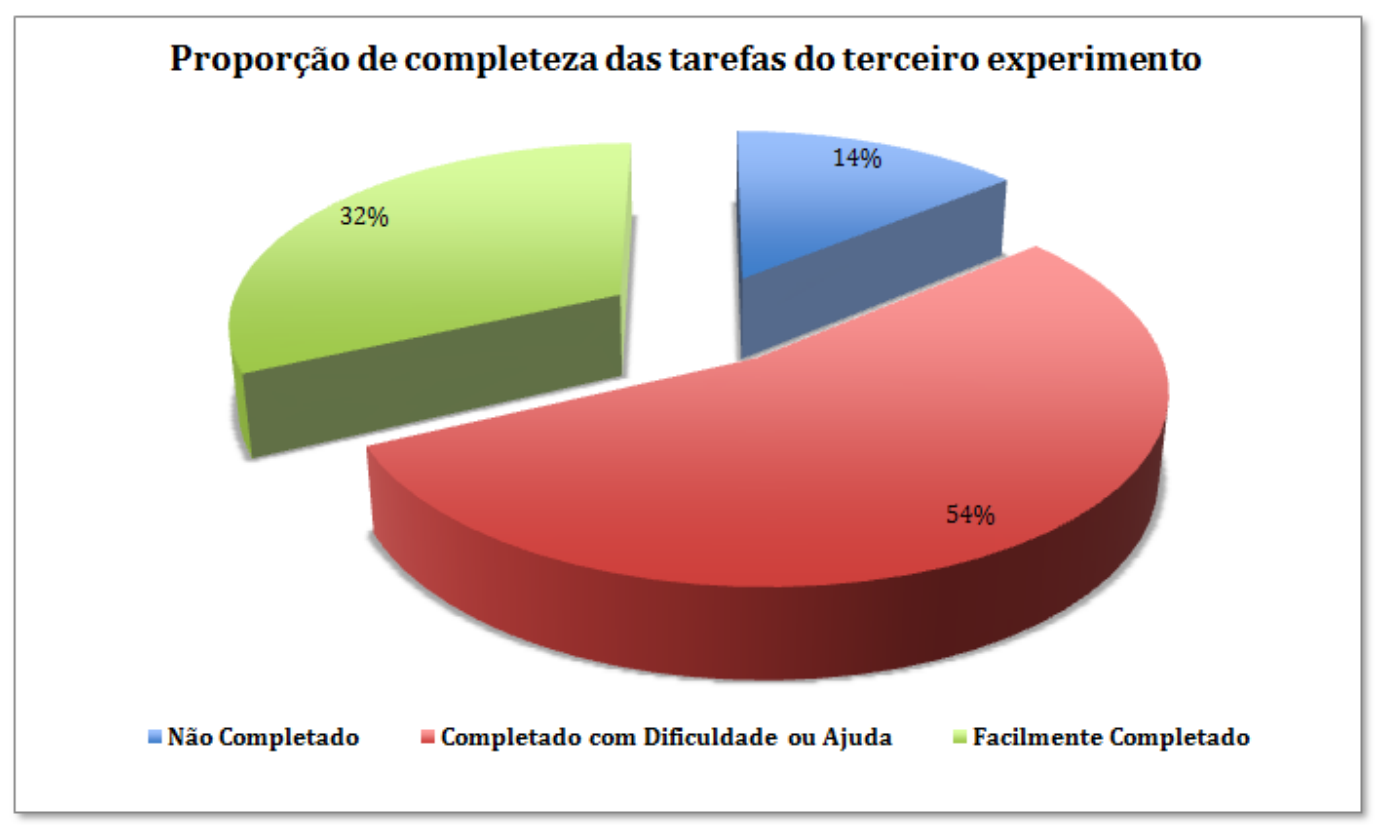

Figura 5.5: Proporção da completeza das tarefas no terceiro experimento

Conforme observado no gráfico a taxa de tarefas não completadas foi baixa, apenas 14\%. Já 32\% das tarefas foram concluídas sem ajuda. A proporção restante, $54 \%$, representam as tarefas completadas com dificuldades ou ajuda. Desse modo conclui-se que a proporção das tarefas completadas com sucesso e sem ajuda foi baixa.

\subsubsection{Quarto Experimento: terceira avaliação da interface do $i Q u i z$}

O objetivo deste experimento foi avaliar as melhorias da interface na terceira versão teste do iQuiz e a taxa de conclusão das tarefas realizadas nessa versão. Após ajuste da interface, e a disponibilização de um vídeo tutorial sobre os recursos do iQuiz para os participantes na tela inicial. Nesse experimento foi realizado com 5 usuários, com faixa etária entre 25 anos a 40 anos, que utilizam o computador em media 15hs semanais. Todos são professores atuantes no ensino fundamental II, com graduação completa e afirmaram não possuir conhecimentos em ambientes virtuais. A Tabela 5.7 apresenta mais informações sobre o perfil desses participantes.

\begin{tabular}{c|c|c|c|c|c}
\hline \multicolumn{7}{c}{ Perfil dos participantes do quarto experimento } \\
\hline Participante & Idade & Gênero & Disciplina & $\begin{array}{c}\text { Uso semanal } \\
\text { computador }\end{array}$ & $\begin{array}{c}\text { Utilizou avaliação } \\
\text { online }\end{array}$ \\
\hline P1 & 26 & Masculino & História & 1h a 10hs & Não \\
\hline P2 & 38 & Masculino & Matemática & 1h a 10hs & Sim \\
\hline P3 & 43 & Feminino & Artes visuais & 1h a 10hs & Sim \\
\hline P4 & 39 & Feminino & Matemática & $1 \mathrm{~h}$ & Sim \\
\hline P5 & 42 & Feminino & Língua Portuguesa & 10h a 20hs & Não \\
\hline
\end{tabular}

Tabela 5.7: Perfil dos participantes do quarto experimento

Os participantes P3 e P4 avaliaram sua familiaridade com computador como baixa, os demais avaliaram como moderada. Apenas o participante P5 possuem pós graduação. O participante P4 
informou utilizar o computador cerca de 1h semanal, já o participante P5 utiliza entre 10hs e 20hs e os demais utilizam de $1 \mathrm{~h}$ a $10 \mathrm{hs}$.

\section{Lista de tarefas}

A lista de tarefas aplicada neste experimento foi a mesma do experimento anterior (segunda avaliação). O Apêndice F contém as tarefas aplicadas nesta fase.

\section{Aplicação do teste}

Todos os participantes demonstraram-se motivados em participar do experimento. Os professores utilizaram um notebook preparado para o teste com acesso via internet.

Ao contrário do experimento anterior, no qual os usuários não tiveram nenhuma instrução prévia sobre o iQuiz, neste foi solicitado aos participantes assistirem um vídeo tutorial com duração de 5 minutos, apresentando os recursos do iQuiz Também foram orientados a consultar a ajuda do sistema e o vídeo tutorial em caso de dúvidas sobre os recursos.

Após a conclusão das tarefas foram convidados a responder os dois questionários utilizados nos experimentos anteriores e já mencionados (o SUS G.3.1 e depois um questionário com 5 questões abertas G.3.2).

Deste questionário pode-se notar que o botão fixar painel, posicionado no canto superior direito do painel do questionário (painel esquerdo), serviu de referência quando foi solicitado aos participantes que expandissem o painel de questões (lado direto). Três dos cinco usuários, acharam que deveria existir o mesmo botão no canto superior direito do painel de questões. Vale ressaltar que antes da introdução deste botão, essa confusão não aparecia. Um dos participantes não sabia o significado de feedback, outros dois não localizaram facilmente a opção obter questão enquanto os blocos de questões estavam abertos, pois a opção ficava escondida.

\section{Resultados}

A maioria dos participantes só teceu elogios ao iQuiz, mais detalhes no Apêndice G.3.2 que apresenta os comentários dos participantes ao responderem o questionário com as perguntas abertas. Já em relação ao SUS, na Tabela G.4 é apresentado o resultado das opiniões de cada participante sobre cada uma das afirmações. Os dados obtidos a partir desse resultado mostram que a média de satisfação dos participantes, em uma escala de 0 a 100, foi de 95,50 com desvio padrão de 5,41. Indicando um aumento significativo na satisfação dos participantes comparado aos experimentos anteriores, com uma baixa variabilidade, uma vez que o coeficiente de variação foi igual a 5,7\%.

A Tabela 5.8 resume a frequência acumulada das respostas por afirmativas. Novamente ressaltase que o percentual acumulado na coluna escala de concordância refere-se a quantidade de vezes que aquele grau da escala foi escolhido para cada afirmativa. Assim as melhores avaliações concentram-se nas extremidades da escala.

Desse modo, as afirmações AF2, AF6 e AF8 pontuaram com 100\% de discordância e AF5, AF9 com 100\% de concordância. As afirmativas AF5, AF6, AF8 estão relacionadas a eficiência/minimização de erros, AF2 à facilidade de memorização e AF9 à satisfação. Depois da utilização do vídeo tutorial a afirmativa AF4 (Eu acho que precisaria do apoio de um suporte técnico para ser possivel usar este sistema) obteve uma discordância plena de $60 \%$ e os demais $40 \%$ entre os graus 2 e 3 na escala de concordância. 


\section{Percentual do grau de concordância acumulado por afirmativa do quarto experimento}

\begin{tabular}{l|ccccc}
\hline \multirow{2}{*}{ Afirmações } & \multicolumn{4}{c}{ Escala de Concordância } \\
\cline { 2 - 6 } & 1 & 2 & 3 & 4 & 5 \\
\hline AF1 - Eu acho que gostaria de utilizar este sistema frequen- & $0 \%$ & $0 \%$ & $0 \%$ & $20 \%$ & $80 \%$ \\
temente & & & & & \\
AF2 - Eu achei o sistema desnecessariamente complexo & $100 \%$ & $0 \%$ & $0 \%$ & $0 \%$ & $0 \%$ \\
AF3 - Eu achei o sistema fácil para usar & $0 \%$ & $0 \%$ & $20 \%$ & $20 \%$ & $60 \%$ \\
AF4 - Eu acho que precisaria do apoio de um suporte técnico & $60 \%$ & $20 \%$ & $20 \%$ & $0 \%$ & $0 \%$ \\
para ser possível usar este sistema & & & & & \\
AF5 - Eu achei que as diversas funções neste sistema foram & $0 \%$ & $0 \%$ & $0 \%$ & $0 \%$ & $100 \%$ \\
bem integradas & & & & \\
AF6 - Eu achei que houve muita inconsistência neste sistema & $100 \%$ & $0 \%$ & $0 \%$ & $0 \%$ & $0 \%$ \\
AF7 - Eu acho que a maioria das pessoas aprenderia a usar & $0 \%$ & $0 \%$ & $0 \%$ & $20 \%$ & $80 \%$ \\
esse sistema rapidamente & & & & & \\
AF8 - Eu achei o sistema muito pesado para uso & $100 \%$ & $0 \%$ & $0 \%$ & $0 \%$ & $0 \%$ \\
AF9 - Eu me senti muito confiante usando esse sistema & $0 \%$ & $0 \%$ & $0 \%$ & $0 \%$ & $100 \%$ \\
AF10 - Eu precisei aprender uma série de coisas antes que & $80 \%$ & $20 \%$ & $0 \%$ & $0 \%$ & $0 \%$ \\
eu pudesse continuar a utilizar esse sistema & & & & \\
\hline
\end{tabular}

Tabela 5.8: Percentual do grau de concordância acumulado por afirmativa do quarto experimento

A visualização gráfica demonstra com mais clareza o alto grau de satisfação alcançado na maioria das afirmações do SUS.

No gráfico 5.6 está representado o grau de concordância das resposta com afirmações ímpares, no qual é possível notar que a maioria das respostas concentram seu pico na extremidade do gráfico, a maioria entre o grau 4 e 5.

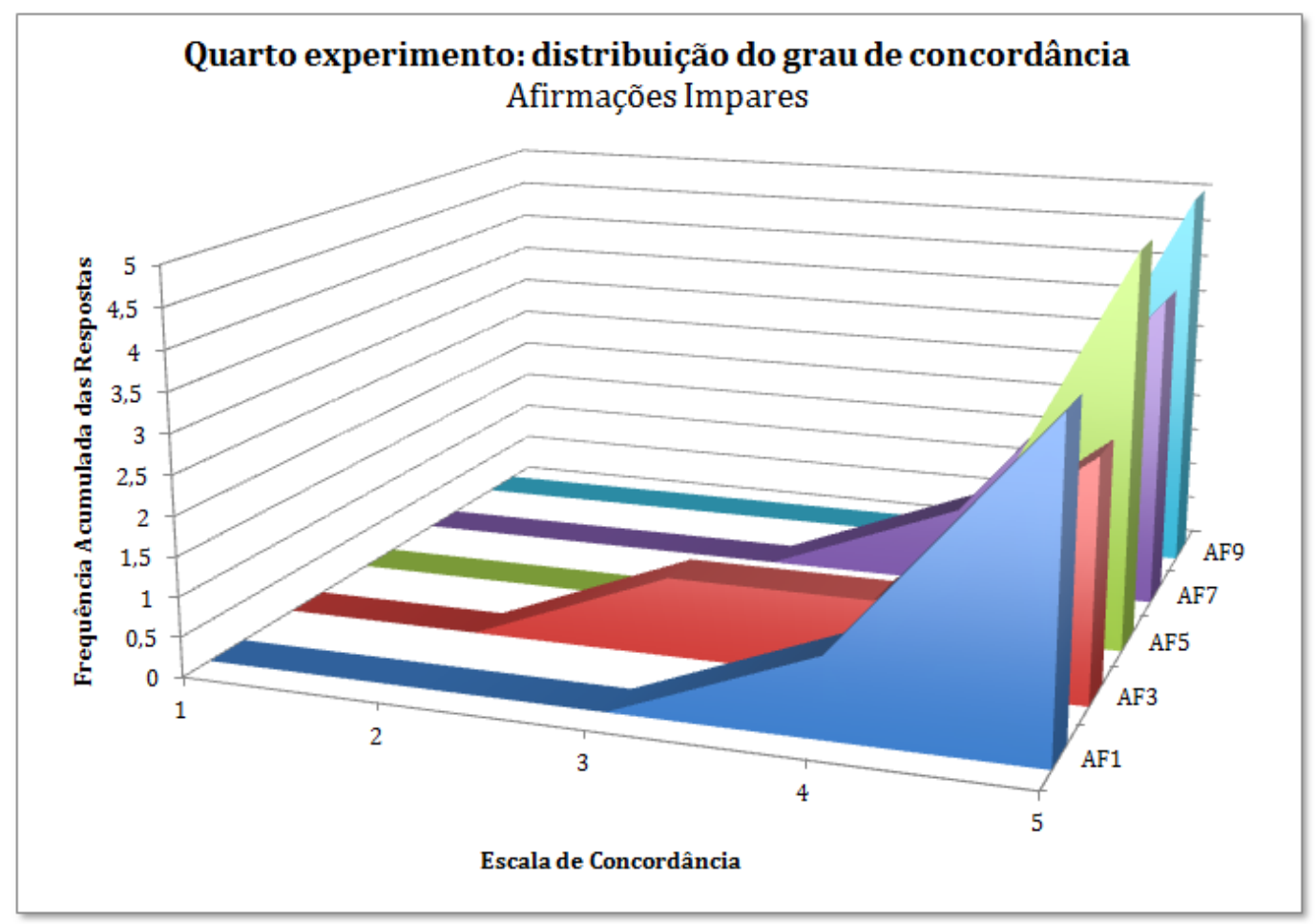

Figura 5.6: Respostas impares do SUS do quarto experimento

O gráfico 5.7, da mesma forma que o gráfico 5.6, também demostra a alta concentração das 
resposta favoráveis, neste caso a discordância com as afirmativas pares.

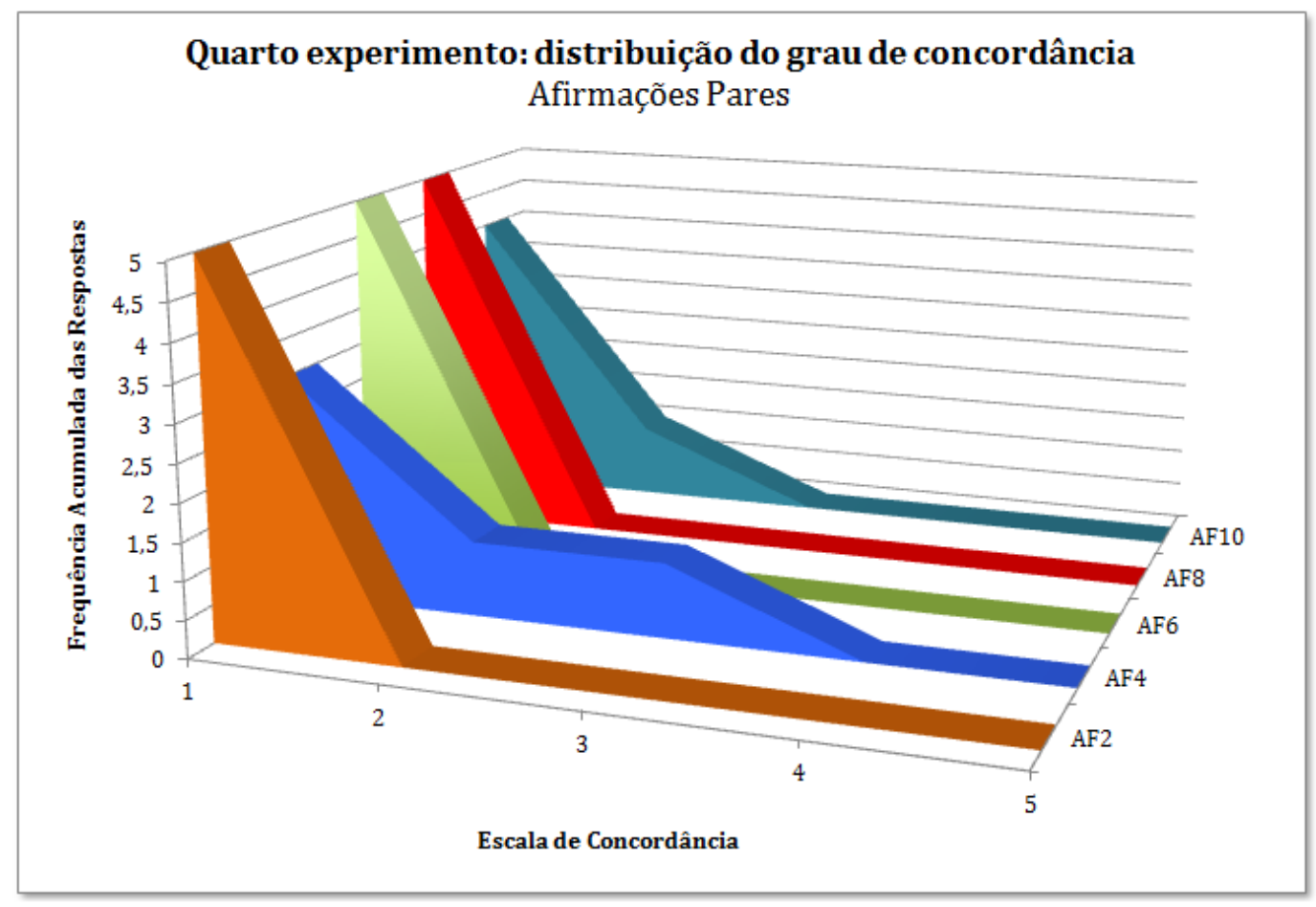

Figura 5.7: Respostas pares do SUS do quarto experimento

Nesta avaliação, houve interesse na verificação da taxa de conclusão das tarefas após a exposição dos recursos do iQuiz por meio de um vídeo tutorial de 5 minutos. O principal interesse para a pesquisa é avaliar a melhoria de desempenho com o treinamento prévio dos usuários, realizado pelo próprio ambiente. Outro fator foi a comparação desse grupo com outro que não recebeu o treinamento com o vídeo tutorial. Os resultados mostraram significativa melhora após os participantes assistirem ao vídeo.

A Tabela G.5 do Apêndice G.3.3 apresenta as marcações atribuídas aos participantes para cada tarefa proposta no teste. De acordo com o Anexo F.0.3, cada participante recebe uma marcação 0 (zero) para uma tarefa não completada, 1(um) para uma tarefa completada com dificuldade ou ajuda e 2 (dois) para uma tarefa completada facilmente. Neste experimento apenas o participante P2 não completou a tarefa T4.2.

Individualmente a tarefa com maior insucesso realizada pelos participantes foi a $T 5$, o gráfico da Figura 5.8 mostra que $60 \%$ dessa tarefa foi realizada com dificuldade ou ajuda. Essa tarefa solicitava a alteração de uma questão e em seguida a inclusão do feedback específico para as alternativas. Não foi problema para os usuários encontrarem o ícone editar questão que aparece sobre o bloco de questões na lista do questionário, mas incluir o feedback específico, a maioria dos participantes acionavam logo a aba feedback, que permite definir o feedback geral e o combinado. A tarefa T3, também está relacionada com feedback e obteve $40 \%$ de dificuldade. As outras duas tarefas, T4.1 e T4.2 estão relacionadas a manipulação de funções cujos os ícones não são muito evidentes e alguns participantes apresentaram dificuldade em identificá-los. O restante das tarefas foram realizadas com facilidade, a uma taxa de $80 \%$. 


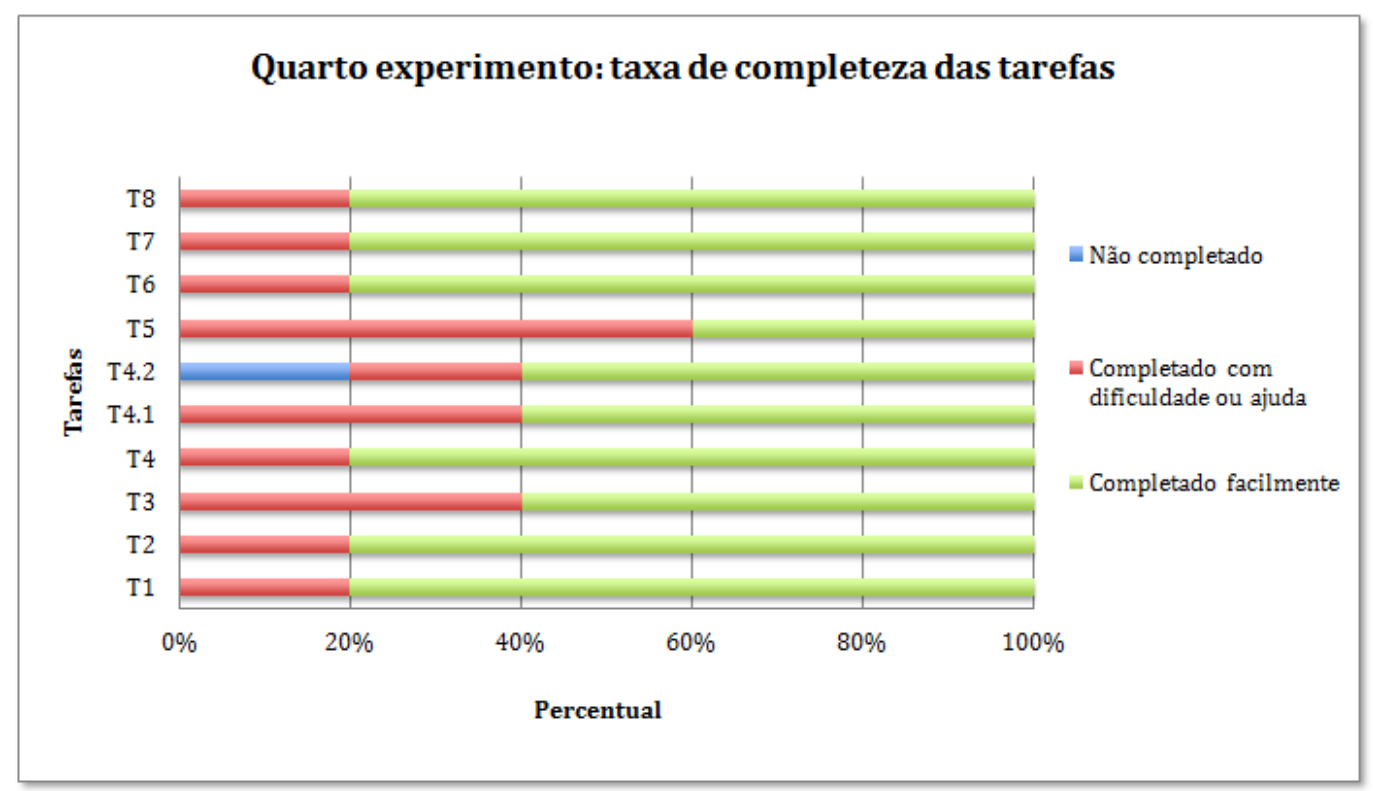

Figura 5.8: Taxa de completeza das tarefas no quarto experimento

Após realizar o calculo da frequência acumulada dos acertos da tabela 4, obtém-se os seguinte resultado:

Total de vezes que uma tarefa não foi completada: 1 ;

Total de vezes que uma tarefa foi completada com dificuldade ou ajuda: 14;

Total de vezes que uma tarefa foi facilmente completada: $\mathbf{3 5}$

O gráfico da Figura 5.9, demonstra que a conclusão de tarefas com facilidade representam $70 \%$, as tarefas com dificuldades ou ajuda $28 \%$ e apenas $2 \%$ não concluídas.

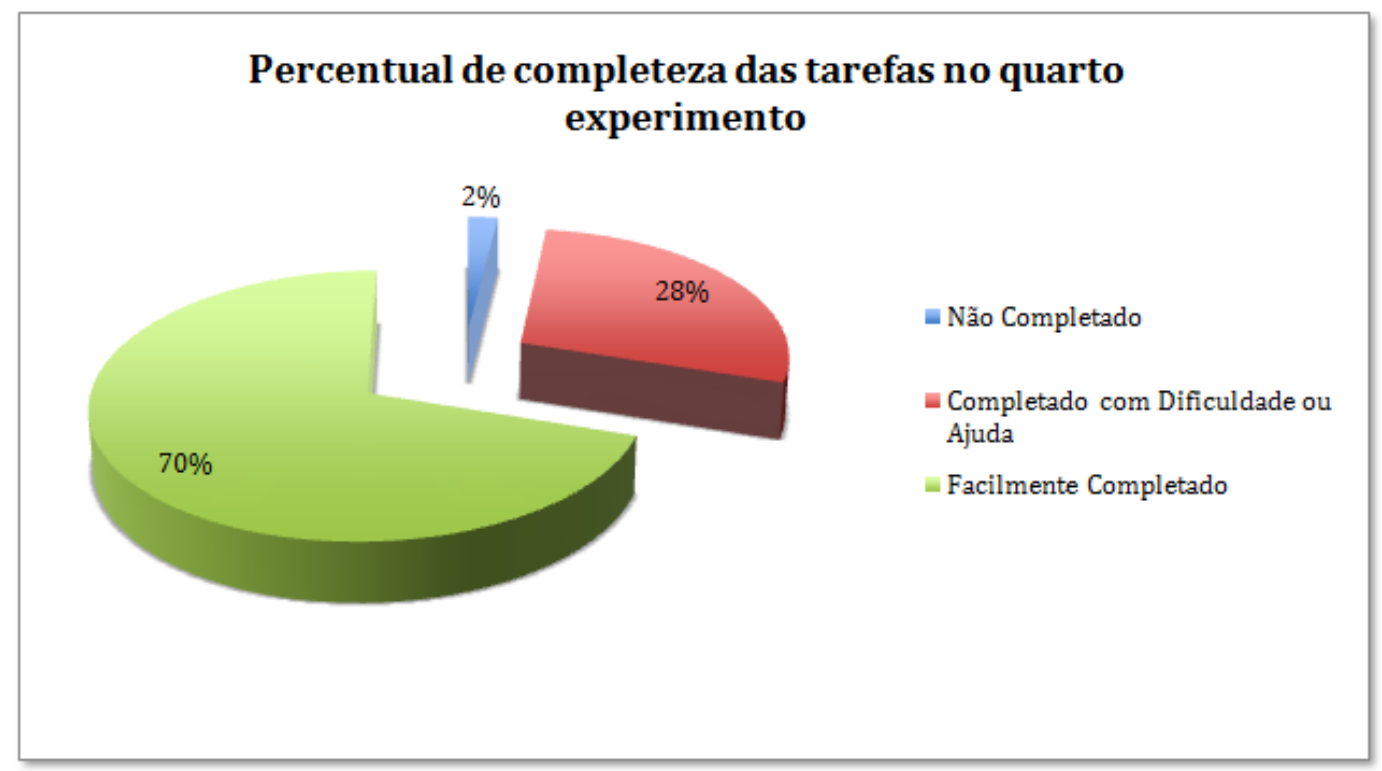

Figura 5.9: Proporção da completeza das tarefas no quarto experimento

Neste experimento pode-se ressaltar que as maiores taxas de insucesso ficaram por conta das tarefas relacionadas com as opções de registros de feedback para os alunos. Um dos fatores que contribuiu foi o número de possibilidades de feedback, tem-se feedback geral, feedback combinado e feedback específico para cada alternativa de uma questão, esse último, pouco aplicado pelos professores, teve o agravante de somente ser acessível quando o ponteiro do mouse está sobre a alternativa. Desse modo os participantes tinham que editar a questão e posicionar o mouse sobre a alternativa. 
Uma possível melhoria será disponibilizar o campo para feedback junto com o campo da alternativa já no momento da inclusão. Outro fator relacionado é que os professores costumavam confundir dicas com informações gerais e mensagens de retorno.

\subsection{Avaliação final}

Nesta seção é feito um comparativo sobre os resultados obtidos nos experimentos com o Quiz e o iQuiz. A comparação a ser realizada utiliza os dados obtidos com a aplicação do questionário SUS. Este questionário além de oferecer a possibilidade de se conhecer a avaliação subjetiva global dos professores sobre cada um dos ambientes, permite também avaliar os componentes da qualidade indicadas por Nielsen (2013c) distribuídas nas afirmativas do questionário. A facilidade de aprendizagem por exemplo é verificado nas afirmativas: 3, 4, 7 e 10; já a eficiência, nas afirmativas: 5, 6 e 8; a facilidade de memorização, nas afirmativa: 2; a minimização de erros é encontrada na afirmativa: 6 e por fim a satisfação, nas afirmativas: 1, 4 e 9 .

Nessa seção será descrito os detalhes das tabelas geradas com o SUS e seus resultados, logo em seguida o mesmo será feito com o iQuiz e por fim uma consolidação dos dados mostra um comparativo entre ambos, iniciando pela Tabela 5.9 que apresenta as respostas dos 13 participantes do primeiro experimento e a pontuação obtida pelo Quiz, já o perfil e as condições do teste foram descritos na Seção 5.2.1,

\begin{tabular}{c|ccccccccccccc}
\hline \multicolumn{10}{c}{ Tabela de Resultados da Avaliação do Moodle Quiz, } \\
\multicolumn{10}{c}{ utilizando o System } & Usability Scale (SUS) \\
\hline \multirow{2}{*}{ Afirmações } & \multicolumn{10}{c}{ Participantes do curso de Verão - IME/USP - 2014 } \\
\cline { 2 - 14 } & P1 & P2 & P3 & P4 & P5 & P6 & P7 & P8 & P9 & P10 & P11 & P12 & P13 \\
\hline AF1 & 5 & 3 & 5 & 5 & 5 & 5 & 3 & 4 & 4 & 5 & 3 & 4 & 4 \\
AF2 & 5 & 3 & 1 & 1 & 3 & 2 & 4 & 1 & 3 & 2 & 3 & 2 & 2 \\
AF3 & 2 & 3 & 3 & 3 & 3 & 3 & 2 & 3 & 3 & 4 & 3 & 3 & 3 \\
AF4 & 4 & 3 & 4 & 4 & 4 & 2 & 4 & 2 & 4 & 4 & 4 & 3 & 3 \\
AF5 & 2 & 4 & 4 & 5 & 4 & 4 & 3 & 4 & 4 & 5 & 3 & 3 & 4 \\
AF6 & 2 & 4 & 2 & 1 & 2 & 1 & 3 & 1 & 1 & 1 & 2 & 1 & 2 \\
AF7 & 3 & 3 & 3 & 3 & 4 & 2 & 3 & 1 & 2 & 3 & 2 & 4 & 3 \\
AF8 & 2 & 4 & 3 & 1 & 2 & 1 & 3 & 1 & 1 & 2 & 3 & 2 & 3 \\
AF9 & 1 & 3 & 4 & 4 & 3 & 4 & 2 & 4 & 4 & 5 & 2 & 4 & 3 \\
AF10 & 5 & 3 & 4 & 1 & 3 & 1 & 3 & 3 & 5 & 4 & 2 & 1 & 3 \\
\hline Pont.Total & 15 & 19 & 25 & 32 & 25 & 31 & 16 & 28 & 23 & 29 & 19 & 29 & 22 \\
\hline Pont. SUS & 37,5 & 47,5 & 62,5 & 80 & 62,5 & 77,5 & 40 & 70 & 57,5 & 72,5 & 47,5 & 72,5 & 55 \\
\hline
\end{tabular}

Tabela 5.9: Resposta dos participantes do experimento com o Moodle Quiz

A coluna "afirmação" contém o código das afirmativas do SUS, seguida pelas colunas de "p1" a "p13", que representam cada participante.

Os valores da escala Likert (1 - descordo plenamente e 5 - concordo plenamente), escolhidos pelos participantes para cada afirmativa, estão no interior da tabela.

Abaixo das afirmativas são totalizados em números absolutos a pontuação dada por cada participante e em seguida a linha "Pontuação SUS" apresenta a pontuação atingida aplicando-se o cálculo recomendado para o questionário, como mencionado no início deste documento. Foi obtido para o experimento com o Moodle Quiz a média 60,19 com desvio padrão 14,08.

$\mathrm{Na}$ Tabela 5.10 foi reproduzido as respostas dos 13 professores dos experimento com o iQuiz, obtidos durante o ciclo de aperfeiçoamento do protótipo. Foram excluídos as respostas dos 3 técnicos da primeira avaliação. Como resultado dessa avaliação foi obtido a média de 88,27 com desvio padrão de 10,57. Nas duas primeiras avaliações do iQuiz não houve qualquer informação sobre o seu funcionamento e na última apenas um vídeo de cinco minutos foi utilizado, assim considera-se 
que o comparativo é justo, pois deu-se vantagem ao Quiz, uma vez que todos participantes desse experimento receberam treinamento prévio com a ferramenta.

\begin{tabular}{|c|c|c|c|c|c|c|c|c|c|c|c|c|c|}
\hline \multicolumn{14}{|c|}{$\begin{array}{c}\text { Tabela de Resultados da Avaliação do iQuiz, } \\
\text { utilizando o System Usability Scale (SUS) }\end{array}$} \\
\hline \multirow{2}{*}{ Afirmações } & \multicolumn{13}{|c|}{ Participantes do curso de Verão - IME/USP - 2014} \\
\hline & P1 & P2 & P3 & $\mathrm{P} 4$ & $\mathrm{P} 5$ & $\mathrm{P} 6$ & P7 & P8 & P9 & P10 & P11 & P12 & P13 \\
\hline AF1 & 4 & 5 & 5 & 5 & 5 & 4 & 5 & 5 & 5 & 4 & 5 & 3 & 5 \\
\hline AF2 & 2 & 2 & 1 & 1 & 1 & 1 & 1 & 1 & 1 & 1 & 2 & 3 & 1 \\
\hline AF3 & 4 & 5 & 5 & 5 & 4 & 3 & 5 & 5 & 5 & 5 & 5 & 4 & 4 \\
\hline $\mathrm{AF} 4$ & 1 & 2 & 1 & 1 & 2 & 3 & 1 & 1 & 5 & 1 & 2 & 5 & 1 \\
\hline AF5 & 5 & 4 & 4 & 5 & 5 & 5 & 5 & 5 & 5 & 4 & 5 & 3 & 5 \\
\hline AF6 & 1 & 2 & 1 & 1 & 1 & 1 & 1 & 1 & 1 & 2 & 1 & 2 & 1 \\
\hline AF7 & 4 & 4 & 4 & 4 & 5 & 5 & 5 & 5 & 5 & 5 & 5 & 4 & 4 \\
\hline AF8 & 2 & 1 & 2 & 1 & 1 & 1 & 1 & 1 & 1 & 1 & 2 & 1 & 1 \\
\hline AF9 & 1 & 4 & 5 & 5 & 5 & 5 & 5 & 5 & 5 & 4 & 5 & 3 & 4 \\
\hline AF10 & 1 & 2 & 2 & 1 & 2 & 1 & 1 & 1 & 1 & 1 & 2 & 2 & 2 \\
\hline Pont.Total & 31 & 33 & 36 & 39 & 37 & 35 & 40 & 40 & 36 & 36 & 36 & 24 & 36 \\
\hline Pont. SUS & 77,5 & 82,5 & 90 & 97,5 & 92,5 & 87,5 & 100 & 100 & 90 & 90 & 90 & 60 & 90 \\
\hline
\end{tabular}

Tabela 5.10: Respostas dos participantes do experimento com o iQuiz

A Tabela 5.11, apresenta os percentuais de concordância para cada afirmativa respondida para Moodle Quiz. Pode ser observado que os melhores resultados permeiam o meio da escala de 2 a 4 $(18 \%, 32 \%, 25 \%)$.

Percentual do Grau de Concordância por Afirmativa da Avaliação do Moodle Quiz, utilizando o SUS

\begin{tabular}{l|ccccc}
\hline \multirow{2}{*}{ Afirmações } & \multicolumn{5}{c}{ Escala de Concordância } \\
\cline { 2 - 6 } & 1 & 2 & 3 & 4 & 5 \\
\hline AF1 - Eu acho que gostaria de utilizar este sistema frequen- & $0,0 \%$ & $0,0 \%$ & $23,1 \%$ & $30,8 \%$ & $46,2 \%$ \\
temente & & & & & \\
AF2 - Eu achei o sistema desnecessariamente complexo & $23,1 \%$ & $30,8 \%$ & $30,8 \%$ & $7,7 \%$ & $7,7 \%$ \\
AF3 - Eu achei o sistema fácil para usar & $0,0 \%$ & $15,4 \%$ & $76,9 \%$ & $7,7 \%$ & $0,0 \%$ \\
AF4 - Eu acho que precisaria do apoio de um suporte técnico & $0,0 \%$ & $15,4 \%$ & $15,4 \%$ & $61,5 \%$ & $7,7 \%$ \\
para ser possível usar este sistema & & & & \\
AF5 - Eu achei que as diversas funções neste sistema foram & $0,0 \%$ & $7,7 \%$ & $23,1 \%$ & $53,8 \%$ & $15,4 \%$ \\
bem integradas & & & & \\
AF6 - Eu achei que houve muita inconsistência neste sistema & $46,2 \%$ & $38,5 \%$ & $7,7 \%$ & $7,7 \%$ & $0,0 \%$ \\
AF7 - Eu acho que a maioria das pessoas aprenderia a usar & $7,7 \%$ & $23,1 \%$ & $53,8 \%$ & $15,4 \%$ & $0,0 \%$ \\
esse sistema rapidamente & & & & & \\
AF8 - Eu achei o sistema muito pesado para uso & $30,8 \%$ & $30,8 \%$ & $30,8 \%$ & $7,7 \%$ & $0,0 \%$ \\
AF9 - Eu me senti muito confiante usando esse sistema & $7,7 \%$ & $15,4 \%$ & $23,1 \%$ & $46,2 \%$ & $7,7 \%$ \\
AF10 - Eu precisei aprender uma série de coisas antes que & $23,1 \%$ & $7,7 \%$ & $38,5 \%$ & $15,4 \%$ & $15,4 \%$ \\
eu pudesse continuar a utilizar esse sistema & & & & & \\
\hline Total Acumulado & $13,8 \%$ & $18,5 \%$ & $32,3 \%$ & $25,4 \%$ & $10,0 \%$ \\
\hline
\end{tabular}

Tabela 5.11: Percentual de Concordância por afirmativa da Avaliação do Moodle Quiz, utilizando o SUS

A Tabela 5.12, apresenta os percentuais de concordância para cada afirmativa respondida para iQuiz. Pode ser observado os melhores resultados permeiam as extremidades da escala. 


\section{Percentual do Grau de Concordância por Afirmativa} da Avaliação do iQuiz, utilizando o SUS

\begin{tabular}{|c|c|c|c|c|c|}
\hline \multirow{2}{*}{ Afirmações } & \multicolumn{5}{|c|}{ Escala de Concordância } \\
\hline & 1 & 2 & 3 & 4 & 5 \\
\hline $\begin{array}{l}\text { AF1 - Eu acho que gostaria de utilizar este sistema frequen- } \\
\text { temente }\end{array}$ & $0,0 \%$ & $0,0 \%$ & $7,7 \%$ & $23,1 \%$ & $69,2 \%$ \\
\hline AF2 - Eu achei o sistema desnecessariamente complexo & $69,2 \%$ & $23,1 \%$ & $7,7 \%$ & $0,0 \%$ & $0,0 \%$ \\
\hline AF3 - Eu achei o sistema fácil para usar & $0,0 \%$ & $0,0 \%$ & $7,7 \%$ & $30,8 \%$ & $61,5 \%$ \\
\hline $\begin{array}{l}\text { AF4 - Eu acho que precisaria do apoio de um suporte técnico } \\
\text { para ser possível usar este sistema }\end{array}$ & $53,8 \%$ & $23,1 \%$ & $7,7 \%$ & $0,0 \%$ & $15,4 \%$ \\
\hline $\begin{array}{l}\text { AF5 - Eu achei que as diversas funções neste sistema foram } \\
\text { bem integradas }\end{array}$ & $0,0 \%$ & $0,0 \%$ & $7,7 \%$ & $23,1 \%$ & $69,2 \%$ \\
\hline AF6 - Eu achei que houve muita inconsistência neste sistema & $76,9 \%$ & $23,1 \%$ & $0,0 \%$ & $0,0 \%$ & $0,0 \%$ \\
\hline $\begin{array}{l}\text { AF7 - Eu acho que a maioria das pessoas aprenderia a usar } \\
\text { esse sistema rapidamente }\end{array}$ & $0,0 \%$ & $0,0 \%$ & $0,0 \%$ & $46,2 \%$ & $53,8 \%$ \\
\hline AF8 - Eu achei o sistema muito pesado para uso & $76,9 \%$ & $23,1 \%$ & $0,0 \%$ & $0,0 \%$ & $0,0 \%$ \\
\hline AF9 - Eu me senti muito confiante usando esse sistema & $7,7 \%$ & $0,0 \%$ & $7,7 \%$ & $23,1 \%$ & $61,5 \%$ \\
\hline $\begin{array}{l}\text { AF10 - Eu precisei aprender uma série de coisas antes que } \\
\text { eu pudesse continuar a utilizar esse sistema }\end{array}$ & $53,8 \%$ & $46,2 \%$ & $0,0 \%$ & $0,0 \%$ & $0,0 \%$ \\
\hline Total Acumulado & $33,8 \%$ & $13,8 \%$ & $4,6 \%$ & $14,6 \%$ & $33,1 \%$ \\
\hline
\end{tabular}

Tabela 5.12: Percentual de Concordância por afirmativa iQuiz

A Tabela 5.13, apresenta a relação de médias dos dois experimentos para todas as afirmativas do questionário SUS.

\begin{tabular}{c|c|c|c|c}
\hline \multicolumn{3}{c}{$\begin{array}{c}\text { Média das Respostas por } \\
\text { para }\end{array}$ Moodle Quiz e iQuiz } \\
iQuativa, \\
\hline \multirow{2}{*}{ Afirmações } & \multicolumn{2}{c}{ Moodle Quiz } & \multicolumn{2}{c}{ iQuiz } \\
\cline { 2 - 5 } & Média & $\%$ & Média & $\%$ \\
\hline AF1 & 4,23 & 84,61 & 4,61 & 92,30 \\
AF2 & 2,46 & 49,23 & 1,38 & 27,69 \\
AF3 & 2,92 & 58,46 & 4,53 & 90,76 \\
AF4 & 3,61 & 72,30 & 2 & 40 \\
AF5 & 3,76 & 75,38 & 4,61 & 92,30 \\
AF6 & 1,76 & 35,38 & 1,23 & 24,61 \\
AF7 & 2,76 & 55,38 & 4,53 & 90,76 \\
AF8 & 2,15 & 43,07 & 1,23 & 24,61 \\
AF9 & 3,30 & 66,15 & 4,30 & 86,15 \\
AF10 & 2,92 & 58,46 & 1,46 & 29,23 \\
\hline
\end{tabular}

Tabela 5.13: Médias das respostas por afirmativa

Para uma análise mais detalhada desses números, são apresentados três gráficos. O gráfico da Figura 5.10, representa as médias das respostas dos participantes para afirmações $(1,3,5,7,9)$ impares. 


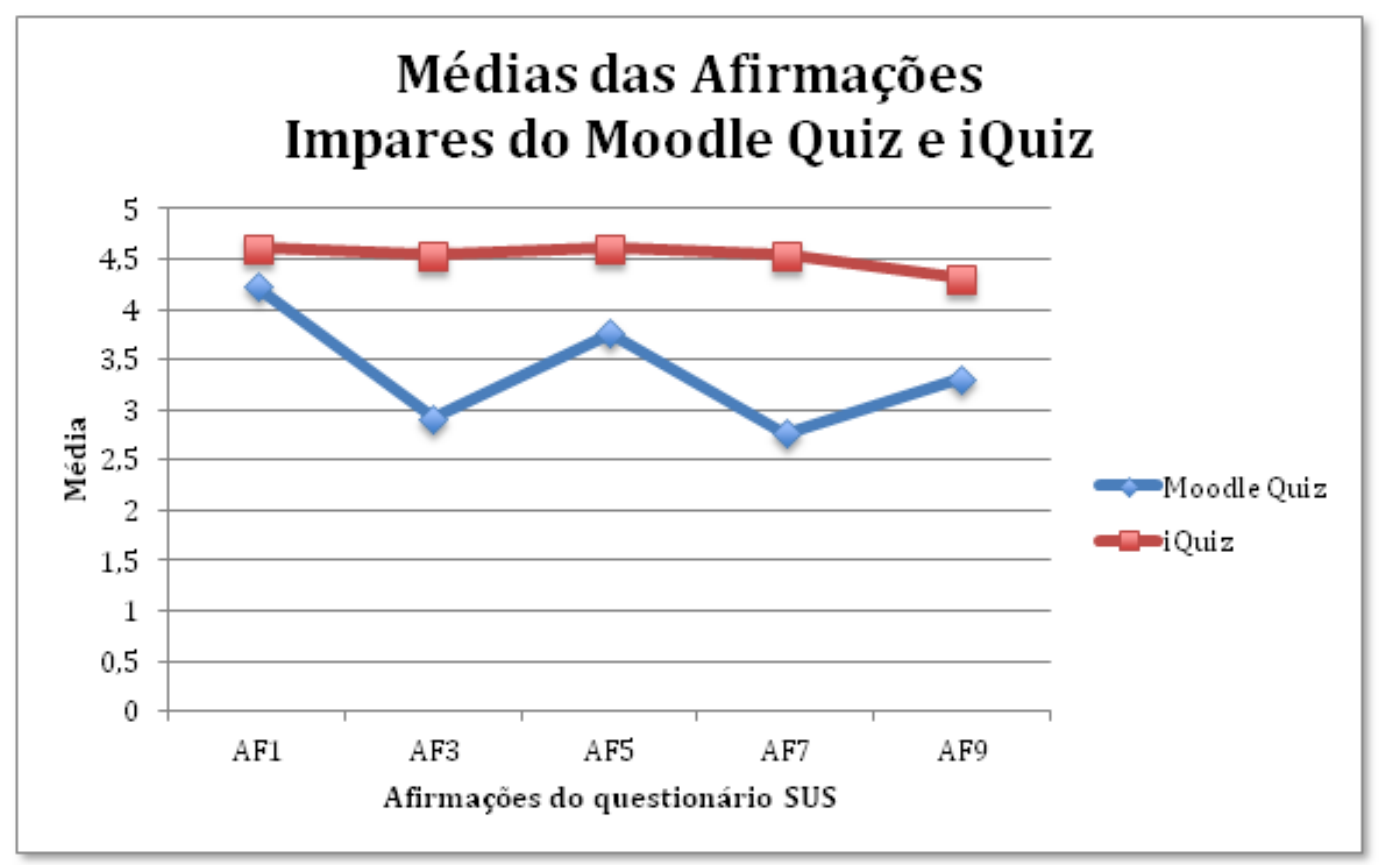

Figura 5.10: Médias das respostas para afirmativas impares do Moodle Quiz e iQuiz

A afirmação AF1 (Eu acho que gostaria de utilizar este sistema frequentemente) apresenta médias bem próximas para os dois ambientes comparados. Isso faz todo sentido, pois neste caso os dois ambientes oferecem os mesmos recursos e portanto a percepção dos benefícios oferecidos pelos ambientes para a criação de testes é a mesma. Então o interesse dos professores pelo uso do ambiente foi mantido.

Nas demais afirmações é claramente destacada a melhoria da satisfação com o uso da nova interface. A afirmação AF3 (Eu achei o sistema fácil para usar) com grau de satisfação médio de 90,76\% e AF7 (Eu acho que a maioria das pessoas aprenderia a usar esse sistema rapidamente) com 90,76\%, contra 58,4\% e 55,3\% respectivamente do Moodle Quiz, evidencia que os usuários acham a interface fácil e que assim como eles, outras pessoas também terão a mesma facilidade. Este ponto de vista tem implicação direta na motivação do uso e na recomendação do sistema para outros usuários, como mostra a Figura 5.11. 


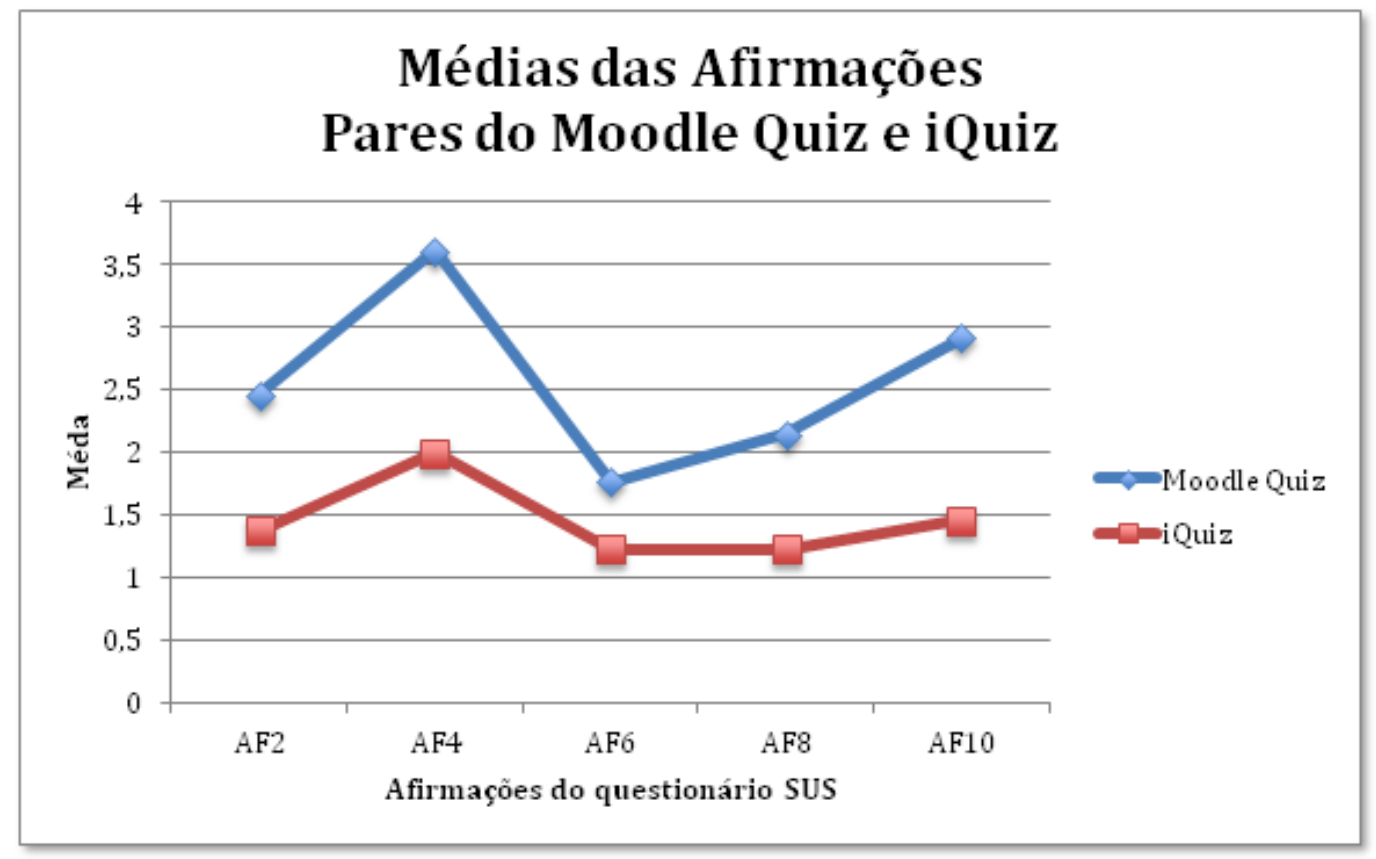

Figura 5.11: Médias das respostas para afirmativas pares do Moodle Quiz e iQuiz

A afirmação AF6 (Eu achei que houve muita inconsistência neste sistema) é a única média do grupo das afirmativas pares que apresenta médias próximas para os dois ambientes comparados, embora tenha obtido melhora significativa $(10,77 \%)$. De acordo com os componentes de qualidade indicado por Nielsen (2013c), esta afirmativa se enquadra no item eficiência. Deste modo os usuários classificam a nova interface com 75,3\% de consistência contra 64,6\% do Moodle Quiz, indicando bom grau de eficiência a ambos os ambientes.

A mais significativa das melhorias entre os dois ambientes está na afirmativa AF4 (Eu acho que precisaria do apoio de um suporte técnico para ser possível usar este sistema), onde 72,3\% dos participantes dizem precisar de suporte técnico para utilizar o Quiz, ao passo que com a nova interface, a média caiu para 40\%. Os participantes do experimento com o Moodle Quiz receberam treinamento na ferramenta antes do experimento, já os participantes do experimento do iQuiz não receberam treinamento anterior e apenas $38 \%$ assistiu a um vídeo tutorial sobre os recursos do $i Q u i z$ antes do experimento.

Outra afirmativa relacionada com o componente facilidade de aprendizagem é a F10 (Eu precisei aprender uma série de coisas antes que eu pudesse continuar a utilizar esse sistema), assim como ocorreu com a afirmativa F4, obteve média expressiva, somente $29,23 \%$ da média de respostas indica a necessidade de algum aprendizado prévio para utilizar o $i$ Quiz, ao passo que a média para o Moodle Quiz foi de $58,4 \%$.

Conforme pode ser observado na Figura 5.12, as médias do questionário SUS para o iQuiz geram um gráfico semelhante a uma senóide, o que é desejável para qualquer avaliação, já que os extremos indicam boa avaliação por parte dos respondentes. 


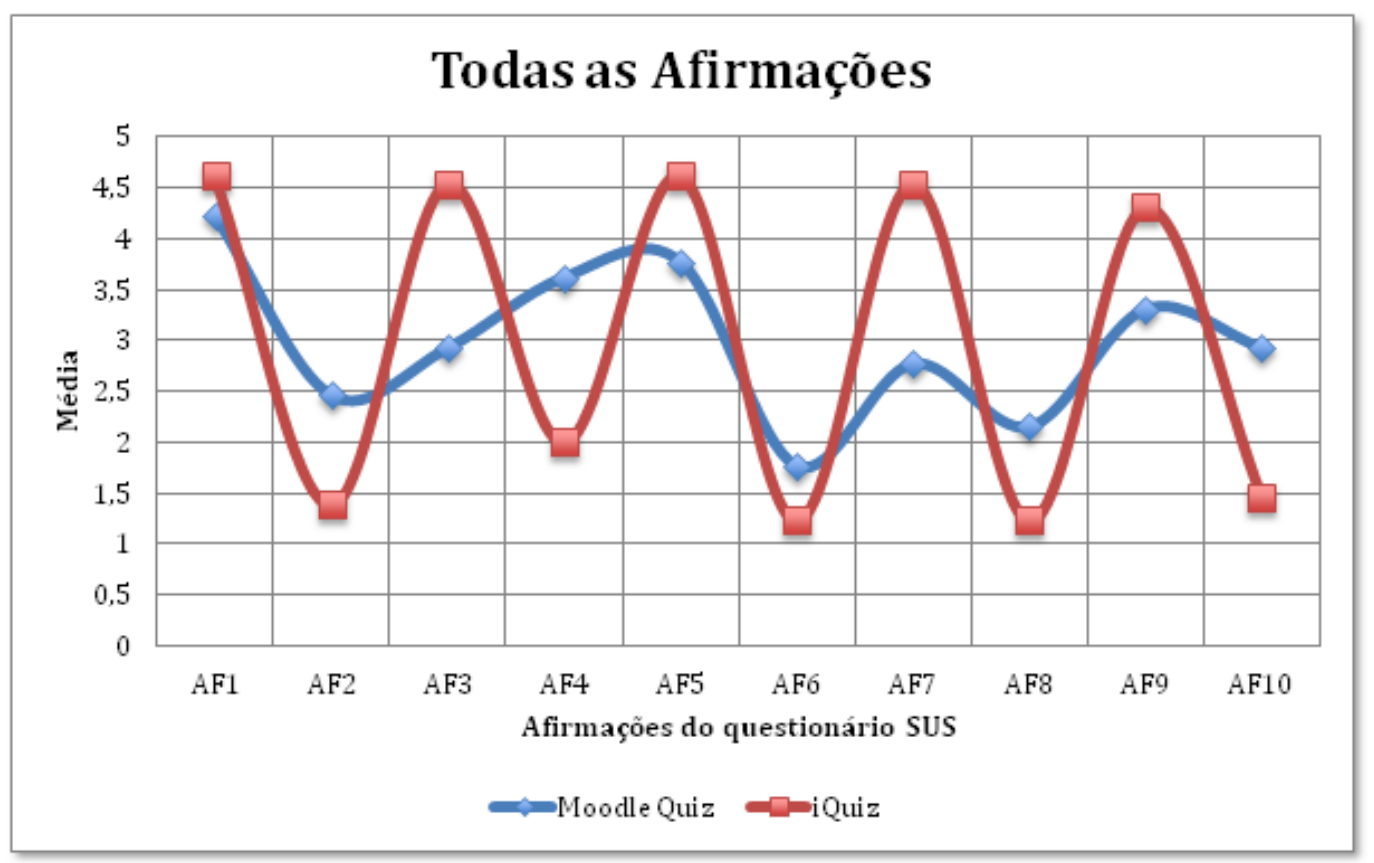

Figura 5.12: Média das Afirmações do SUS para o Moodle Quiz e iQuiz

O cálculo das medias do SUS, indica uma melhoria global com aplicação da nova interface de $28 \%$ em relação ao Moodle Quiz. Mas representa um grau de satisfação geral dos participantes de $88,26 \%$. Um resultado altamente satisfatório para o projeto até o momento. 


\section{Capítulo 6}

\section{Conclusão}

Os Sistemas Gerenciadores de Cursos, como o Moodle, dispõem de variadas ferramentas com objetivos diferenciados. O mais frequente é que as ferramentas apresentem uma interface de aprendizagem, direcionada aos usuários no papel aluno, ao mesmo tempo que disponibiliza as interfaces de relatório e também interfaces de autoria para usuários no papel professor.

Ao se produzir sistemas com tais características é importante definir claramente a interface e as funcionalidades para cada grupo de usuários. Se isso não é feito problemas na usabilidade do sistema tornam-se inevitáveis, causando ineficiência e desmotivação aos usuários. Durante esta pesquisa evidenciou-se que o uso do módulo Quiz do Moodle é difícil para os professores, de modo que isso pode privá-los da aplicação de certas abordagens pedagógicas que utilizam a perspectiva avaliativa. Assim neste trabalho realizou-se um estudo para identificação dos principais elementos que interferem na usabilidade de ferramentas para autoria de questionários online. Os resultados obtidos foram utilizados na modelagem e prototipação de um ambiente alternativo ao do módulo Quiz, denominado de $i$ Quiz, que resultou na contribuição de uma interface para aplicação sobre o núcleo do Quiz e um modelo para integração dos componentes envolvidos na composição do novo ambiente. O objetivo foi melhorar o processo de autoria realizado pelos professores com o módulo Quiz

Para atingir tal objetivo foi utilizado a abordagem de desenvolvimento centrado no usuário, durante o qual empregou-se um processo iterativo, realizando em cada ciclo testes de usabilidade com a finalidade de atingir as métricas previamente estabelecidas. Observando-se desses testes que: (i) houve melhora progressiva nos resultados dos testes realizados com a interface; (ii) ocorreu significativa melhora na taxa de conclusão das tarefas após a implementação de recomendações de usabilidade e utilização de vídeo tutorial para explicar recursos com conceitos pouco explorados pelos professores; (iii) melhora da satisfação dos professores; (iv) redução do índice de professores que precisaram de suporte para utilizar o protótipo.

Para avaliar as melhorias obtidas, os resultados alcançados com o protótipo foram consolidados e comparados com os resultados das avaliações realizadas com o Quiz. Verificou-se que em todos os itens analisados, o protótipo foi melhor avaliado, constatando-se melhoria no processo de autoria e aumento no índice de satisfação dos professores.

Portanto foi respondida a questão de pesquisa que se colocou neste trabalho que era: "Quais são as possíveis melhorias na usabilidade da ferramenta Quiz do Moodle para tratar as dificuldades na utilização dessa ferramenta". Confirmando a hipótese de que melhorar a usabilidade do Quiz diminui as dificuldades encontradas pelos professores na autoria de questionários com essa ferramenta, contribuindo para a maior satisfação e desempenho dos professores.

\subsection{Considerações finais}

Além do principal objetivo traçado para este trabalho outro também importante foi estabelecido, a integração $\operatorname{dos}(i M A)$ ao questionário do Moodle, mais uma das motivações para a pesquisa. Para atingir esse objetivo um módulo (tipo de questão $i M A$ ) foi desenvolvido e encontra-se em teste, 
sendo que esse módulo já habilita os $i M A$ para serem utilizados no questionário, faltando apenas a integração do iQuiz ao Moodle para efetivar o uso dos $i M A$ no processo de autoria e permitir as tentativas de respostas pelo questionário.

Até o encerramento deste trabalho verificou-se avanços da comunidade Moodle sobre as questões de usabilidade, provavelmente devido ao trabalho realizado por Savolainen (2010) e Hunt (2013). Hoje em dia, o Moodle já tem algumas diretrizes de trabalho sobre usabilidade e incentiva a participação de colaboradores para realizar testes de usabilidade com os usuários e submetê-los ao Moodle.

Com os resultados desta pesquisa, procurou-se contribuir com melhorias para o Quiz e seus utilizadores, ao encontrar formas para diminuir as dificuldades evidenciadas e incentivando as práticas de aplicação dos métodos da área de engenharia de usabilidade para melhorar a satisfação e o desempenho dos potenciais usuários envolvidos no processo de autoria dos questionários de avaliação em ambientes online ou mesmo em outros tipos de sistemas para avaliação do aprendizado.

Por fim, conclui-se que um estudo como esse pode ser importante no apontamento de caminhos que outros desenvolvedores possam seguir e implementar em suas práticas de desenvolvimento. Como aponta Hunt (2013), houve muitos avanços, desde a versão 1.9 do Moodle, mas ainda é preciso realizar muitas melhorias para tornar o Quiz e o Moodle cada vez mais úteis para seus usuários.

\section{Lições aprendidas}

Se de um lado, usuários com pouco experiência, muitas vezes avaliam positivamente determinados aspectos da interface que não implicam em agilidade de produção, de outro lado, usuários mais experientes valorizam recursos que aumente a produtividade. Por isso é interessante disponibilizar uma interface que permita um usuário novato conseguir produzir, mesmo que lentamente, mas também deve-se providenciar atalhos para que o usuário experiente consiga produzir mais rapidamente.

Definitivamente, usuários não gostam de consultar a ajuda, pior ainda se for material escrito, vídeos tutoriais são mais atrativos, principalmente se forem curtos e objetivos.

A análise de sistemas concorrentes ou similares pode fornecer boas ideias e economizar tempo na avaliação de problemas e erros frequentes em tarefas comuns.

\subsection{Sugestões para pesquisas futuras}

Em razão do escopo desta pesquisa ser parte de um projeto mais amplo, outros desafios se colocaram, alguns deles são apontados como sugestões para a continuidade ou apoio a esse projeto:

(i) implementar a camada de integração com o Moodle para disponibilizar o ambiente como um plugin; (ii) realizar observações e medições com o iQuiz em funcionamento, e acompanhar as melhorias ocorridas em relação a satisfação e utilização para avaliações formativas, verificando se ocorre aumento no uso de questões que não sejam do tipo múltipla escolha ou falso/verdadeiro; (iii) avaliar a utilização dos componentes do ambiente, tais como, o iRepositório, verificando se ocorrem melhorias no trabalho colaborativo e o compartilhamento de questões e questionários entre professores, assim como a avaliação do uso dos $i M A$ e seu impacto como um tipo de questão; (iv) uma investigação pode ser realizada fim de constatar se os problemas de usabilidade do Quiz implicam na subutilização de seus recursos, um ponto de partida é avaliar a causa da concentração no uso das questões do tipos múltipla escolha e falso/verdadeiro; (v) realizar pesquisa no evento MoodleMoot que ocorre em outros países pode ajudar a traçar um perfil de usuários mais realístico, a caracterização poderia ser agrupada por região ou um perfil mundial. 


\section{Apêndice A}

\section{Relatório pesquisa MoodleMoot 2013}

\section{A.1 Relatório preliminar sobre a pesquisa no evento MoodleMoot}

No levantamento de dados realizado no evento MoodleMoot 2013 foi aplicado o questionário ilustrado na Figura A.1, a 450 participantes, convidados aleatoriamente durante a realização do evento.

O evento foi organizado por eixos temáticos, sendo eles: Moodle em processos educacionais; Moodle em domínios corporativos; Tecnologias e ferramentas.

No eixo "Moodle em processos educacionais"foram distribuídos 300 questionários, nesse eixo a maioria dos participantes eram professores. Nos demais eixos foram distribuídos 150 questionários, nesse a maioria dos participantes são administradores de sistema, desenvolvedores, tecnólogos e profissionais de Tecnologias de Informação (TI).

Dos 450 questionários distribuídos, 49 foram preenchidos, dos quais 24 foram respondido por 'professores' e 25 por 'não professores'. Dos 24 'professores' 18 utilizam o Moodle e 14 utilizam o Quiz, como mostra a Tabela A.1.

\begin{tabular}{|l|r|r|}
\hline Total de professores & 24 & $100 \%$ \\
\hline Total de Professores que usam Moodle & 18 & $75 \%$ \\
\hline Total de Professores que usam Quiz & 14 & $78 \%$ \\
\hline
\end{tabular}

Tabela A.1: Distribuição de professores que usam o Moodle $e$ o Quiz 
WLInE

www.matematica.br
IME - Instituto de Matemática e Estatística- USP Pesquisa - Sistemas de Avaliação Online

\section{Identificação / Qualificação}

1. Idade:

2. Sexo $\square$ Feminino

$\square$ Masculino

3. Qual o grau de formação abaixo representa seu nível de escolaridade

$\square$ Sem formação de nível superior

$\square$ Tecnólogo

$\square$ Especialização

$\square$ Mestrado

Você é professor? $\square \operatorname{Sim} \square$ Não

4.1. Se você não é professor, qual é sua Função?

(vá para o item 6)

4.2. Se você é professor, indique o tipo de instituição em que leciona.

$\square$ Pública $\square$ Privada

4.3. Quais os níveis ou modalidades de ensino que você atua?
$\square$ Fundamental I
$\square$ Fundamental II
$\square$ Médio
$\square$ Técnico/Profissional
$\square \mathrm{EaD}$
Superior

5. Informe a(s) disciplina(s) que leciona:

\section{Conhecimentos técnicos}

6. Com que frequência você usa o computador semanalmente?
$\square$ Menos de $1 \mathrm{~h}$ semanais
$\square$ Entre $1 \mathrm{~h}$ e $10 \mathrm{hs}$
$\square$ Entre $10 \mathrm{hs}$ e $20 \mathrm{hs}$
Mais de 40hs

7. Como você classifica sua familiaridade no uso do computador?
$\square$ Nenhuma
Pouca
Moderada
$\square$ Muita
Excelente

8. Você já participou de algum tipo capacitação tecnológica? $\square$ Sim $\square$ Não

9. Você já utilizou o Moodle para disponibilizar conteúdo? $\square \operatorname{Sim} \square$ Não

10. Indique abaixo os recursos do Moodle que você utiliza com mais frequência. Informe a ordem de importância assinalando (1) para o mais usado, (2) para o segundo mais usado, (3) para o terceiro mais usado, (4) para o quarto mais usado e (5) para o quinto mais usado.

\begin{tabular}{|l|c|c|c|c|c|}
\hline Recursos & Arquivo & Tarefa & Questionário & Fórum & Lição \\
\hline Classificação & $($ ) & $($ ) & $($ ) & $($ ) & $(~)$ \\
\hline
\end{tabular}

11. Você já utilizou a atividade Questionário (Quiz) para realizar avaliações? $\square \operatorname{Sim} \square$ Não

11.1. Se sim, para realizar quais tipos de avaliação?

$\square$ Diagnóstica $\square$ Somativa $\square$ Formativa $\square$ Outra:

11.2. Se não, Por quê?

12. Referente às afirmações abaixo indique o seu grau de concordância sobre o Quiz (atividade Questionário do Moodle)

\begin{tabular}{|lccccc|}
\hline & $\begin{array}{c}\text { Concordo } \\
\text { totalmente }\end{array}$ & Concordo & Neutro & Discordo $\begin{array}{c}\text { Discordo } \\
\text { totalmente }\end{array}$ \\
\hline A criação de questionários no Quiz é rápida. & $\square$ & $\square$ & $\square$ & $\square$ \\
\hline $\begin{array}{l}\text { O processo de criação de um questionário no Quiz } \\
\text { não é intuitivo. }\end{array}$ & $\square$ & $\square$ & $\square$ & $\square$ \\
\hline $\begin{array}{l}\text { Criar questões do tipo múltipla escolha é } \\
\text { preferível por ser mais fácil. }\end{array}$ & $\square$ & $\square$ & $\square$ & $\square$ \\
\hline $\begin{array}{l}\text { O formulário que o Quiz apresenta para criação de } \\
\text { questões é muito extenso. }\end{array}$ & $\square$ & $\square$ & $\square$ & $\square$ \\
\hline $\begin{array}{l}\text { A maioria das pessoas aprende o Quiz } \\
\text { rapidamente. }\end{array}$ & $\square$ & $\square$ & $\square$ & $\square$ \\
\hline $\begin{array}{l}\text { O Quiz possui todos os recursos necessários para } \\
\text { criar questionários de avaliação. }\end{array}$ & $\square$ & $\square$ & $\square$ & $\square$ \\
\hline
\end{tabular}

Evento: MoodleMoot Brasil 2013 - Realização Universidade Presbiteriana Mackenzie - CEA@D 23/05/2013

Figura A.1: Questionário pesquisa MoodleMoot 2013 


\section{A.1.1 Perfil do professor encontrado na pesquisa do MoodleMoot}

Dos 18 professores que utilizam o Moodle, $57 \%$ são do sexo masculino, $57 \%$ dos professores tem especialização, lecionam em instituição pública e privada de forma equilibrada. A modalidade em que atuam é predominantemente EAD e Ensino Superior. Os professores classificaram sua fluência digital entre muito boa e excelente $(79 \%)$, sendo que a maioria já participou de algum tipo de capacitação tecnológica (71\%). Dos professores que utilizam o Moodle, $22 \%$ não utilizaram o Quiz, não explicitaram razões. Dos $78 \%$ que utilizam o Quiz, apenas $29 \%$ utilizam para realizar avaliação formativa.

A Tabela A.2 apresenta a consolidação das respostas para as seis afirmações da questão 12 da pesquisa. Para fins de comparação as respostas foram agrupadas em 'discordo', ' neutro' e 'concordo'. E os participantes foram agrupados em professores e técnicos.

Consolidação da opinião sobre o Quiz no MoodleMoot 2013

\begin{tabular}{l|c|c|c|c|c|c}
\hline & \multicolumn{2}{|c|}{ Discordo } & \multicolumn{2}{c|}{ Neutro } & \multicolumn{2}{c}{ Concordo } \\
\hline Afirmação & Profs. & Técnicos & Profs. & Técnicos & Profs. & Técnicos \\
\hline $\begin{array}{l}\text { A criação de } \\
\text { questionários no Quiz é } \\
\text { rápida }\end{array}$ & $50 \%$ & $25 \%$ & $14 \%$ & $13 \%$ & $36 \%$ & $63 \%$ \\
\hline $\begin{array}{l}\text { O processo de criação de } \\
\text { questionários no Quiz não } \\
\text { éntuitivo. }\end{array}$ & $29 \%$ & $0 \%$ & $21 \%$ & $75 \%$ & $50 \%$ & $25 \%$ \\
\hline $\begin{array}{l}\text { Criar questóes do tipo } \\
\text { múltipla escolha é } \\
\text { preferível por ser mais } \\
\text { fácil. }\end{array}$ & $28 \%$ & $13 \%$ & $29 \%$ & $25 \%$ & $43 \%$ & $62 \%$ \\
\hline $\begin{array}{l}\text { O formulário que o Quiz } \\
\text { apresenta para criação de } \\
\text { questões é muito extenso. }\end{array}$ & $29 \%$ & $13 \%$ & $14 \%$ & $63 \%$ & $57 \%$ & $24 \%$ \\
\hline $\begin{array}{l}\text { A maioria das pessoas } \\
\text { aprende o Quiz } \\
\text { rapidamente. }\end{array}$ & $57 \%$ & $25 \%$ & $21 \%$ & $37 \%$ & $21 \%$ & $38 \%$ \\
\hline $\begin{array}{l}\text { O Quiz possui todos os } \\
\text { recursos necessários para } \\
\text { criar questionários de } \\
\text { avaliação }\end{array}$ & $71 \%$ & $13 \%$ & $14 \%$ & $25 \%$ & $15 \%$ & $63 \%$ \\
\hline
\end{tabular}

Tabela A.2: Consolidação da opinião sobre o Quiz no MoodleMoot 2013

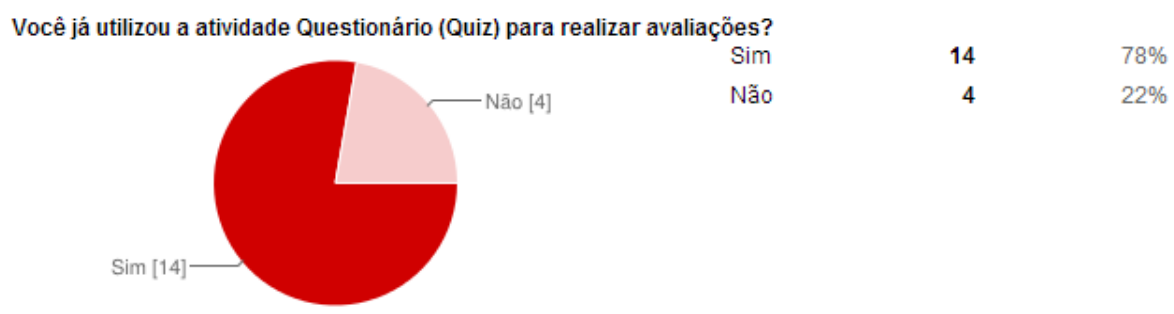

Figura A.2: Você já utilizou o Quiz para realizar avaliações? 
Quais tipos de avaliação você realiza com o Quiz?

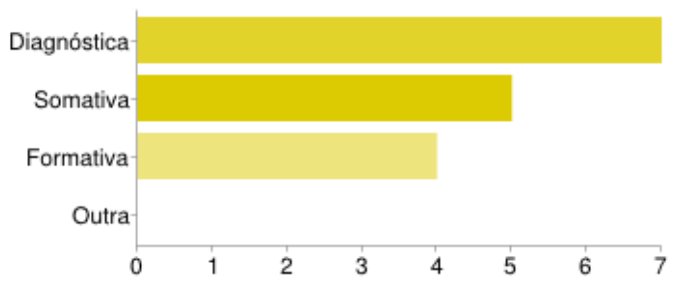

$\begin{array}{lrr}\text { Diagnóstica } & 7 & 50 \% \\ \text { Somativa } & 5 & 36 \% \\ \text { Formativa } & 4 & 29 \% \\ \text { Outra } & 0 & 0 \%\end{array}$

As pessoas podem marcar mais de uma caixa de seleção, então a soma das percentagens pode ultrapassar $100 \%$.

Figura A.3: Quais tipo de avaliações você realizar com o Quiz?

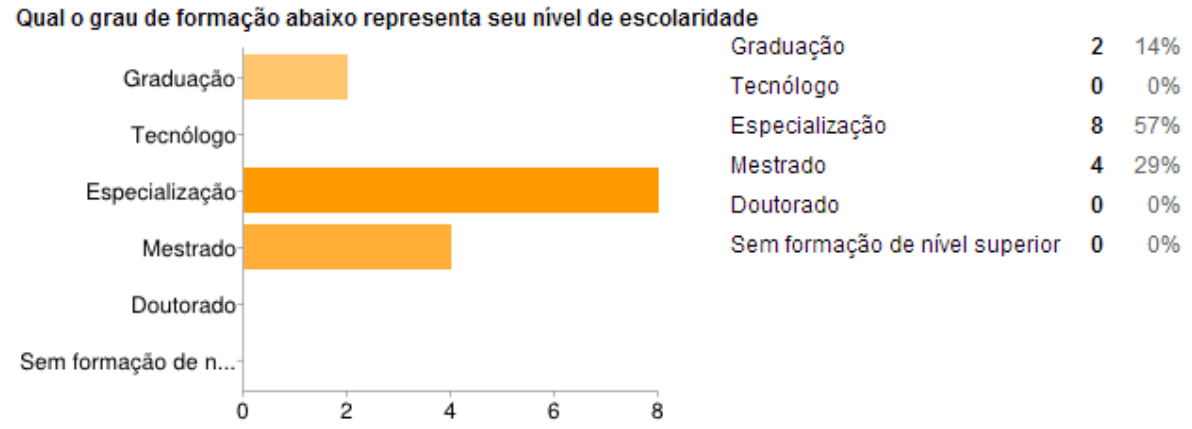

Figura A.4: Formação dos participantes

Qual o tipo de instituição em que você leciona?

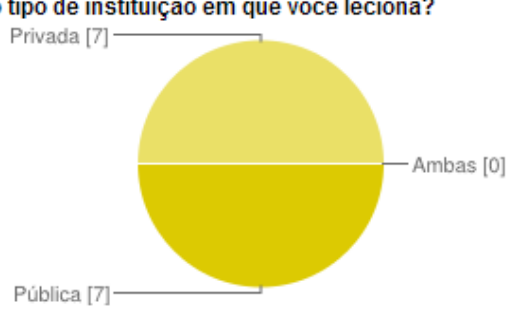

$\begin{array}{llr}\text { Pública } & 7 & 50 \% \\ \text { Privada } & 7 & 50 \% \\ \text { Ambas } & 0 & 0 \%\end{array}$

Figura A.5: Instituição onde os professores participantes lecionam

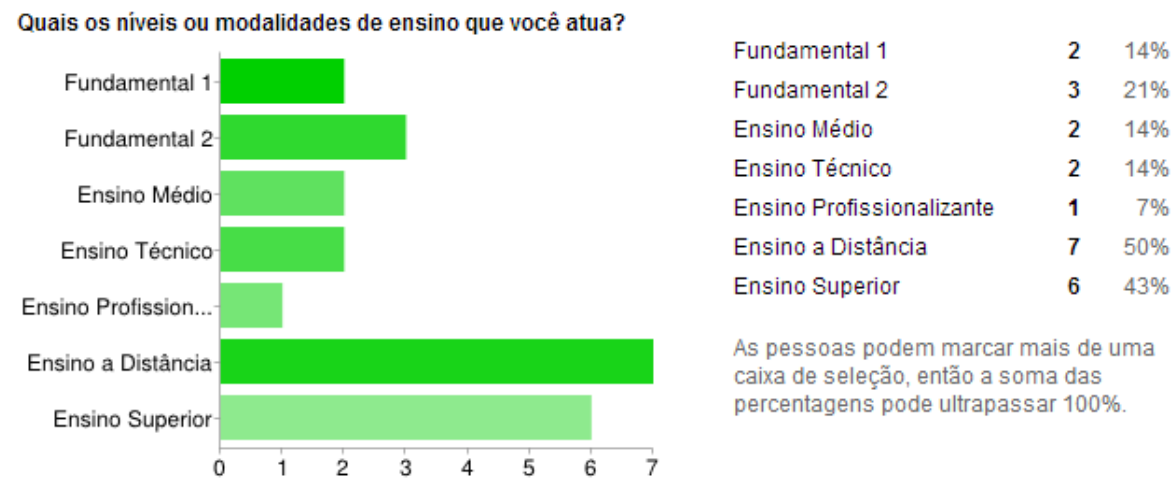

Figura A.6: Modalidade de ensino de atuação dos professores participantes 


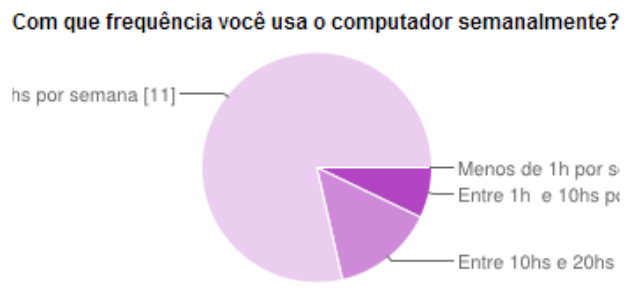

$\begin{array}{lrr}\text { Menos de } 1 \text { h por semana } & 0 & 0 \% \\ \text { Entre 1h e 10hs por semana } & \mathbf{1} & 7 \% \\ \text { Entre 10hs e 20hs por semana } & \mathbf{2} & 14 \% \\ \text { Mais de 40hs por semana } & \mathbf{1 1} & 79 \%\end{array}$

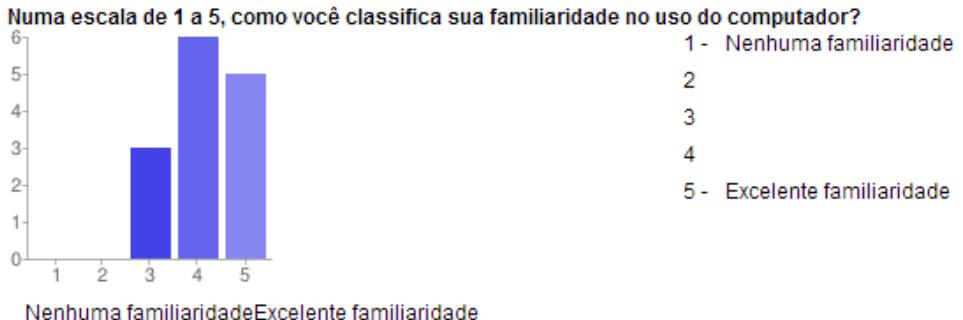

Nenhuma familiaridadeExcelente familiaridade

Figura A.7: Frequência de uso do computador

Você já participou de algum tipo de capacitação tecnológica?

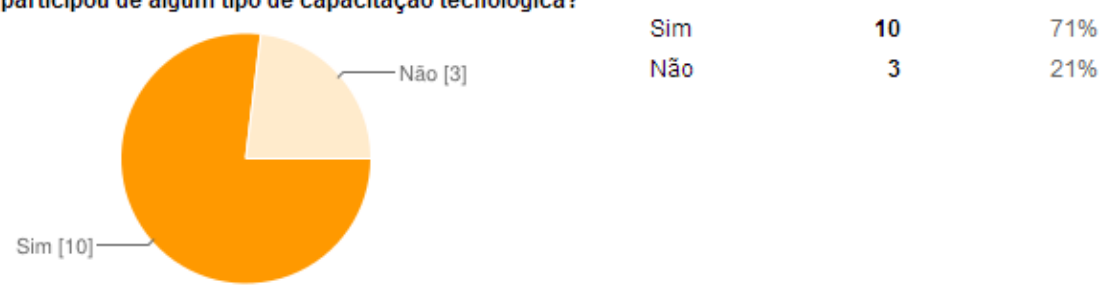

Figura A.8: capacitação tecnológica

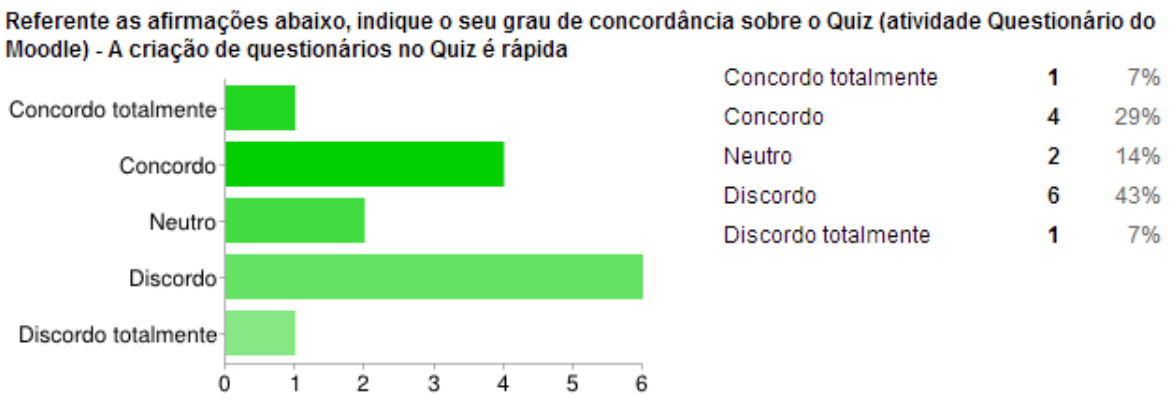

Figura A.9: A criação de questionário no Quiz é rápida? 
Referente as afirmações abaixo, indique o seu grau de concordância sobre o Quiz (atividade Questionário do Moodle) - 0 processo de criação de um questionário no Quiz não é intuitivo

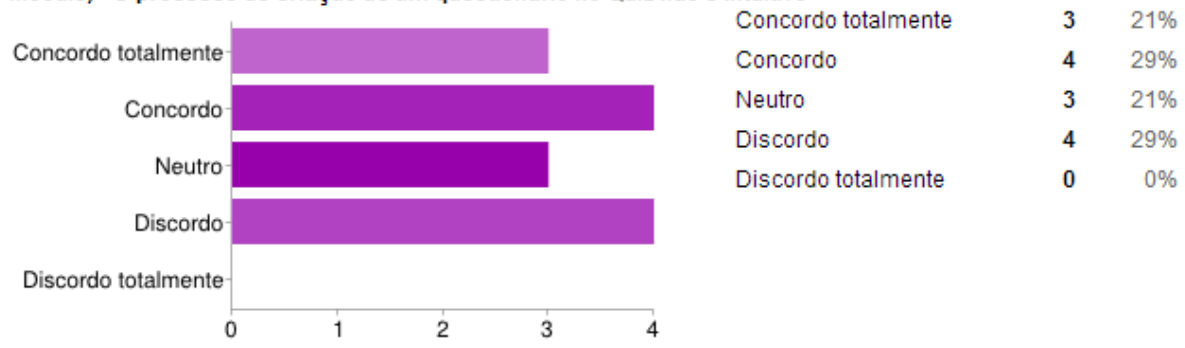

Figura A.10: O processo de criação de questionário no Quiz é intuitiva?

Referente as afirmações abaixo, indique o seu grau de concordância sobre o Quiz (atividade Questionário do Moodle) - Criar questões do tipo múltipla é preferivel por ser mais fácil

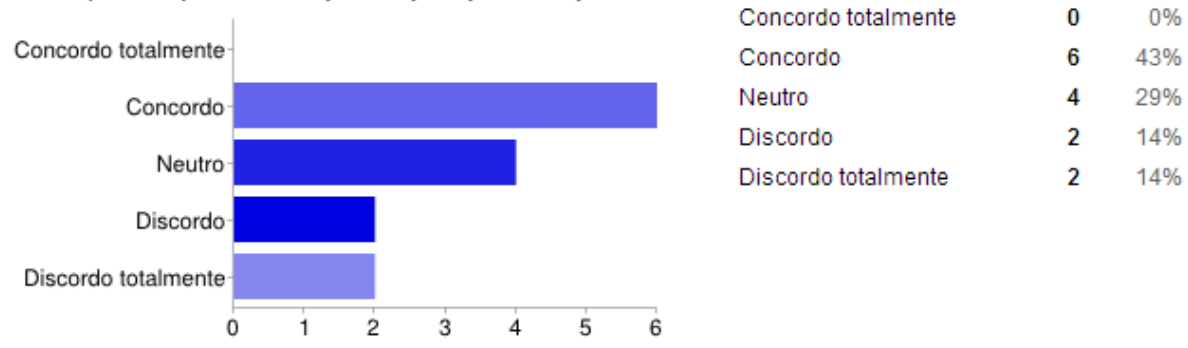

Figura A.11: Criar questôes múltipla escolha no Quiz é mais fácil?

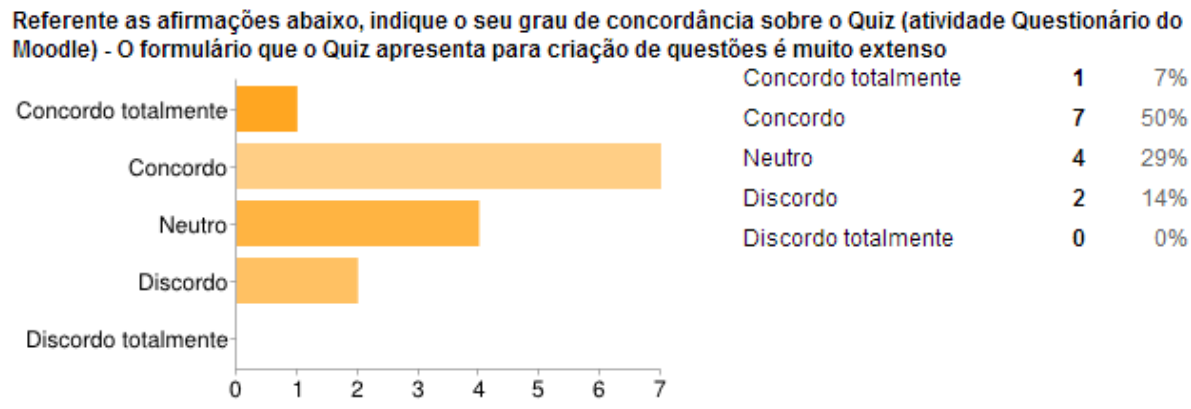

Figura A.12: Os formulários do Quiz são extensos?

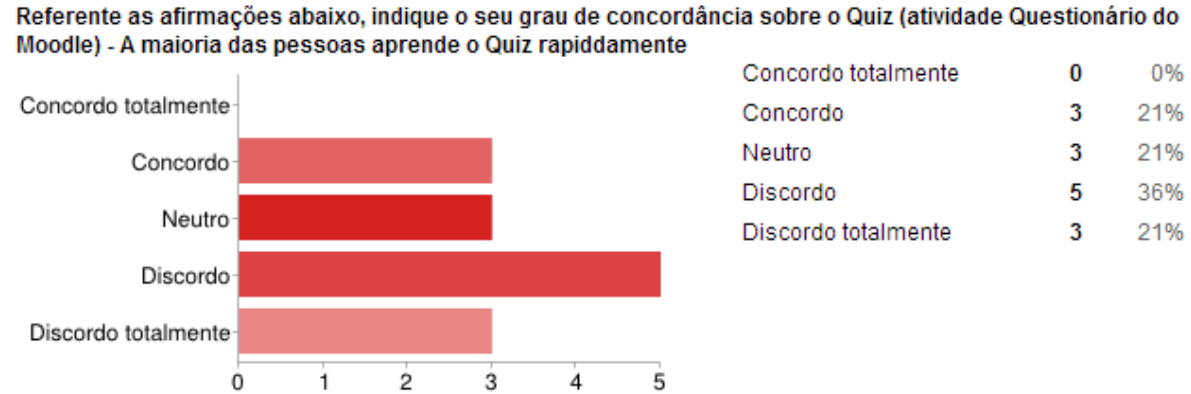

Figura A.13: As pessoas aprendem o Quiz rapidamente? 


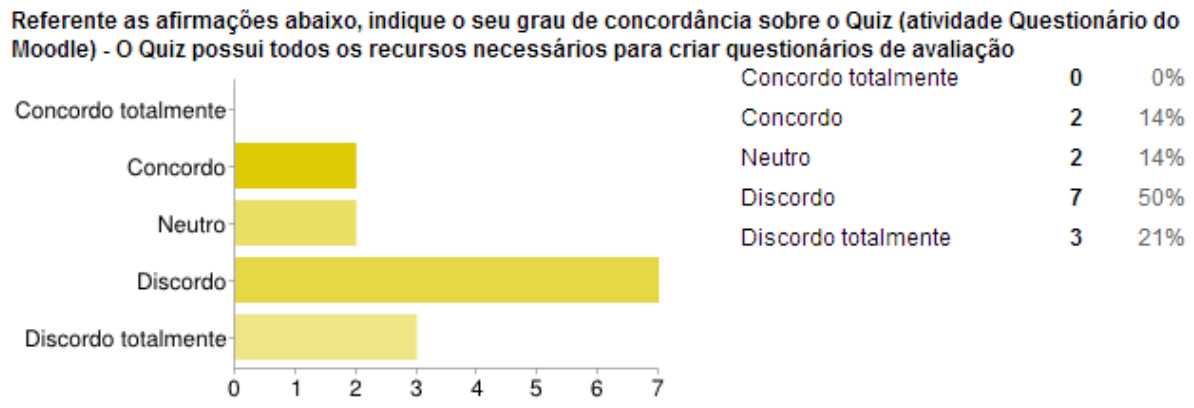

Figura A.14: Recursos da Quiz

\section{A.1.2 Perfil dos 'não professores' encontrados na pesquisa do MoodleMoot}

\begin{tabular}{|l|r|r|}
\hline Total de não professores & 25 & $100 \%$ \\
\hline Total que usam Moodle & 21 & $84 \%$ \\
\hline Total que usam Quiz & 15 & $71,5 \%$ \\
\hline Total de técnicos que já usam Quiz & 8 & $38 \%$ \\
\hline
\end{tabular}

Tabela A.3: Distribuição de professores que usam o Moodle e o Quiz

O ponto de vista dos técnicos sobre o Quizfoi um pouco diferente, como era de se esperar. Embora os representantes desse grupo não sejam em igual quantidade ao grupo analisado de professores, servem como indícios de que as visões entre ambos os grupos é distinta.

\begin{tabular}{|l|r|r|r|}
\hline Afirmação & Discordam & Neutro & Concordam \\
\hline A criação de questionários no Quiz é rápida. & $25 \%$ & $13 \%$ & $63 \%$ \\
\hline $\begin{array}{l}\text { O processo de criação de questionários no Quiz } \\
\text { não é intuitivo. }\end{array}$ & $0 \%$ & $75 \%$ & $25 \%$ \\
\hline $\begin{array}{l}\text { Criar questões do tipo múltipla escolha é prefe- } \\
\text { rível por ser mais fácil. }\end{array}$ & $13 \%$ & $25 \%$ & $62 \%$ \\
\hline $\begin{array}{l}\text { O formulário que o Quiz apresenta para criação } \\
\text { de questões é muito extenso. }\end{array}$ & $13 \%$ & $63 \%$ & $24 \%$ \\
\hline $\begin{array}{l}\text { A maioria das pessoas aprende o Quiz rápida- } \\
\text { mente. }\end{array}$ & $25 \%$ & $37 \%$ & $38 \%$ \\
\hline $\begin{array}{l}\text { O Quiz possui todos os recursos necessários para } \\
\text { criar questionários de avaliação. }\end{array}$ & $13 \%$ & $25 \%$ & $63 \%$ \\
\hline
\end{tabular}

Tabela A.4: Consolidação da opinião dos não professores sobre o Quiz

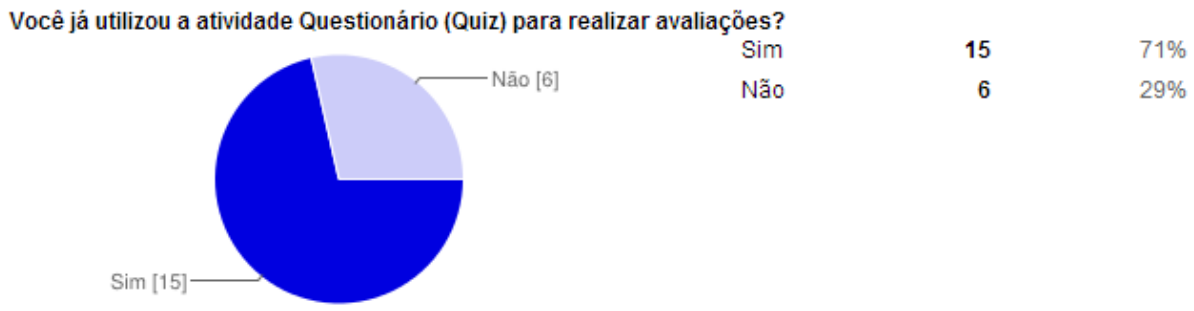

Figura A.15: Utilizou o Quiz para realizar atividades? 
Entre os 15 que utilizaram o Quiz, foi extraído 8 que representam um grupo técnico. Foi levado em conta a formação e a função.

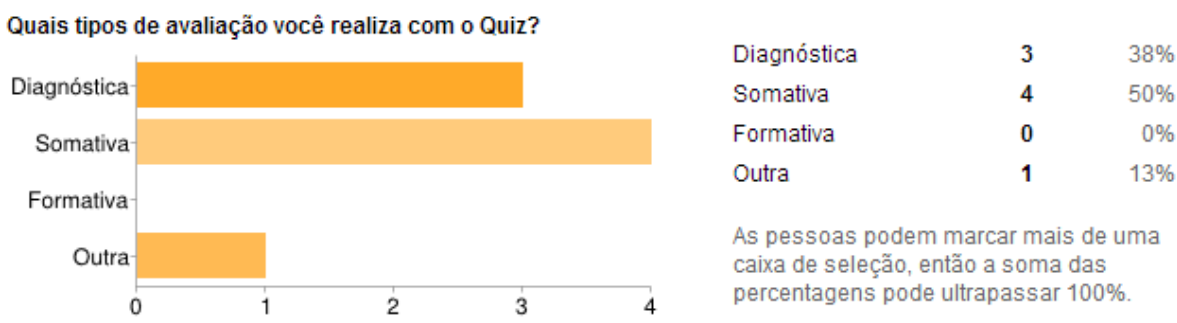

Figura A.16: Para qual tipo de avaliação?

Sexo

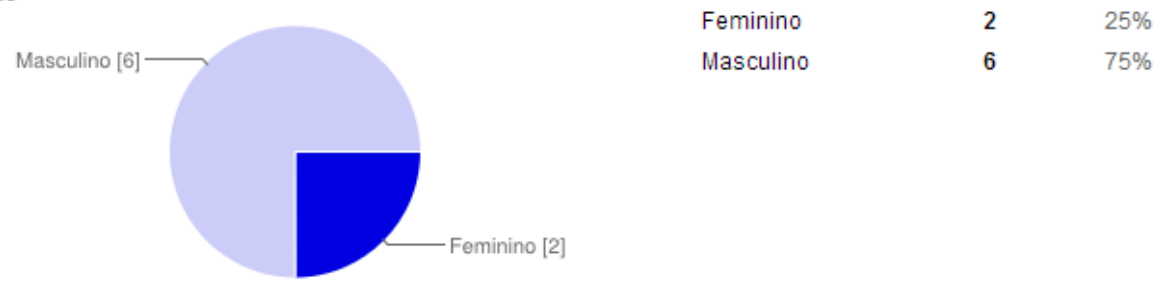

Figura A.17: Distribuição do gênero dos não professores

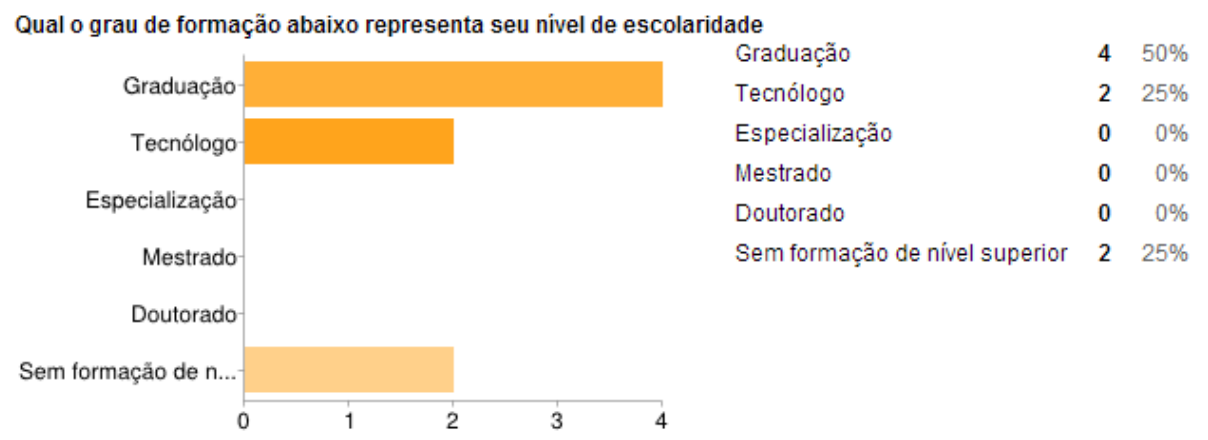

Figura A.18: Formação dos não professores 
Referente as afirmações abaixo, indique o seu grau de concordância sobre o que se diz do Quiz (atividade Questionário do Moodle) - A criação de questionários no Quiz é rápida

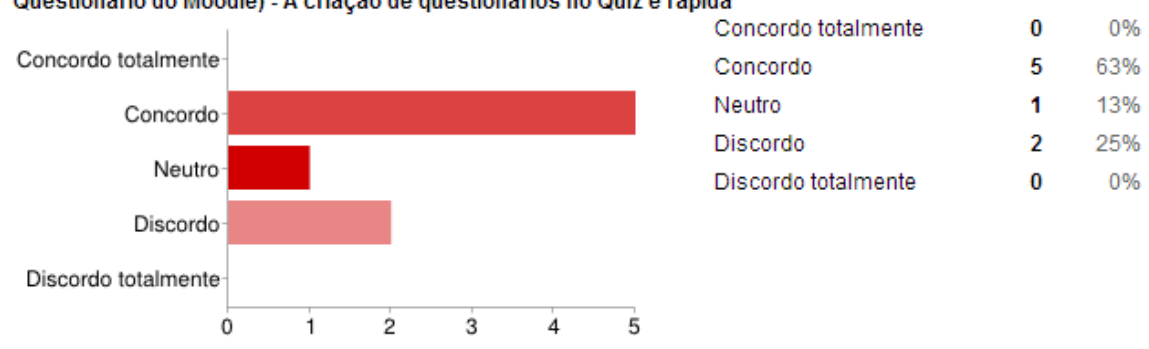

Referente as afirmações abaixo, indique o seu grau de concordância sobre o que se diz do Quiz (atividade Questionário do Moodle) - 0 processo de criação de um questionário no Quiz não é intuitivo

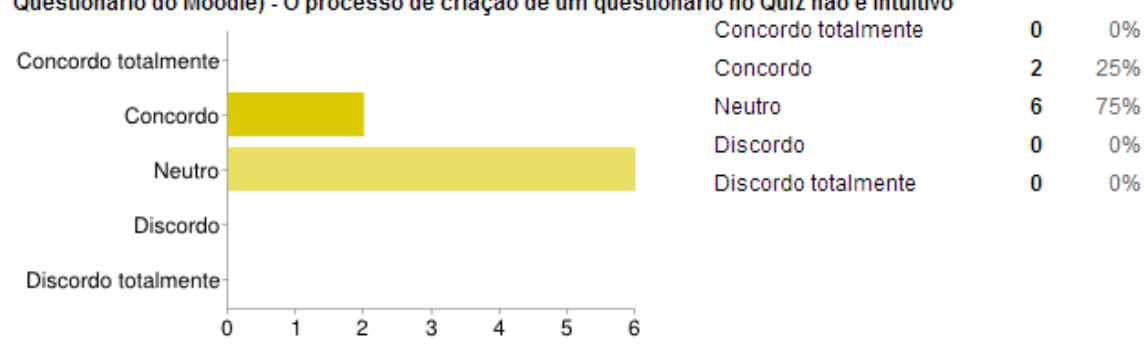

Figura A.19: Opnião sobre processo de criação de questionários dos não professores
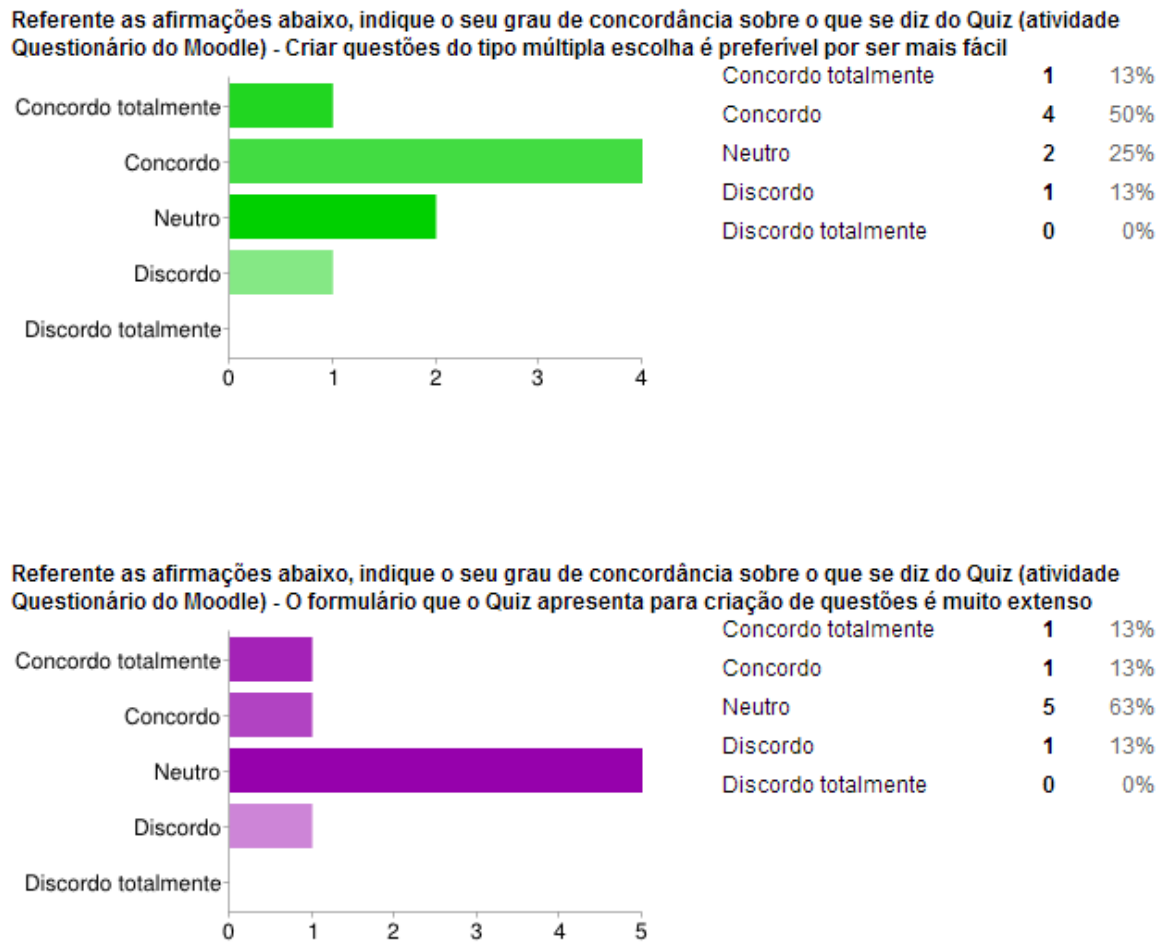

Figura A.20: Preferência dos não professores por questões múltipla escolha 
Referente as afirmações abaixo, indique o seu grau de concordância sobre o que se diz do Quiz (atividade Questionário do Moodle) - A maioria das pessoas aprende o Quiz rapidamente

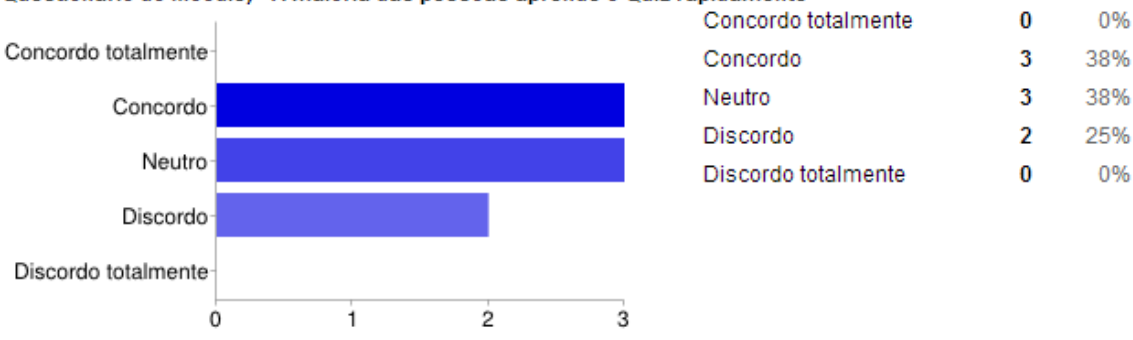

Referente as afirmações abaixo, indique o seu grau de concordância sobre o que se diz do Quiz (atividade Questionário do Moodle) - O Quiz possui todos os recursos necessários para criar questionários de avaliação

Concordo totalment

Concordo

$0 \%$

$\begin{array}{lll}\text { Concordo } & 5 & 63 \%\end{array}$

Neutro

Neutro

$25 \%$

Discordo

$113 \%$

Discordo

Discordo totalmente

$0 \quad 0 \%$

Discordo totalmente

\begin{tabular}{llllll}
\hline 0 & 1 & 2 & 3 & 4 & 5
\end{tabular}

Figura A.21: Aprendizagem do Quiz 


\section{Apêndice B}

\section{Contexto de sistema e usuários}

\begin{tabular}{l|l}
\hline \multicolumn{2}{c}{ Resumo do projeto } \\
\hline Questões & Verificar \\
\hline Qual é o sistema ou serviço? & $\begin{array}{l}\text { Um ambiente para autoria de questionários de } \\
\text { avaliação on-line }\end{array}$ \\
\hline $\begin{array}{l}\text { Que funções ou serviços o sistema pretende for- } \\
\text { necer? }\end{array}$ & $\begin{array}{l}\text { Criação de questionários para avaliação online, } \\
\text { questões com avaliação automática. }\end{array}$ \\
\hline Quais são os objetivos do projeto? & $\begin{array}{l}\text { Melhorar o processo de autoria de questionário, } \\
\text { Inserir os IMAS como tipos de questões, Forne- } \\
\text { cer uma interface intuitiva de fácil uso }\end{array}$ \\
\hline $\begin{array}{l}\text { Para quem o sistema é destinado? (Mercado } \\
\text { alvo) }\end{array}$ & $\begin{array}{l}\text { Instituições de ensino e professores autônomos. } \\
\text { Quem vai usar o sistema? }\end{array}$ \\
\hline Por que o sistema é necessário? & $\begin{array}{l}\text { Professores e criadores de conteúdo para cursos } \\
\text { on-line. }\end{array}$ \\
\hline Onde o sistema será usado? & $\begin{array}{l}\text { Suprir necessidade especificas e melhorar o pro- } \\
\text { cesso atual existente }\end{array}$ \\
\hline Como o sistema será usado? & $\begin{array}{l}\text { Nas escolas ou em qualquer local que tenha com- } \\
\text { putador e acesso a internet }\end{array}$ \\
\hline Como o usuário obtém o sistema? & $\begin{array}{l}\text { Da maneira usual com computador mouse e te- } \\
\text { clado ou com tablets }\end{array}$ \\
\hline Como o usuário aprende a usar o sistema? & $\begin{array}{l}\text { Obtém-se a partir da internet e instalação no } \\
\text { Moodle }\end{array}$ \\
\hline Como o sistema será instalado? & $\begin{array}{l}\text { A operação deverá ser intuitiva e auto explica- } \\
\text { tiva. Mas acompanha tutorial escrito e vídeo ? } \\
\text { tutorial }\end{array}$ \\
\hline Como o sistema será mantido? & $\begin{array}{l}\text { Um administrador ou responsável por uma ins- } \\
\text { talação moodle estará capacitado }\end{array}$ \\
\hline
\end{tabular}

Tabela B.1: Resumo do projeto 


\begin{tabular}{|c|c|c|}
\hline \multicolumn{3}{|c|}{ Usuários e Interessados } \\
\hline Usuário diretos & Papel no sistema ou uso do sistema & Expandir \\
\hline Professores & $\begin{array}{l}\text { Fazem uso direto e constante do sistema para } \\
\text { avaliar os seus alunos }\end{array}$ & $\mathrm{x}$ \\
\hline Criadores de conteúdo & $\begin{array}{l}\text { Criam módulos de aprendizagem como lições, } \\
\text { pacotes, scorm para ambientes online }\end{array}$ & $\mathrm{x}$ \\
\hline Administradores & $\begin{array}{l}\text { Instalam e configuram o sistema para utilização } \\
\text { dentro do ambiente online }\end{array}$ & \\
\hline Usuário indiretos & Objetivos/Tarefa & Expandir \\
\hline $\begin{array}{l}\text { Grupos de pesquisas, } \\
\text { desenvolvedores para } \\
\text { área educacional }\end{array}$ & $\begin{array}{l}\text { Os grupos de pesquisa e a comunidade de de- } \\
\text { senvolvedores podem implementar plugins para } \\
\text { o ambiente ou incluir em seus processos os bons } \\
\text { resultados alcançados no iQuiz }\end{array}$ & \\
\hline Alunos & $\begin{array}{l}\text { Terão acesso a novos tipos de questões, assim } \\
\text { como maior disponibilização de testes por parte } \\
\text { dos professores }\end{array}$ & \\
\hline
\end{tabular}

Tabela B.2: Usuários e Interessados

\begin{tabular}{|c|c|c|c|}
\hline \multicolumn{4}{|c|}{ Objetivo do usuário e tarefas } \\
\hline \multicolumn{4}{|l|}{ Sistema: iQuiz } \\
\hline & Professores & Equipe EAD & Administrador \\
\hline Criar questionário & $\mathrm{X}$ & $\mathrm{X}$ & \\
\hline Configurar questionário & $\mathrm{X}$ & $\mathrm{X}$ & \\
\hline Gerenciar banco de questões & $\mathrm{X}$ & $\mathrm{X}$ & \\
\hline Criar questões múltipla escolha & $\mathrm{X}$ & $\mathrm{X}$ & \\
\hline Instalar configurações e pacotes & & & $\mathrm{X}$ \\
\hline
\end{tabular}

Tabela B.3: Objetivos do usuário e tarefas 


\section{Características dos grupos de usuários}

\begin{tabular}{|c|c|}
\hline \multicolumn{2}{|l|}{ Grupo de usuário: Professores } \\
\hline Características & necessidades dos utilizadores potenciais \\
\hline \multicolumn{2}{|l|}{$\begin{array}{l}\text { Tamanho do grupo de usuários: Todos os profes- } \\
\text { sores envolvidos com aprendizagem online }\end{array}$} \\
\hline Faixa etária: 21 a 60 anos & $\begin{array}{l}\text { Levar em consideração que uma parcela dos pro- } \\
\text { fessores podem ter limitações por causa da idade }\end{array}$ \\
\hline Gênero: Masculino e Feminino & Incluir números iguais no teste de usabilidade \\
\hline Idioma e cultura: Português & $\begin{array}{l}\text { O protótipo será desenvolvido em Português, } \\
\text { mas utilizará o padrão multilinguagem supor- } \\
\text { tado pelo Moodle }\end{array}$ \\
\hline $\begin{array}{l}\text { Nível de escolaridade / qualificação: Graduados } \\
\text { e pós-graduados }\end{array}$ & $\begin{array}{l}\text { Nível educacional dos usuários não deve repre- } \\
\text { sentar restrição ao sistema }\end{array}$ \\
\hline $\begin{array}{l}\text { Limitações físicas / Deficiência: Incluir pessoas } \\
\text { com restrições pela idade }\end{array}$ & $\begin{array}{l}\text { Tratar aspectos da melhoria da apresentação das } \\
\text { telas em modo ampliado apresentar informações } \\
\text { e ícones maiores }\end{array}$ \\
\hline $\begin{array}{l}\text { Habilidades especiais (por exemplo, digitação, } \\
\text { uso do mouse, consciência espacial) }\end{array}$ & Não se aplica \\
\hline $\begin{array}{l}\text { Experiência com sistema similares: Não foi pos- } \\
\text { sível estimar a quantidade de usuários com este } \\
\text { tipo de experiência }\end{array}$ & $\begin{array}{l}\text { Desconsiderar experiências prévias para produ- } \\
\text { zir interface. }\end{array}$ \\
\hline \multicolumn{2}{|l|}{$\begin{array}{l}\text { Experiência em TI: acima de } 79 \% \text { tem boa fami- } \\
\text { liaridade }\end{array}$} \\
\hline $\begin{array}{l}\text { Conhecimento da tarefa: } 78 \% \text { dos usuários do } \\
\text { Moodle utilizam o Quiz }\end{array}$ & $\begin{array}{l}\text { Censo EAD ABED (2012) aponta que } 63 \% \text { das } \\
\text { instituições utiliza o próprio pessoal de EAD } \\
\text { para produzir conteúdo (professor, tutor, coor- } \\
\text { denador) apoiado por especialista em conteúdo. } \\
\text { Embora os professores que utilizam o Quiz já co- } \\
\text { nheçam a tarefa, a interface não deve levar esse } \\
\text { conhecimento em consideração. }\end{array}$ \\
\hline $\begin{array}{l}\text { Formação anterior: Necessita de esclarecimentos } \\
\text { conceituais sobre o uso dos tipos de questões. }\end{array}$ & $\begin{array}{l}\text { Fazer vídeos tutoriais e aplicar linguagem mais } \\
\text { clara nos textos de ajuda. }\end{array}$ \\
\hline \multicolumn{2}{|l|}{$\begin{array}{l}\text { Frequência de uso: pode ser muito freqüente de- } \\
\text { pendente da facilidade de utilização. }\end{array}$} \\
\hline $\begin{array}{l}\text { Motivação para usar: Diminuição de trabalho } \\
\text { acompanhamento do progresso dos alunos. }\end{array}$ & $\begin{array}{l}\text { Facilitar o fluxo das tarefas e diminuir o tempo } \\
\text { e o trabalho na autoria. }\end{array}$ \\
\hline $\begin{array}{l}\text { Prováveis preocupações: Preocupa-se em fazer } \\
\text { algo irreversível ou inapropriado, fraude / plá- } \\
\text { gio }\end{array}$ & $\begin{array}{l}\text { Deixar claro a possibilidade de desfazer um pro- } \\
\text { cesso. }\end{array}$ \\
\hline $\begin{array}{l}\text { Outras características relevantes: Pouco tempo } \\
\text { disponível e muitas tarefas a fazer }\end{array}$ & \\
\hline
\end{tabular}

Tabela B.4: Grupos de usuários 


\section{Ambiente Técnico}

Nome do sistema: iQuiz

Professores, desenvolvedores de conteúdo

Características

Hardware que o usuário poderá interagir PCs, MAC, Desktops, Notebook, Netebook e Tablets

Ambiente de software em que o sistema será executado por exemplo, Windows browser wwww: navegadores WEB

Ambiente de software a ser usado para desenvolver o sistema: HTMLs, Java, Script, PHP, Maquetta, NetBeans / Eclipse

Outro equipamento necessário para a utilização em paralelo com sistema

Materiais de referência necessário, quer para executar tarefas com o sistema ou para aprender sobre ou sistema de operar: Sistema de ajuda on-line e vídeo-tutorial

necessidades dos utilizadores potenciais

O sistema é multiplataforma.

Garantir o funcionamento nos principais navega-

dores I. E., Firefox, Chrome

Uso de IDE para o desenvolvimento dos scripts

e modelagem da interface com Maquetta.

Será necessário um servidor web com moodle.

A interface deve ser o mais auto explicativa possível e contar com o suporte do sistema de ajuda.

Tabela B.5: Ambiente Técnico 


\section{Apêndice C}

\section{Etapas para criação de um questionário no Quiz}

Os passos para se construir um questionário é iniciado pela introdução das questões ao banco de questões. Se as questões já estiverem criadas, então segue-se para o segundo passo, criar a atividade questionário. Para completar o processo de criação da atividade é necessário inserir dados sobre a configuração do questionário, iniciando pelo preenchimento de campos como o título do questionário (nome do teste), descrição, data de abertura e encerramento, método para atribuição de notas e vários outros campos relacionados ao comportamento do questionário, tais como tipo de feedback forma de visualização, segurança etc. Como pode ser observado, quando o usuário intenciona criar o questionário na verdade ele está configurando, ou seja, definindo como e quando o questionário deve ser disponibilizado aos alunos e somente depois as questões são incluídas nele. Entretanto se o usuário ainda não criou as questões, poderá fazê-lo na etapa seguinte, a edição do questionário.

As Figuras C.1, C.2 e C.3 ilustram a sequência de passos que um professor no Moodle precisa realizar para inserir uma atividade ou recurso ao seu curso. As figuras apresentadas nos exemplos foram geradas no Moodle versão 2.5.

Primeiro é preciso ativar o modo de edição, acionando o botão (Ativar edição) no canto superior da tela.

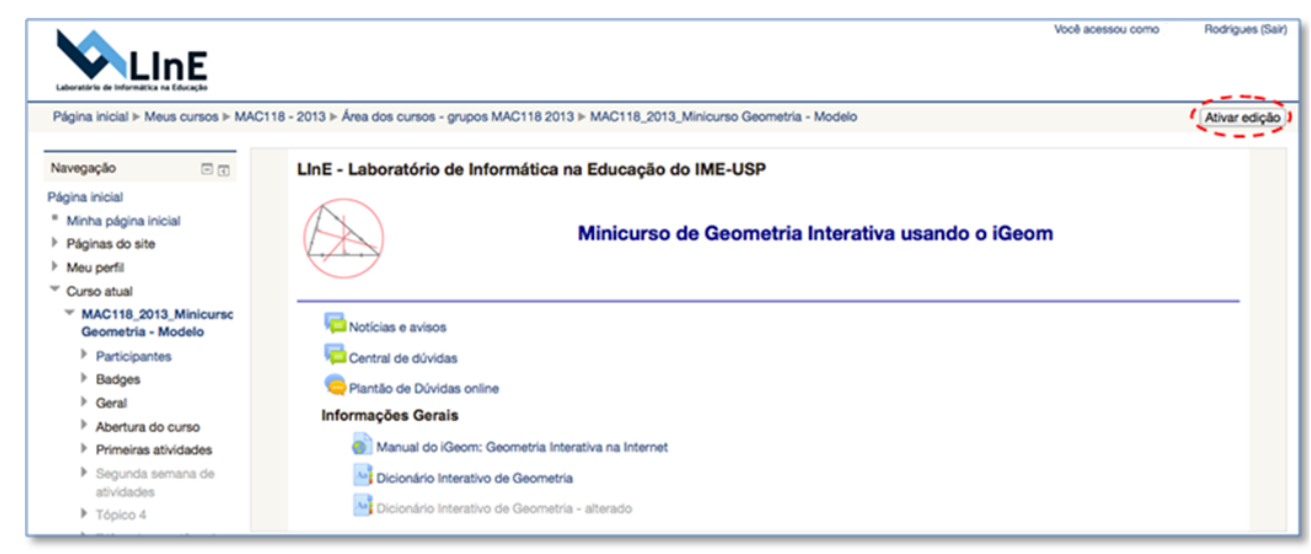

Figura C.1: Ativar modo de edição

Após o acionamento do botão para ativar a edição surge a opção (+Adicionar uma atividade ou recurso) ao final de cada bloco do curso no canto inferior da tela. 


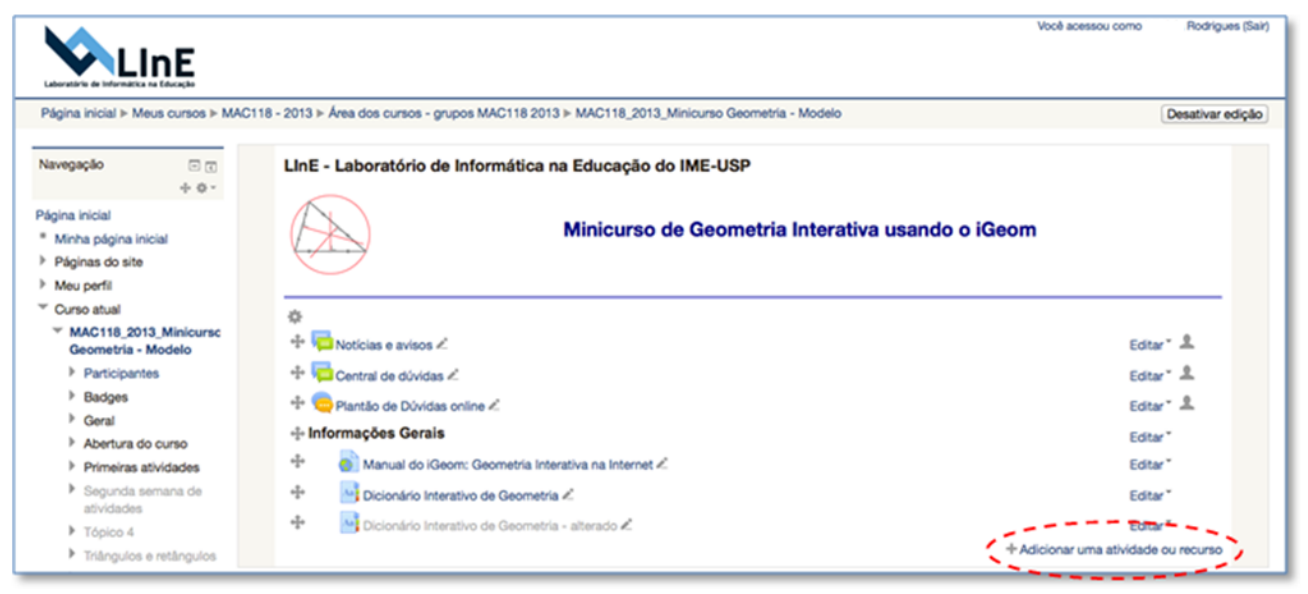

Figura C.2: Adicionar uma atividade ou recurso

Após o botão para adicionar a atividade ser acionado, então é apresentado uma tela com a lista de atividades ou recursos instalados e disponíveis no Moodle.

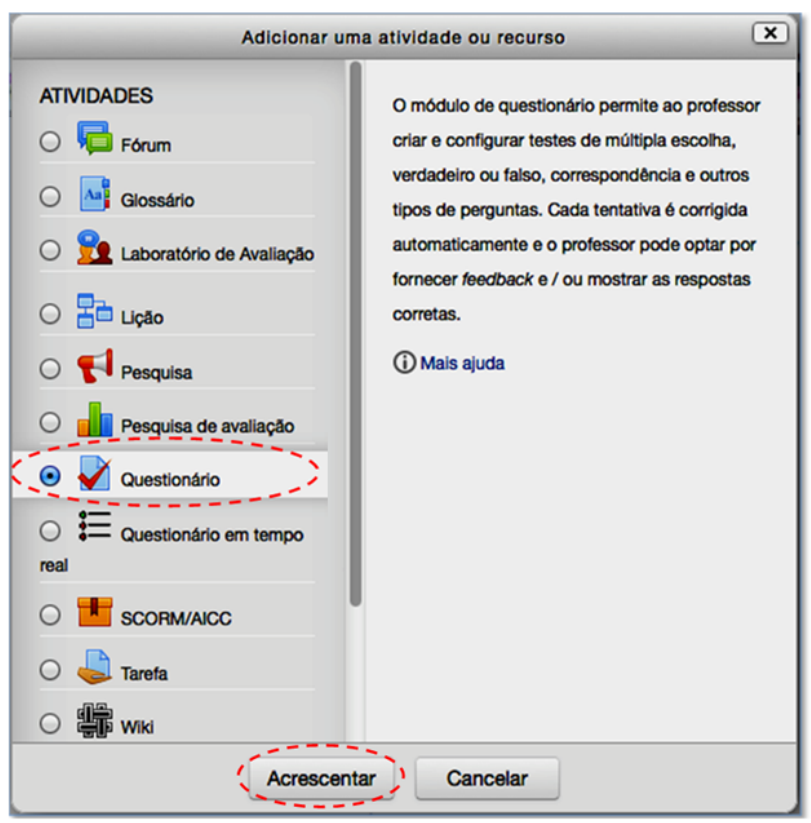

Figura C.3: Selecionar o questionário

Quando o professor escolhe a opção (Questionário) e aciona o botão (Acrescentar), uma nova janela é apresentada e inicia-se o processo de configuração do questionário.

A Figura C.4 apresenta o primeiro bloco de uma sequência deles para ser preenchido, somente depois deste processo o professor inicia a inserção das perguntas no questionário. A partir da versão 2.5, o Moodle agrupou em blocos as opções de configuração, esses blocos ficam geralmente fechados, mas podem ser expandidos um por um ou todos de uma só vez. O ponto negativo do questionário com os blocos expandidos é o trabalho de rolagem, costuma ser desmotivador para o professor. Já os blocos contraídos obrigam os professores a dar mais um clique para cada bloco durante a configuração, mas torna a tela mais amigável e organizada.

\section{C.1 Configuração do questionário}

Geral: permite atribuir um nome e inserir uma breve introdução sobre o questionário que está sendo criado; 


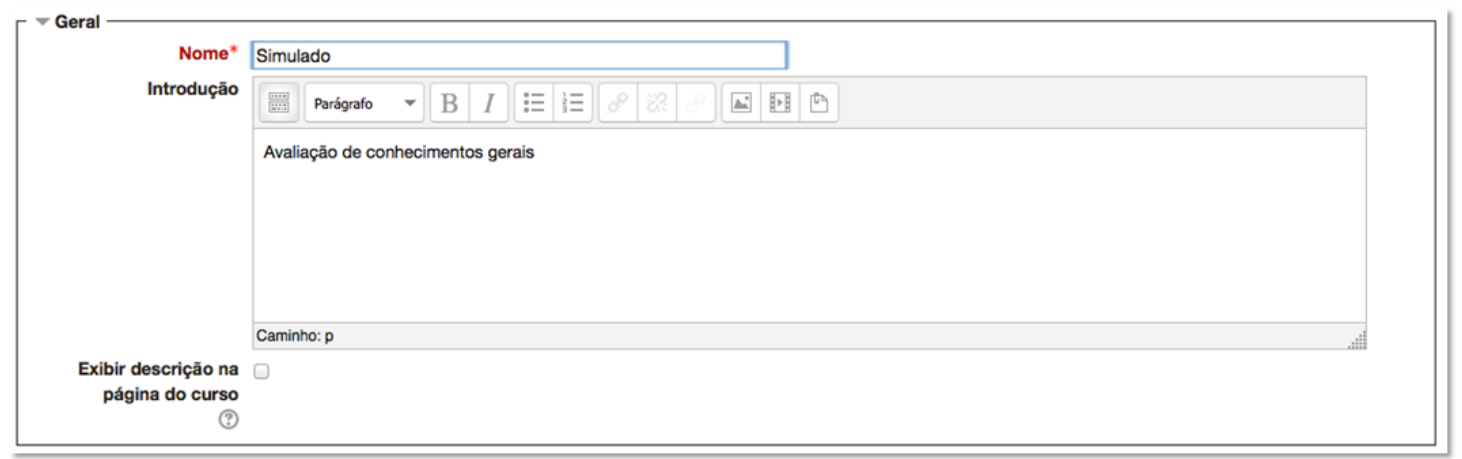

Figura C.4: Bloco geral

Duração: este bloco permite atribuir a data e o horário de abertura e encerramento do questionário, o tempo que o aluno terá para concluir o questionário e o período que o questionário ficará liberado para o envio da atividade.

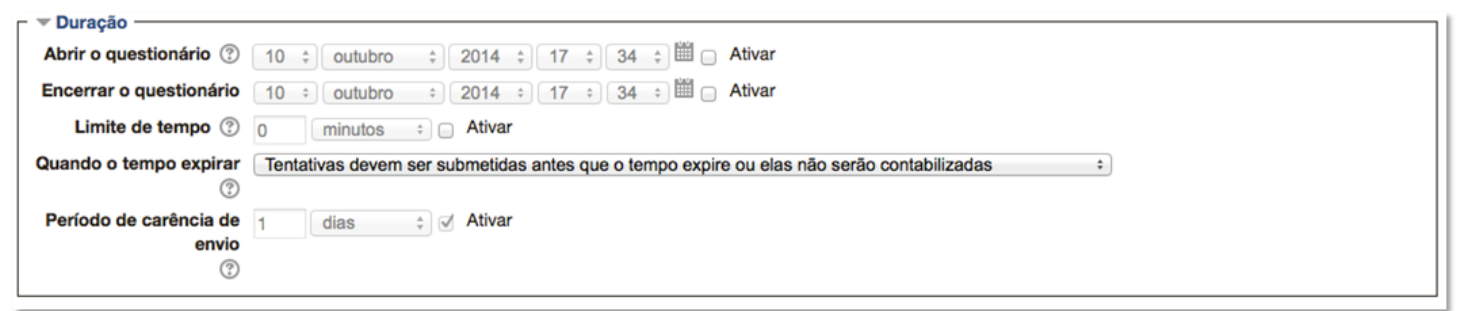

Figura C.5: Bloco duração

Nota: neste bloco, é possível categorizar as notas através da categoria de notas, ou seja, definir por exemplo se a nota atribuída será como trabalho, prova ou outra atividade; é possível ainda limitar o número de tentativas que será permitido ao aluno ou definir como a nota do aluno será calculada.

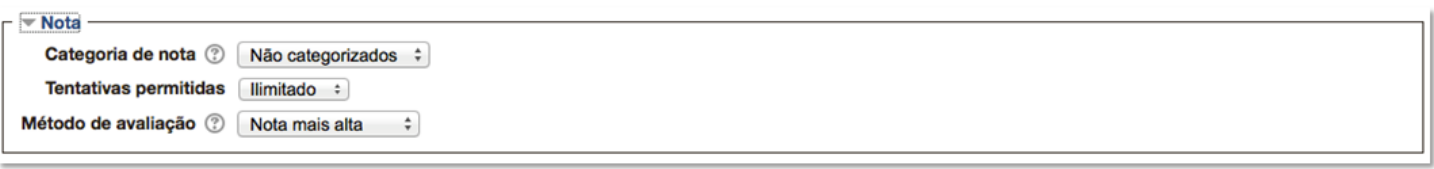

Figura C.6: Bloco nota

Layout: possibilita configurar como as perguntas aparecerão para o estudante, ou seja, se sempre aparecerão na mesma ordem ou em ordem aleatória; pode-se definir também o número de perguntas por página, isso geralmente é usado quando o questionário possui muitas questões.

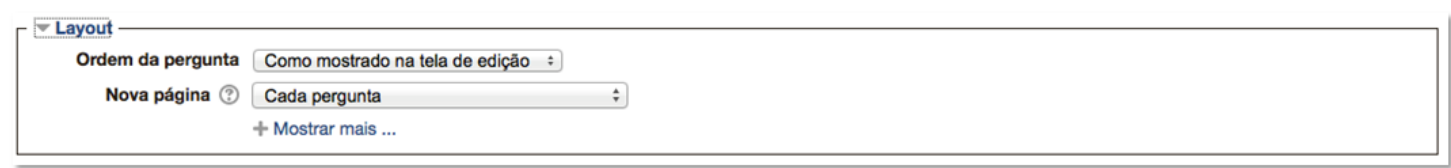

Figura C.7: Bloco layout

Comportamento da questão: por meio desse bloco pode-se configurar as alternativas para que apareçam em ordem aleatória para o aluno, ou seja, a cada vez que o aluno iniciar a questão as alternativas aparecerão em posições diferentes; pode-se ainda dizer como a questão se comportará, 
determinando como os alunos interagem com o questionário, podendo configurá-lo como feedback adiado, nesse caso o aluno submete o questionário inteiro, antes de ser avaliado, ou ainda pode-se configurar o feedback imediato, a cada questão concluída o aluno receberá uma mensagem positiva ou negativa de sua resposta ou no modo interativo com múltiplas tentativas, onde o aluno que não acertar na primeira tentativa terá uma nova chance para responder a questão, porém a cada nova tentativa sua nota será diminuída. Os detalhes da pontuação ou dicas é definido durante a criação da questão.

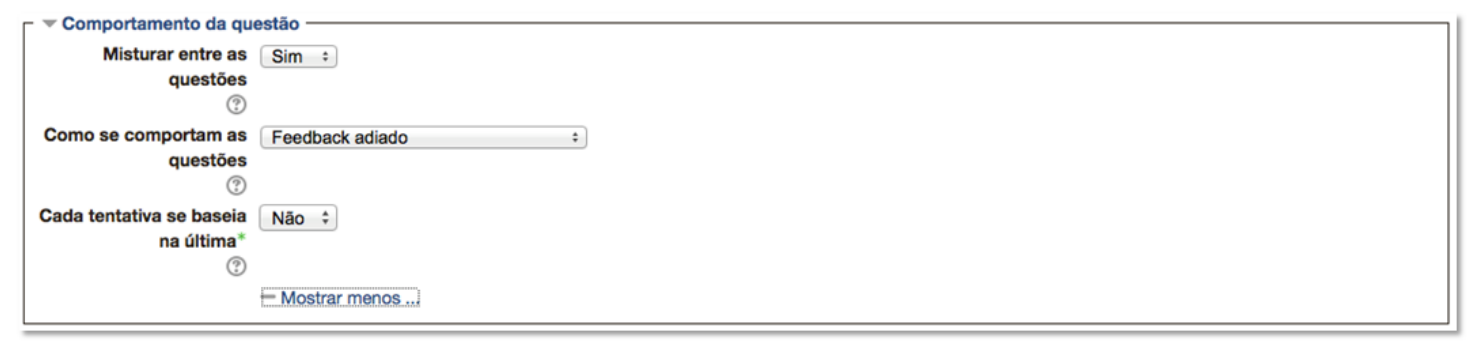

Figura C.8: Bloco comportamento da questão

Opções de revisão: neste bloco configura-se quais informações serão mostradas aos alunos durante e depois de responder o questionário e também informações que serão visualizadas quando o questionário estiver aberto ou depois quando ele já estiver encerrado.

\begin{tabular}{|c|c|c|c|}
\hline Durante a tentativa & Após a tentativa & $\begin{array}{l}\text { Mais tarde, enquanto ainda estiver } \\
\text { aberto }\end{array}$ & $\begin{array}{l}\text { Depois do fechamento do } \\
\text { questionário }\end{array}$ \\
\hline$\checkmark$ A tentativa (?) & A tentativa & A tentativa & A tentativa \\
\hline$\checkmark$ Acertos/Erros (?) & (v) Acertos/Erros & ( Acertos/Erros & (v) Acertos/Erros \\
\hline$\checkmark$ Notas (?) & $\searrow$ Notas & $\nabla$ Notas & $\approx$ Notas \\
\hline$\checkmark$ Feedback especifico (?) & Feedback específico & Feedback especifico & 『 Feedback especifico \\
\hline$\checkmark$ Feedback geral (?) & $\nabla$ Feedback geral & Feedback geral & Feedback geral \\
\hline$\checkmark$ Reposta correta (?) & 『 Reposta correta & 『 Reposta correta & هeposta correta \\
\hline Feedback final ? & $\nabla$ Feedback final & Feedback final & F Feedback final \\
\hline
\end{tabular}

Figura C.9: Bloco opções de revisão

Visualização: permite configurar se a foto do aluno será mostrada durante a tentativa de resposta ou na revisão, além de poder configurar quantas casas decimais será atribuída a nota do aluno.

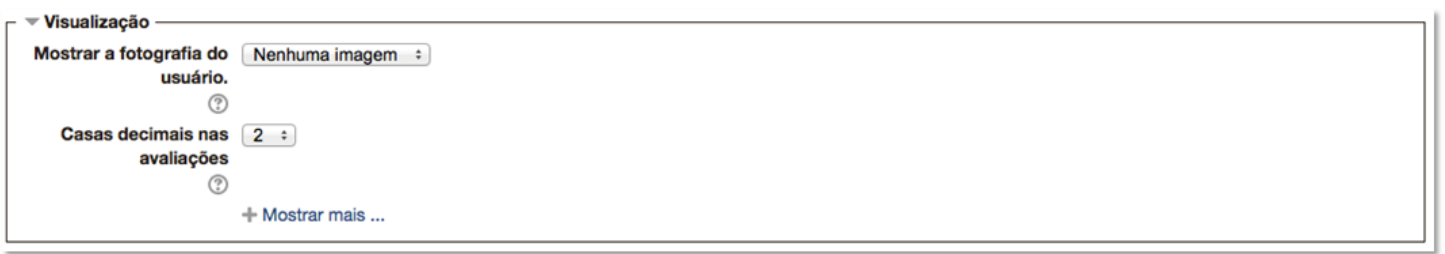

Figura C.10: Bloco visualização

Restrições extras nas tentativas: permite configurar uma senha para o acesso ao questionário, restringir o acesso ao questionário especificando endereços de IP, determinar um tempo mínimo entre as tentativas para responder o questionário ou possibilitar (quando o JavaScript está habilitado) apresentação do questionário em tela cheia, sem controles de navegação e atalhos, impedindo os estudantes de utilizarem recursos como copiar e colar. 


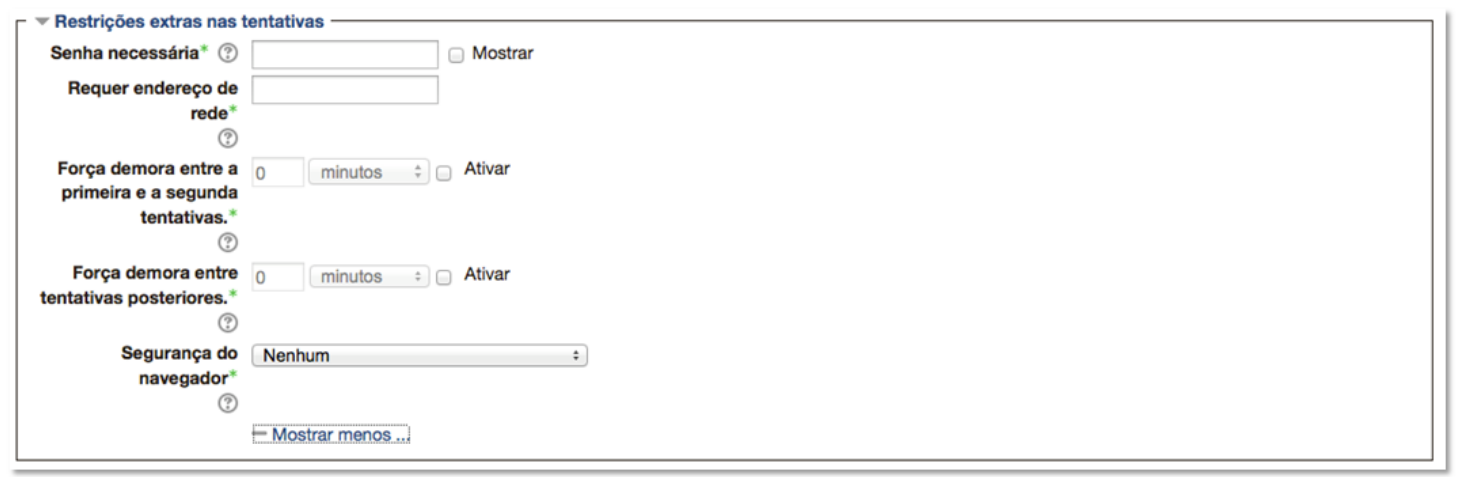

Figura C.11: Bloco restrições extras nas tentativas

Feedback geral: possibilita configurar uma mensagem que irá aparecer para o aluno quando ele terminar de responder o questionário, esse mensagem pode ser vinculada ao desempenho do aluno, por exemplo, se o questionário vale 100\%, e o aluno obteve essa pontuação a mensagem configurada pode ser "Parabéns, você foi excelente.", se o aluno obteve $70 \%$ a mensagem pode ser "Você foi muito bem, mas pode melhorar ainda mais!", na tela aparece 5 campos para colocar feedback e o limite de notas, mas caso seja necessário é possível adicionar mais campos.

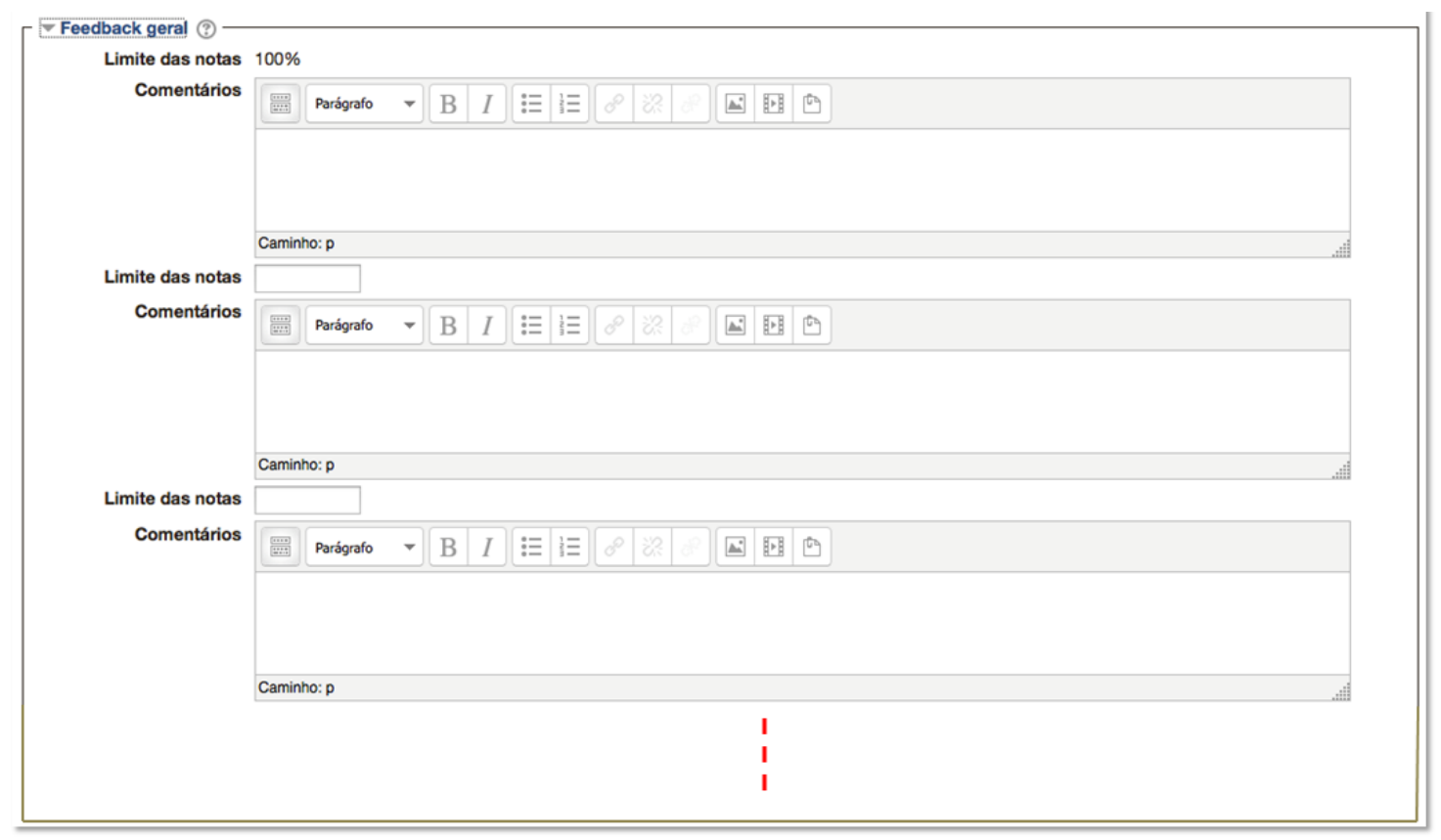

Figura C.12: Bloco feedback geral

Configurações comum de módulo: é possível configurar se a atividade ficará visível ou não ao aluno.

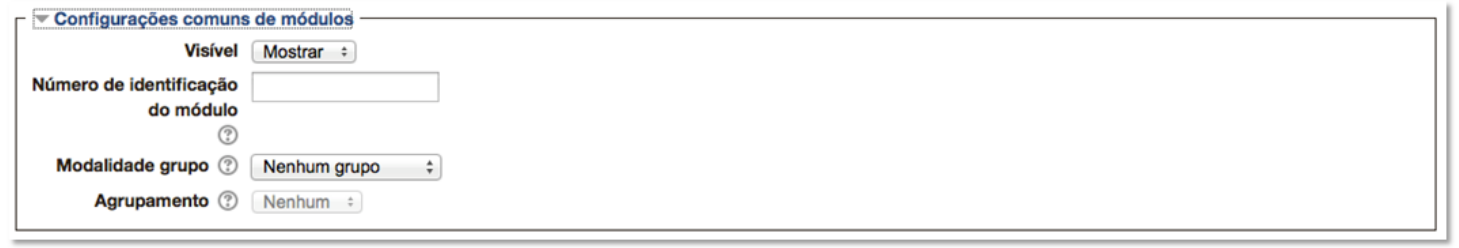

Figura C.13: Bloco configurações comum de módulo 


\section{C.1.1 Inserção das questões no questionário}

Após o questionário ser gravado com a opção (Salvar e Mostrar) ou ser gravado e acessado pela área de atividades do curso, a tela ilustrada na Figura C.14 será apresentada.

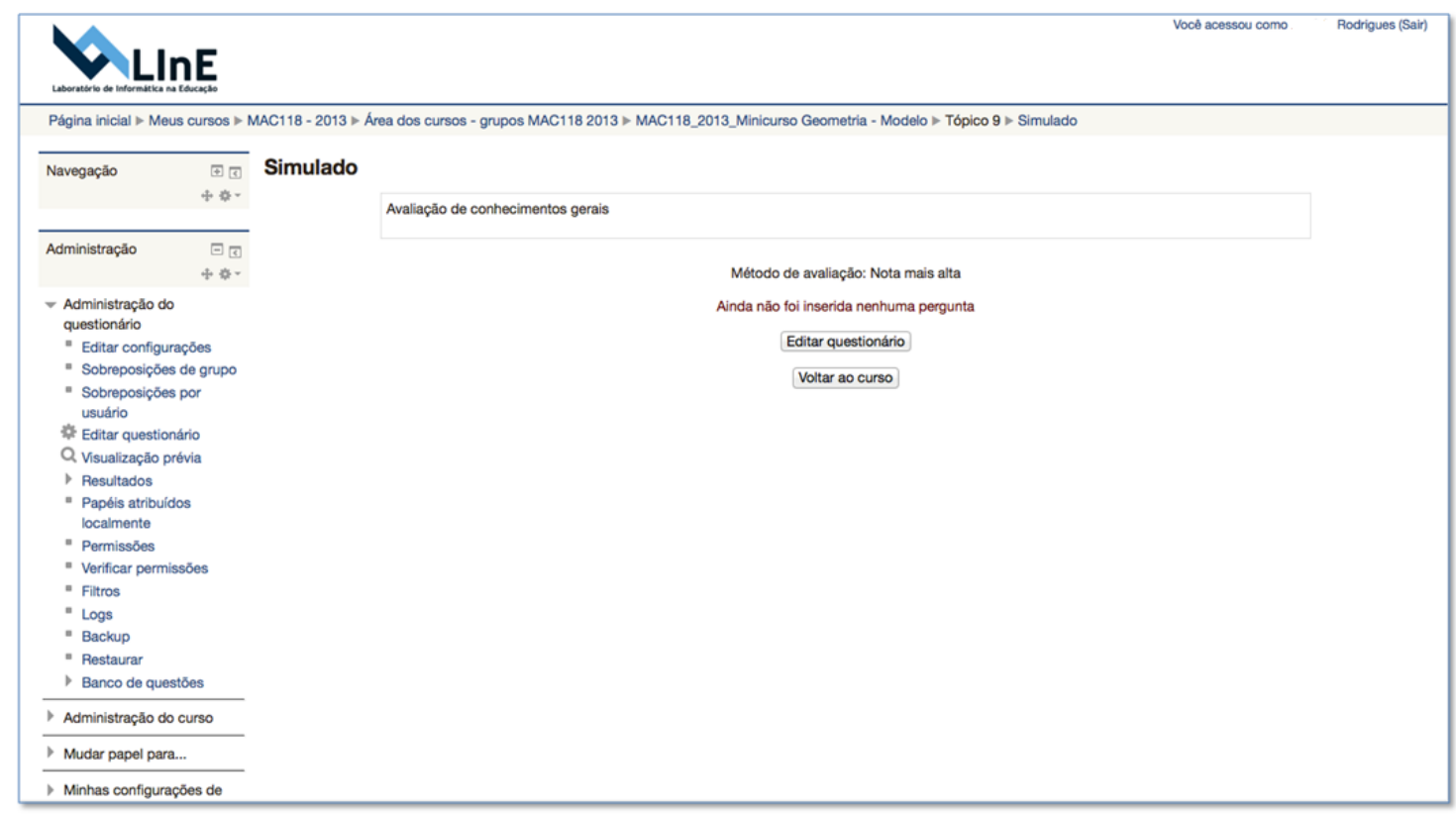

Figura C.14: Inserir questões ao questionário

Neste passo do processo ainda não existem questões dentro do questionário, por isso o professor será obrigado a acionar a opção (Editar questionário) disponibilizada no centro da tela ou selecionála no menu administração, neste exemplo posicionado na lateral esquerda da tela. O próximo passo é ilustrado pela Figura C.15.

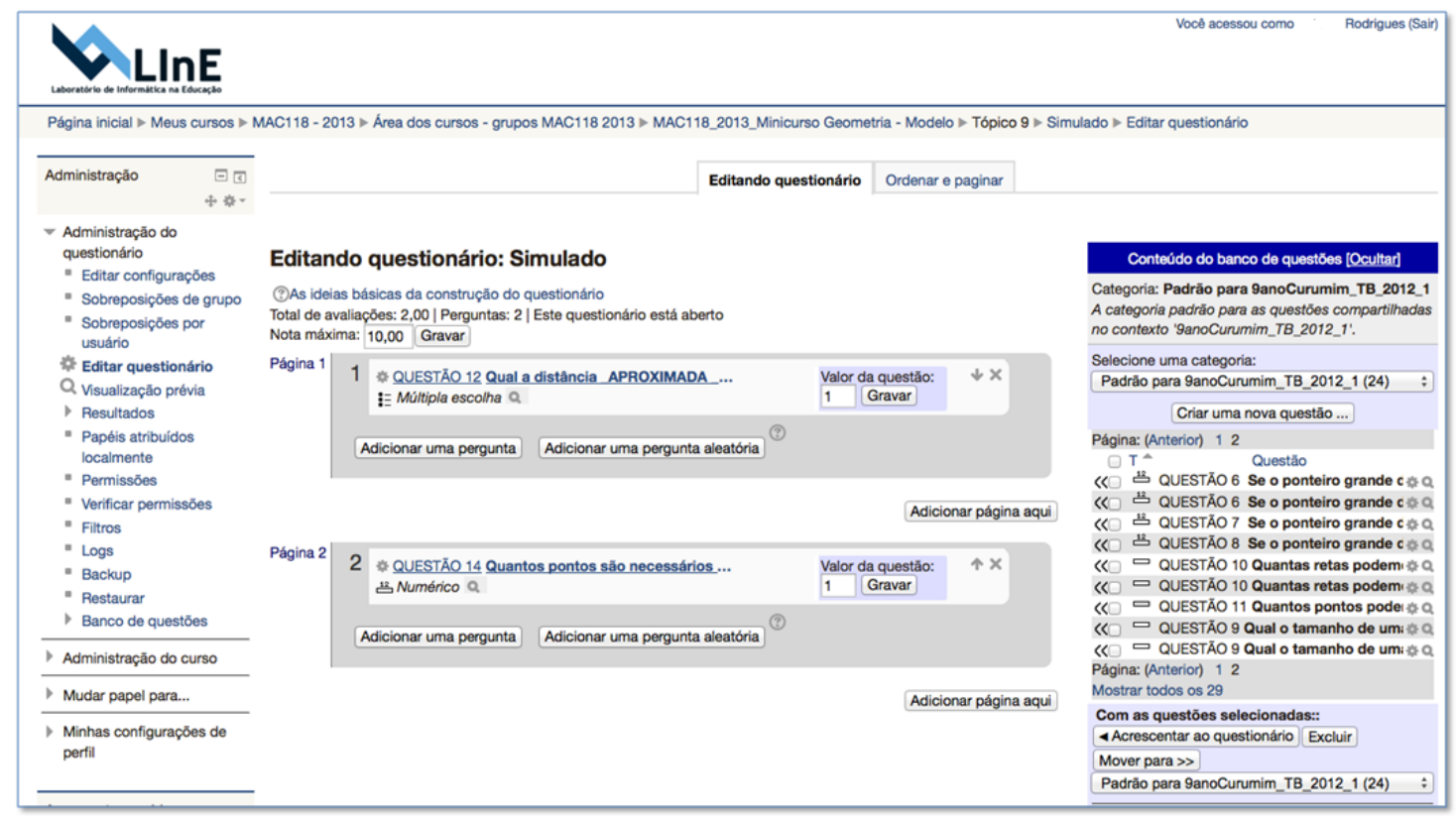

Figura C.15: Editar um questionário

No topo da tela mostrado na Figura C.15, é apresentado o nome do questionário que está em edição e logo abaixo são apresentadas informações com o número de questões no questionário, o total das notas das questões inseridas e a nota máxima do questionário. Em seguida é apresentado um 
quadro para cada questão, dentro do quadro um breve trecho da questão é apresentado, juntamente com o titulo, o tipo, a pontuação e logo abaixo dois botões: um para criar uma nova questão e adicioná-la imediatamente no questionário e no banco de questões e outro para inserir uma questão escolhida aleatoriamente pelo sistema, bastando ser especificado uma categoria.

$\mathrm{Na}$ lateral direita da tela é apresentado o banco de questões, neste bloco o professor pode selecionar uma categoria e escolher questões prontas da lista apresentada ou criar uma nova questão para ser inserida naquele momento no banco de questões e depois poderá ser selecionada para ser inserida no questionário. Uma forma mais rápida é escolher o botão (Adicionar uma pergunta) que depois de criada a questão, faz a inserção tanto no banco quanto no questionário.

\section{C.1.2 Criação das questões}

A criação de questões no Quiz também pode ser realizada durante a edição do questionário, mas sempre serão inseridas primeiro no banco de questões e depois utilizadas para compor o questionário. A Figura C.16 ilustra essa etapa, que consiste em acessar o banco de questões, a partir da página principal do curso, em seguida selecionar ou criar uma categoria, depois escolher o tipo de questão e por último preencher o formulário da questão. 


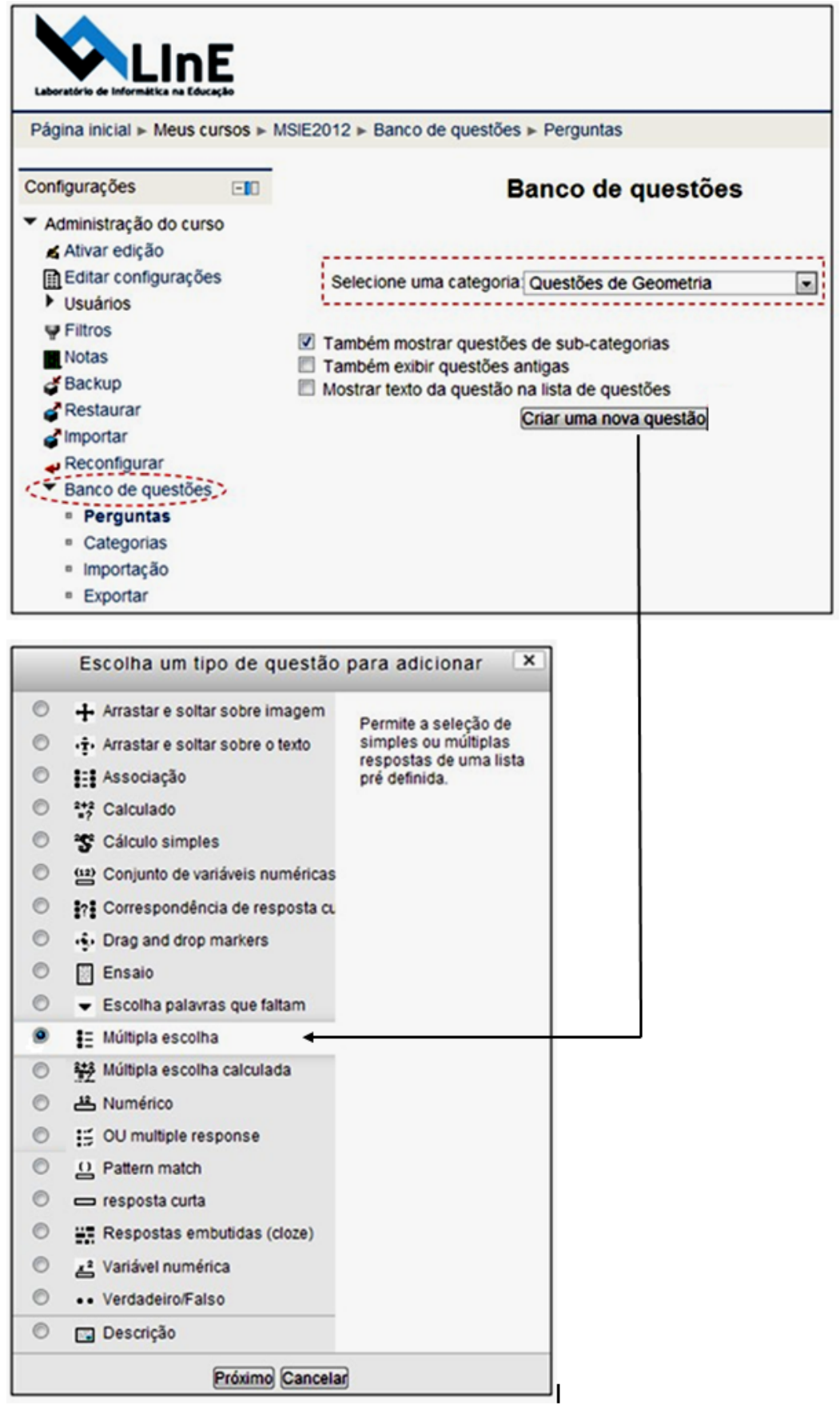

Figura C.16: Inclusão de perguntas ao banco de questões

Para ilustrar o preenchimento do formulário com os dados de uma questão, será apresentado o processo para criação de uma questão do tipo múltipla escolha, o tipo de questão mais utilizada pelos usuários do Moodle. Assim como ocorre com a configuração do questionário o formulário das questões também são agrupados em blocos e podem ser expandidos um por um ou todos de uma só vez. A seguir será detalhado cada um deles, iniciando pelo bloco (Geral) apresentado na Figura C.17.

Geral: este bloco permite definir em qual categoria a questão será inserida, um nome para a questão, o enunciado da questão, a pontuação, configurar o feedback geral, ativar a opção de uma ou múltiplas escolhas, misturar opções e ainda configurar se as opções de repostas serão numeradas ou sem numeração. 


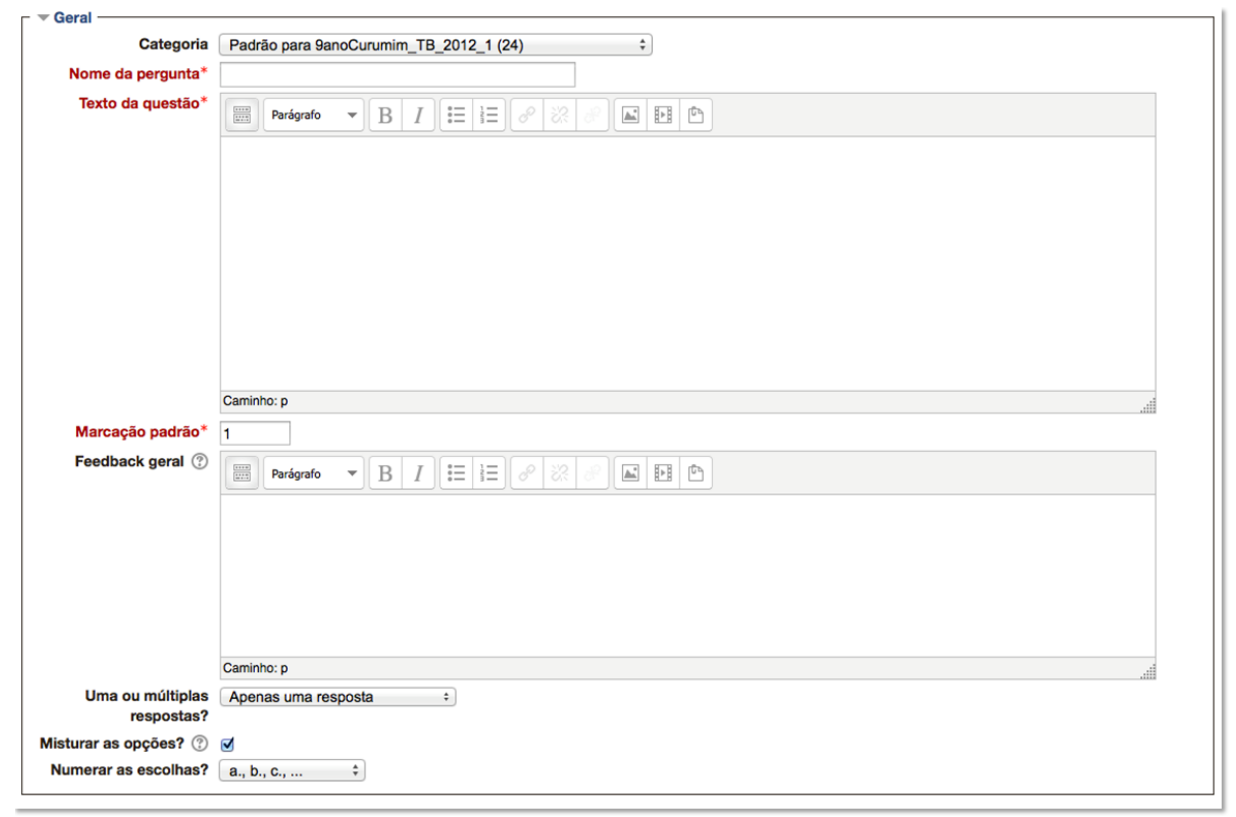

Figura C.17: Bloco geral

Respostas: este bloco, representado pela Figura C.18 é utilizado para inserir as alternativas da questão; nesse campo é possível também atribuir o grau de acerto, sendo $100 \%$ para representar uma única resposta correta e (Nenhum) uma resposta errada. Quando a opção múltiplas respostas é definida no bloco (Geral), pode-se ter por exemplo duas resposta onde a primeira pode valer $30 \%$ e a segunda $70 \%$ perfazendo $100 \%$ de acerto para a questão inteira. O mesmo é válido para os valores negativos entre -5\% a -100\%. Também é possível inserir um feedback específico para cada alternativa, diferente do feedback geral disponível no bloco (Geral), este tipo de comentário é atribuído a cada alternativa. Assim toda vez que o aluno responder uma questão, uma mensagem específica será apresentada ao lado da alternativa. Já no feedback geral, a mensagem é única, independente da alternativa escolhida e geralmente fornece informações ou orientações sobre a questão.

$\mathrm{Na}$ ilustração apenas alguns blocos são mostrados, mas são cinco, o número de blocos que aparecem inicialmente para se inserir as alternativas, depois podem ser acrescentados outros três por vez. Como pode ser observado, dentro de cada bloco é apresentado repetidamente a barra de ferramentas para edição em cada campo do tipo texto. Essa prática ocorre em todos os blocos do formulário de questões e também durante a configuração do questionário.

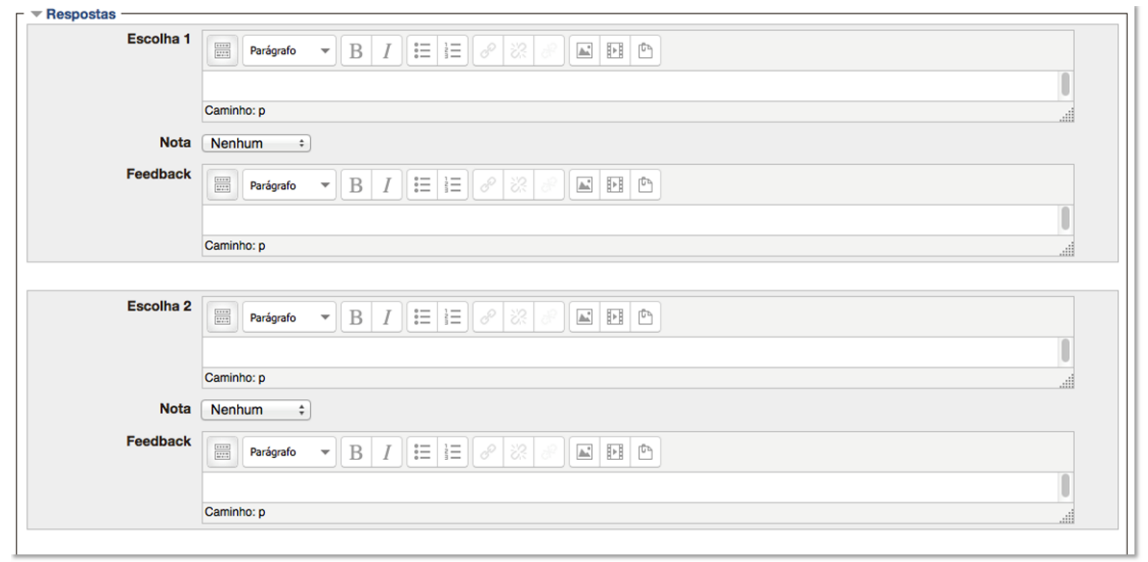

Figura C.18: Bloco repostas

Feedback combinado: neste bloco é possível inserir mensagens para quando uma resposta estiver correta, incorreta ou parcialmente correta. Uma resposta será considerada parcialmente correta 
quando pelo menos uma das respostas de uma questão com múltiplas respostas for respondida.

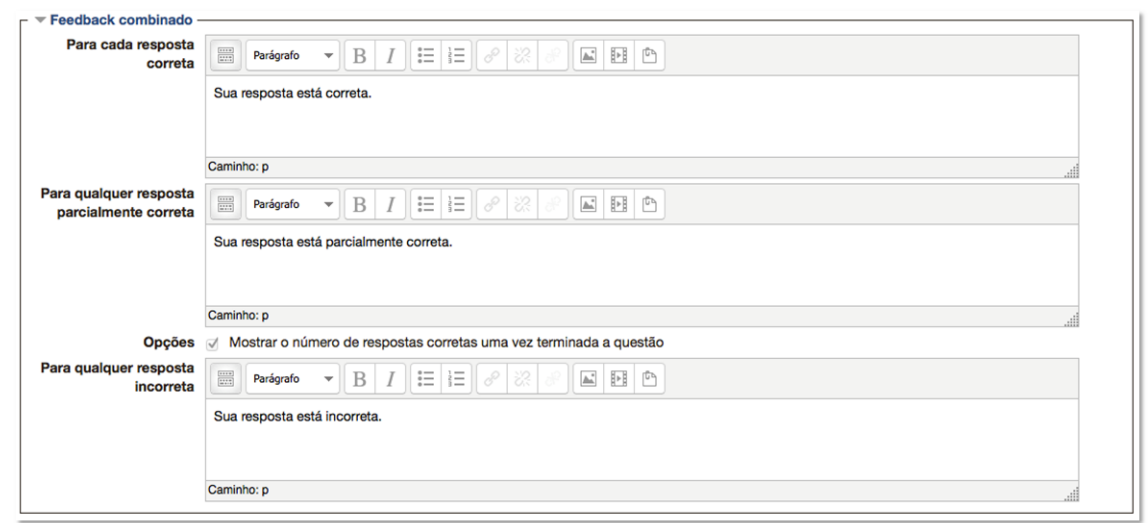

Figura C.19: Bloco feedback combinado

Definição para múltiplas tentativas: este bloco permite definir uma penalidade para cada tentativa de resposta incorreta, seguido de uma dica. Neste caso uma dica é um comentário que favorece o aluno no acerto da questão, a cada nova tentativa o aluno é punido com a diminuição da sua nota.

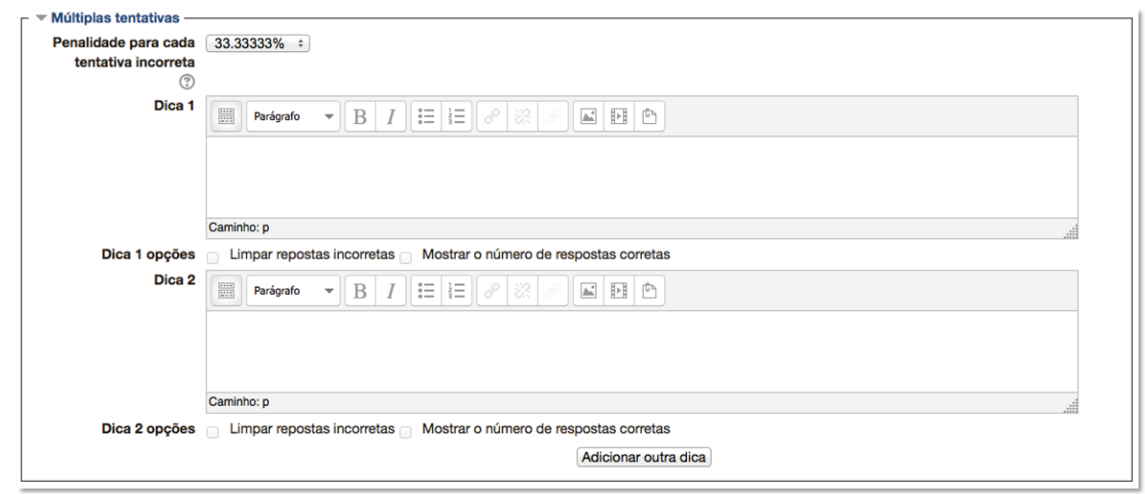

Figura C.20: Bloco definição para múltiplas tentativas

Este passo finaliza o fluxo das tarefa criar questionário e criar questões do tipo múltipla escolha. Algumas questões possuem o fluxo muito parecido com da questão múltipla escolha, entretanto outras como o tipo Calculada, pode apresentar um fluxo diferenciado, mais trabalhoso e complexo. 


\section{Apêndice D}

\section{Etapas para criação de um questionário no iQuiz}

Para criar um questionário no iQuiz é preciso primeiro ativar o modo de edição de atividades na página inicial do curso, acionando o botão (Ativar edição) no canto superior da tela, como mostra a Figura D.1

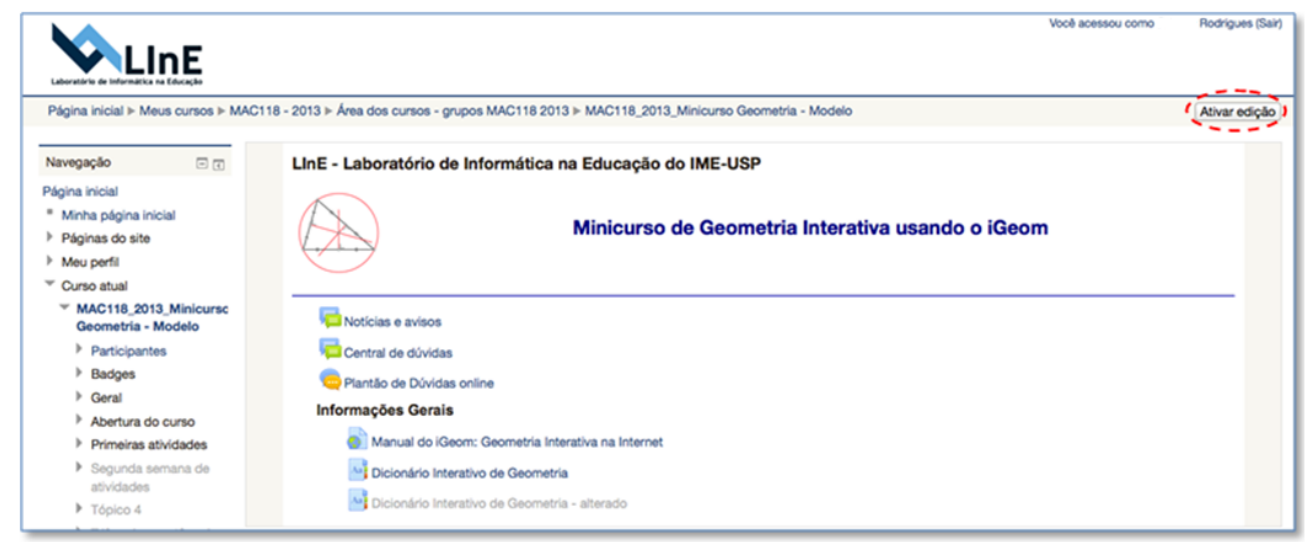

Figura D.1: Ativar modo de edição

Após acionar o botão ativar edição, surge na parte inferior da tela a opção ( + Adicionar uma atividade), ilustrada na Figura D.2

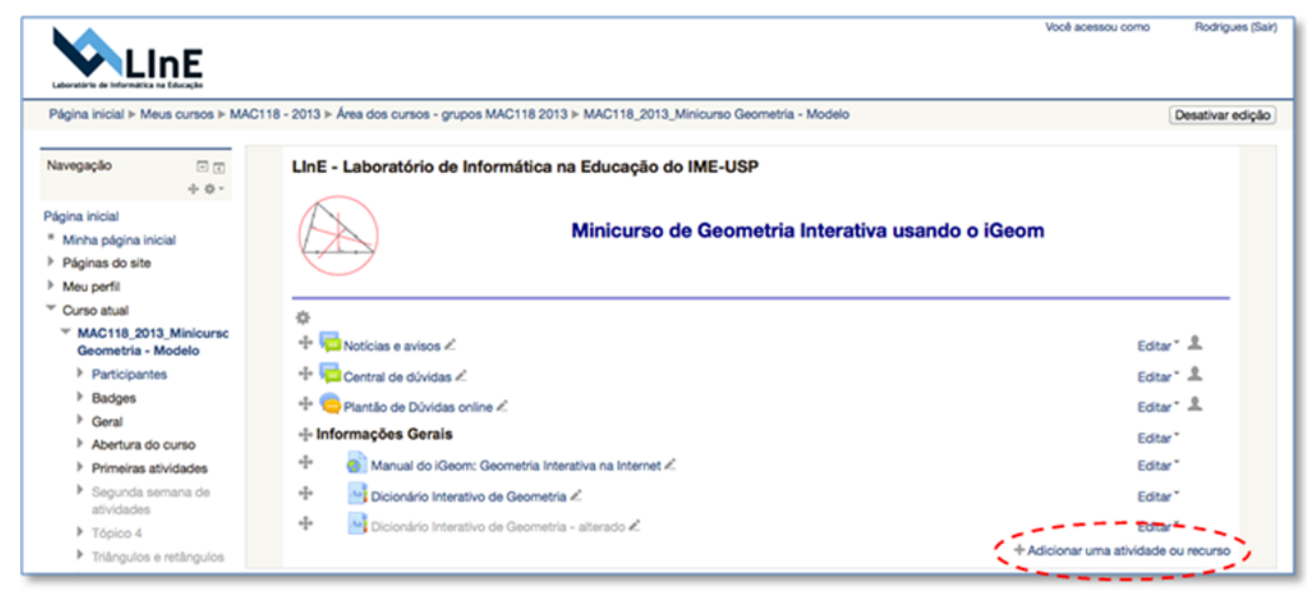

Figura D.2: Adicionar uma atividade ou recurso

Após o botão adicionar a atividade ser acionado, a Figura D.3 ilustra a tela com a lista de 
atividades ou recursos instalados e disponíveis no Moodle. Nessa tela é possível selecionar a atividade desejada, nesse caso o iQuiz.

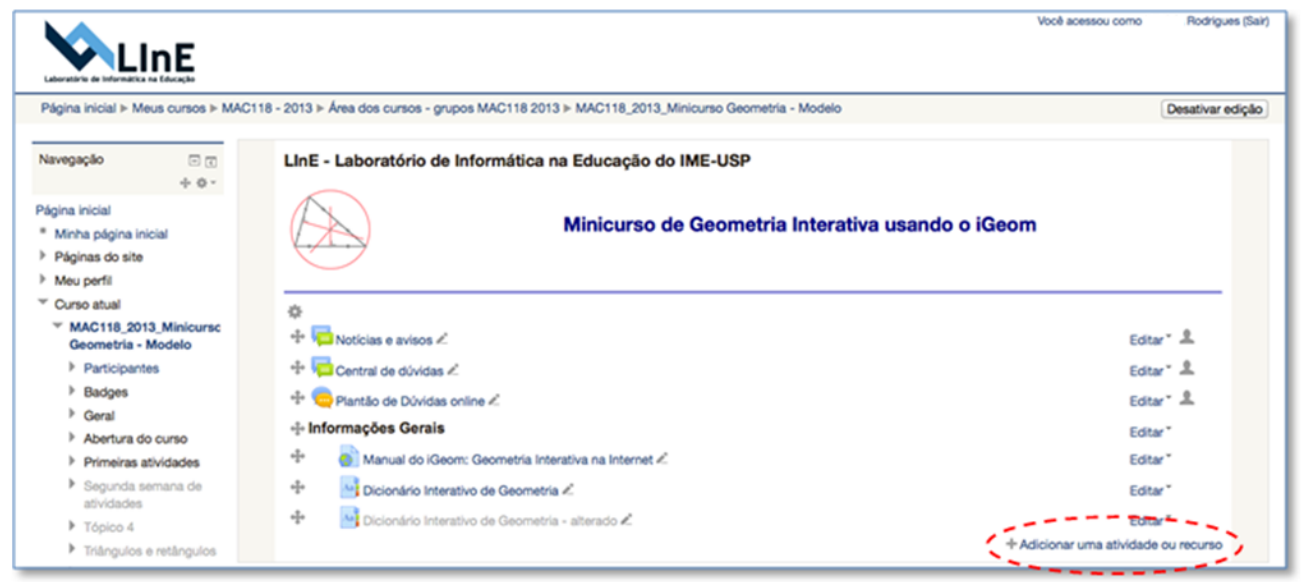

Figura D.3: Selecionar o questionário

Ao ser selecionada a opção iQuiz e confirmar clicando no botão (acrescentar) será apresentado a tela principal do iQuiz como mostra a Figura D.4, essa tela apresenta as seguintes opções:

- Novo teste: permite criar um novo questionário;

- Abrir teste: permite abrir um questionário existente;

- Utilizar modelos: permite iniciar um questionário com uma configuracao pré existente;

- Utilizar assistente: auxilia o professor na criação do questionário;

- Banco de questão: permite gerenciar o banco de questões.

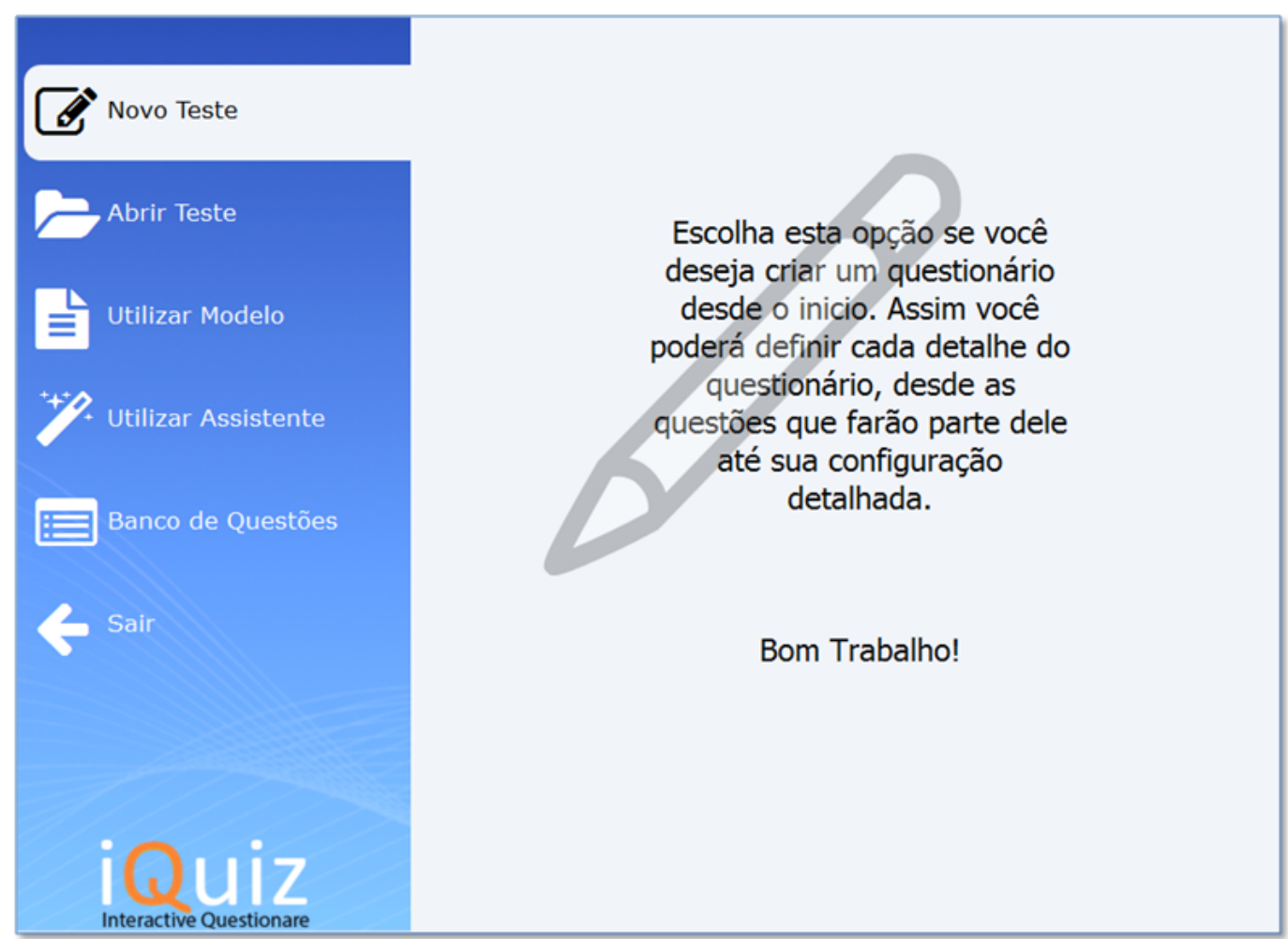

Figura D.4: Tela inicial iQuiz 


\section{D.1 Criando um questionário}

Ao escolher (Criar novo teste) inicia-se o processo de criação do questionário, a Figura D.5 mostra a tela que é apresentada ao professor. Nessa etapa são inseridos o Título do teste (questionário), breve descrição do teste e a escolha do tipo de questão a ser criada ou ainda obter questões prontas.

Para ilustrar a autoria de questionários no iQuiz com dados de uma questão, será apresentado o processo para criação de uma questão do tipo múltipla escolha, esse tipo de questão é o mais utilizado pelos usuários do Moodle.

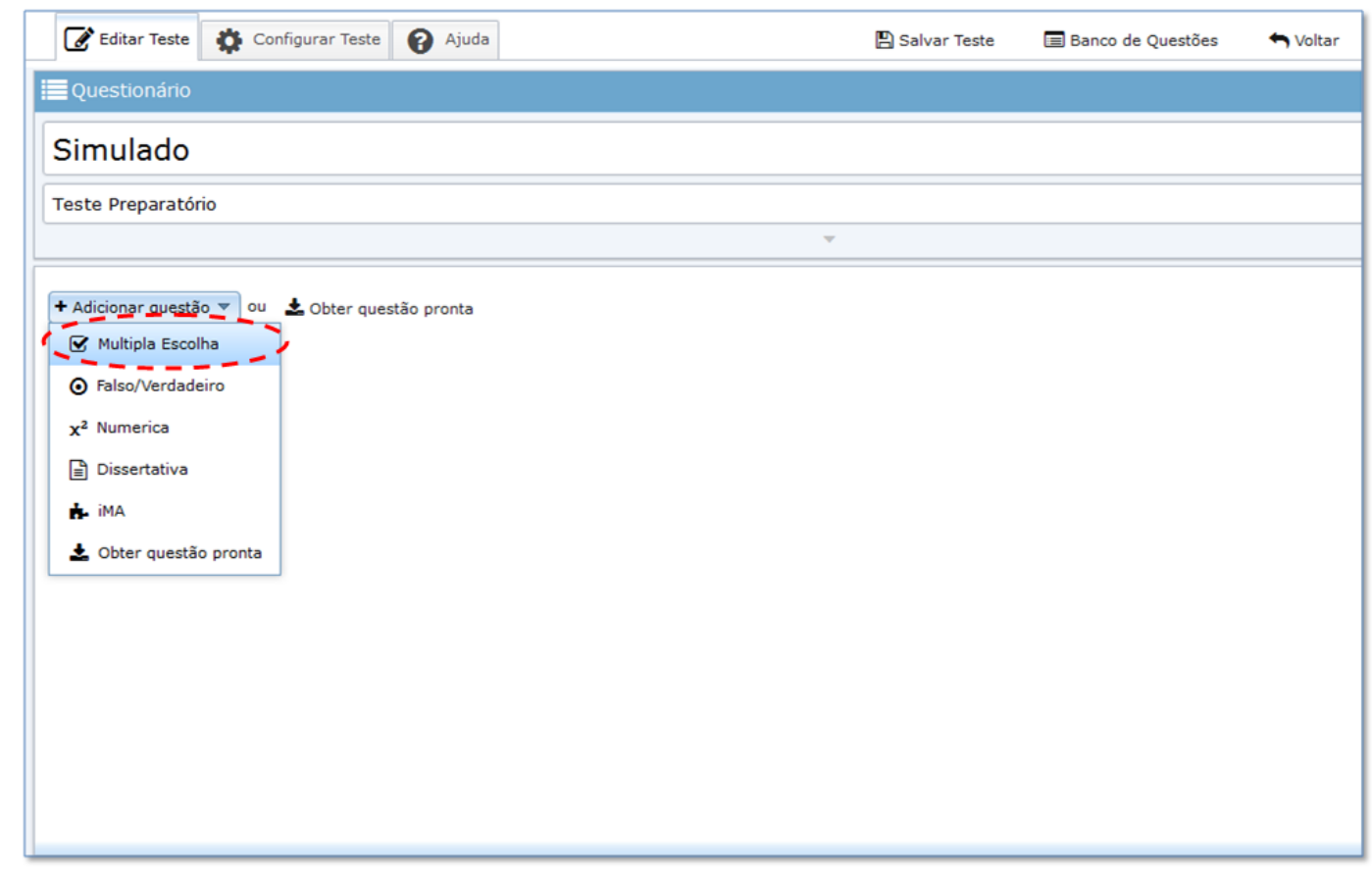

Figura D.5: Atribuir nome, descrição e escolher o tipo da questão

Após escolher o tipo de questão múltipla escolha, uma tela será apresentada, no canto direito dessa tela existe três abas, sendo elas: Questão, Feedback e Múltiplas Tentativas.

A aba (Questão) aparece ativada apresentando área de edicao da questão, essa área apresenta as seguintes opções:

- Identificação da questão: permite inserir um código de identificação, por exemplo, Questão 1.

- Pergunta/Enunciado: permite inserir o enunciada da questão.

- Respostas: a área de resposta é subdividida em: (Acerto) que permite-se atribuir um valor percentual para as alternativas corretas; (Alternativa) onde sao inseridas informacoes das alternativas; (Múltiplas respostas) essa opção deve ser ativada quando houver mais de uma alternativa correta para a questão; (Embaralhar) altera a ordem das alternativas a cada nova tentativa.

- Ponto: permite atribuir uma pontuação a questão.

A Figura D.6 ilustra a tela de preenchimento da área da questão. 


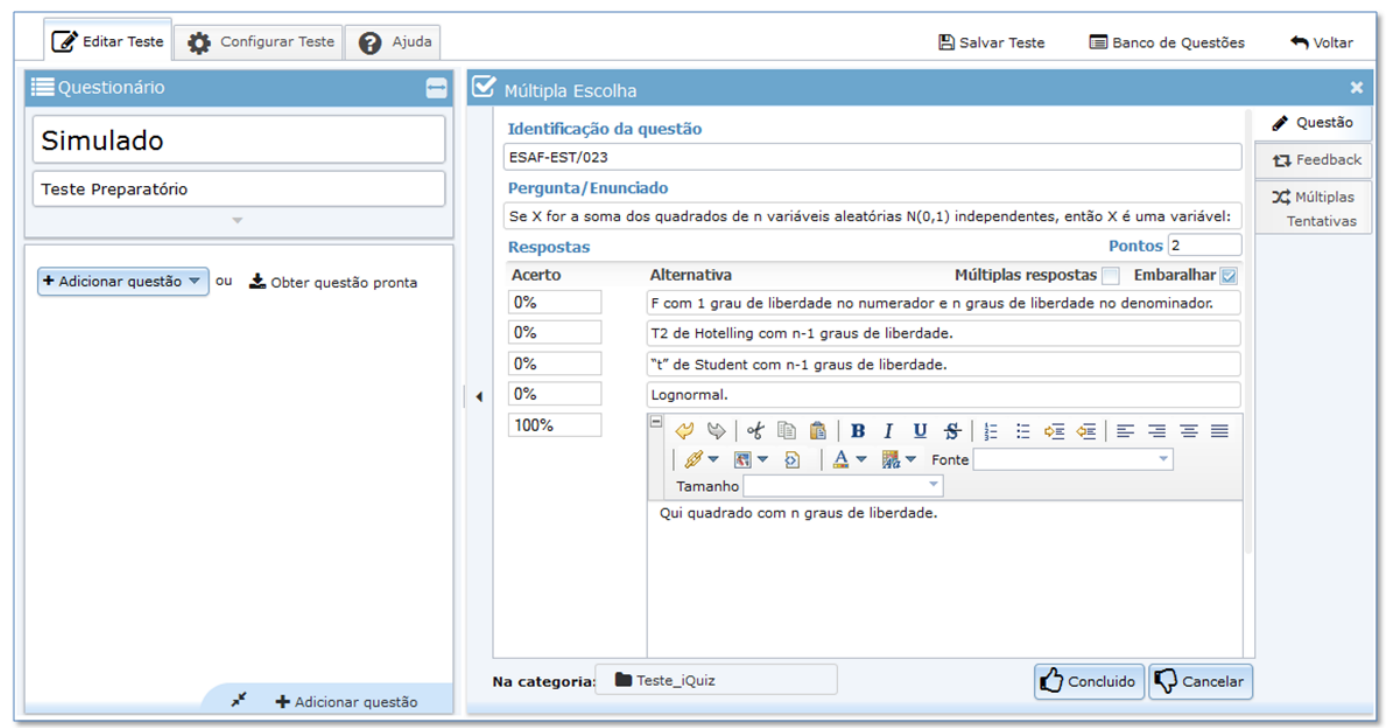

Figura D.6: Preenchendo os dados do questionário

Ao digitar a questão ou o enunciado irá aparecer na caixa de texto uma barra de ferramentas, através dessa barra é possível alterar a aparência das informações, atribuindo negrito, itálico, sublinhado, inserindo imagens, tabelas entre outras formatações. Caso o professor prefira uma área maior e mais limpa, pode ocultar a barra de formatação acionando no sinal de (-) na parte superior esquerda da caixa de texto para que a barra seja exibida novamente basta clicar no sinal $(+)$.

Outra personalização que pode ser feita pelo professor é expandir a área onde foi digitada as alternativas, como padrão a caixa de texto aumenta de tamanho enquanto está sendo editada, depois de concluída ela reduz o tamanho para apenas uma linha, caso o professor queira visualizar a alternativa completa, mesmo após a conclusão, basta posicionar o mouse sobre a alternativa, que será apresentado três botões, o primeiro permite inserir um feedback específico para a alternativa, o segundo permite expandir a área da alternativa para que ela apareça completa e o terceiro permite excluir a alternativa.

A Figura D.7 ilustra a caixa de ferramentas em exibição e oculta, também apresenta os botões de personalização específicos das alternativas.

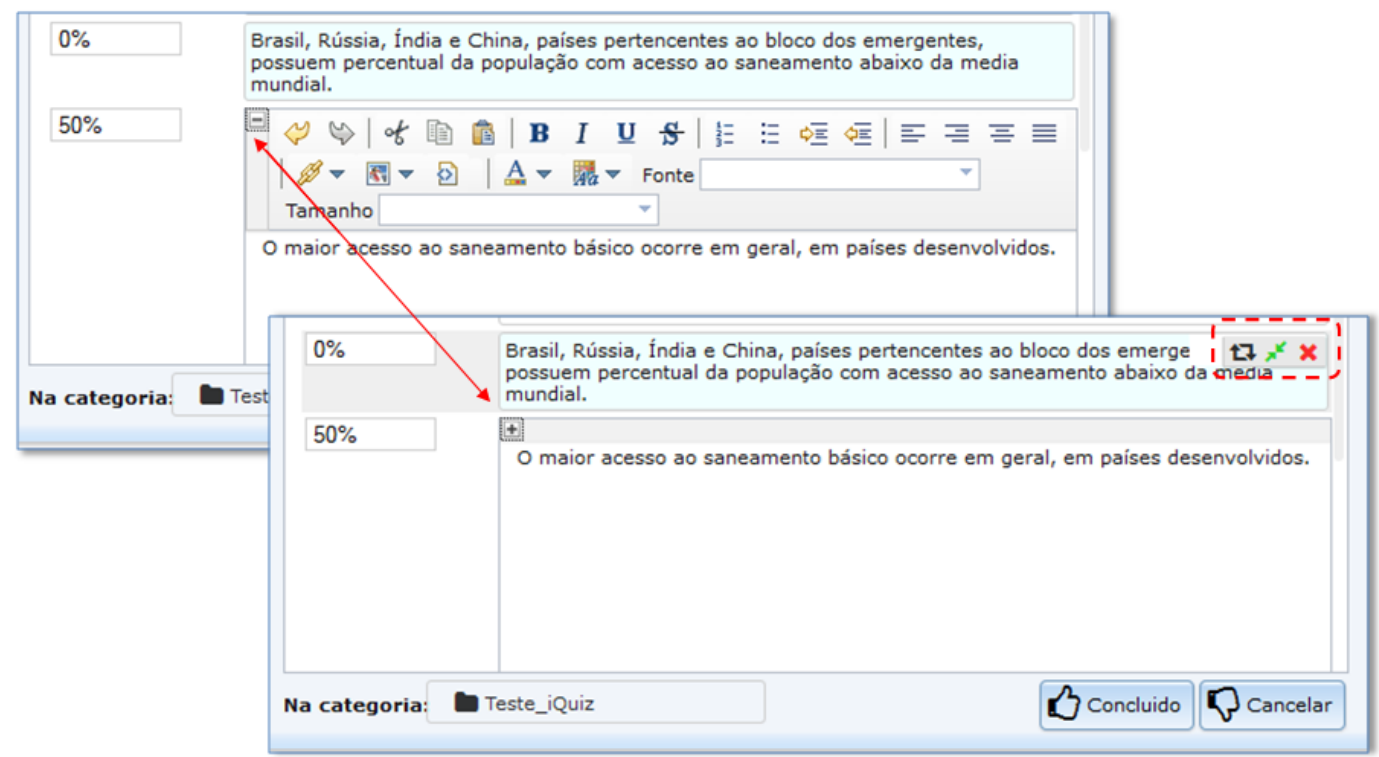

Figura D.7: Ocultando e expandindo a barra de formatação e a área da alternativa

Após preencher os dados da questão deve-se acionar a aba Feedback, caso exista algum comen- 
tario a ser feito quando o aluno responder a questao.

\section{D.1.1 Feedback}

$\mathrm{Na}$ área do Feedback o professor pode adicionar mensagens que irão ser mostradas ao aluno, quando ele terminar de responder a questão, o feedback não é obrigatório.

Caso o professor tenha dúvida de qual informação deve inserir, basta posicionar o mouse próximo do campo que irá aparecer um sinal de interrogação (?), ao clicar será apresentada a tela de ajuda. A Figura D.8 ilustra a área do Feedback geral, do Feedback combinado e a área de ajuda.

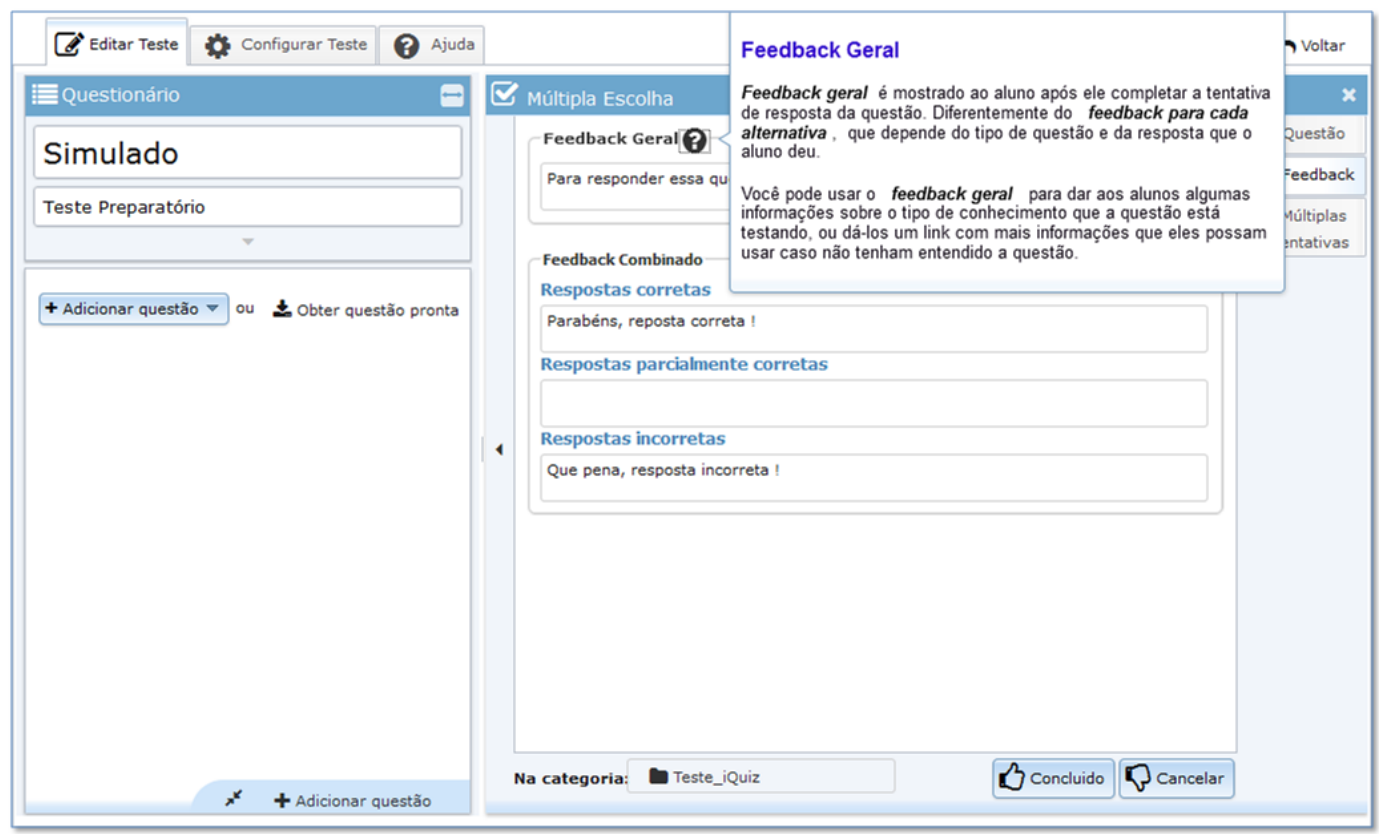

Figura D.8: Configuração do Feedback

Feedback geral é usado para dar aos alunos algumas informações sobre o tipo de conhecimento necessário para responder a questão ou ainda inserir um link onde possa ser encontrado informações caso não tenham entendido a questão. Já o feedback combinado pode ser usado para informar aos alunos o nível de erro ou acerto a cada questão respondida. A Figura D.9 mostra como essas informações irão aparecer para o aluno.

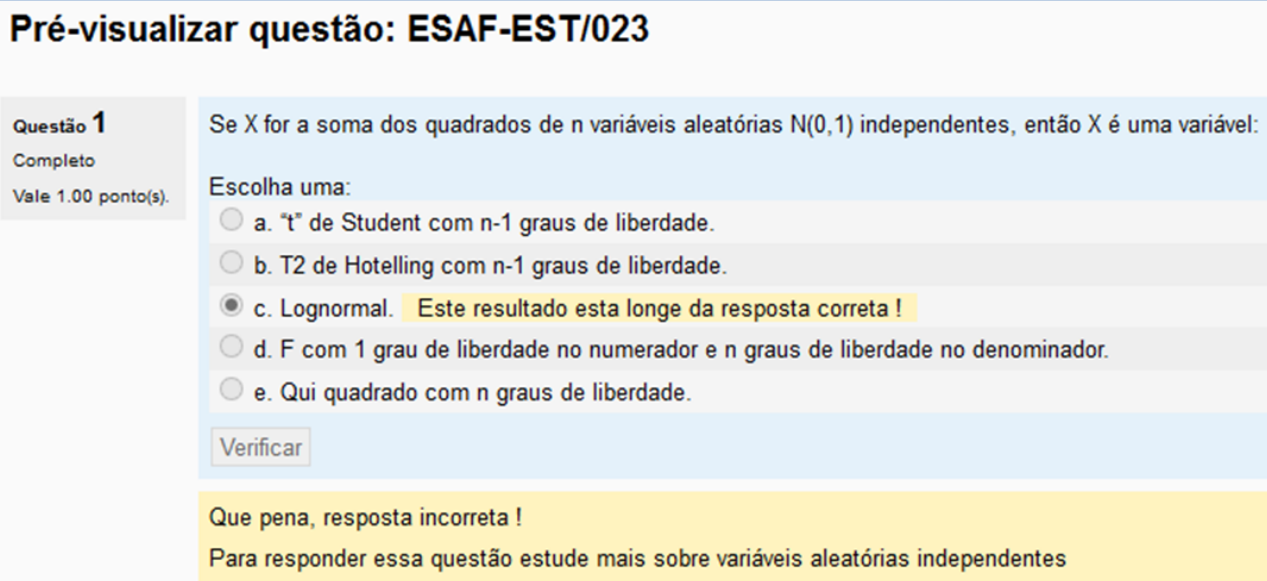

Figura D.9: Pré visualização da questão 
Após preencher o feedback, ativa-se a aba de (Múltiplas Tentativas), essa opção só será preenchida se o professor permitir que o aluno responda mais de uma vez a mesma questão.

\section{D.1.2 Múltiplas tentativas}

A área de múltiplas tentativas é composta pelos campos (tentativas) e (penalidade). Em tentativas é possível inserir uma dica ao aluno, uma ajuda, porém a cada nova tentativa o aluno receberá uma penalidade.

A penalidade é uma proporção do quanto será descontado à cada resposta incorreta, na Figura D.10 mostra como atribuir vários tipos de penalidade.

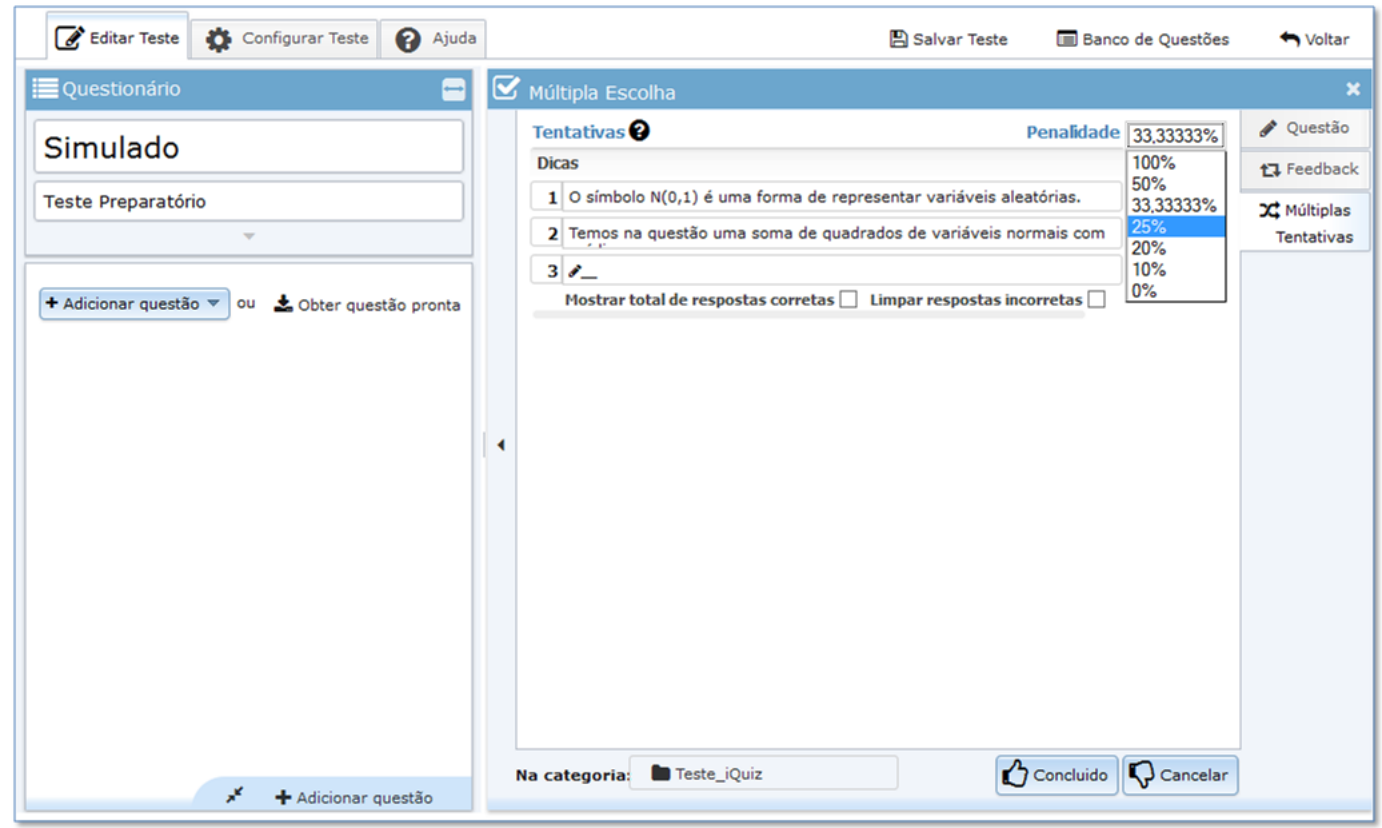

Figura D.10: Múltiplas tentativas

Ao terminar a questão é possível escolher em qual categoria ela será armazenada, como ilustrado na Figura D.11. 


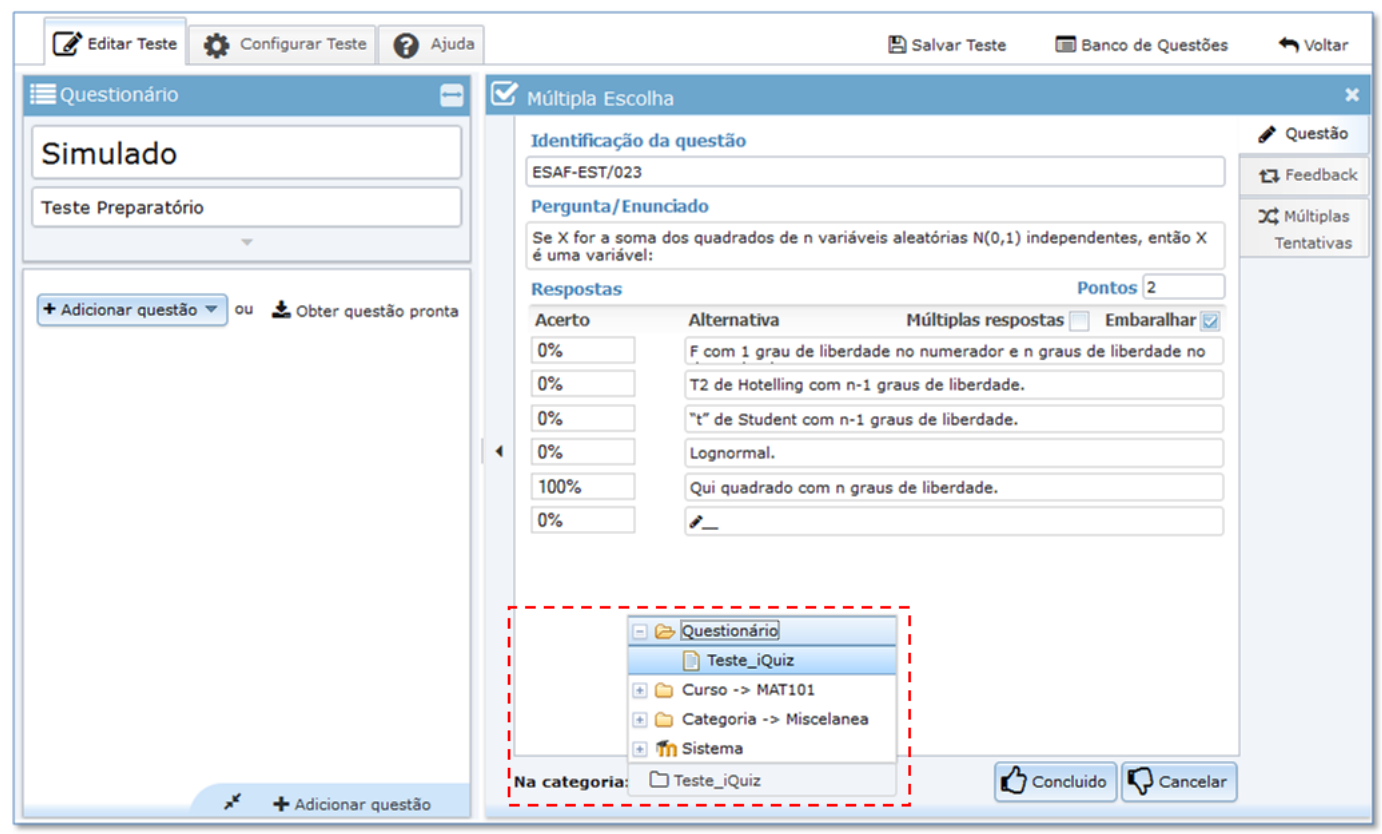

Figura D.11: Atribuindo uma categoria

Para concluir a edição da questão atual e ir para a próxima, é necessário acionar o botão (Concluído), ao fazer isso a questão irá aparecer no canto esquerdo da tela, e no lado direito aparecerá os campos em branco para a criação de uma nova questão do mesmo tipo.

Para escolher uma questão de outro tipo basta clicar na opção (Adicionar questão) que a lista de tipos de questão será apresentada na tela, como ilustrado na Figura D.12.

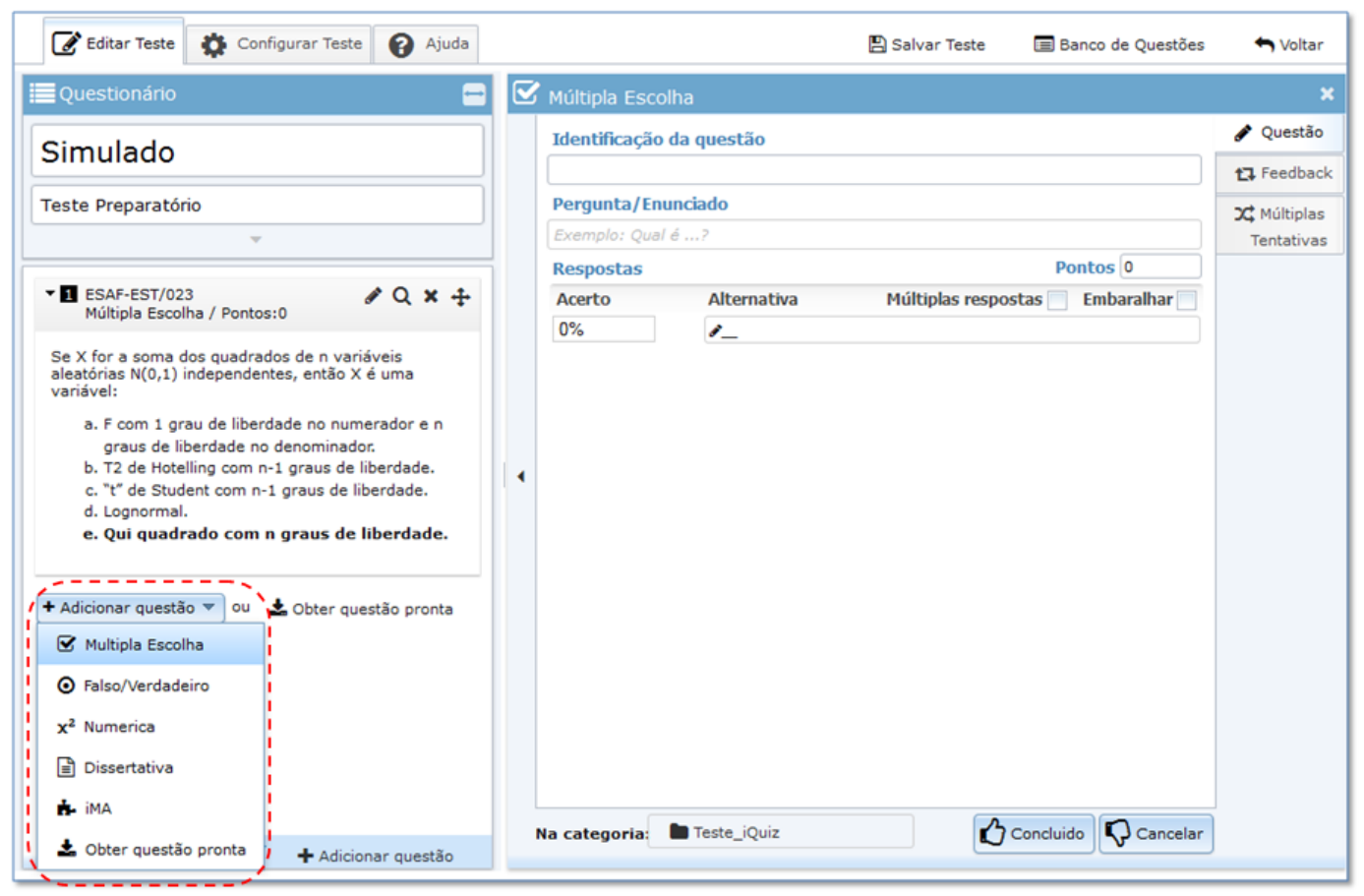

Figura D.12: Criar um novo tipo de questão

Após criar as questões que irão compor o questionário (teste) é preciso disponibilizá-lo aos usuários, definindo como e quando o questionário deve ser disponibilizado aos alunos, A seção D.2 mostra como configurar o teste. 


\section{D.2 Configurar teste}

Nessa etapa é configurado como será o comportamento do questionário, ao ativar a aba (Configurar teste) é apresentado o formulário com os campos a serem preenchidos, e está dividido em: Geral, Abertura/Duração, Nota, Layout, Comportamento da questão, Opções de tentativa, Visualização, Restrições de acesso, Feedback Final e Configurações de módulos.

A área de configuração do teste é ilustrada na Figura D.13.

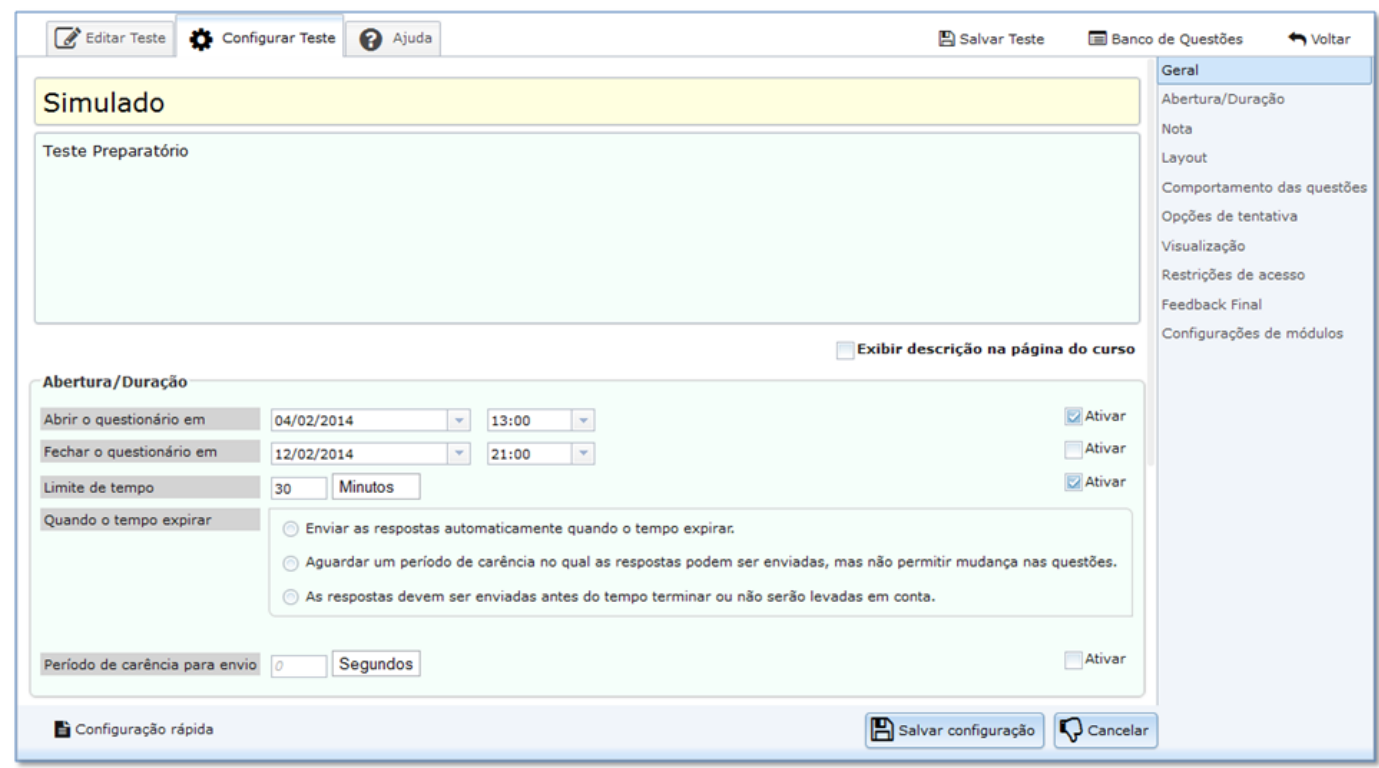

Figura D.13: Configurar Teste

Para que as configurações feitas, sejam atribuídas ao questionário é necessário ativar a opção (Salvar Configurações), ao acionar esse botão será apresentada a tela com a mensagem de confirmação e voltará para a aba (Editar teste).

Para finalizar o questionário, deve-se ativar a opção (Salvar Teste) ou fechar (x) no canto direito superior. 


\section{Apêndice E}

\section{Lista de Tarefas do Quiz}

\section{Questão1 - Múltipla escolha}

Fonte: ENEM 2012 MAT

A capacidade mínima, em BTU/h, de um aparelho de ar-condicionado, para ambientes sem exposição ao sol, pode ser determinada da seguinte forma:

- $600 \mathrm{BTU} / \mathrm{h}$ por m2, considerando-se até duas pessoas no ambiente;

- para cada pessoa adicional nesse ambiente, acrescentar $600 \mathrm{BTU} / \mathrm{h}$;

- acrescentar mais $600 \mathrm{BTU} / \mathrm{h}$ para cada equipamento eletroeletrônico em funcionamento no ambiente.

Será instalado um aparelho de ar-condicionado em uma sala, sem exposição ao sol, de dimensões $4 \mathrm{~m} \times 5 \mathrm{~m}$, em que permaneçam quatro pessoas e possua um aparelho de televisão em funcionamento. A capacidade mínima, em BTU/h, desse aparelho de ar-condicionado deve ser:
a) 12000
b) 12600
c) 13200
d) 13800 (resposta)
e) 15000

\section{Questão2 - Numérica}

ENEM 2012 (adaptado)

Um forro retangular de tecido traz em sua etiqueta a informação de que encolherá após a primeira lavagem mantendo, entretanto, seu formato.

Qual será a área após a lavagem de um forro com medida igual a $6 \mathrm{~m}$ de largura x $3 \mathrm{~m}$ de comprimento, antes da primeira lavagem? Sabendo que o tamanho do encolhimento foi de 0,5m na largura e de $0,25 \mathrm{~m}$ no comprimento.

Resposta: 14,375

\section{Questão3 - Verdadeiro/Falso}

João decidiu contratar os serviços de uma empresa por telefone através do SAC (Serviço de Atendimento ao Consumidor). O atendente ditou para João o número de protocolo de atendimento da ligação e pediu que ele anotasse. Entretanto, João não entendeu um dos algarismos ditados pelo atendente e anotou o número 1399820 7, sendo que o espaço vazio é o do algarismo que João não entendeu.

De acordo com essas informações, a posição ocupada pelo algarismo que falta no número de protocolo é a de centena de milhar. 
Resposta: verdadeiro

\section{Questão4 - Calculado}

Uma mãe recorreu à bula para verificar a dosagem de um remédio que precisava dar a seu filho. $\mathrm{Na}$ bula, recomendava-se a seguinte dosagem: a1 gotas para cada bkg de massa corporal a cada 8 horas.

Se a mãe ministrou corretamente a2 gotas do remédio a seu filho a cada 8 horas, então a massa corporal dele é de

Resposta: $\mathrm{a} 2 * \mathrm{~b} / \mathrm{a} 1$

\section{Questão5 - Resposta Curta}

Um laboratório realiza exames em que é possível observar a taxa de glicose de uma pessoa. Os resultados são analisados de acordo com o quadro a seguir. Hipoglicemia: taxa de glicemia menor ou igual a $70 \mathrm{mg} / \mathrm{dl}$ Normal : taxa de glicemia maior que $70 \mathrm{mg} / \mathrm{dl}$ e menor ou igual a $100 \mathrm{mg} / \mathrm{dl}$ pré-diabetes : taxa de glicemia maior que $100 \mathrm{mg} / \mathrm{dl}$ e menor ou igual a 125mg/dl diabetes melito : taxa de glicemia maior que $125 \mathrm{mg} / \mathrm{dl}$ e menor ou igual a 250mg/dl Hiperglicemia: taxa de glicemia maior que $250 \mathrm{mg} / \mathrm{dl}$

Um paciente fez um exame de glicose nesse laboratório e comprovou que estava com hiperglicemia. Sua taxa de glicose era de $300 \mathrm{mg} / \mathrm{dL}$. Seu médico prescreveu um tratamento em duas etapas. Na primeira etapa ele conseguiu reduzir sua taxa em 30\% e na segunda etapa em 10Ao calcular sua taxa de glicose após as duas reduções, o paciente verificou que estava na categoria de

Resposta: diabetes melito 


\section{Apêndice F}

\section{Lista de Tarefas do $i Q u i z$}

\section{F.0.1 Contextualização da Tarefa}

A instituição em que você trabalha irá aplicar uma avaliação online ao final do semestre para todos os alunos envolvendo todas as disciplinas ministradas. Alguns professores elaboraram as perguntas e outros ficaram encarregados de produzir os questionários (provas/avaliação) utilizando o sistema de avaliação online que recentemente foi implantado na instituição. Você foi daqueles escolhidos para utilizar o sistema, assim você recebeu fichas com as perguntas prontas e detalhes sobre a composição do questionário (prova/avaliação). Utilizando essas fichas crie o questionário, sempre atentando para os detalhes que são solicitados para cada questão, descrito na lista de tarefas a seguir.

\section{F.0.2 Lista de Subtarefas}

\section{Tarefa 1}

Você precisa criar um questionário com a lista de questões que lhe foi fornecida, pois tais questões ainda não estão disponíveis no sistema. Assim você criará um questionário utilizando a opção que você acha ser a mais conveniente dentre aquelas oferecidas pelo sistema.

\section{Tarefa 2}

Você já preencheu as informações sobre seu questionário de avaliação e agora deseja completá-lo com as questões do tipo múltipla escolha que lhe foram entregues. Crie a primeira questão utilizando as informações que constam na ficha 1 e adicione-a ao questionário.

\section{Ficha 1}

1) ESAF-EST/023 - (1 ponto)

Se $\mathrm{X}$ for a soma dos quadrados de $\mathrm{n}$ variáveis aleatórias $\mathrm{N}(0,1)$ independentes, então $\mathrm{X}$ é uma variável:

a) $\mathrm{F}$ com 1 grau de liberdade no numerador e $\mathrm{n}$ graus de liberdade no denominador.

b) T2 de Hotelling com n-1 graus de liberdade.

c) "t"de Student com n-1 graus de liberdade.

d) Lognormal.

e) Qui quadrado com n graus de liberdade. (correta)

\section{Tarefa 3}

Agora você precisará criar mais uma questão do tipo múltipla escolha, utilizando as informações na ficha 2. Para esta questão você observa que: 
i) Existem duas alternativas corretas. Para cada resposta correta, o aluno recebe metade da pontuação da questão.

ii) O aluno receberá uma mensagem após ter respondido a questão. Tal mensagem porém depende da seguintes condições:

a) Se a resposta estiver correta a mensagem será: "Parabéns sua resposta está correta"

b) Se a resposta estiver errada a mensagem será: "Que pena, sua resposta está errada"

\section{Ficha 2}

2) ENAD-GER/005 - (2 pontos)

O Mapa abaixo representa as áreas populacionais sem acesso ao saneamento básico.

Endereço da figura: http://www.ime.usp.br/ jrar/questoes/fig-qger005.png

Considerando o mapa apresentado, analise as afirmações que se seguem e responda quais afirmações estão corretas.

a) A globalização é fenômeno que ocorre de maneira desigual entre os países, e o progresso social independe dos avanços econômicos.

b) Existe relação direta entre o crescimento da ocupação humana e o maior acesso ao saneamento básico.

c) Brasil, Rússia, Índia e China, países pertencentes ao bloco dos emergentes, possuem percentual da população com acesso ao saneamento abaixo da média mundial.

d) O maior acesso ao saneamento básico ocorre em geral, em países desenvolvidos. (correta)

e) Para se analisar o índice de desenvolvimento humano (IDH) de um país, deve-se diagnosticar PIB per capita, a saúde e a educação. (correta)

\section{Tarefa 4}

Agora você precisa criar mais uma questão múltipla escolha (ficha 3) e desta vez deve ser permitido ao aluno duas tentativas de resposta. Desse modo se o aluno responder e acertar na primeira tentativa, receberá a pontuação total da questão. Entretanto se tentar mais uma vez, terá a nota reduzida pela metade como punição.

\section{Ficha 3}

3) HIST-H001 - (3 pontos)

Leia o extrato de uma letra musical abaixo:

"Eu vejo eles dançando / Em cima do muro / No meio do mundo / No meio do mundo dividido / Spielberg, Eisenstein / Vodka, CIA / Las Vegas, Kremlin / Tolstói, John Wayne / Champagne, Caviar / Mickey Mouse em Moscou / Batman, Trotsky / Bolshoi, Rock'n roll".

O trecho acima foi extraído da música "Mickey Mouse em Moscou", interpretada por Capital Inicial. A letra retrata um momento da história contemporânea conhecido como Guerra Fria. A respeito da Guerra Fria é CORRETO afirmar que:

a) A dicotomia "Batman, Trotsky"e "Bolshoi, Rock'n roll"mencionados na letra da música, são elementos representativos da cultura americana e russa que remetem à divisão bipolar do mundo encerrada, simbolicamente, com a queda do Muro de Berlim em 1989 e instaurando uma nova ordem geopolítica internacional. (correta)

b) A Guerra Fria dividiu o mundo entre capitalistas e socialistas, influenciando a geopolítica internacional desde o final da Segunda Guerra Mundial, sendo responsável pela instalação de ditaduras militares nos países da América Latina a partir da segunda metade do século XIX.

c) A expressão "no meio do mundo dividido", contida na letra da música, é uma referência à forma como a organização geopolítica internacional foi representada a partir da ascensão de dois modelos ideológicos que dividiram Berlim, na Alemanha, em duas partes: ocidental e oriental após a Guerra Fria. 


\section{Tarefa 4.1}

As alternativas da questão três exigiram algumas linhas de informação cada, mas apenas uma linha pode ser visualizada, entretanto você deseja que seja apresentado o conteúdo completo de cada alternativa.

\section{Tarefa 4.2}

Você gostaria que a área de edição da questão fosse expandida para ocupar toda a tela e desta forma ganhar mais espaço para visualizar melhor a questão.

\section{Tarefa 5}

A segunda questão que você criou, precisa receber alguns ajuste. Você decidiu que haverá uma mensagem (feedback) ao aluno para cada alternativa errada que ele escolher como resposta. As mensagens são as seguintes:

Alternativa (a): Estude mais sobre a globalização, acesse: pt.wikipedia.org/wiki/globalizacao

Alternativa (b): Entenda como ocorre a relação entre crescimento populacional e saneamento, consulte o capítulo 3 do seu livro.

Alternativa (c): Entenda melhor como fazer a Leitura e Interpretação de gráficos, clique aqui.

\section{Tarefa 6}

Você decidiu incluir mais uma questão no questionário, porém como não tem mais fichas, resolveu utilizar uma questão pronta, fornecida pelo sistema.

\section{Tarefa 7}

O seu questionário tem apenas nome e descrição. Agora você deseja definir a data de abertura e o tempo que o questionário irá ficar disponível para o aluno. Você também gostaria de determinar que os alunos poderão tentar responder o questionário no máximo 3 vezes. Encontre o local onde você pode realizar tais definições.

\section{Tarefa 8}

Embora o seu questionário esteja pronto, você gostaria de aproveitar seu tempo livre e criar mais algumas questões para utilizá-las posteriormente. entretanto as questões a serem criadas não farão parte de um questionário como ocorreu anteriormente. Encontre o local onde você pode criar e deixar suas questões armazenadas para uso futuro.

\section{F.0.3 Modelo do guia do observador}

\section{Tarefa 1 - Criar um questionário}

Você precisa criar um questionário com a lista de questões que lhe foi fornecida, pois tais questões ainda não estão disponíveis no sistema. Assim você criará um questionário utilizando a opção que você acha ser a mais conveniente dentre aquelas oferecidas pelo sistema. 


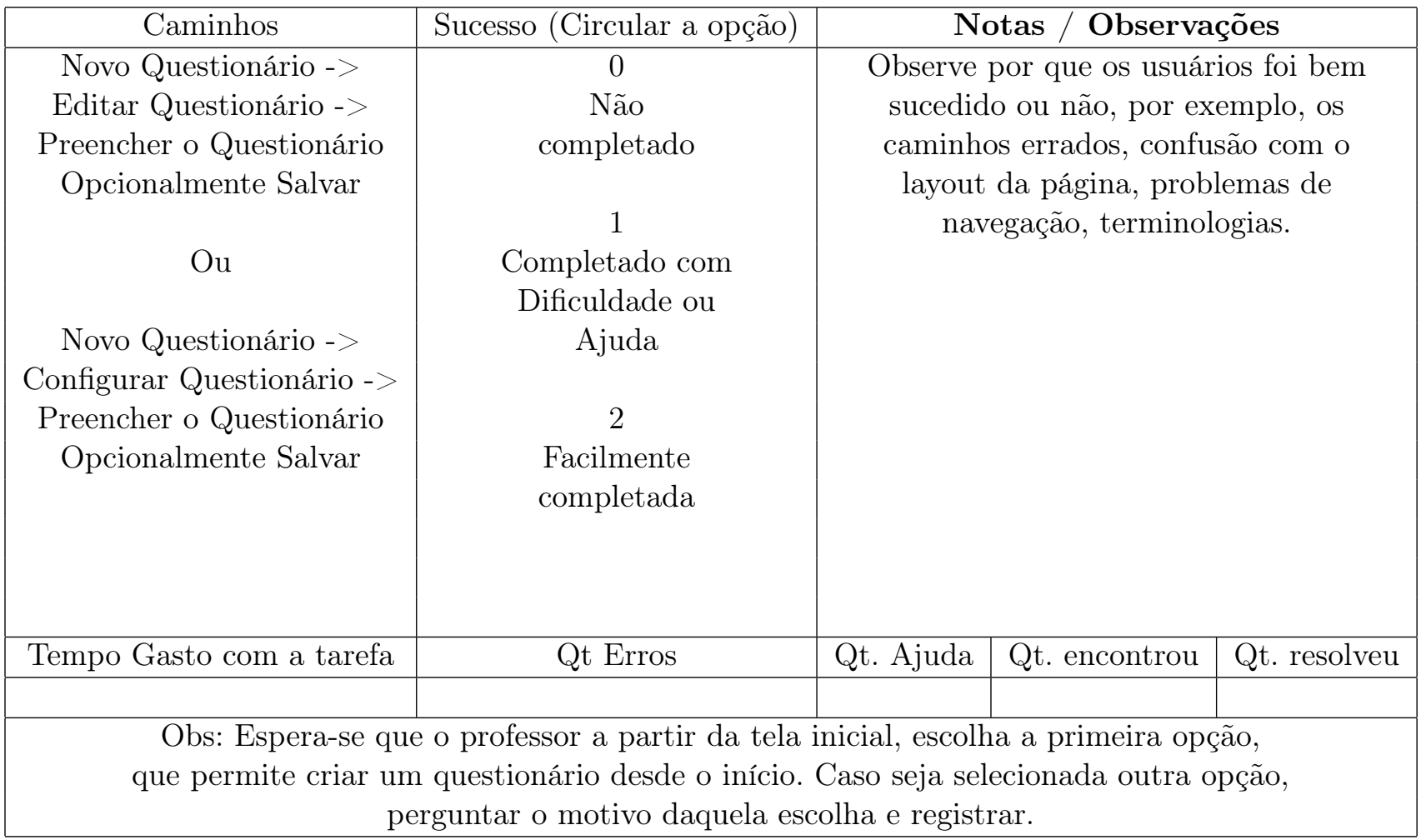

Tabela F.1: Modelo do guia do observador 


\section{Apêndice G}

\section{Informações complementares dos experimentos com o Quiz e iQuiz}

Neste Apêndice são apresentados os resultados brutos coletados nos experimentos realizados durante o desenvolvimento deste trabalho.

\section{G.1 Segundo Experimento: primeira avaliação da interface do iQuiz}

\section{G.1.1 Resultado da avaliação SUS}

Na Tabela G.1 é apresentado o resultado das opiniões de cada participante sobre cada uma das afirmações. Ao final da tabela é dada a totalização em valores absolutos e também a pontuação do SUS, aplicando-se a seguinte regra:

Somar as contribuições de cada item com valores de 0 a 4 . Para as questões ímpares a contribuição é calculada pela posição da escala menos 1. Para as questões pares, calcula-se 5 menos o valor da posição da escala. Depois multiplica-se a soma dos valores por 2,5 e obtém-se a pontuação com amplitude entre 0 a 100.

\begin{tabular}{c|cccccc}
\hline \multicolumn{7}{c}{\begin{tabular}{c} 
Resultado da Avaliação SUS \\
\multicolumn{7}{c}{ Primeira avaliação da interface do } \\
iQuiz
\end{tabular}} \\
\hline \multirow{2}{*}{ Afirmações } & P1 & P2 & P3 & P4 & P5 & P6 \\
\hline AF1 & 4 & 5 & 5 & 3 & 4 & 2 \\
AF2 & 2 & 2 & 1 & 2 & 4 & 3 \\
AF3 & 4 & 5 & 5 & 4 & 2 & 3 \\
AF4 & 1 & 2 & 1 & 1 & 1 & 1 \\
AF5 & 5 & 4 & 4 & 3 & 5 & 3 \\
AF6 & 1 & 2 & 1 & 2 & 4 & 2 \\
AF7 & 4 & 4 & 4 & 5 & 3 & 4 \\
AF8 & 2 & 1 & 2 & 1 & 1 & 1 \\
AF9 & 1 & 4 & 5 & 3 & 2 & 5 \\
AF10 & 1 & 2 & 2 & 1 & 3 & 1 \\
\hline Totalização & 31 & 33 & 36 & 31 & 23 & 29 \\
\hline Pontuação SUS & 77,5 & 82,5 & 90 & 77,5 & 57,5 & 72,5 \\
\hline
\end{tabular}

Tabela G.1: Resultado da Avaliação SUS: Primeira avaliação da interface do iQuiz

\section{G.1.2 Respostas do questionário avaliativo (Questões abertas)}

1. Qual é a sua impressão geral sobre o $i Q u i z$ ? 
- O sistema é de fácil uso com acessíveis e de interface agradável do ponto de vista da visualização.

- É uma boa ferramenta para a criação de questionários. Acho que pode copiar alguns recursos dos questionários do Google.

- Ideia legal e interessante.

- Boa proposta, recursos suficientes para a elaboração de problemas, interface para entrada de dados é bem problemática.

\section{O que você mais gostou no $i Q u i z ?$}

- Visualização da questões e o recurso dos feedbacks geral e por alternativas que facilitam a compreensão das alternativas incorretas. As dicas também são interessantes e bastante úteis.

- Organização da tela e visualização do questionário.

- Layout ficou bonito e muitas funcionalidades interessantes.

- Mostra-se uma forma rápida de se elaborar tarefas para estudo à distância. Visual bastante limpo.

\section{O que você menos gostou no iQuiz?}

- Gostei dos recursos utilizados na tarefa proposta.

- Fonte, cores e alguns bugs.

- Em alguns pontos deveria ser mais direto.

- Sistema de entrada de dados.

4. Se você pudesse fazer uma mudança significativa no iQuiz, que mudança você gostaria de fazer?

- Nada a declarar.

- Trocaria a porcentagem por frações ou pensaria em algo diferente.

- No modo de exibição tentaria simplificar um pouco a interface (estilo Google Forms).

- Melhorar a forma de captação de dados.

\section{Existe alguma coisa que você sente que está faltando no $i Q u i z$ ?}

- Nada a declarar.

- Editor de fórmulas matemáticas e criação de tabelas.

- Não.

- Não senti falta de algo.

6. Se você tivesse que descrever o $i Q u i z$ a um amigo em uma ou duas frases, o que diria?

- Fácil e bastante útil enquanto ferramenta para criar avaliações.

- Sisteminha para criação de questionário para o Moodle.

- Crie questionários e provas online.

- Um bom sistema para elaboração de questões online, para estudo. 


\section{Você tem outros comentários finais ou perguntas?}

- No momento não.

- Me preocupe com a inclusão dos iMA em termos de "ocupação"da área.

- Marcar claramente a edição e novas questões, deixam a entrada da questão/alternativas por padrão sem editor visual, permitir voltar para navegador (Back padrão do navegador) e checar.

- Para questionários com mais de 10 perguntas, como ficaria a apresentação destas na coluna à esquerda?

\section{G.2 Terceiro Experimento: segunda avaliação da interface do $i Q u i z$}

\section{G.2.1 Resultado da avaliação SUS}

\begin{tabular}{c|ccccc}
\hline \multicolumn{5}{c}{ Resultado da avaliação SUS } \\
Segunda avaliação da interface do iQuiz \\
\hline \multirow{2}{*}{ Afirmações } & P1 & P2 & P3 & P4 & P5 \\
\cline { 2 - 6 } & 5 & 4 & 5 & 3 & 5 \\
AF1 & 1 & 1 & 2 & 3 & 1 \\
AF2 & 5 & 5 & 5 & 4 & 4 \\
AF3 & 5 & 1 & 2 & 5 & 1 \\
AF4 & 5 & 4 & 5 & 3 & 5 \\
AF5 & 1 & 2 & 1 & 2 & 1 \\
AF6 & 5 & 5 & 5 & 4 & 4 \\
AF7 & 1 & 1 & 2 & 1 & 1 \\
AF8 & 5 & 4 & 5 & 3 & 4 \\
AF9 & 1 & 1 & 2 & 2 & 2 \\
AF10 & 36 & 36 & 36 & 24 & 36 \\
Totalização & 90 & 90 & 90 & 60 & 90 \\
\hline Pontuação SUS & & & &
\end{tabular}

Tabela G.2: Resultado da Avaliação SUS: Segunda avaliação da interface do iQuiz

\section{G.2.2 Respostas do questionário avaliativo (Questões abertas)}

\section{Qual é a sua impressão geral sobre o $i Q u i z$ ?}

- Facilita o trabalho do professor na preparação de provas e exercícios.

- Bom, mais ainda pode ser melhorado com o tempo.

- Bom.

- Amigável.

\section{O que você mais gostou no $i Q u i z ?$}

- Possibilidade da utilização de um banco de questões e interatividade com o aluno.

- É interativo.

- Feedback.

- Da possibilidade de fazer feedback. 


\section{O que você menos gostou no $i Q u i z ?$}

- Não se aplica.

- Difícil responder, todavia pequenas instruções podem estar mais visíveis.

- Disposição das alternativas.

- Nada.

4. Se você pudesse fazer uma mudança significativa no iQuiz, que mudança você gostaria de fazer?

- Não se aplica.

- Tamanho das fontes e o tipo das fontes.

- Questões pré-formatadas.

- Adicionar "título" / nome aos ícones ao passar o mouse por cima do "botão".

5. Existe alguma coisa que você sente que está faltando no $i Q u i z$ ?

- Entendo que está completo, com o uso pode ser que eu sinta falta de alguma coisa.

- Área para respostas discursivas, com justificativas.

- Dicas de uso.

- Nada.

6. Se você tivesse que descrever o iQuiz a um amigo em uma ou duas frases, o que diria?

- É um aplicativo que ajuda o professor no preparo de provas e exercícios.

- Moderno e prático.

- Prático.

- "Programa"para organizar e disponibilizar conteúdos para alunos.

\section{Você tem outros comentários finais ou perguntas?}

- No momento não tenho perguntas. Gostaria muito de usar o aplicativo.

- Nada me ocorre nesse momento.

- Não.

- Nada.

Opinião geral sobre o sistema: "Maravilhoso o sistema. Acredito que a prática de algumas vezes levará a uma utilização automática e sem dúvidas. Descreveria como um sistema que facilitaria a tua vida na elaboração de provas e armazenamento das questões". 


\section{G.2.3 Taxa de conclusão das tarefas no terceiro experimento}

\begin{tabular}{l|c|c|c|c|c}
\hline Taxa de conclusão das tarefas no terceiro experimento \\
\hline \multirow{2}{*}{ Tarefa } & \multicolumn{5}{|c}{ Participantes } \\
\cline { 2 - 6 } & P1 & P2 & P3 & P4 & P5 \\
\hline T1 & 1 & 0 & 2 & 1 & 2 \\
T2 & 1 & 1 & 1 & 1 & 1 \\
T3 & 1 & 1 & 1 & 1 & 2 \\
T4 & 1 & 2 & 1 & 1 & 2 \\
T4.1 & 1 & 1 & 2 & 1 & 1 \\
T4.2 & 0 & 0 & 0 & 1 & 1 \\
T5 & 2 & 1 & 0 & 1 & 1 \\
T6 & 1 & 2 & 1 & 2 & 2 \\
T7 & 1 & 2 & 2 & 0 & 2 \\
T8 & 2 & 0 & 2 & 2 & 1 \\
\hline
\end{tabular}

Tabela G.3: Taxa de conclusão das tarefas no terceiro experimento

Na Tabela acima foram utilizados os seguintes indicadores para medir a taxa de conclusão das tarefas: 0 para não completado; 1 para completado com dificuldade ou ajuda; 2 para facilmente completado.

\section{G.3 Quarto Experimento: terceiro avaliação da interface do iQuiz}

\section{G.3.1 Resultado da avaliação SUS}

\begin{tabular}{c|ccccc}
\hline \multicolumn{5}{c}{ Resultado da avaliação SUS } \\
\multicolumn{5}{c}{ Terceira avaliação da interface do iQuiz } \\
\cline { 2 - 6 } Afirmações & P1 & P2 & P3 & P4 & P5 \\
\hline AF1 & 5 & 5 & 4 & 5 & 5 \\
AF2 & 1 & 1 & 1 & 1 & 1 \\
AF3 & 5 & 4 & 3 & 5 & 5 \\
AF4 & 1 & 2 & 3 & 1 & 1 \\
AF5 & 5 & 5 & 5 & 5 & 5 \\
AF6 & 1 & 1 & 1 & 1 & 1 \\
AF7 & 4 & 5 & 5 & 5 & 5 \\
AF8 & 1 & 1 & 1 & 1 & 1 \\
AF9 & 5 & 5 & 5 & 5 & 5 \\
AF10 & 1 & 2 & 1 & 1 & 1 \\
Totalização & 39 & 37 & 35 & 40 & 40 \\
\hline Pontuação SUS & 97,5 & 92,5 & 87,5 & 100 & 100 \\
\hline
\end{tabular}

Tabela G.4: Resultado da Avaliação SUS: Terceira avaliação da interface do iQuiz

\section{G.3.2 Respostas do questionário avaliativo (Questões abertas)}

\section{Qual é a sua impressão geral sobre o $i Q u i z$ ?}

- Achei o sistema muito interessante. 
- Boa.

- Eu gostei muito, achei que ao solicitar (ajuda) fica muito fácil de entender o programa.

- Gostei e quero usar.

\section{O que você mais gostou no iQuiz?}

- A facilidade para criar questões.

- Dicas para os alunos em cada questões.

- Eu gostei muito, achei que ao solicitar (ajuda) fica muito fácil de entender o programa.

- Todas as etapas foram fáceis de usar.

\section{O que você menos gostou no iQuiz?}

- Nada.

- Toda vez que retorno a questão o valor da questão sumiu.

- Nada.

- Eu gostei de usar porque para mim todas as funções foram fáceis de compreender.

4. Se você pudesse fazer uma mudança significativa no iQuiz, que mudança você gostaria de fazer?

- Eu não mudaria nada no sistema.

- Como expandir a tela das questões.

- Nada.

- Não faria nenhuma, mas gostaria de ter um assim para montar minhas provas.

5. Existe alguma coisa que você sente que está faltando no $i Q u i z$ ?

- Não.

- Não.

- Nada.

- Não.

6. Se você tivesse que descrever o $i Q u i z$ a um amigo em uma ou duas frases, o que diria?

- É um sistema interessante e fácil de usar.

- Que tem um sistema que pode ajudar muito no nosso dia a dia.

- Para indicar a um amigo diria: "Usa este programa, pois ele te oferece confiança".

- Um programa simples e fácil para montar questões para construir uma avaliação.

7. Você tem outros comentários finais ou perguntas?

- Não.

- Muito bom o sistema pode ajudar e muito. 
- Nada.

- Quando poderei utilizá-lo? O programa precisará ser comprado ou posso adquiri-lo baixando o programa?

Opinião geral sobre o sistema:

"Gostei muito do iQuiz, achei simples e fácil de ser utilizado, assim tornaria as avaliações mais atrativas para nossos alunos com respostas objetivas e simultâneas, sem ter que esperar o professor corrigir para dar uma devolutiva sobre a avaliação e a questão realizada".

\section{G.3.3 Taxa de conclusão das tarefas no quarto experimento}

\begin{tabular}{l|c|c|c|c|c}
\hline Taxa de conclusão das tarefas no quarto experimento \\
\hline \multirow{2}{*}{ Tarefa } & \multicolumn{5}{|c}{ Participantes } \\
\cline { 2 - 6 } & P1 & P2 & P3 & P4 & P5 \\
\hline T1 & 1 & 2 & 2 & 2 & 2 \\
T2 & 2 & 2 & 1 & 2 & 2 \\
T3 & 1 & 2 & 1 & 2 & 2 \\
T4 & 2 & 2 & 1 & 2 & 2 \\
T4.1 & 1 & 2 & 1 & 2 & 2 \\
T4.2 & 2 & 0 & 1 & 2 & 2 \\
T5 & 2 & 1 & 1 & 1 & 2 \\
T6 & 2 & 2 & 2 & 1 & 2 \\
T7 & 2 & 2 & 1 & 2 & 2 \\
T8 & 2 & 2 & 2 & 2 & 2 \\
\hline
\end{tabular}

Tabela G.5: Taxa de conclusão das tarefas no quarto experimento 
APÊNDICE G 


\title{
Apêndice $H$
}

\section{Questionário SUS em inglês}

\author{
System Usability Scale (SUS)
}

1. I think that I would like to use this system frequently.

2. I found the system unnecessarily complex.

3. I thought the system was easy to use.

4. I think that I would need the support of a technical person to be able to use this system.

5. I found the various functions in this system were well integrated.

6. I thought there was too much inconsistency in this system.

7. I would imagine that most people would learn to use this system very quickly.

8. I found the system very cumbersome to use.

9. I felt very confident using the system.

10. I needed to learn a lot of things before I could get going with this system. 
APÊNDICE H 


\section{Apêndice I}

\section{Telas de sistemas similares}

A Figura I.1 apresenta a tela com a aba de edição de questionário ativa e também a aba de edição de uma questão múltipla escolha.

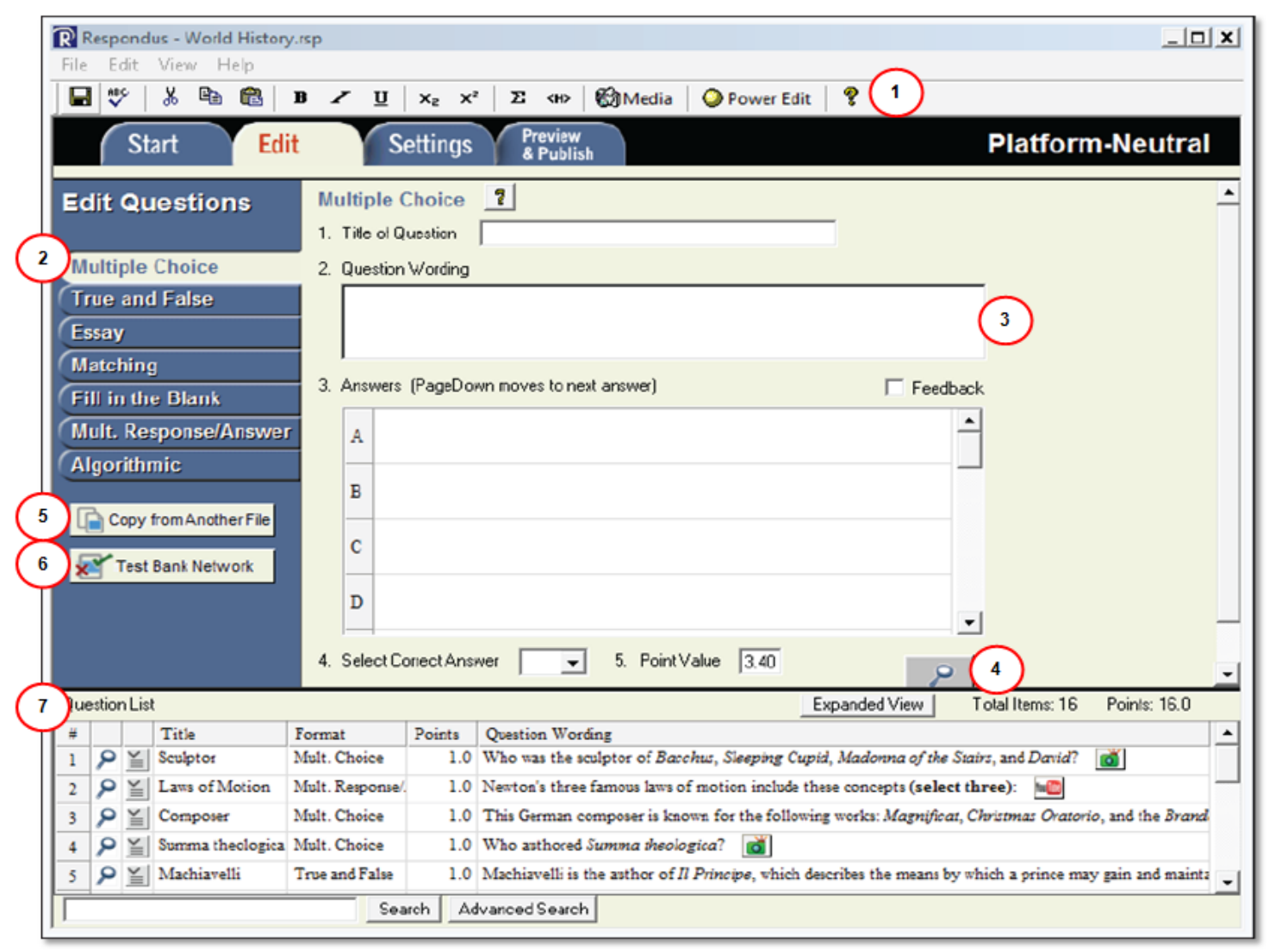

Figura I.1: Tela para edição de questionário no Respondus

1. Barra de Ferramentas: Sempre visível e fixa no topo da tela, os ícones são habilitados contextualmente, ou seja, quando o recurso é aplicável.

2. Tipo de questão: Todos os tipos de questão oferecidas, ficam disponíveis como abas, basta clicar e usar.

3. Edição da questão: Área para inserir os dados da questão.

4. Visualizar questão: Mostra uma pré-visualização das questões

5. Copia questões de outro arquivo Respondus: Permite copiar uma questão de outro questionário e editá-la. 
6. Banco de questões: Copia questões de um banco de questões previamente registrado para o Respondus

7. Lista de questões: Apresenta a lista de questões do questionário em edição.

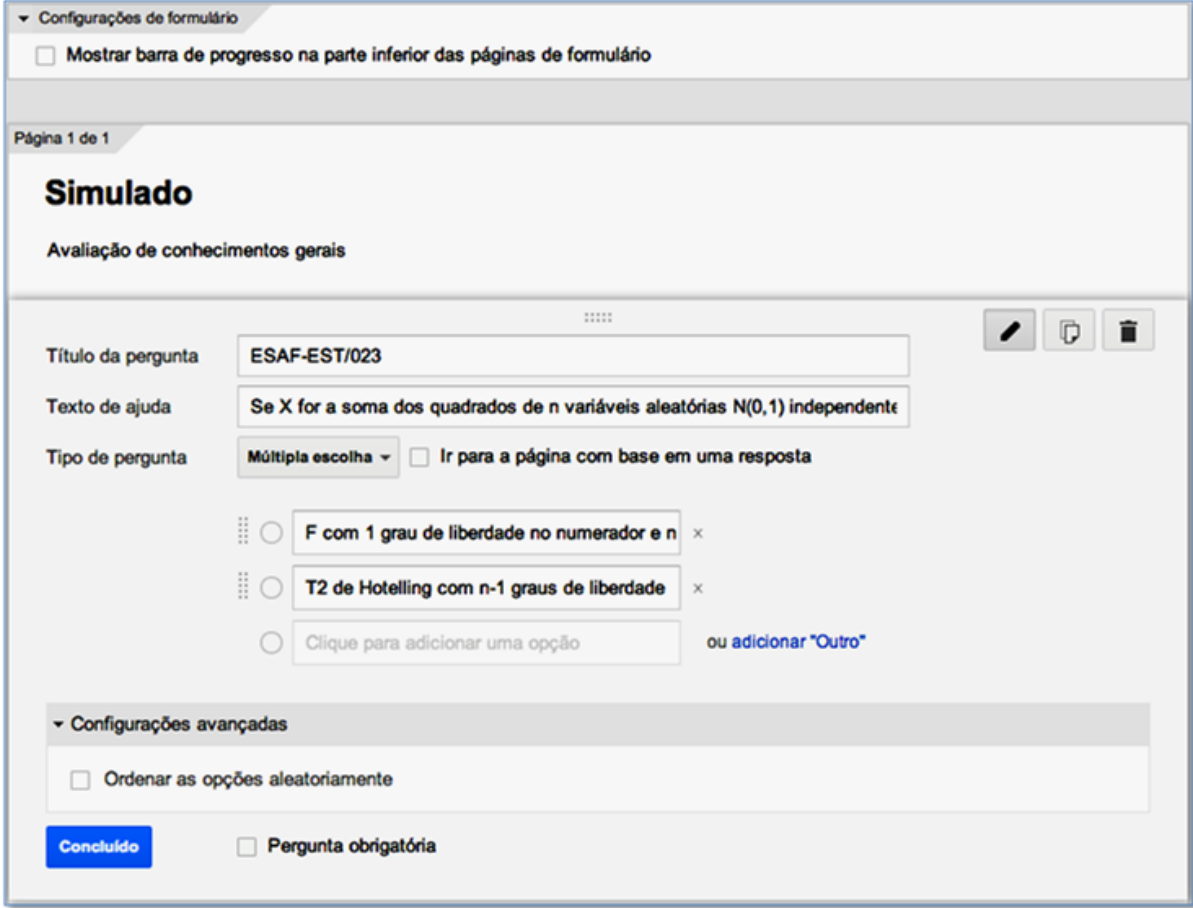

Figura I.2: Tela para edição de questionário no Google Docs

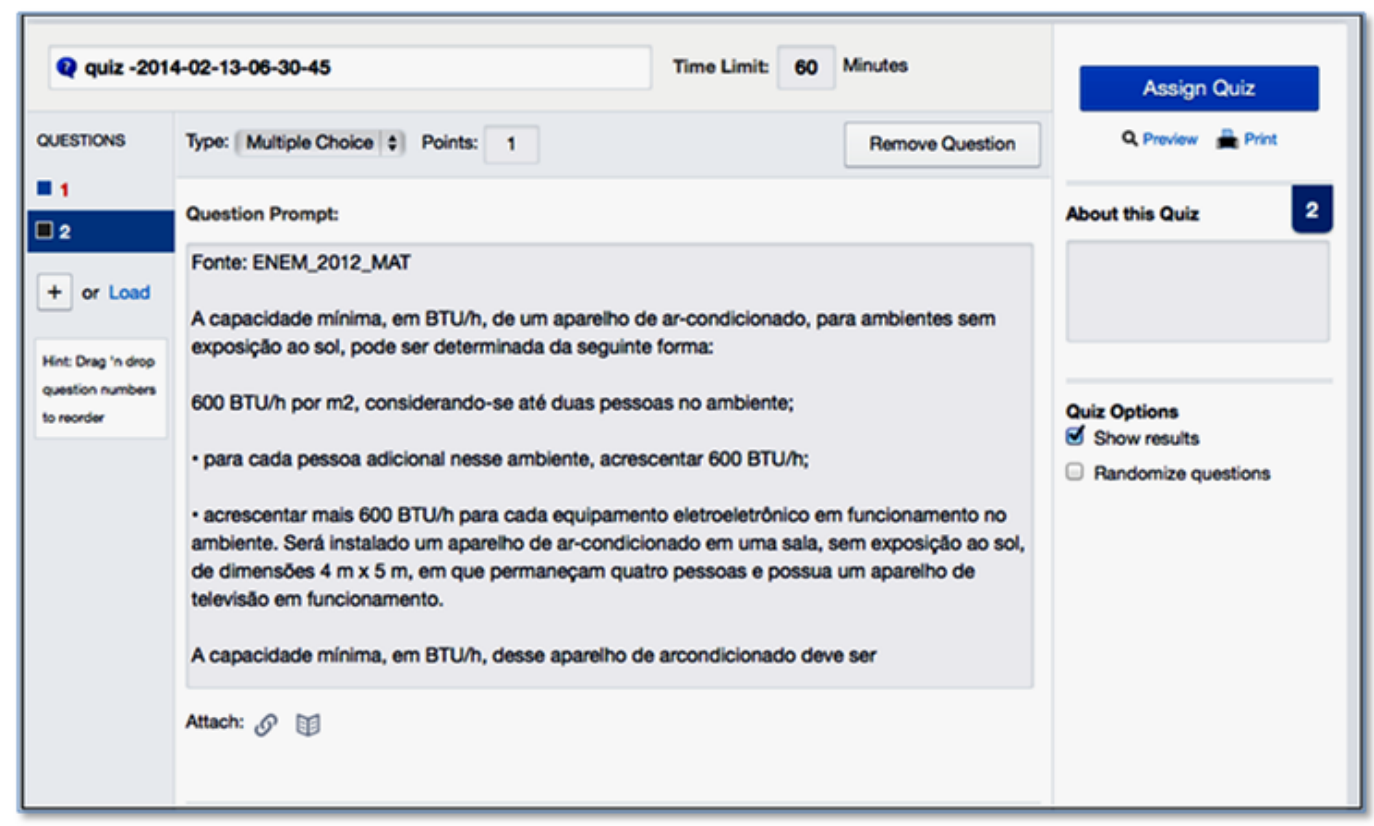

Figura I.3: Tela para edição de questionário no Edmodo 


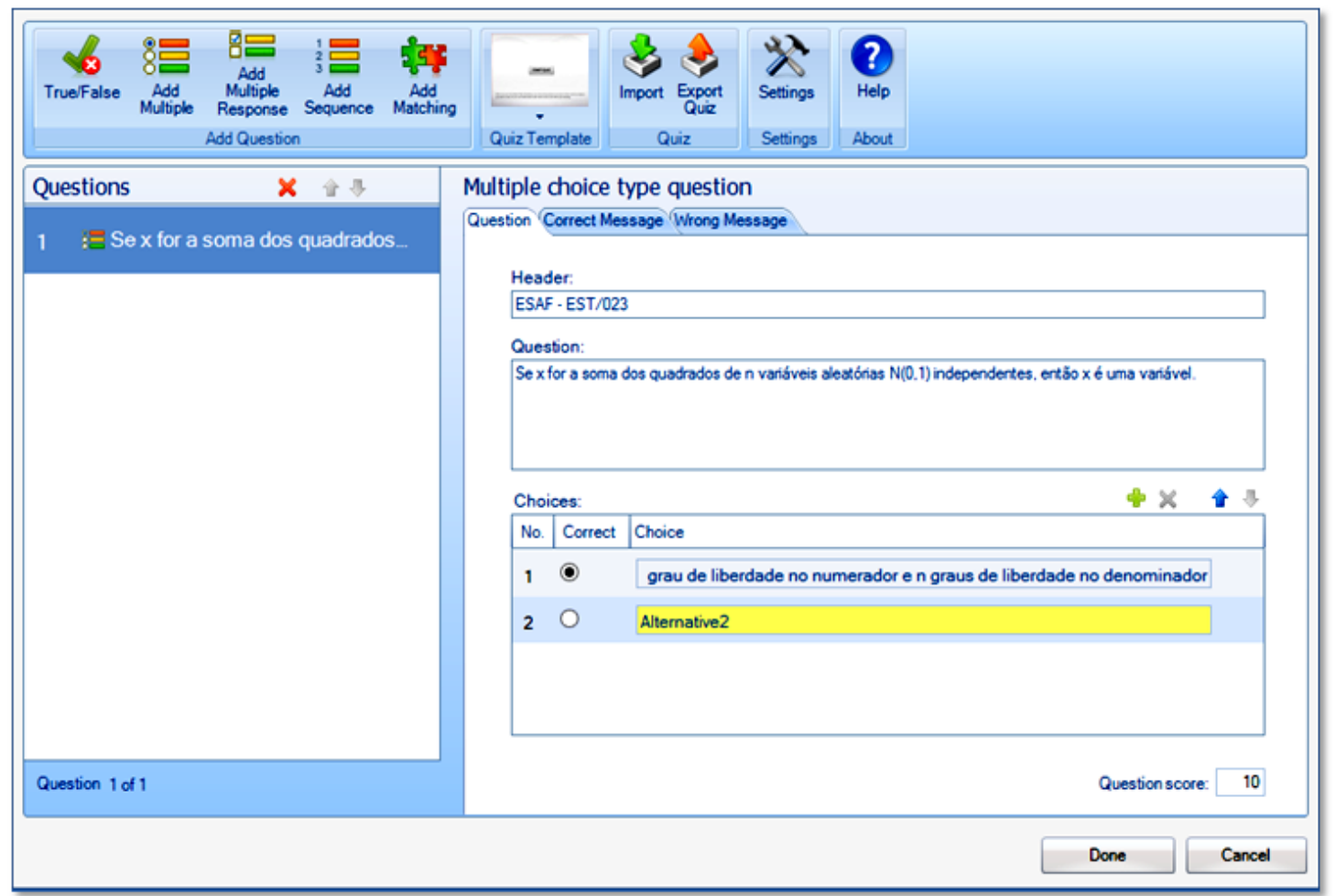

Figura I.4: Tela para edição de questionário no Zenler

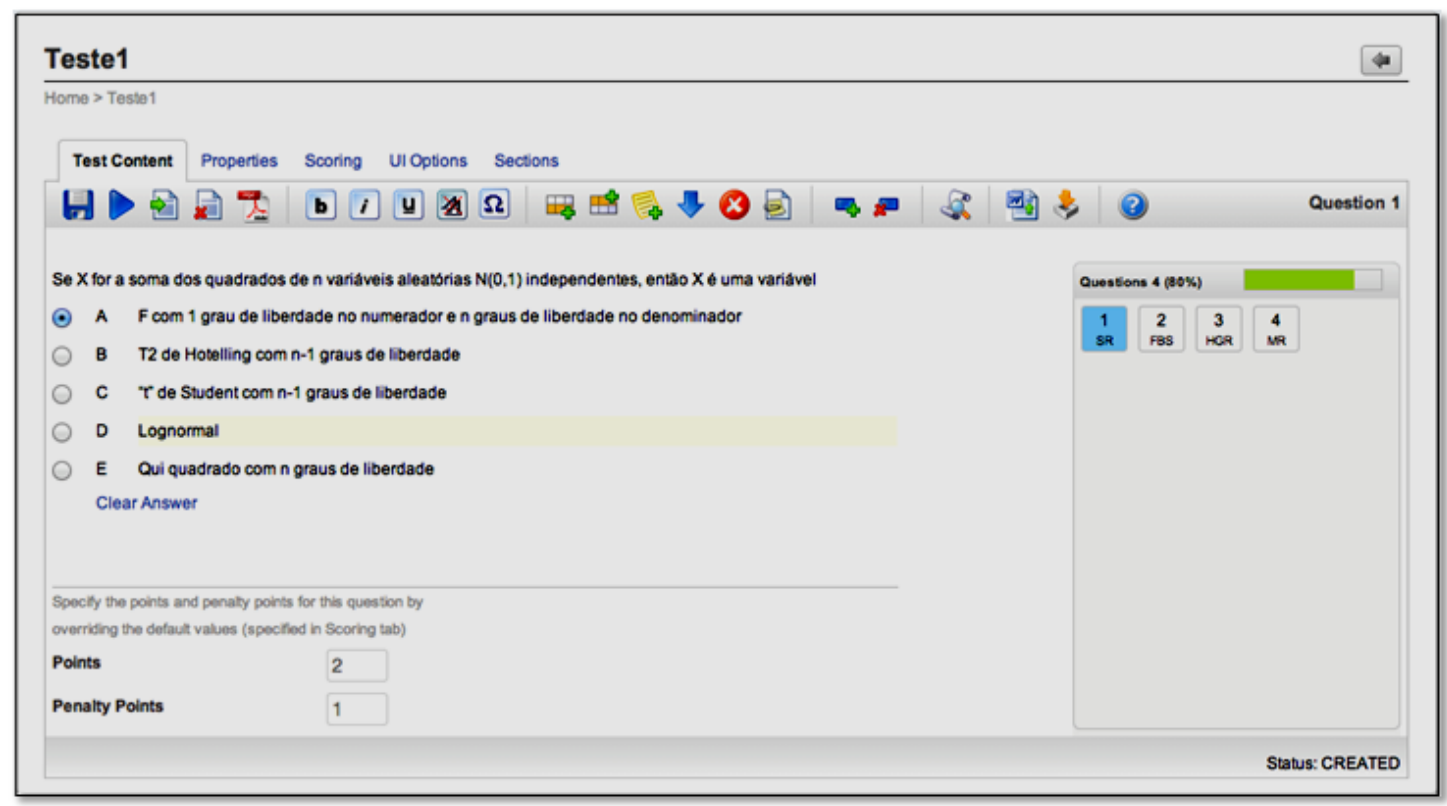

Figura I.5: Tela para edição de questionário no Edubrite 


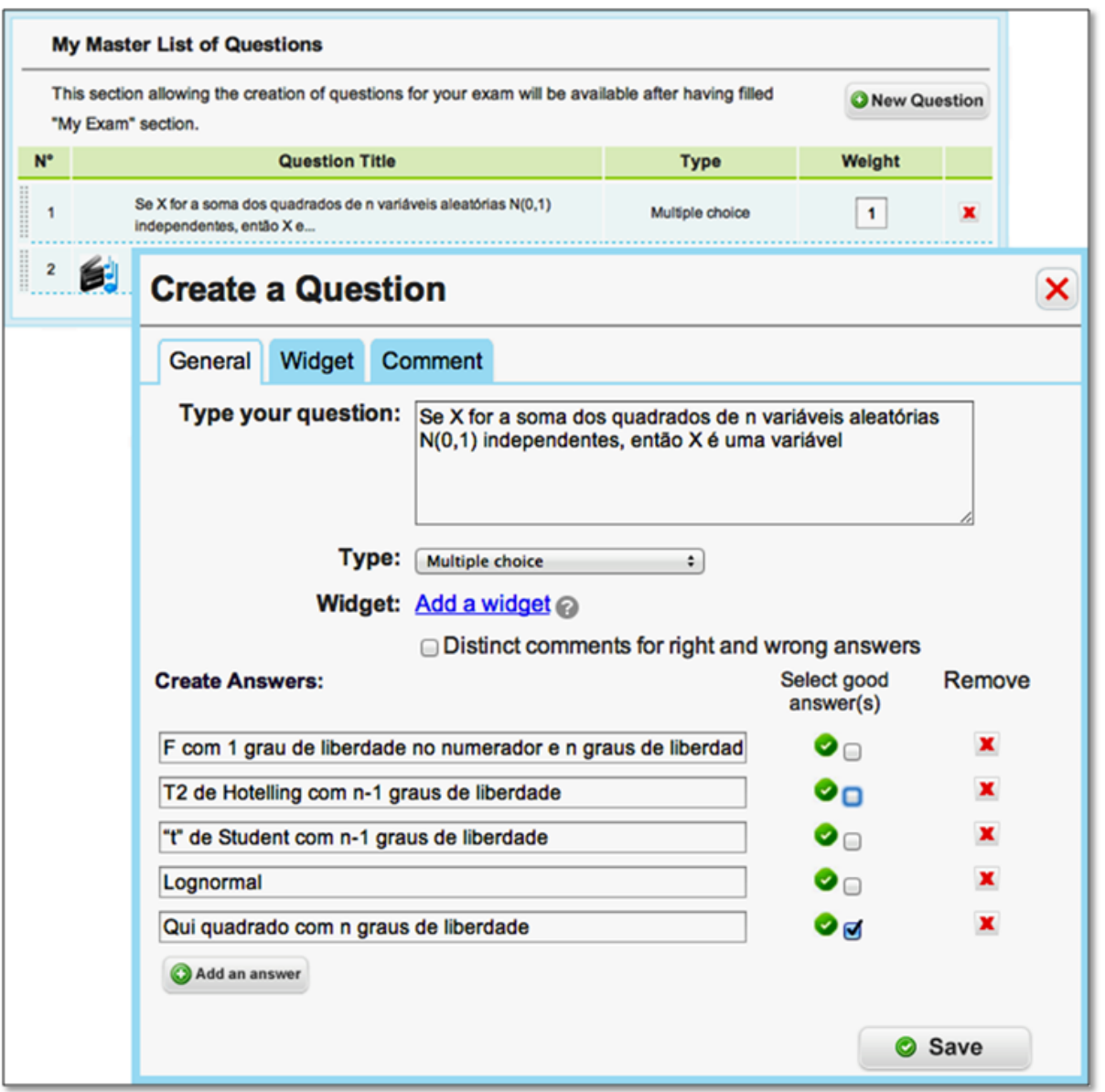

Figura I.6: Tela para edição de questionário no Exam General 


\section{Referências Bibliográficas}

ABED (2012) ABED. Censo ead brasil 2012. http://www.abed.org.br/censoead/censoEAD.BR_ 2012 _pt.pdf, 2012. Último acesso em 05/08/2012. Citado na pág. 30, 101

Aldrich (2008) Clark Aldrich. Learning by Doing: A Comprehensive Guide to Simulations, Computer Games, and Pedagogy in e-Learning and Other Educational Experiences. Wiley. Citado na pág. 1

Barbosa e Silva (2012) Simone Diniz Junqueira Barbosa e Bruno Santana da Silva. Interação Humano-computador. Elsevier Brasil. Citado na pág. 15

Bastien e Scapin (1993) J.M. Christian Bastien e Dominique L. Scapin. Ergonomic criteria for the evaluation of human-computer interfaces. Relatório Técnico 156, INRIA - Institut National de Recherche en Informatique et en Automatique, France. Citado na pág. 15

Baytiyeh (2011) Hoda Baytiyeh. Work in progress - open source usability evaluation: The case of moodle. Em Proceedings of the 2011 Frontiers in Education Conference, páginas F4E-1-1-F4E-2. IEEE Computer Society. Citado na pág. 18, 20

Bevan (1995) Nigel Bevan. Usability is quality of use. Proceedings of the 6th International Conference on Human Computer Interaction, Yokohama, July. Anzai $\&$ Ogawa (eds), Elsevier. Citado na pág. 12

Black e Wiliam (1998) Paul Black e Dylan Wiliam. Kappan classic: Inside the black box: Raising standards through classroom assessment formative assessment is an essential component of classroom work and can raise student achievement. Phi Delta Kappan, 80:139-148. Citado na pág. 2

Brandão e Isotani (2003) Leônidas O. Brandão e Seiji Isotani. Uma ferramenta para o ensino de Geometria Dinâmica na Internet: iGeom. Anais do IX Workshop de Informática na Educação, 1:146-148. Citado na pág. 23, 24

Brooke (2014) John Brooke. System usability scale. http://www.usability.gov/how-to-and-tools/ methods/system-usability-scale.html, 2014. Último acesso em 10/04/2014. Citado na pág. 17

CAA (2013) CAA. Caa conference. http://caaconference.co.uk/, 2013. Último acesso em 26/06/2013. Citado na pág. 3

Caladine et al. (2010) Richard Caladine, Trish Andrews, Belinda Tynan, Robyn Smyth e Deborah Vale. New communications options: a renaissance in videoconference use. Citado na pág. 1

Calm et al. (2012) R. Calm, J. Ripoll, R. Masia, T. Sancho-Vinuesa, C. Olive, N. Pares e F. Pozo. Wiris quizzes: An automatic and self-study tool for online mathematics: The teaching experience in engineering courses at universitat oberta de catalunya. páginas 1-6. Computers in Education (SIIE), 2012 International Symposium on. Citado na pág. 2

Chagas et al. (2011) Daniel A. Chagas, Rafaela P. Lisboa e Elizabeth S. Furtado. Framework maava: Metodologia de avaliação de ambientes virtuais de aprendizagem. Anais do XXII SBIE XVII WIE, páginas 856-859. Citado na pág. 18, 19 
Cole e Foster (2008) Jason Cole e Helen Foster. Using Moodle. O’Reilly. Citado na pág. 10

Costa et al. (2011) Adriana C. R. Costa, Lucila Ishitani e Silvio J. F. Guimarães. Estudo comparativo de usabilidade do moodle mobile e quiz mobile em relação ao moodle para computadores. Anais do XXII SBIE - XVII WIE, páginas 860-863. Citado na pág. 18

Cybis et al. (1998) Walter Abreu Cybis, Marcelo Soares Pimenta, Mário Cesar Silveira e Luciano Gamez. Uma abordagem ergonômica para o desenvolvimento de sistemas interativos. Workshop em fatorres humanos em sistemas computacionais. Citado na pág. 12

Dalmon (2012) Danilo Leite Dalmon. Uma linha de produto de software para módulos de aprendizagem interativa. Dissertação de Mestrado, Instituto de Matemática e Estatística, Universidade de São Paulo, Brasil. Citado na pág. 24, 25

Deitel e Deitel (2008) Paul Deitel e Harvey Deitel. Deitel囚 developer series ajax, rich internet applications, and web development for programmers. Prentice Hall Press. Citado na pág. 35

Dul e Weerdmeester (2004) J. Dul e B. Weerdmeester. Ergonomia prática. Edgard Blücher. Citado na pág. 15, 17

Eisenmann (2009) Alexandre Luís Kundrát Eisenmann. iComb: Um sistema para o ensino e aprendizagem de combinatória em ambiente Web. Dissertação de Mestrado, Instituto de Matemática e Estatística, Universidade de São Paulo, Brasil. Citado na pág. 24

Ethel e Cruz (2012) Ludhimila Ethel e Wallace R. Cruz. Análise de temas relações e tendencias na produção cientifica em tecnologias e educação. Iniciação Científica Cesumar, páginas 135-142. Citado na pág. 2

Filho e Rangel (2009) Pulino Filho e Athail Rangel. A atividade questionário em moodle. https://capacitacao2.moodle.ufsc.br/pluginfile.php/16882/mod_resource/content/0/ questionarios.pdf., 2009. Último acesso em 30/06/13. Citado na pág. 11

Forment et al. (2012) Marc A. Forment, Xavier De Pedro, Maria J Casañ, Jordi Piguillem e Nikolas Galanis. Wikis in collaborative educational scenarios: Integrated in lms or standalone wikis? Int. J. Distance Educ. Technol. Citado na pág. 18, 19

Gomes (2009) Maria João Gomes. Problemáticas da avaliação em educação online. Citado na pág. 2

Gomes (2003) Maria João Gomes. Gerações de inovação tecnológica no ensino a distância. Revista Portuguesa de Educação. Universidade do Minho, Portugal, 16(1):137-156. Citado na pág. 8

Good et al. (1986) M. Good, T. M. Spine, J. Whiteside e P. George. User-derived impact analysis as a tool for usability engineering. ACM Anais da Conferência SIGCHI sobre Fatores Humanos em Sistemas Computacionais, 17:241-246. Citado na pág. 12

Haydt (1995) R. C. Haydt. Avaliação do Processo Ensino-Aprendizagem. Ática. Citado na pág. 8

Health e Services (2006) Health e Human Services. Research-based Web Design and Visibility Guidelines. U.S. Department of Health and Human Services. Citado na pág. 15, 58

Hunt (2013) Tim J. Hunt. Goals of an online assessment system. http://docs.moodle.org/dev/ index.php?title=Goals_of_an_online_assessment_system\&oldid=16013, 2013. Último acesso em 26/06/2013. Citado na pág. 2, 23, 35, 88

Hunt (2012) Tim J. Hunt. Computer-marked assessment in moodle: Past, present and future. CAA - International Computer Assisted Assessment, páginas 1-12. Citado na pág. 2, 11, 50

IMS (2013) IMS. Ims global learning consortium. http://www.imsglobal.org/index.html, 2013. Último acesso em 26/06/2013. Citado na pág. 3 
ISO (1998) Technical Committee ISO. International standard iso 9241-11. http://www.iso.org/ iso/home/store/catalogue_tc/catalogue_detail.htm?csnumber $=16883,1998$. Último acesso em 20/07/2014. Citado na pág. $\overline{12}$

ISO (2010) Technical Committee ISO. International standard iso 13407. https://www.iso.org/ obp/ui/iso:std:iso:13407:ed-1:v1:en, 2010. Último acesso em 20/07/2014. Citado na pág. 12, 13

JISC (2007) JISC. Effective practice with e-assessment. http://www.jisc.ac.uk/media/ documents/themes/elearning/effpraceassess.pdf, 2007. Disponível em:. Citado na pág. 3

Jordan (1998) P.W. Jordan. An Introduction to Usability. Taylor \& Francis Group. Citado na pág. 15,17

Junqueira (2012) Eduardo Junqueira. Novas perspectivas de avaliação do aluno de ead no paradigma da cibercultura ea web 2.0. Linhas Críticas, 18:417-432. Citado na pág. 9

Kakasevski et al. (2008) G. Kakasevski, M. Mihajlov, S. Arsenovski e S. Chungurski. Evaluating usability in learning management system moodle. Em Information Technology Interfaces, 2008. ITI 2008. 30th International Conference on, páginas 613-618. IEEE Computer Society. Citado na pág. 18,20

Kamiya e Brandão (2009) Reginaldo Rideaki Kamiya e Leônidas O. Brandão. iVProg - um sistema para introdução à Programação através de um modelo Visual na Internet. Anais do XX Simpósio Brasileiro de Informática na Educação.Florianópolis, SC. Citado na pág. 24

Kissel (1995) George V. Kissel. The effect of computer experience on subjective and objective software usability measures. Em Conference Companion on Human Factors in Computing Systems, CHI '95, páginas 284-285, New York, NY, USA. ACM. ISBN 0-89791-755-3. doi: 10.1145/223355.223676. URL http://doi.acm.org/10.1145/223355.223676. Citado na pág. 30

Lisbôa et al. (2009) Eliana Santana Lisbôa, João Batista Bottentuit Junior e Clara Pereira Coutinho. Avaliação de aprendizagens em ambientes online: o contributo das tecnologias web 2.0. Citado na pág. 2

Magalhães et al. (2010) Edna Magalhães, Viviane Gomes, Alexandre Rodrigues, Leonardo Santos e Tayana Conte. Impacto da usabilidade na educação a distância: um estudo de caso no moodle ifam. Em Proceedings of the IX Symposium on Human Factors in Computing Systems, páginas 231-236. Brazilian Computer Society. Citado na pág. 18, 20

Maguire (1998) Martin C. Maguire. User-Centred Requirements Handbook. HUSAT Research Institute. Citado na pág. 13, 14, 45

Mantovani et al. (2008) Osmar Mantovani, Douglas Pasquali Pedroso, Maria Helena Pereira Dias e Hans Liesenberg. Letramento digital de professores na web 2. Em Anais do Workshop de Informática na Escola, volume 1. Citado na pág. 1

Martins et al. (2013) Ana I. Martins, Alexandra Queirós, Nelson P. Rocha e Beatriz S. Santos. Avaliação de usabilidade: Uma revisão sistemática da literatura. Revista Ibérica de Sistemas e Tecnologias de Informação, (11):31-23. Citado na pág. 17

Matos e Piconez (2012) Ecivaldo S. Matos e Stela C. B. Piconez. Usabilidade técnica percebida a serviço de uma proposta pedagógica mediada pela internet. 230 Simpósio Brasileiro de Informática na Educação (SBIE 2012). Citado na pág. 18, 19

Means et al. (2010) Barbara Means, Yukie Toyama, Robert Murphy, Marianne Bakia e Karla Jones. Evaluation of evidence-based practices in online learning: A meta-analysis and review of online learning studies. Citado na pág. 1, 2, 3, 9 
Miccione (2006) Domênico Góes Miccione. O quadro de escrever como recurso facilitador de interação e aprendizagem dos alunos no processo de avaliação. Dissertação de Mestrado, Núcleo Pedagógico de Apoio ao Desenvolvimento Científico - NPADC, Universidade Federal do Pará, Brasil. Citado na pág. 8

Moodle (2013a) Moodle. Moodle architecture. http://docs.moodle.org/dev/Moodle architecture, 2013a. Último acesso em 02/07/2013. Citado na pág. 37

Moodle (2013b) Moodle. Quiz usability portal/different paginating features in quiz. http://docs. moodle.org/dev/Quiz.Usability.portal, 2013b. Último acesso em 26/06/2013. Citado na pág. 22, 23, 28,35

Moore e Kearsley (1996) M. G. Moore e G. R. Kearsley. Distance education: a systems view. Belmont, CA: Wadsworth, 1 ed. Citado na pág. 8

Moran (2000) José Manuel Moran. Educação inovadora na Sociedade da Informação. In 23 Reunião Anual da ANPED (Associação Nacional de Pós-Graduação em Educação). Caxambu $M G$., 1. Citado na pág. 8

Moreira e Conforto (2011) Michele Borges Moreira e Débora Conforto. Objetos de aprendizagem: Discutindo a acessibilidade e a usabilidade. Anais do XXII SBIE - XVII WIE, páginas 390-393. Citado na pág. 18, 19

Murphy e Lebans (2008) Janet Murphy e Robert Lebans. Unexpected outcomes: Web 2.0 in the secondary school classroom. International Journal of Technology in Teaching and Learning, 4(2):134-147. Citado na pág. 1

Nakamura (2011) Rodolfo Nakamura. Moodle: como criar um curso usando a plataforma de Ensino à Distância. Farol do Norte. Citado na pág. 11

Nascimento (2014) Mauricio G. F. Nascimento. irepositório - repositório interativo de conteúdos digitais para cursos baseados na internet. Dissertação de Mestrado, Instituto de Matemática e Estatística, Universidade de São Paulo, Brasil. Citado na pág. 25, 38

Nielsen (2005) Jakob Nielsen. 10 usability heuristics for user interface design. http://www. nngroup.com/articles/ten-usability-heuristics/, 2005. Último acesso em 26/06/2013. Citado na pág. $15,16,19,64$

Nielsen (2013a) Jakob Nielsen. Why you only need to test with 5 users. http://www.nngroup. com/articles/why-you-only-need-to-test-with-5-users/, 2013a. Último acesso em 26/06/2013. Citado na pág. 15

Nielsen (2013b) Jakob Nielsen. How many test users in a usability study? http://www.nngroup. com/articles/how-many-test-users/, 2013b. Último acesso em 26/06/2013. Citado na pág. 15

Nielsen (2013c) Jakob Nielsen. Usability 101: Introduction to usability. http://www.nngroup. com/articles/usability-101-introduction-to-usability/, 2013c. Último acesso em 01/07/2013. Citado na pág. $12,80,84$

Nielsen (1993) Jakob Nielsen. Usability Engineering. Elsevier Science. Citado na pág. 2, 12, 15, 19

Nielsen (1995) Jakob Nielsen. How to conduct a heuristic evaluation. http://www.nngroup.com/ articles/how-to-conduct-a-heuristic-evaluation/, 1995. Último acesso em 01/07/2013. Citado na pág. 17,32

Nielsen e D. (1995) Jakob Nielsen e Sano D. Sun web: User interface design for sun microsystem's internal web. http://www.nngroup.com/articles/ 1994-design-sunweb-sun-microsystems-intranet/, 1995. Último acesso em 18/07/2014. Citado na pág. 16 
NMC (2012) NMC. Perspectivas tecnológicas para o ensino fundamental e médio brasileiro de 2012 a 2017: Uma análise regional por nmc horizon project. http://zerohora.clicrbs.com.br/pdf/ 14441735.pdf, 2012. Disponível em:. Citado na pág. 2

Oliveira (2010) Gerson Pastre de Oliveira. Estratégias multidimensionais para a avaliação da aprendizagem em cursos on-line. Citado na pág. 2

Oliveira (2007) GP de Oliveira. Avaliação formativa nos cursos superiores: verificações qualitativas no processo de ensino-aprendizagem e a autonomia dos educandos. Revista Iberoamericana de Educación, 13:1-5. Citado na pág. 2, 7, 8

OpenLearn (2013) OpenLearn. eassessment at the open university with open source software. http://labspace.open.ac.uk/mod/oucontent/view.php?id=470290, 2013. Último acesso em 12/06/2013. Citado na pág. 3

Penedo et al. (2012) Janaina R Penedo, Morganna Diniz, Simone B. L. Ferreira, Denis S. Silveira e Eliane Capra. Análise de usabilidade de um sistema de ead baseada em modelos markovianos e em taxonomia. 230 Simpósio Brasileiro de Informática na Educação (SBIE 2012). Citado na pág. 18

Piteira e Costa (2006) Martinha Piteira e Carlos Costa. Avaliação da usabilidade percebida: Plataforma de e-learning moodle de usabilidade de sites web. Disponivel em http://design.itml. org/carlos/papers/2006/CIAWI2006.pdf. Citado na pág. 30

Prado (2008) Reginaldo Prado. iGraf: Uma proposta de sistema para ensino de função via Web. Dissertação de Mestrado, Instituto de Matemática e Estatística, Universidade de São Paulo, Brasil. Citado na pág. 24

Preece et al. (2005) J. Preece, Y. Rogers e H. Sharp. Design de Interacao. Bookman. Citado na pág. 2, 11, 31, 49

Queiroz (2011) Elivânia Maria da Silva Queiroz. Prática docente nos ambientes virtuais de aprendizagem: possibilidades de inovação pedagógica, 2011. Citado na pág. 2

Raob et al. (2012) Ismail Raob, Hussein Al-Oshaibat e Saw Lan Ong. A factor analysis of teacher competency in technology. New Horizons in Education, 60(1):13-22. Citado na pág. 1

Rea (2014) Jennifer Rea. Tablet technology learning outcomes in elementary education. Citado na pág. 1

Reynolds et al. (2008) PA Reynolds, R Mason e KA Eaton. Remember the days in the old school yard: from lectures to online learning. British dental journal, 204(8):447-451. Citado na pág. 1

Rocha e Júnior (2010) Bruno C. Rocha e Rafael T. S. Júnior. Utilização de árvores de decisão no processo de determinação das melhores heurísticas de usabilidade para acelerar o processo de inclusão digital. Anais do Simpósio Brasileiro de Iformática na Educação 2010. Citado na pág. 18, 19

Rodrigues e Borges (2013) Nice Vânia Machado Rodrigues e Fabrícia Teixeira Borges. Avaliação da aprendizagem em educação a distância através do fórum (interface educacional). Ideias e Inovação-Lato Sensu, 1:25-34. Citado na pág. 9

Rodrigues (2011) Patricia Alves Rodrigues. iTarefa:componente moodle para incorporar módulos de aprendizagem interativa em cursos Web. Dissertação de Mestrado, Instituto de Matemática e Estatística, Universidade de São Paulo, Brasil. Citado na pág. 25

Rodrigues e Brandão (2012) Patrícia Alves Rodrigues e Leônidas de Oliveira Brandão. itarefa: componente moodle para incorporar módulos de aprendizagem interativa em cursos web. volume 1. Citado na pág. 38 
Santarosa et al. (2011) Lucila M C. Santarosa, Débora Conforto e Lourenço O. Basso. Ferramentas de autoria e de colaboração: discutindo a acessibilidade e a usabilidade na perspectiva da web 2.0. Anais do XXII SBIE - XVII WIE, páginas 578-587. Citado na pág. 18, 19

Santos (2006) Robson L. G. Santos. Usabilidade de interfaces para sistemas de recuperação de informação na web. Pontifícia Universidade Católica do Rio de Janeiro, páginas 1-344. Citado na pág. $12,13,31$

Sarmento et al. (2011) Wellington W. F. Sarmento, Cátia L. Harriman, Katryne F. Rabelo e Andrei B. B. Torres. Avaliação de usabilidade no processo de desenvolvimento contínuo em ambientes virtuais de aprendizagem: um estudo de caso com o ambiente solar. Anais do XXII Simpósio Brasileiro da Informática na Educação, páginas 781-791. Citado na pág. 18

Saul (2012) Ana Maria Saul. Referenciais freireanos para a prática da avaliação. Revista de Educação PUC-Campinas, 25:17-24. Citado na pág. 7

Savolainen (2010) Olli Savolainen. User experience design in open source development: Approaches to usability work in the moodle community. Faculty of Information Sciences / Department of Computer and Information Sciences / Interactive Technology, páginas 1-88. Citado na pág. 2, $18,20,21,22,23,28,35,36,40,45,46,47,88$

Schelemmer (2005) Eliane Schelemmer. Cap. 9 - Ambiente Virtual de Aprendizagem (AVA): uma proposta para a sociedade em rede de cultura de aprendizagem. In VALENTINI, Carla Beatris e SOARES, Eliana M. S. Aprendizagem em ambientes virtuais: compartilhando idéias e construindo cenários, 1 ed. Citado na pág. 9

Sell Filho et al. (2012) Paulo Sell Filho et al. Uma reflexão sobre a avaliação matemática no ensino fundamental do município de palhoça. Citado na pág. 7, 8

Shneiderman (1998) B. Shneiderman. Designing the user interface: strategies for effective humancomputer-interaction. Addison Wesley Longman. Citado na pág. 15

Silva Ribeiro et al. (2012) Romenig Silva Ribeiro, Leônidas Oliveira Brandão, Patrícia Alves Rodrigues, Anarosa AF Brandão e Seiji Isotani. ivprog e itarefa: aprimorando o ensino de algoritmos e programação para iniciantes. volume 1. Citado na pág. 24

Silveira e Carneiro (2012) Milene S. Silveira e Mára L. F. Carneiro. Diretrizes para a avaliação da usabilidade de objetos de aprendizagem. Anais do Simpósio Brasileiro de Iformática na Educação 2012. Citado na pág. 18,19

Skellas e Ioannidis (2011) A.I. Skellas e G.S. Ioannidis. Web-design for learning primary school science using lmss: Evaluating specially designed task-oriented design using young schoolchildren. Em Interactive Collaborative Learning (ICL), 2011 14th International Conference on, páginas 313-318. IEEE Computer Society. Citado na pág. 18

Souza (1996) Paulo R. Souza. Presidência da república - lei de diretrizes e bases da educação nacional (lei n. 9.394, de 20/12/1996). http://www.planalto.gov.br/ccivil_03/Leis/L9394.htm, 1996. Último acesso em 05/08/2012. Citado na pág. 1

Tenório et al. (2011) Joceli M. Tenório, Vera L. Sdepanian, Ivan T. Pisa e Marcio B. Amaral. Desenvolvimento e avaliação de um protocolo eletrônico para atendimento e monitoramento do paciente com doença celíaca. Disponivel em http://www.sbis.org.br/cbis11/arquivos/693.pdf. Citado na pág. 32

Tenório et al. (2010) Josceli M. Tenório, Vera L. Sdepanian, Ivan T. Pisa e Márcio B. Amaral. Desenvolvimento e avaliação de um protocolo eletrônico para atendimento e monitoramento do paciente com doença celíaca. Revista de Informática Téorica e Aplicada - RITA, páginas 1-5. Citado na pág. 33 
Tyldesley (1988) D. A. Tyldesley. Employing usability engineering in the development of office products. Oxford University Press, 31:431-436. Citado na pág. 12

Usabilitynet (2013) Usabilitynet. Methods table. http://www.usabilitynet.org/tools/methods. htm, 2013. Último acesso em 26/06/2013. Citado na pág. 31

Winckler e Pimenta (2002a) Marco Winckler e Marcelo Soares Pimenta. Avaliação de usabilidade de sites web. Disponivel em http://lis.univ-tlse1.fr/winckler/publications.html. Citado na pág. 12

Winckler e Pimenta (2002b) Marco Winckler e Soares M. Pimenta. Avaliação de usabilidade de sites web. http://www.funtec.org.ar/usabilidadsitiosweb.pdf, 2002b. Último acesso em 20/07/2014. Citado na pág. xiii, 16, 53

Young (2011) Rowin Young. Padrões técnicos em educação, parte 6: Padrões para avaliação e bancos de itens. IBM developerWorks, 6. Citado na pág. 2

Álfredo Figueira e Cunha (2009) Álfredo Figueira e Elizabete Cunha. Work in progress - w2: an easy-to-use workshop module. Em Proceedings of the 39th IEEE international conference on Frontiers in education conference, páginas 1611-1612. IEEE Press. Citado na pág. 18, 20 